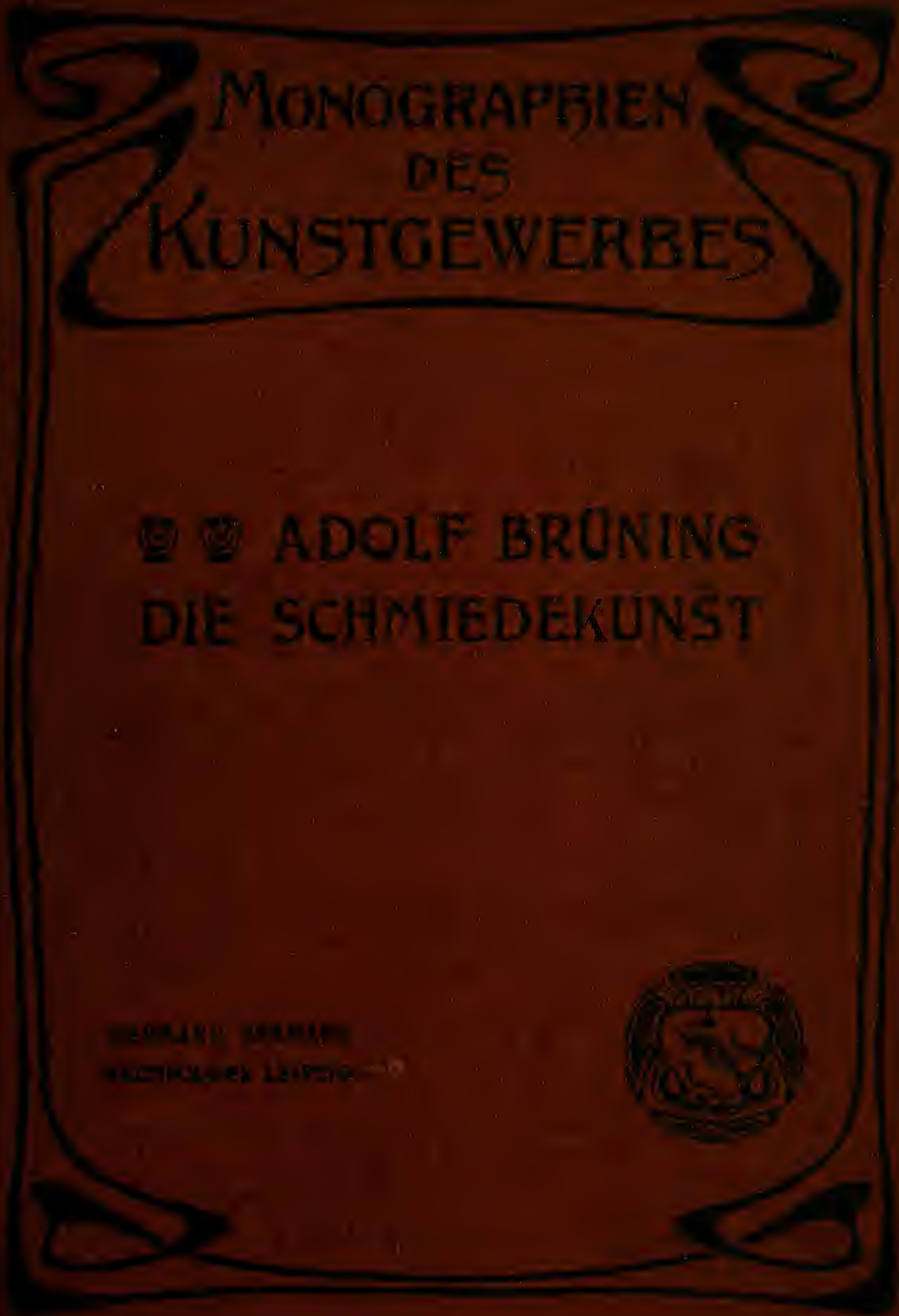




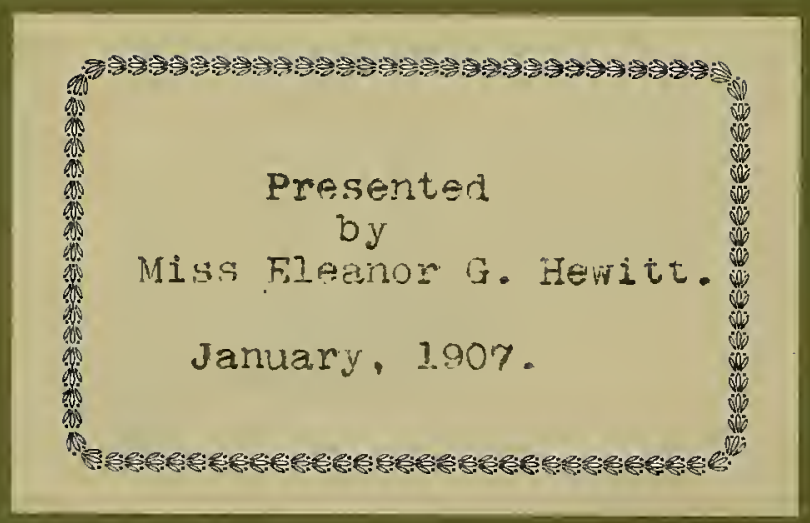




\section{MONOGRAPHIEN DES KUNSTGEWERBES}

HERAUSGEGEBEN VON JEAN LOUIS SPONSEL

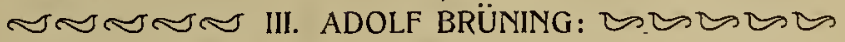
DIE SCHMIEDEKUNST SEIT DEM ENDE DER RENAISSANCE 


\section{MONOGRAPHIEN DES KUNSTGEWERBES}

HERAUSGEGEBEN VON

JEAN LOUIS SPONSEL

III.

ADOLF BRÜNING: DIE SCHMIEDEKUNST SEIT DEM ENDE DER RENAISSANCE 


\title{
DIE SCHMIEDEKUNST SEIT DEM ENDE DER RENAISSANCE
}

\author{
VON \\ ADOLF BRÜNING
}

MIT 150 ABBILDUNGEN

ZWEITES TAUSEND

VERLAG VON HERMANN SEEMANN NACHFOLGER IN LEIPZIG । 
Alle Rechte vom Verleger vorbehalten.

E. Haberland in Leipzig-R. 


\section{MEINEN \\ LIEBEN ELTERN GEWIDMET}




\section{In halt.}

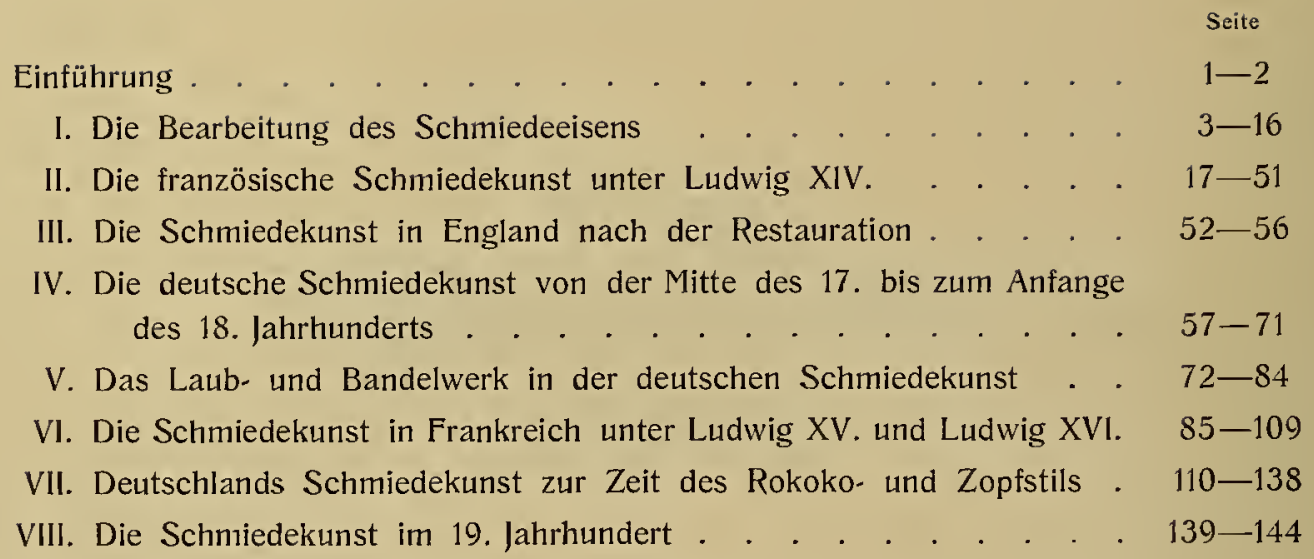




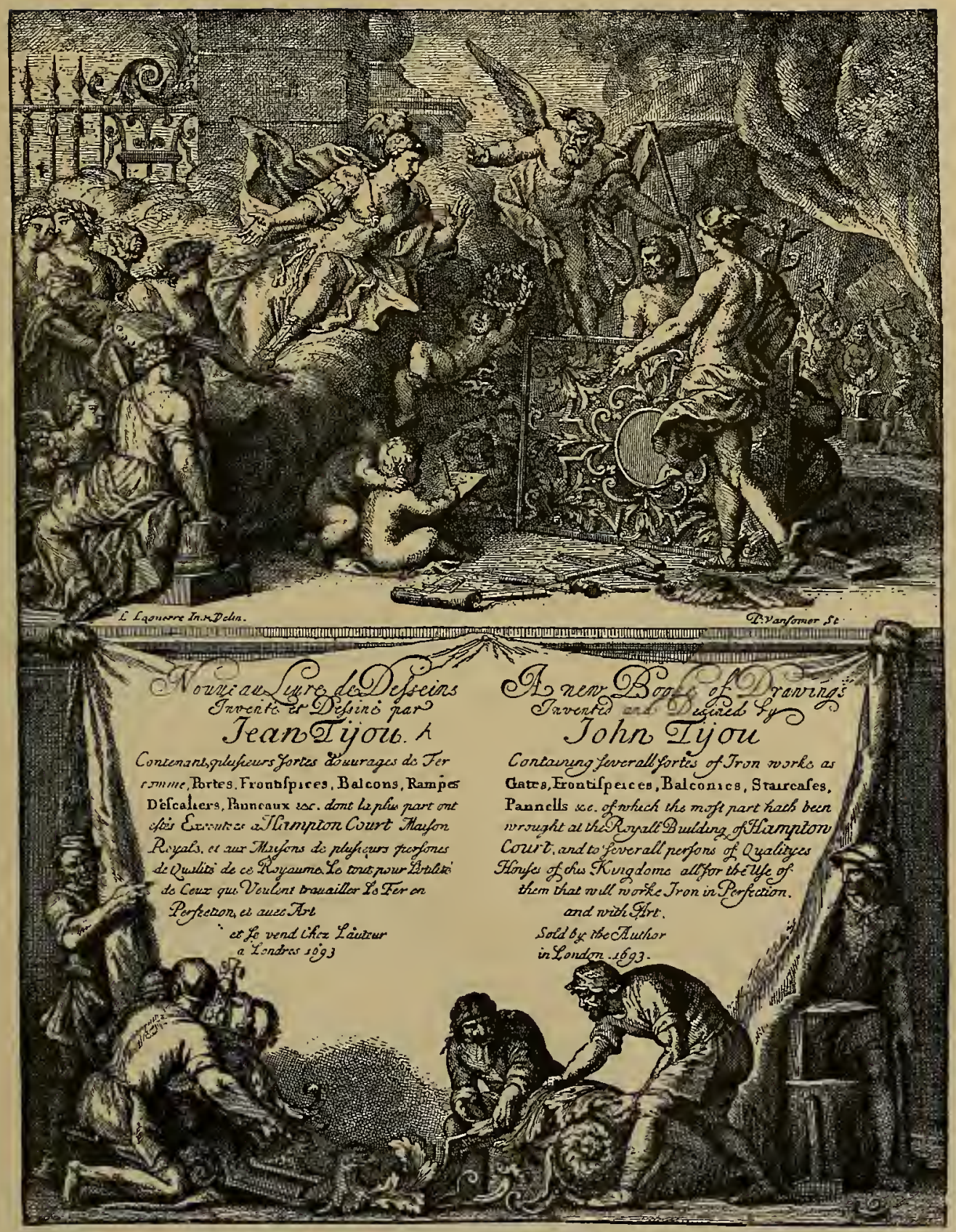

Abb. 1. Titelblatt zu Jean Tijous Schlosserbuch. 



\section{Einführung.}

Schriftliche Nachrichten und vereinzelte Funde von Eisenstücken lassen auf ein beträchtliches Alter der Schmiedekunst schliessen. Der Rost hat jedoch fast alle Eisenarbeiten des Altertums und frühen Mittelalters vernichtet. Infolgedessen wird das Bild, welches man sich von der Schmiedekunst jener Zeiten zu entwerfen versucht, stets unvollständig und mangelhaft sein. Soweit die spärlichen Dokumente ein Urteil gestatten, benutzte man das Eisen damals nur zu einfachen Nutzformen, zu Waffen, Werkzeugen und ähnlichem. Wenn es sich um künstlerische Gestaltung handelte, zog man in den meisten Fällen die Bronze oder andere Stoffe vor.

Erst aus dem 11. u. 12. Jahrhundert n. Chr. sind uns kunstvolle Schmiedewerke in einiger Zahl erhalten, noch spärlich, aber doch hinreichend, um an diesen Zeitpunkt den fortlaufenden Faden der Geschichte der Schmiedekunst anzuknüpfen. Die frühsten Arbeiten, bei denen das Eisen eine künstlerische Formgebung erfuhr, waren Beschläge von Thüren und Möbeln, sowie Gitter. Das glänzendste Beispiel kunstreicher Beschläge bieten die Angelbänder der beiden seitlichen Thore des Westportals der Kathedrale Notre-Dame zu Paris aus dem Anfang des dreizehnten Jahrhunderts, bei welchen ein grosser Reichtum plastischer Formen entfaltet ist. Wie über die grossen ungebrochenen Flächen der Kirchenthüren, welche aus zusammengespundeten oder nur einfach nebeneinander gesetzten und durch Quer- hölzer verbundenen Brettern gebildet sind, so breitet sich auch der Eisenbeschlag über die Kastenmöbel nach allen Seiten hin aus und erfüllt zugleich den doppelten Zweck der Verzierung und konstruktiven Verstärkung. Erst mit der Wiedereinführung der gestemmten Arbeit im Laufe des 14. Jahrhunderts, bei der die Flächen der Möbel in Rahmen und Füllungen gegliedert werden, zieht sich der Eisenbeschlag immer mehr zurück, bis er schliesslich im Laufe des 17. Jahrhunderts gänzlich aus dem Mobiliar verschwindet. Nur bei der Truhe hält er sich in einzelnen Gegenden bis in das 18. Jahrhundert. Dafür erweitert aber im späten Mittelalter die Schmiedekunst nach anderer Richtung hin den Kreis der in ihren Bereich fallenden Gegenstände. Kunstvolle Schlösser und Schlüssel, Thürklopfer, Kassetten, Geräte aller Art, besonders Beleuchtungskörper, Brunnenlauben, ja selbst Kanzeln und ganze Sakramentshäuser werden aus Eisen gebildet.

Frankreich, England und Deutschland sind die Länder, in denen uns die meisten mittelalterlichen Schmiedewerke begegnen. In Italien, und zwar nur in der nördlichen Hälfte, treten, soweit sich nachweisen lässt, erst seit dem 14. Jahrhundert Schmiedearbeiten, besonders Gitter, in grösserer Zahl auf; dic eigentliche Heimat der Schmiedekunst scheinen die Länder diessẹits der Alpen gewesen zu sein.

Der gewaltige Aufschwung, den die Waffenschmiedekunst im 15. und 16. Jahr- 
hundert, der Zeit des Plattenharnisches, nimmt, bleibt auch für die übrige Schmiedekunst nicht ohne bedeutende Folgen. Die Technik wird durch zahlreiche, in der Waffenkunst geübte Verzierungsweisen, Treiben, Aetzen, Tauschieren u. s. w. bereichert. $\mathrm{Zu}$ besonders stattlichen Leistungen schwingt sich die Schlosserkunst im 16. Jahrhundert in Spanien auf. Die eigentümliche Einrichtung der spanischen Kathedralen erforderte nämlich eine weitgehende Verwendung von Gitterwerk. Der Coro (Chor) mit den Sitzen der Geistlichkeit befindet sich als ein für sich $a b$ geschlossener Raum im Mittelschiff. Um nun den Geistlichen den Anblick des Hauptaltars in der Capilla mayor zu gestatten, ist die Seite des Chors nach dem Altarraum hin durch ein hohes Gitter ab. gegrenzt. Ein noch grösseres und schöneres, oft bis zu $15 \mathrm{~m}$ Höhe ansteigendes Gitter erhebt sich vor der Capilla mayor, andere kleinere vor den übrigen Kapellen. Auch eiserne Kanzeln kommen vor. Die in der Waffenschmiedekunst grossgezogene Treibarbeit findet dabei in umfangreichem Masse Anwendung.

In Italien lassen kostbarere Stoffe, der Marmor und die Bronze, das Schmiedeeisen - von der Waffenschmiedekunst abgesehen - nicht so sehr zu Worte kommen. Als vereinzelte Leistungen von virtuoser Technik stellen sich die Laternen und Fackelhalter des Palazzo Strozzi in Florenz, Werke des Niccolò Grosso gen. Caparra, dar. In Frankreich beschränkt sich die Schmiedekunst im 16. Jahrhundert auf die Herstellung kunstvoller Schlüssel, Schlösser, Riegel und Thürklopfer; wenigstens ist von grösseren Arbeiten nichts erhalten geblieben. Auch Deutschland vermag den gewaltigen spanischen Gittern nichts Ähnliches zur Seite zu stellen. Aber trotz seines bescheideneren Umfangs gehört das Gitterwerk der deut- schen Renaissance, das sich aus mannigfach verschlungenen, durchschobenen Rundstäben zusammensetzt, in seiner reizvollen, phantastischen Bildung zu den anziehendsten Leistungen der Schmiedekunst überhaupt. Es erfreute sich, wie wir sehen werden, bei den deutschen Schlossern einer solchen Beliebtheit, dass es sich auch noch das ganze 17. Jahrhundert mit geringen Abänderungen erhält. Seine letzten Ausläufer reichen sogar bis ins 18. Jahrhundert hinein.

Wie in der Geschichte der Kunst überhaupt, so bedeutet auch für die Schmiedekunst der Regierungsantritt Ludwigs XIV. den Beginn einer neuen Epoche, welche die zweite Hälfte des 17. und das ganze 18. Jahrhundert umfasst. Es ist die Zeit der Vorherrschaft Frankreichs sowohl in politischer wie künstlerischer Hinsicht. Der Geschichte der Schmiedekunst dieses Zeitabschnittes bis auf uns ist das vorliegende Buch gewidmet. Wenn ja auch die Kunstentwicklung gleich einem vorbeifliessenden Strome nirgendwo eine Trennung, eine Lücke aufweist, jede Zerlegung in einzelne Abschnitte etwas Gewaltsames hat, so hat für die Schmiedekunst eine Zusammenfassung dieses Zeitraumes zu einem geschlossenen Ganzen insofern eine Berechtigung, als in der zweiten Hälfte des 17. Jahrhunderts nicht nur neue Formen aufkommen, sondern auch neue Aufgaben an diese Kunst herantreten, vor allem der Schmuck der Profanarchitektur mit Gitterwerken in einem Umfang, wie es bis dahin unbekannt war. Frankreich und Deutschland sind die Länder, in denen sich die Schlosserkunst in diesem Zeitabschnitt am glänzendsten entwickelt. England kommt nur für eine kurze Zeit in Betracht. Die übrigen europäischen Länder sprechen wenig mit, so dass sie aus dem engen Rahmen dieses Buches fortgelassen werden können. 


\section{Die Bearbeitung des Schmiedeeisens.}

Für die Formgebung des Schmiedeeisens kommen vor allem zwei sehr wichtige Eigenschaften desselben in Betracht, seine $\mathrm{Schmiedbarkeit}$ und seine Schweissbarkeit. Die Schmiedbarkeit besteht darin, dass es sich in rotglühendem Zustande durch Schlag und Druck, also Hämmern und Walzen, in beliebige Formen bringen lässt, die Schweissbarkeit darin, dass sich zwei Stücke Eisen in der Weissglühhitze in eins zusammenhämmern lassen, ebenso wie man etwa zwei Kügelchen Wachs durch Kneten mit den Fingern in eines verwandeln kann. Die erste Eigenschaft ermöglicht eine reiche plastische Bildung des Schmiedeeisens, die zweite gestattet eine innige, höchst dauerhafte Verbindung der einzelnen Eisenteile zu einem Ganzen. Ausserdem aber kann das Schmiedeeisen auch in kaltem Zustande sowohl geformt, wie auch zusammengefügt werden.

Die Arbeiten, welche erforderlich sind, um das rohe, aus den Erzen gewonnene Eisenstück, die "Rohluppe", in eine Kunstform zu verwandeln, lassen sich am zweckmässigsten in zwei Gruppen gliedern.

1. Die Vorarbeit, wodurch die Rohluppe in handliche Formen, Stäbe, Schienen, Bleche u. dgl. verwandelt wird, also die Arbeit der Hammer- und Walzwerke.

2. Die Arbeiten des Kunstschmiedes, welche wieder dreifacher Art sind: a) Verfahren, wodurch eine weitere Formveränderung des Materials erzielt wird, das Schmieden, Treiben, Gravieren, der Eisenschnitt und das Aetzen. b) Die Verbin- dung der einzelnen Teile zu einem Ganzen, das Schweissen, Löten, Nieten. c) Die farbige Behandlung: das Tauschieren, Blauanlaufen, Ueberziehen mit anderem Metall, wie Gold, Zinn u.s. w. und endlich die Bemalung.

Ein näheres Eingehen auf das, was als Vorarbeit bezeichnet ist, ist schon deshalb notwendig, weil diese Vorarbeit, welche dem Schlosser das Eisen in einer mehr oder minder zubereiteten Gestalt liefert, im Laufe der Jahrhunderte eine Veränderung erfahren hat, die auch auf die Kunstformen nicht ganz ohne Einfluss geblieben ist.

Im Altertum und im Mittelalter musste der Schlosser sich jeden Stab und jedes Blech, das er gebrauchte, selbst ausstrecken. Er bekam das Eisen in der Form der Rohluppe, welche nur ein wenig überschmiedet war. Erst seitdem man gelernt hatte, in den Eisenhütten sich die Wasserkraft dienstbar zu machen, wurde ihm diese Arbeit abgenommen. Wann dieses geschehen, lässt sich nicht genau feststellen, vielleicht schon im 14. Jahrhundert. Man benutzte die Wasserkraft sowohl zur Bewegung der Pochwerke, als auch der Blasebälge und grossen eisernen Schmiedehämmer. Es wurden nun mit den Eisenhütten, in denen das Eisen aus den Erzen gewonnen wurde, Stab- und Blechhämmer verbunden, in denen das Eisen in handliche, verschiedenartige Stäbe, Schienen und Bleche verwandelt wurde. Ausser den üblichen Eisensorten liessen sich die Schlosser auch nach einge- 
schickten Modellen bestimmte Formen, welche öfter gebraucht wurden, auf Vorrat anfertigen. In den Stabhämmern wurden zugleich gröbere Werkzeuge und solche Gegenstände gefertigt, deren Herstellung den Schlossern mit ihren kleinen Handhämmern nicht möglich war, wie Anker, Ambosse, grosse Hämmer, Pflugscharen, Zapfen und Ringe zu Mühlrädern u.s.w.

Ausserdem erfüllten diese Hammerwerke auch noch den Zweck, das Eisen zu reinigen und zu verbessern. Dies geschah besonders dadurch, dass man die Rohluppen zu Stäben ausschmiedete, mehrere derselben zu einem Paket oder einer Garbe, wie man es nannte, vereinigte, diese zusammenschweisste und daraus wieder einen Stab herstellte, der an Güte und Gleichmässigkeit der Textur die früheren Produkte weit übertraf. Denn durch das wiederholte Schweissen und Schmieden wurden nicht nur die Unreinlichkeiten, die der Rohluppe infolge der mangelhaften Gewinnung aus den Erzen anhafteten, herausgetrieben, sondern auch das ganze Gefüge des Metalls wurde dichter und gleichmässiger. ${ }^{1}$ )

Vielfach entstanden auch besondere von den Eisenhütten unabhängige Hammerwerke, die sog. Reck- oder Zainhämmer, die von einem eigenen Gewerk, den Zajnern, betrieben wurden. Das Innere eines derartigen Zainhammers stellt die Abbild. 2 dar. Sie ist einem Werke des Christoph Weigel in Regensburg vom Jahre 1698 entnommen, das den Titel führt: „Abbildung der Gemein-Nützlichen Hauptstände von denen Regenten und ihren so in Friedens- und Kriegszeiten zugeordneten Bedienten an bis auf alle Künstler und Handwerker." Die Hämmer, drei an der Zahl, von verschiedener Grösse, hängen in einem aus kräftigen Balken gezimmerten Gerüst. Sie werden durch eine von einem Wasserrade gedrehten Welle bewegt, an der in radialer Anordnung starke Zapfen,

1) Vgl. für diesen und die folgenden $A b$ schnitte: Beck, L., Geschichte des Eisens, Bd. 1-4. Braunschweig 1884-99. sogen. Daumen, befestigt sind. Mehrere derselben sind zwischen den Balken des Gerüstes sichtbar. Diese Daumen drücken auf das Ende des Hammers und heben ihn dadurch empor; sobald ein Daumen sich infolge der Drehung der Welle wieder entfernt hat, fällt der Hammer durch seine Schwere nieder, um sogleich wieder vom folgenden Zapfen ergriffen und emporgehoben zu werden. Der Zainer braucht also bloss das Eisen unter den Hammer zu halten und darauf zu sehen, dass derselbe immer die richtige Stelle trifft. Merkwürdig sind die Beischriften des Bildes. Solche moralisierende Sentenzen auch bei Gelegenheiten, wo man sie am wenigsten erwartet, waren ganz im Geschmack der damaligen Zeit.

Der grosse Umfang, welchen die Verwendung des Eisens im 17. und 18. Jahrhundert annahm, liess dann auf weitere Hilfsmittel sinnen, dem rohen Eisenstück möglichst schnell handliche Formen für die weitere Verarbeitung zu geben. Man erfand zu diesem Zwecke die Walz- und Schneidewerke. Schon Lionardo da Vincis allumfassender Geist hatte den Plan zu einem Walzwerk entworfen. 1532 beschreibt Eoban Hesse in seinem Gedichte „Urbs Norimberga" eine Eisenspalterei mit Streck- und Schneidewerk, die aber wohl nur zur Herstellung von Draht- und Nageleisen verwandt wurde. Auch in den Münzen, wo es besonders auf eine gleichmässige Dicke und Breite der Flachschienen ankam, aus denen die Münzen geschlagen werden sollten, finden wir schon im 16. Jahrhundert zur Herstellung solcher Flachschienen Streckwalzwerke in Gebrauch.

Gegen Ende des 17. Jahrhunderts scheinen die zunãchst in kleinen Massstäben arbeitenden Eisenspaltereien allmählich grösseren Umfang gewonnen zu haben. 1683 erbot sich ein gewisser Johann Friedrich Müller, eine Eisenschneidemühle auf dem Harz anzulegen, auf der man unter anderem schon Eisenstäbe zu Hufeisen bis zu 12 Fuss Länge herstellen könne. Die erste Abbildung einer solchen 
Eisenspalterei aus der Gegend von Lüttich bringt das Werk von Swedenborg De ferro aus dem Jahre 1734. Von Lüttich sollen nach Swedenborg diese Eisenspaltereien von Diderot und d'Alembert vom lahre 1773 (Abbild. 3). Im Hintergrunde erscheint der grosse Glühofen, in welchem die Eisenstäbe, die gestreckt und

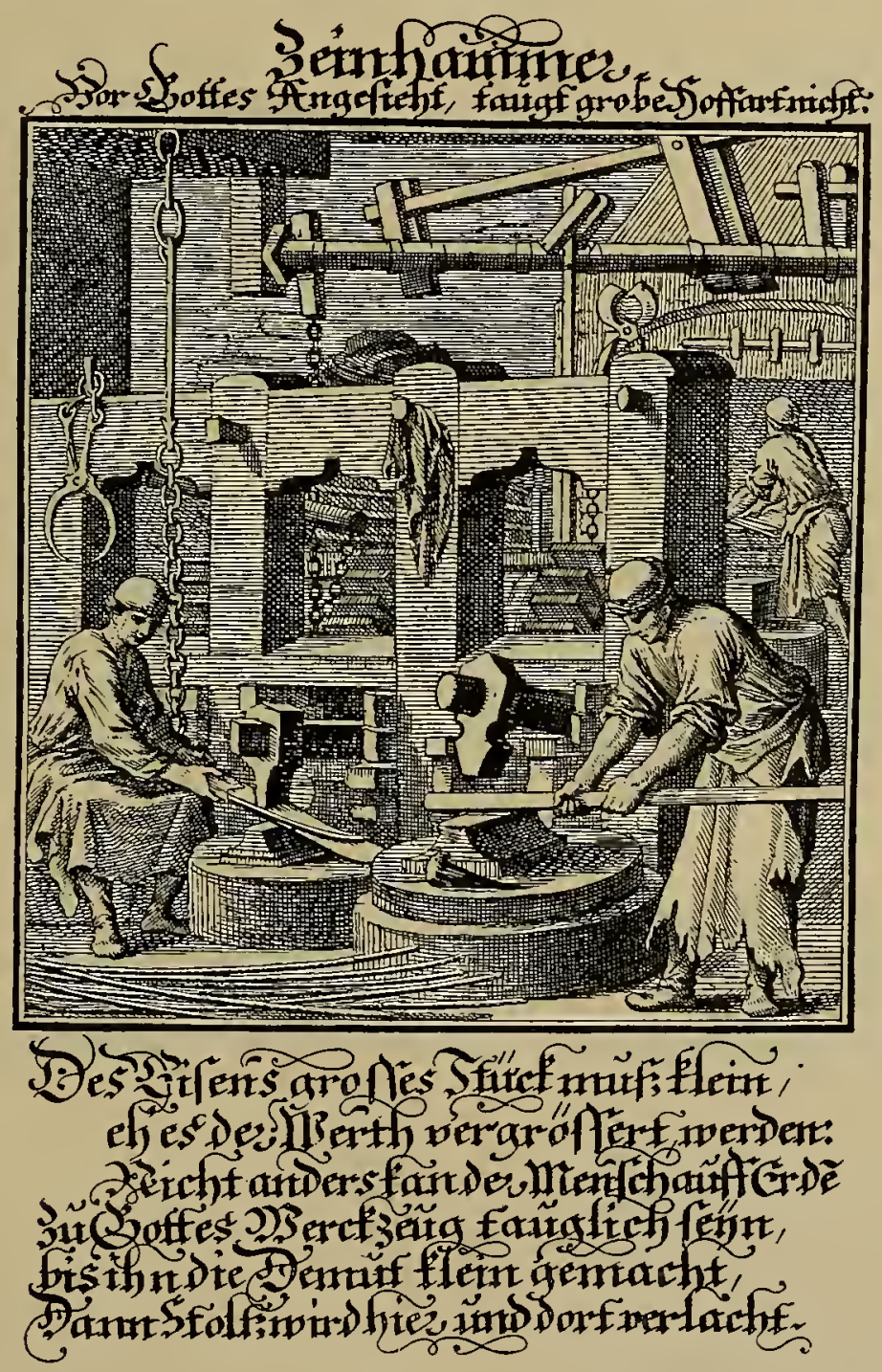

Abb. 2.

Zainhammer (Ch. Weigel, Abbildung der Gemein-Nützlichen Hauptstände, Regensburg 1698).

nach Deutschland und England verbreitet worden und auch in Schweden in Gebrauch gekommen sein.

Eine anschauliche Darstellung solcher Schneidewerke bringt sodann der 3. Tafelband der grossen französischen Encyklopädie dann zerschnitten werden sollen, zunächst erhitzt werden. Ein Arbeiter nimmt mit der Zange das glühende Eisenstück aus dem Ofen heraus und lässt es zwischen zwei Walzen hindurchgehen, welche sich in derselben Weise bewegen, wie die 


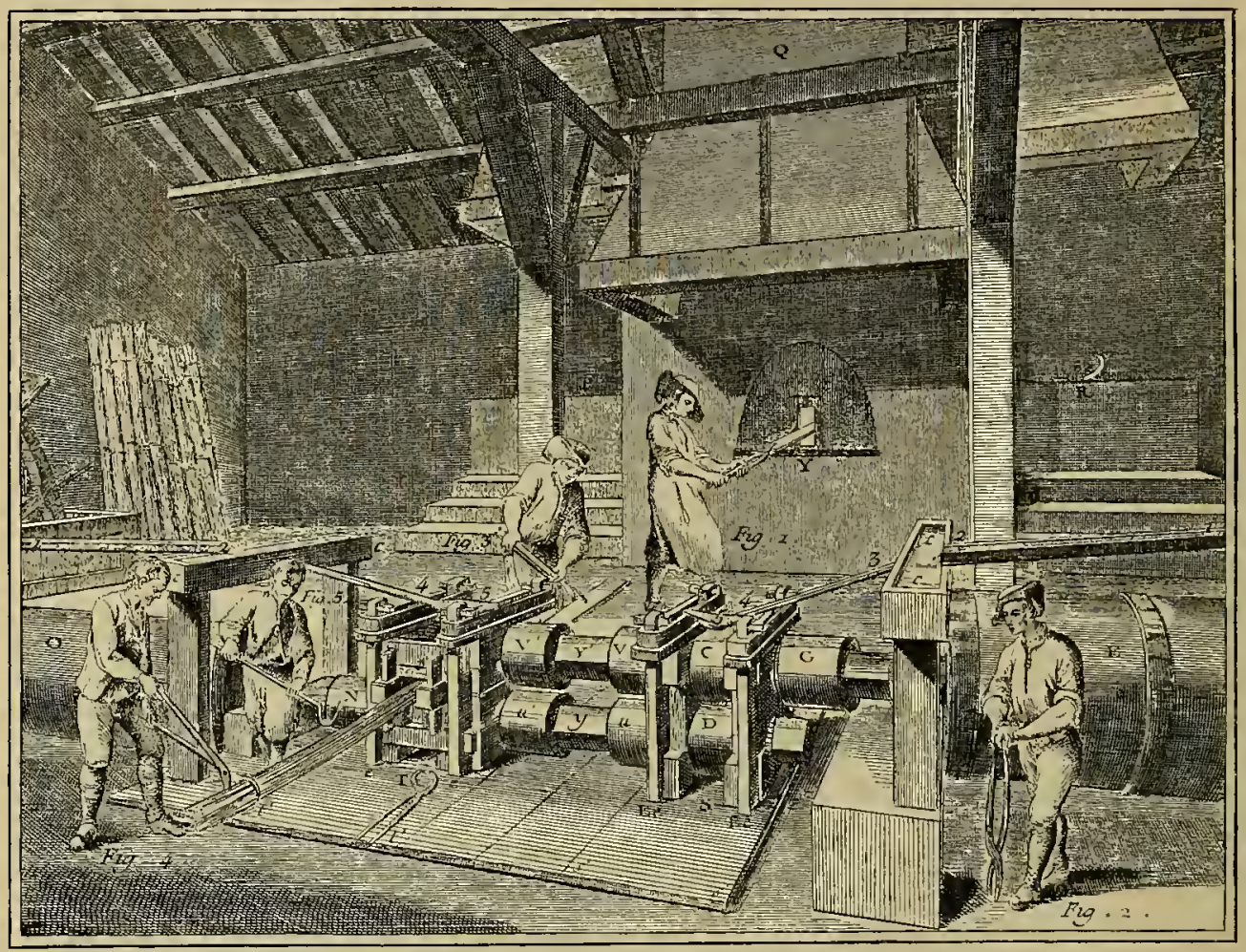

Abb. 3. Eisenspalterei (Diderot et d'Alembert, Encyclopédie, 1773, Planches, Ill, 135).

Walzen einer Wäscherolle. Beim Durchziehen durch die Walzen wird das Eisenstück sowohl dünner und breiter, als auch bedeutend länger. Die so gestreckte Flachschiene wird dann von dem Manne, der auf seine Zange gestützt dasteht, ergriffen, über das Walzwerk seinem Genossen auf der anderen Seite hinübergereicht und geht dann, noch in glühendem Zustande, durch die Schneidewalzen, von denen sie in dünne Stäbe zerschnitten wird. Die Drehung der Walzen geschieht durch Mühlräder. Um die bei der Arbeit sich erhitzenden Walzen abzukühlen, ist eine Leitung eingerichtet, welche ständig Wasser in die siebartigen Schalen oberhalb der beiden Walzenpaare führt, von wo aus es in Tropfen auf die Walzen herabfällt. Jede der Schneidewalzen (Abbild. 4) besteht aus mehreren stählernen Scheiben, welche in Zwischenräumen, die der Dicke der Scheiben gleich sind, nebeneinander auf einer Welle befestigt sind. Indem die Scheiben der oberen Schneidewalze zwischen die Scheiben der unteren greifen, wirken sie wie die Schneiden einer Schere und zerlegen die zwischen sie gebrachte Eisenplatine in einzelne schmale Stäbe, deren Breite der Dicke der Schneidescheiben entspricht, während ihre Höhe von der Stärke der eingeschobenen Platine abhängt. Die Anzahl der auf diese Weise hergestellten Stäbe ist gleich der Summe der Scheiben beider Walzen weniger zwei.

Es gab auch Eisenspaltereien, bei denen, wie bei der im Werke von Swedenborg abgebildeten, die beiden Walzenpaare nicht nebeneinander, sondern hintereinander lagen, so dass die gestreckte Eisenschiene direkt zwischen die Schneidewalzen gebracht werden konnte, das lästige, einen besonderen Arbeiter erfordernde Herüberreichen der gestreckten Schiene infolgedessen fortfiel. Die Streckwalzen wurden nicht nur in Verbindung mit den Schneide- 
walzen, sondern auch für sich allein zur Herstellung flacher Eisensorten und von Blechen verwandt. In der noch näher zu besprechenden Art du serrurier von Duhamel du Monceau von 1767 werden die von den Walzwerken gefertigten Flach. schienen wegen ihrer regelmässigen Gestalt als besonders brauchbar hervorgehoben.

Auch Walzwerke zur Gewinnung von Stäben von verschiedenen Querschnitten kamen im Laufe des 18. Jahrhunderts auf. Schon 1728 erhält der Engländer John Payne ein Patent für ein Façonwalzwerk. Auch der Schwede Christoph Polhem erwähnt 1746 in seinem "patriotischen Testament" Walzwerke zur Herstellung von Stäben verschiedenen Durchschnitts, Teilen von Schlössern und Schlüsseln. Ein Pariser Schlosser, Namens Chopitel ${ }^{1}$ ), er-. richtete zu Essone bei Corbeil ein derartiges Walzwerk, welches am 28. Januar 1751 von einer Kommission der französischen Akademie der Wissenschaften geprüft wurde; es ist ebenfalls in der Encyklopädie abgebildet (Abbild. 5). Dieses Façonwalzwerk unterscheidet sich von dem Streckwalzwerk insofern, als in die obere Walze eine umlaufende Vertiefung eingegraben ist und zwar von der Form, welche dem Stabe mitgeteilt werden soll. Liess man nun einen glühenden Stab durch die Mitte der beiden Walzen gehen, so wurde er nicht nur seiner Länge nach gestreckt, sondern er erhielt auch das in die obere Walze eingeschnittene Profil. In der Abbildung ist die obere Walze noch besonders für sich dargestellt. Darunter ist ein Stück der Welle, welche die untere Walze bewegt, sowie die Kuppelung der Welle und Walze abgebildet.

Im 19. Jahrhundert sind dann diese Walzwerke bedeutend vervollkommnet worden. Die Einführung der Eisenbahnen um 1830 und der dadurch hervorgerufene kolossale Verbrauch von Eisenschienen gab den Anstoss dazu. Der grösste Teil des Stabeisens wird jetzt in den Walz-

1) Siehe: Duhamel du Monceau, Art du serrurier 1767, Seite 64. werken hergestellt. Die Profile sind meistens in beide Walzen je zur Hälfte eingeschnitten; man nennt diese Vertiefungen Kaliber. Da es in der Regel nicht möglich ist, sofort bei einem einmaligen Durchziehen durch ein Walzenpaar dem Stabe die gewünschte Form zu geben, so pflegt man mehrere Walzenpaare hintereinanderzustellen, deren Kaliber allmählich zu der endgültigen Form hinüberführen. Auf diesen Walzwerken werden nicht nur die Rohschienen, sowie die verschiedensten Sorten des Stab- und Profileisens, sondern auch Zierformen allerlei Art, welche in die Walzen eingeschnitten sind, hergestellt. Bekannt sind besonders die Mannstädtschen Ziereisen, welche von dem Walzwerk L. Mannstädt \& Cie. in Kalk bei Köln a. Rh. angefertigt werden. In Hammerwerken werden nur noch in sehr beschränktem Masse die kleineren für Kunstschmiede in Betracht kommenden Eisensorten hergestellt; ebenso macht man von den Eisenspaltereien nur noch wenig Gebrauch, da die geschnittenen

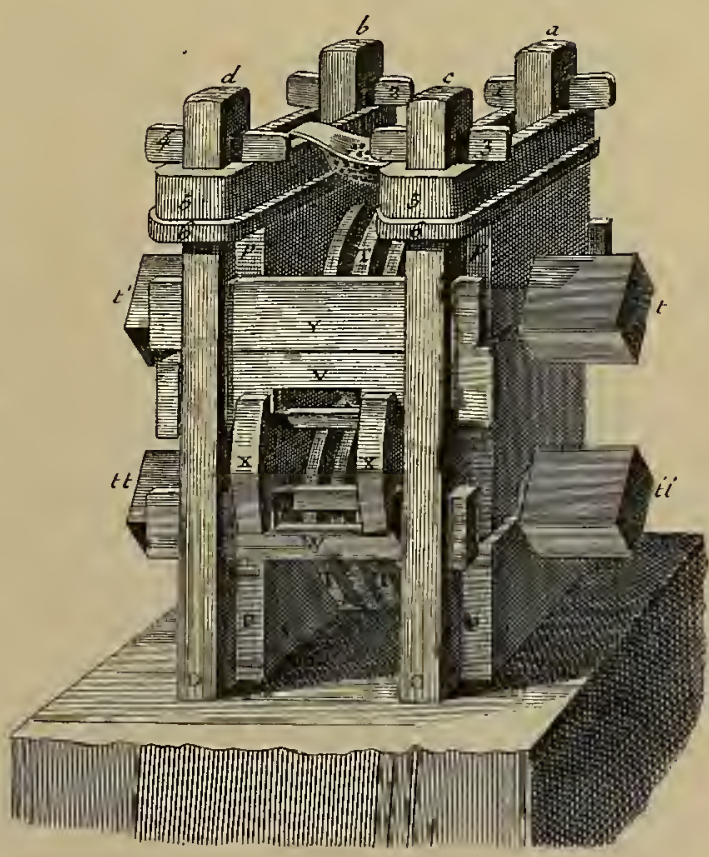

Abb. 4. Schneidewalzen der in der Abb. 3 dargestellten Eisenspalterei (Diderot et d'Alembert, Encyclopédie, 1773, Planches III, 140). 
Stäbe scharfe Grate haben, nie so gleichmässig und haltbar sind, als die gewalzten. Auch das Blech wird nur noch auf Walzwerken angefertigt.

Während die Vorarbeit demnach im Laufe der Jahrhunderte sich wesentlich verändert hat, ist dagegen die weitere Verarbeitung des Schmiedeeisens zu künstlerischen Zwecken, abgesehen von einigen besonderen Zierverfahren, zu allen Zeiten ungefähr dieselbe gewesen. Auch die

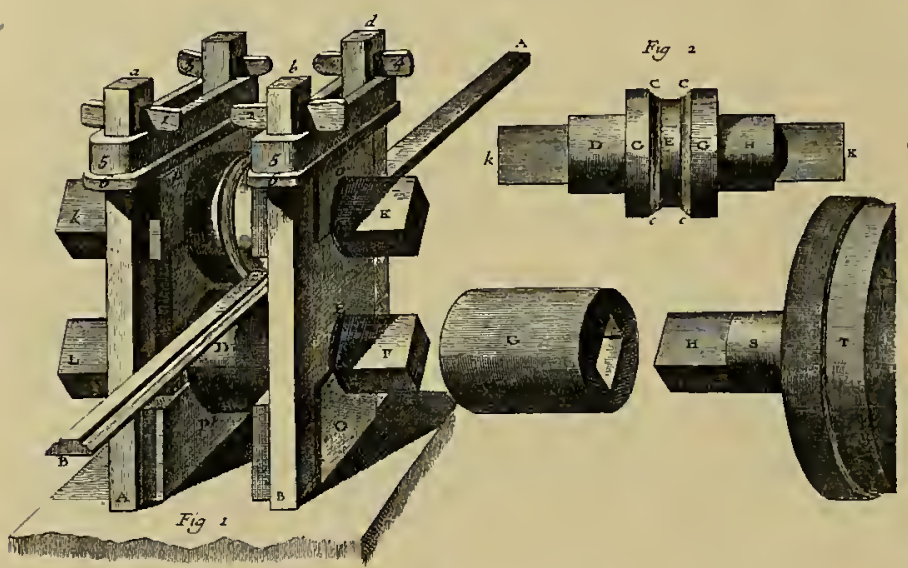

Abb. 5. Façonwalzwerk (Diderot et d'Alembert, Encyclopédie, 1773, Planches III, 137).

Werkzeuge haben sich nur wenig in den letzten Jahrhunderten verändert. Wenn auch die moderne Maschine mancherlei Handleistungen untergeordneter Art übernommen hat, welche der Schlosser früher mit mangelhaften Instrumenten auszuführen pflegte, z. B. Bohrungen, so sind doch die Werkzeuge, mit denen die eigentliche Formgebung des Schmiedeeisens sich vollzieht, fast genau dieselben geblieben. Eine anschauliche Vorstellung von der Einrichtung einer Schmiedewerkstatt und die wichtigsten Arbeiten des Schmiedes im 18. Jahrhundert giebt uns eine ausführliche Abhandlung, welche auf Anregung der französischen Akademie der Wissenschaften 1767 herausgegeben worden ist. Sie ist der Teil eines umfangreichen Sammelwerkes, in welchem eine grössere Anzahl von Handwerken und Industrien beschrieben werden. Die Aka- demie hatte anfangs Réaumur, den Erfinder des nach ihm benannten Thermometers, mit dieser Aufgabe betraut. Réaumur hinterliess indessen nach seinem Tode nur Bruchstücke einzelner Abhandlungen. Dieses Material wurde dann 1759 samt 200 Kupfertafeln, die schon fertig gestellt worden waren, verschiedenen Gelehrten zur Herstellung der "Description des arts et métiers" ïbergeben. Duhamel du Monceau unternahm unter anderem auch die "Art du serrurier ", welche 1767 herauskam, während der grössere Teil der darin enthaltenen Kupferstiche aus den Jahren 1716 und 1717 stammen. Das ganze Sammelwerk erschien seit 1762 in einer deutschen Uebersetzung unter dem Titel „Schauplatz der Künste und Handwerke", herausgegeben von dem National. öknnomen Joh. Heinr. Gottlob von Justi. Das Buch Duhamel du Monceaus wurde von Daniel Gottfried Schreber unter dem Titel „Die Schlösserkunst" übersetzt.

Die erste Tafel des Werkes giebt die Einrichtung einer Schmiedewerkstatt und die wichtigsten Werkzeuge des Schlossers wieder (Abbild. 6). Links im Hintergrunde erscheint der Herd, dessen Feuer durch zwei Blasebälge in die zum Erhitzen des Eisens nötige Glut gebracht wird. Zwei Lehriungen bewirken, indem sie an Ketten ziehen, die Bewegung der Bälge. Ungefähr in der Mitte des Raunies steht ein grosser Amboss mit rechteckiger Bahn, an dem der Meister selbst arbeitet. $\mathrm{Er}$ hält mit einer Zange ein glühend gemachtes Eisenstück und bezeichnet durch Aufschlagen des Hammers die Stellen, auf welche die Schläge der von den beiden Gesellen gehandhabten grossen Hämmer fallen sollen. An einem zweiten Amboss mit zwei Hörnern ist ein anderer 
Geselle im Begriff, mit Meissel und Hammer einen Eisenstab in zwei Teile zu zerlegen. Rechts daneben führt ein Mann an einem grossen Schraubstock eine Vernietung aus. Vier andere Gehilfen arbeiten an der Werkbank vor den Fenstern und links im Vordergrunde mit Feilen.

Unter der Werkstatt sind eine grosse Anzahl Werkzeuge des Schlossers dargestellt, zunächst mehrere Ambosse (Fig. 1-6) von verschiedener Grösse und Gestalt. Die kleineren wurden entweder in eine besondere Oeffnung eines der grossen Ambosse eingezapft (Fig. 2b) oder in einen Schraubstock eingespannt. In Fig. 7-12 sind Hämmer, in $17-23$ Zangen mannigfaltiger Form und in 51-56 grosse und kleine Feilen abgebildet. Zum Festhalten des zu bearbeitenden Eisenstücks dienen die Schraubstöcke $(48,49)$. Der betreffende Gegenstand wird in die Backen derselben, die sich zusammenschrauben lassen, eingespannt. Sie werden an den Werktisch, wie aus der Darstellung der Werkstatt ersichtlich ist, befestigt. Ein kleiner Schraubstock zum Handgebrauch, Handschraube oder Feilkloben genannt, ist in Fig. 50 abgebildet. Feine Gegenstände bringt man nicht direkt zwischen die Backen des Schraubstockes, da sie durch das Gebiss derselben beschädigt werden könnten, sondern sie werden von Kluppen festgehalten (63-66), die man in die Mäuler der Schraubstöcke einspannt. In der hölzernen Kluppe 63 wurden polierte Stücke befestigt. Unentbehrliche Werkzeuge sind sodann die Meissel (Fig. 45 bis 47,62 u. 63). Sie dienen zum $A b$ trennen, Aushauen und zum Einhauen von furchenartigen Vertiefungen. Die Setzhämmer und Setzmeissel (41-44) werden mit der breiten Bahn oder der Schneide auf das Arbeitsstück gesetzt, auf das andere Ende wird dann mit dem Hammer aufgeschlagen. Will man ein Eisenstück mit viereckigen oder runden Löchern versehen, so bedient man sich zur Erweiterung derselben der Dorne. Vier von verschiedener Gestalt sind in Fig. 30-33 abgebildet.
Unter den zu durchlochenden Gegenstand legt man beim Einhauen der Löcher sogen. Lochringe ( 71 u. 72 ) oder ein Eisen von der Form des in Fig. 73 dargestellten. Anstatt der mannigfaltigen modernen Bohrapparate ist hier nur die primitive Bohrrolle (Fiedelbohrer) vorhanden. Dieselbe besteht aus drei Teilen, zunächst einem ovalen Brett mit Handgriff (58), auf dem ein Eisenband mit kleinen Vertiefungen angebracht ist. Dieses setzte sich der Schlosser, wenn er ein Loch bohren wollte, auf die Brust, stellte in eine der Aushöhlungen das untere Ende des Bohrers (57), das andere Ende mit der Schneide richtete er auf die Stelle, wo das Loch gebohrt werden sollte. Die Drehung des Bohrers geschah nun in der Weise, dass der Schlosser die Schnur des Bogens (59) um die Rolle des Bohrers schlang und dann den Bogen auf- und abwärts bewegte, so dass die Rolle samt dem Bohrer sich herumdrehte. Uebrigens gab es ausser diesem Instrument auch noch andere Bohrer, welche aber auch nicht viel vollkommener waren. Von den übrigen Werkzeugen ist noch die Sprenggabel (60) zu erwähnen. Mit ihr biegt man Eisenstäbe, indem man sie vermittels des Hakens festhält. Ausserdem bedarf der Kunstschmied noch verschiedenartiger Messinstrumente, von denen hier zwei Zirkel (37 u. 38), ein Zollstab (34) und Winkelmasse (35 น. 36) abgebildet sind. Zum Bedienen des Feuers sind endlich Kohlenschaufeln (26 u. 27), ein Löschspiess (25), ein Schüreisen (24) und ein Löschwedel (29) zum Anfeuchten der Kohlen erforderlich.

Unter den verschiedenen Arbeiten des Kunstschmiedes steht obenan das Sch mieden, als das dem Charakter des Schmiedeeisens am meisten angemessene Bearbeitungsverfahren. In der Rotglut wird das Eisen so weich, dass es sich leicht mit dem Hammer bearbeiten und in die verschiedensten Formen bringen lässt. Durch wiederholte Hammerschläge kann das Eisenstück verlängert oder verbreitert werden; man nennt das Strecken. An- 
dererseits kann es aber auch verkürzt oder verdickt werden, indem man das Arbeitsstück in der Längsrichtung gegen den Amboss oder einen besonderen Klotz stösst, oder indem man mit dem Hammer auf das Ende desselben kräftig zuschlägt. Diesen Vorgang bezeichnet man als Stauchen. Ein Biegen des Eisenstabes lässt sich leicht bewirken. Ein Abbiegen im rechten Winkel erfolgt durch Herumschlagen um eine Kante des Ambosses, während runde Biegungen an den Hörnern des Ambosses ausgeführt werden.

Von den übrigen beim Schmieden vorkommenden Handgriffen, die natürlich höchst mannigfaltig sind und sich nicht in jedem Falle besonders bezeichnen lassen, ist das Schmieden in Gesenken ein für die Formgebung des Eisens sehr wichtiges Verfahren. Man bedient sich desselben, um einem Stabe ein bestimmtes Profil zu geben oder um kleine Zierrate, welche sich in grösserer Anzahl wiederholen sollen, herzustellen. Während die Gesenke heutzutage durch die Vorarbeit der Walzwerke, welche Stäbe mit den verschiedensten Querschnittprofilen und allerlei Zierrat fertig den Schlossern liefern, für zahlreiche Formen entbehrlich geworden sind, spielten sie in den früheren Jahrhunderten in der Schmiedearbeit eine grosse Rolle. Ihr mannigfaltiger Gebrauch im 18. Jahrhundert wird auf der Tafel IX (Abbild. 7) der "Art du serrurier" von Duhamel du Monceau erläutert, indem gezeigt wird, wie der Schlosser am zweckmässigsten Balkon- und Treppengeländer von der Art der in Fig. 9 und 7 ab. gebildeten herstellen kann, besonders wie er sich die Verfertigung der einzelnen Zierteile durch die Benutzung von Gesenken erleichtern kann. Als Beispiele sind der Teil eines Balkongitters (Fig. 9) und eines nach links umbiegenden Treppengeländers (Fig. 7), welche beide dem Stile nach dem Anfange des 18. Jahrhunderts angehören, gewählt. Um die Umbiegung des Geländers richtig herauszubekommen, bediente man sich eines gewölbten Brettes (Fig. 8), auf dem die Stäbe und Zierteile des Geländers abgepasst wurden; links in der Werkstatt ist ein Geselle (Fig. 5) mit dieser Arbeit beschäftigt. $\mathrm{Da}$ die Gitter sich aus einer grossen Zahl gleichartiger Formen zusammensetzen, so erleichterte man sich die Herstellung dieser oft wiederkehrenden Zierteile durch verschiedene Hilfsmittel. Für die C-förmig gebogenen Stäbe waren besondere eiserne Lehren vorhanden (Fig. 10), an denen die in Fig. 11 dargestellten Schnörkel gebogen wurden. Die Verbindung der Stäbe zu einem Ganzen geschah zum Teil durch umgelegte profilierte Leisten, die man Bunde nennt (Fig. $7 \mathrm{~N}, 9 \mathrm{~N}$ u. a). Die verschiedenen Teile eines solchen Bundes sind in Fig. 12 dargestellt, unter a die Leisten, aus denen die Bunde angefertigt wurden. Fig. 13 giebt eine Spannkluppe zum Festhalten der Bunde bei der Arbeit wieder. Um nun das Profil dieser Leisten herzustellen, bedient man sich der Gesenke, d. h. verstählter Hohlformen, welche auf dem Amboss (Fig. 15 u. 16) durch Bänder befestigt werden. Wird nämlich ein Eisenstab glühend in das Gesenk eingeschlagen, wie es in der Werkstatt rechts geschieht (Fig. 1 u. 2), so erhält er die Form des eingegrabenen Profils, ebenso wie glühendes Siegellack die Gestalt des in das Petschaft eingravierten Siegels annimmt. Um den zweiten Arbeiter zu ersparen, war zum Festhalten des Stabes auf dem Gesenk zuweilen noch eine Klammer an dem Amboss befestigt (Fig. 16i, k, 1).

Auch bei der Verfertigung der sich wiederholenden Planzenformen wird von Gesenken Gebrauch gemacht. Die zum Schmuck der beiden Gitterteile verwandten ausgezackten (Akanthus-)Blätter (Fig. $7 \mathrm{~K}$ u. $9 \mathrm{~K}$ ) können nämlich in folgender Weise ausgeführt werden. Zunächst wird ein Stück Blech zu der in Fig. $18 \mathrm{u}$ abgebildeten Form ausgeschnitten. Um sodann dem Oberteil dieses Blattes die Form zu geben, die es in $u_{2}$ und $u_{3}$ hat, benutzt man ein doppeltes Gesenk, ein Unter- und Obergesenk (Fig. $19 t_{1}$ u. $t_{3}$ ). Leider giebt die $\mathrm{Ab}$ bildung keine gute Vorstellung, da der 


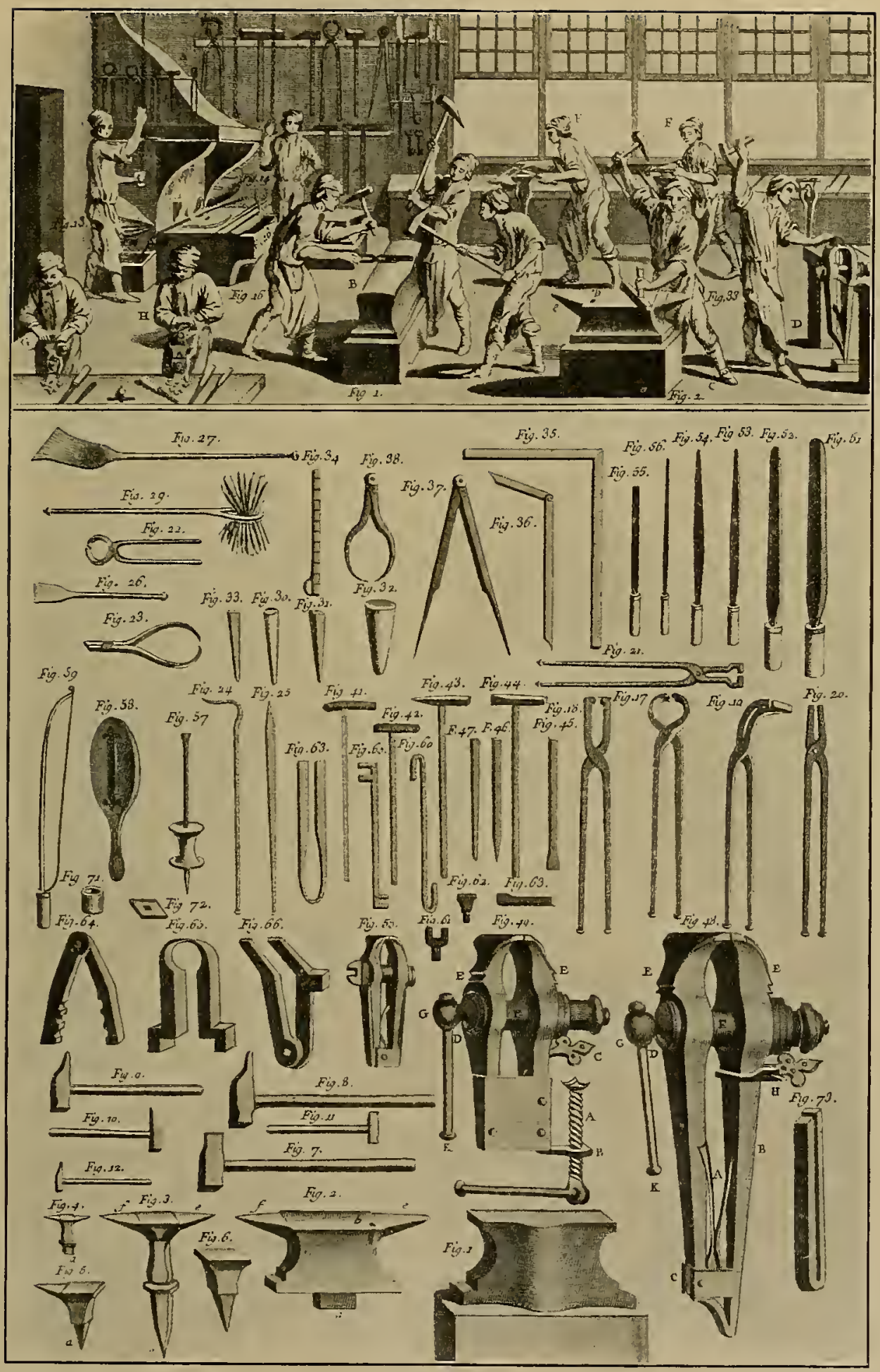

Abb. 6.

Die Werkzeuge des Schlossers (Duhamel du Monceau, Art du serrurier, 1767, pl. I). 
Massstab beider, doch zusammengehörender Gesenke verschieden ist. Auch sonst lässt die Zeichnung sowohl bei dieser wie bei anderen Tafeln viel $z u$ wünschen übrig. In dem Untergesenk (Querschnitt desselben in $t_{2}$ ) ist die Form der Blattspitze hohl, auf dem Obergesenk erhaben dargestellt. Legt man nun die Spitze des Bleches $\mathfrak{u}$ auf das Untergesenk, setzt das Obergesenk darüber und schlägt kräftig mit dem Hammer auf dieses, wie der Mann in Fig. 3, so erhält das Blatt die in $u_{2}$ vorgeführte Form. Man kann auch diese Form mit dem einfachen Gesenk $t_{4}$ zu stande bringen. Dann gilt es, dem bis dahin flachen Blatte eine rinnenförmige Gestalt zu geben, wie in $u_{4}$. Das erreicht man leicht durch Einhämmern in das runde Gesenk $t_{5}$. Die Umbiegung des Blattes $w_{4}$ u. ff. geschieht mit Hilfe der Gabel $t_{6}$, in welche man die Spitze des Blattes hineinlegt. Die wellenförmige Auszackung des Blattes endlich $\left(u_{6}\right.$ und $\left.u_{7}\right)$ wird aus freier Hand auf besonderen kleinen Ambossen $t_{7}$ verrichtet. Ebenso werden die Zierknöpfe des aus den Blättern hervorwachsenden Schosses (Fig. 7M u. 9M) vermittelst eines Doppelgesenkes (Fig. 21) hergestellt. Zur Verfertigung kleiner Zierrate benutzt man auch Doppelgesenke in Form von Zangen. Fig. $20 \mathrm{D}_{2}$ stellt einen Palmzweig dar, der von Epheuranken umwunden ist. Die Palmblätter werden aus den Blechen $B_{2}$ mit Benutzung der Zange $\mathrm{A}_{2}-4$ geformt. Die Schnejden dieser Zange bilden nämlich ein Ober- und Untergesenk (Querschnitt in mangelhafter Darstellung in $A_{3}$ ). Die einzelnen so gewonnenen Palmblätter werden dann zu mehreren zusammengeschweisst und mit Nieten $\left(B_{4}\right)$ am $Z$ weige befestigt. Die allmähliche Entstehung der Epheuranke wird aus den Abbildungen $E_{2-7}$ ersichtlich. Die übrigen auf der Tafel in Fig. 22-24 dargestellten Werkzeuge sind Bohrwerkzeuge. Eins derselben wird von dem Manne Fig. 6 benutzt.

Einen wesentlichen Anteil an der Herstellung von Kunstformen hat sodann die Treibarbeit, die bei dünnen Blechen auch in kaltem Zustande ausgeführt werden kann. Auch hier mag eine Tafel (XI) des Werkes von Duhamel du Monceau, welche die Unterschrift trägt: „Reniere del 1717 Lucas scul.", als Illustration dienen (Abbild. 8). Als Beispiel ist hier ein Akanthusblatt gewählt, das in seiner vollen Grösse zunächst auf Papier vorgezeichnet (Fig. $8 \mathrm{n}$ ), und dann auf Blech gepaust wurde. Aus den Blechen wird es darauf ausgehauen, und zwar in drei Stücken $T, V, X$. Diese Teile werden getrieben $\left(T_{2}, V_{2}, X_{2}\right)$ und mit Nieten aneinander befestigt. Die endgültige Form des Blattes erscheint in Fig. Y.

Die Treibarbeit, bei der das Eisen leicht hart und brïchig wird und deshalb öfter ausgeglüht werden muss, geschah zunächst auf sogenannten Untersätzen, von denen mehrere in Fig. $6 \mathrm{E}-\mathrm{K}$ abgebildet sind. Der Untersatz $K$ dient als Lochring, $L$ als Dorn; zu denselben $Z$ wecken, nämlich zur Herstellung von Löchern oder kleiner grubenartigen Vertiefungen, kann M gebraucht werden. Die Untersätze wurden in den Schraubstock gespannt und dann das Blech mit Hämmern (Fig. 7 A-D) bearbeitet. Die verschiedenartige Form der Untersätze und Hammerbahnen kommen der Herstellung vielfacher Formen, Furchen, runder oder länglicher Vertiefungen u. s. w. entgegen. In der Werkstatt sind die beiden Leute rechts und links im Vordergrunde mit dieser Art der Arbeit beschäftigt. Die feinere Treibarbeit wird auf einem Holzklotz (Fig. 12) oder besser auf Blei ausgeführt. Das auf den Untersätzen vertiefte Blech wird auf der Rückseite mit Blei ausgegossen und dann von vorn mit Punzen verschiedener Gestalt (Fig. 16c-h) bearbeitet. Zum Festhalten des Bleches auf dem Holzklotz dienen die in Fig. 13 dargestellten Nägel. In der Werkstatt treiben die beiden Arbeiter in der Mitte auf Blei. Handelt es sich darum, einen Gegenstand herzustellen, der aus zwei gleichen Hälften besteht, wie der Akanthuskeich Fig. $9 \mathrm{~m}$, so kann man beide Seiten zugleich treiben, indem man, wie auf Fig. $9 \mathrm{i}$ ersichtlich 


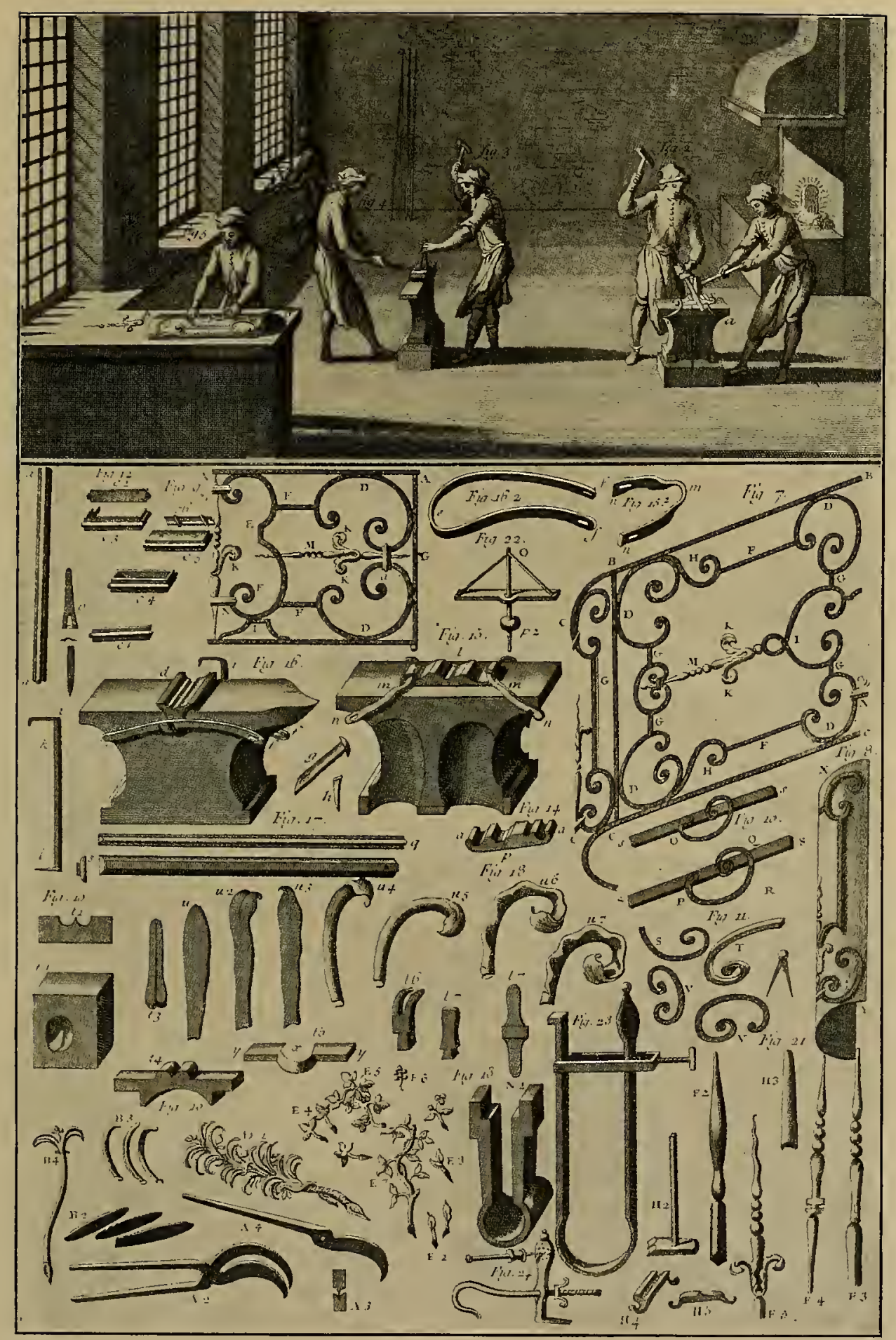

Abb. 7.

Das Schmieden in Gesenken (Duhamel du Monceau, Art du serrurier, 1767, pl. IX). 
ist, zwei Bleche ïbereinander legt und sie dadurch vor dem Verschieben bewahrt, dass man ihre Ecken umschlägt. Die in Fig. $11 \mathrm{~A}-\mathrm{Y}$ dargestellten Stücke veranschaulichen die Herstellung einer grossen eisernen Vase.

Ausser durch Treibarbeit kann auch durch Gravierung die breite Fläche des Eisenbleches Belebung erfahren. Sie besteht darin, dass mit dem Grabstichel eine Zeichnung in den Grund vertieft eingeschnitten wird. Mit dieser Technik verwandt ist das Verfahren, durch Einhauen mit dem Meissel oder durch das Einschlagen von Punzen Linien und Punkte hervorzubringen.

Auch der Eisenschnitt geschieht ebenso wie das Gravieren in kaltem $\mathrm{Zu}$ stande. Der betreffende Gegenstand, Thürklopfer, Schlüsselgriff u. a. wird zunächst in rohen Formen vorgeschmiedet und dann mit Bohrern, Meisseln, Grabsticheln u. s. w. weiter bearbeitet. Die Kunstform wird auf diese Weise aus dem rohen Eisenstück herausgeholt, wie die Statue aus dem Marmorblock. Gleichmässige Rundungen werden auf der Drehbank ausgeführt.

Ein besonders im 16. Jahrhundert geübtes Verfahren, welches im 19. Jahrhundert wieder hier und da aufgenommen worden ist, ist das Aetzen. Es ist eine ähnliche Technik, wie sie bei der Radierung in Gebrauch ist. Die Eisenfläche wird zunächst mit dem sog. Aetzgrund überzogen, für den es verschiedene Recepte giebt, z. B. Asphalt-Terpentinlack oder Wachs und Asphalt zu gleichen Teilen in Terpentin aufgelöst. ${ }^{1}$ ) Wie aber auch seine Zusammensetzung sein mag, jedenfalls muss er die Eigenschaft haben, das Eisen vor dem Angriff von Säuren zu schützen. In diesen auf das erwärmte Eisen aufgetragenen Aetzgrund wird die Zeichnung mit einem Griffel eingeritzt, der das Eisen blosslegt. Dann wird ein Rand von Wachs um die Platte gelegt und auf die Zeich-

1) Vgl. Krauth und Meyer, das Schlosserbuch I. Leipzig 1891. S. 79 . nung Aetzwasser gebracht, welcher den freigelegten Grund tief ätzt. Als geeig. netes Aetzwasser werden vier Teile konzentrierter Essigsäure, ein Teil absoluten Alkohols und ein Teil konzentrierter Salpetersäure empfohlen. ${ }^{2}$ ) Wird schliesslich, nachdem das Aetzwasser genügend lange gewirkt, der Aetzgrund entfernt, so steht die Zeichnung vertieft auf dem blanken Eisengrunde oder umgekehrt. Um die Ornamente noch besser hervorzuheben, reibt man die Vertiefungen mit einer schwarzen oder andersfarbigen Masse ein. Charakteristisch für die geätzte Arbeit sind die kleinen Unregelmässigkeiten der Linien, welche nie so gleichmässig glatt gezogen sind, als es bei der Gravierung der Fall ist. Aber gerade darin liegt auch wieder ein besonderer Reiz der geätzten Arbeit.

Unter den Arbeiten des Schmiedes, welche die Zusammensetzung der einzelnen Teile zu einem Ganzen bezwecken, steht obenan die Schweiss. arbeit als die dauerhafteste Eisenverbindung. Gewöhnlich werden die beiden Eisenstücke, welche aneinandergeschweisst werden sollen, an den Verbindungsstellen abgeschrägt und diese schrägen Flächen beim Schweissen aufeinandergelegt. Da bei grösseren Stücken die Schweissung mit sehr viel Schwierigkeiten verbunden ist, so ersetzt man sie vielfach durch die kalte Nietung, bei der die zu verbin. denden Teile durchlocht und vermittels eines Nietnagels vereinigt werden. Das Löten mit Kupfer und Messing findet nur selten Anwendung und auch dann nur bei kleineren Stücken. Von anderen Eisenverbindungen ist der Bund schon erwähnt (S. 12). Die Durchschiebung, bei welcher der eine Stab durch Aufhauen gelocht und ein zweiter durchschoben wird, ist ein besonders beliebtes Verfahren bei deutschen Gittern des 16. und 17. Jahrhunderts.

Der vornehmste farbige Schmuck des Eisens ist die Tauschierarbeit, bei der Gold-, Silber-, Kupfer- oder Messing-

2) Krauth und Meyer a. a. O., S. 79. 


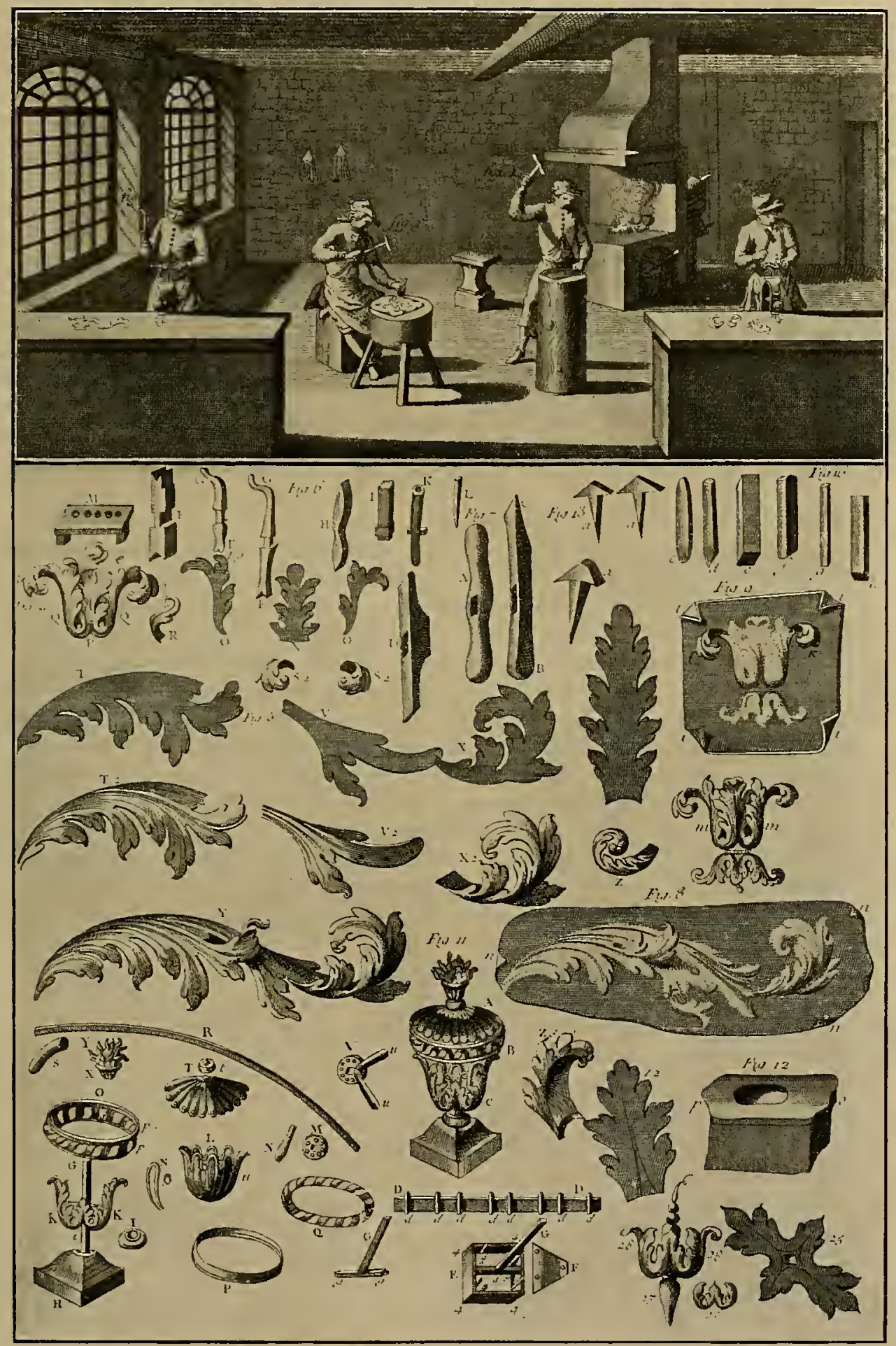

Abb. 8 .

Die Treibarbeit (Duhamel du Monceau, Art du serrurier, 1767, pl. XI). 
teilchen in das Eisen eingelegt werden. Entweder rauht man den Grund feilenartig auf, hämmert die ein bestimmtes Ornament bildenden Goldteilchen darauf fest und glättet dann die Oberfläche wieder, oder man graviert Linien in die Oberfläche des Eisens und schlägt dünne Drähte des andersfarbigen Metalls ein.

Während die Tauschierarbeit nicht nur auf Eisen, sondern auch auf Messing und Bronze vorkommt, ist dagegen die sog. Blaumalerei eine dem Eisen speciell eigentümliche Dekoration. Sie beruht auf der Eigenschaft des polierten Eisens, beim Erhitzen anzulaufen und verschiedene Farben anzunehmen. Man lässt zunächst die Fläche blau anlaufen, überzieht sie dann mit Wachs und stellt durch Abnehmen desselben das erwünschte Bild oder Ornament her. Die Bläuung entfernt man von den blossgelegten Stellen, indem man das Eisenstück für eine kurze Zeit in eine schwache Säure taucht. Nach dem Abwaschen des Aetzgrundes steht dann die Zeichnung blank auf blauem Grunde oder umgekehrt. Zumeist wird die Zeichnung noch durch eingravierte Linien umschrieben, um sie schãrfer vom Grunde abzuheben. Man kann auch die Zeichnung aus dem blauen Grunde ausschaben. Soll ein Teil der Oberfläche oder auch der ganze
Gegenstand den blanken Glanz des Stahles erhalten, so feilt man die obere Haut ab, schleift das Eisen mit Schmirgel oder poliert es mit feinem Pulver.

Ein anderes Mittel, die Oberfläche des Eisens zu veredeln, besteht in dem Ueberziehen mit anderen Metallen, mit Gold, Zinn u. s. w. Beim Vergolden bedient man sich entweder der Feuervergoldung, bei der das Gold als Amalgam aufgetragen und dann das Quecksilber durch Erhitzen verdampft wird, oder der Blattvergoldung, bei der das Gold in Blattform aufgetragen wird.

Sowohl zur Verfeinerung der Oberfläche wie zum Verhüten des Rostes dient auch die Bemalung mit Oel-oder Lackfarben. Während man heutzutage Gitter und andere Eisenarbeiten gewöhnlich schwarz anzustreichen pflegt, liebte man in früheren Jahrhunderten eine reiche Vergoldung und Bemalung. Zur Zeit der Renaissance prangte das Gitterwerk im Schmucke verschiedener Farben und Vergoldung. Später pflegte man zumeist das Stabwerk grün oder schwarz anzustreichen, die Ornamente aber zu vergolden, nicht nur in einfarbigem, sondern auch mehrfarbigem Golde. Doch machte man auch noch im 18. Jahrhundert von der bunten Bemalung Gebrauch. 


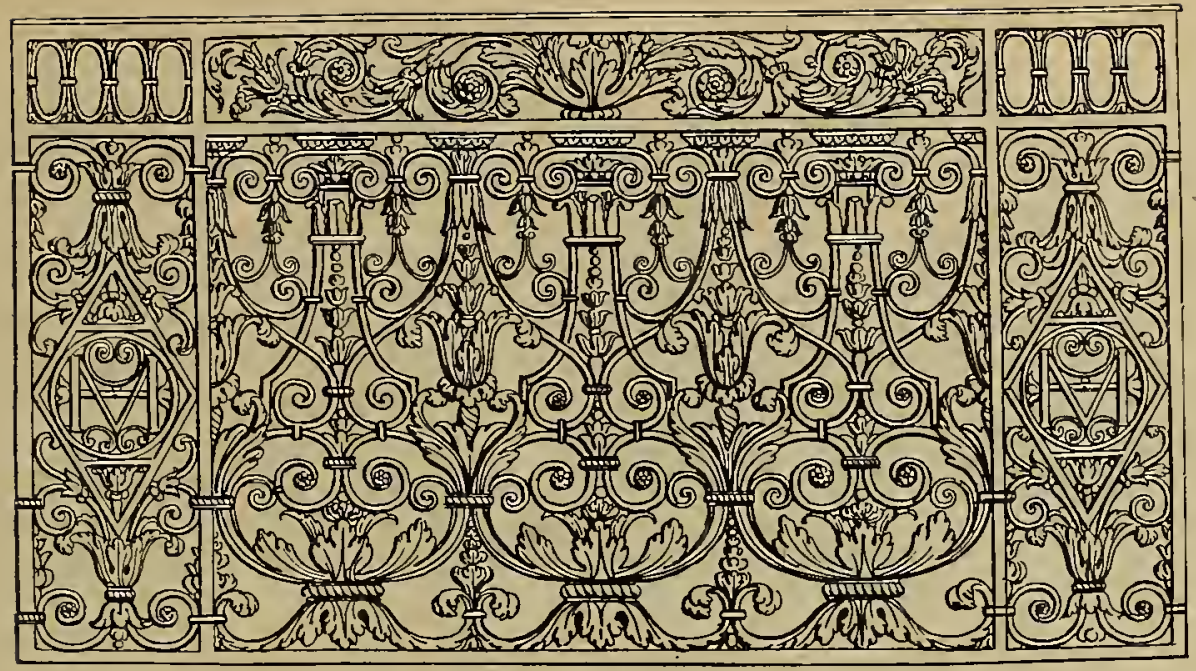

Abb. 9. Balustrade nach einem Stiche von 1. Marot.

\section{Die französische Schmiedekunst unter Ludwig XIV.}

Die Geschichte der Kunst kennt keine Revolutionen. Niemals bedeutet der Uebergang zu neuen Stilformen einen schroffen Bruch mit der Vergangenheit. Noch lange lebt das Alte neben dem Neuen einträchtig beisammen. Auch die glanzvolle Erhebung der französischen Kunst unter der Regierung Ludwigs XIV. beruhte auf den sicheren Fundamenten alter, lang. bewährter Kunstübung und gestattete neben sich ein ruhiges Fortleben der alten Formen. Besonders auf denjenigen Gebieten des Kunstschaffens, die nicht so leicht dem Wechsel der Mode folgen, wie gerade in der Schmiedekunst, macht sich das Alte noch lange geltend.

Freilich lässt sich nur annähernd eine Vorstellung gewinnen, wie die Entwicklung der Kunstformen auf dem uns beschäftigenden Kunstgebiete sich vollzog. Denn von all den zahlreichen Schmiedewerken, welche die französischen Schlösser, Kirchen, Staatsgebäude und Privathäuser schmückten, ist fast nichts mehr erhalten. Was nicht im natürlichen Laufe der Dinge der Zeit zum Opfer fiel, vernichteten die Stürme der Revolution. Die köstlichen Schmiedearbeiten, welche unter den letzten drei Königen geschaffen worden waren, wurden zu Waffen gegen das eigene Volk und auswärtige Feinde umgeschmiedet.

Zum Glück ist man indessen nicht auf die wenigen erhaltenen Werke allein angewiesen. Eine reiche Quelle für die Erkenntnis des französischen Kunstgewerbes, insbesondere der Schmiedekunst, bilden die sog. Ornamentstiche, das sind Kupferstiche und Radierungen von Entwürfen für die dekorativen Künste und Abbildungen ausgeführter Arbeiten, die als Vorbilder verbreitet wurden. Sie sind zum Teil von Schlossern selbst, zum andern Teil von Architekten und berufsmässigen "Dessinateurs", d. h. Zeichnern für das Kunstgewerbe, ausgeführt worden. Dazu kommen die vereinzelt in Stichen und Abbildungswerken zumeist im $\mathrm{Zu}$ sammenhange mit der Architektur dargestellten Schmiedearbeiten. Während die in Deutschland erhaltenen Arbeiten an Zahl die in den Ornamentstichen und sonstigen Abbildungen wiedergegebenen Schmiedewerke weit übertreffen, ist dagegen in Frankreich die Anzahl der noch vorhandenen Schmiedearbeiten von Ludwig XIV. bis zum ersten Kaiserreich sehr gering. 


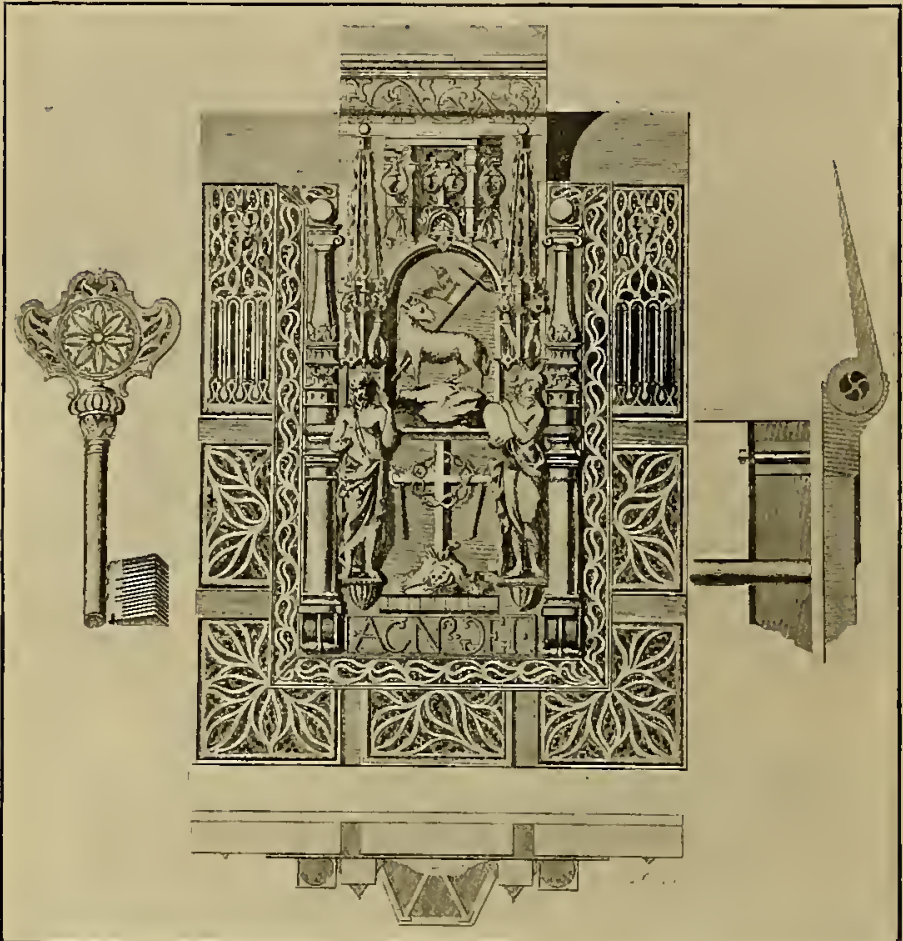

Abb. 10. Truhenschloss aus J. Lamour, Recueil des ouvrages en serrurerie.

Der Mittelpunkt künstlerischer Thätig. keit in Frankreich während dieses Zeitraumes war die vom Minister Colbert 1662 in Paris gegründete Manufacture royale des meubles de la couronne, in der Künstler und Handwerker durch grossartige Arbeiten für die Schlösser der französischen Krone herangebildet wurden. Während von hier aus die neuen Gedanken der Künstler, in den verschiedenen Zweigen des. Kunstgewerbes zur Verkörperung gebracht, ihren Siegeszug über die Grenzen Frankreichs antraten, gab es eine andere Stätte, wo sogar noch mittelalterliche Kunstformen ein kümmerliches Dasein fristeten, von den verknöcherten Satzungen einer greisenhaften Einrichtung in starrer Unerbittlichkeit festgehalten, nämlich die Zunft.

Seitdem Karl VI. 1411 im 17. Artikel der Statuten ${ }^{1}$ ), welche er den Schlossern gegeben, die Anfertigung eines mit besonderen

1) Duhamel du Monceau, a. a. O., S. 203.
Zierraten versehenen Truhenschlosses an die Erlangung des Meisterrechts geknüpft hatte, hatte die Zunft durch drei Jahrhunderte hindurch an der Verfertigung eines solchen Meisterstückes streng festgehalten. Die gotischen Ornamente, mit denen die Schauseite der Schlösser im 15. Jahrhundert geschmückt worden war, wurden bis zum 18. Jahrhundert zum grössten Teil beibehalten. $\left.{ }^{2}\right)$ Die Formgebung der figürlichen Zierrate und mancher Einzelheiten konnte sich freilich der wechselnden Mode nicht ganz entziehen. In der Art du serrurier von Duhamel du Monceau ist in dem Abschnitt über die Schlösser, welcher noch von Réaumur selbst verfasst ist, ein derartiges Truhenschloss auf der Tafel 29 abgebildet, die Tafel ist im Jahre 1716 gestochen. Vielleicht ist auch Réaumurs Abhandlung nicht viel später entstanden. Nach des Verfassers Angaben sei das Schloss vor mehr als 40 Jahren von einem Schlosser Namens Bridou angefertigt, der zu den Aeltesten der Innung gehört habe. Es ist also wohl in den letzten Jahrzehnten des 17. Jahrhunderts entstanden.

Auch Jean Lamour, der berühmte Hofschlosser des Königs Stanislaus Leszczynski in Nancy, bildet in seinem Recueil des ouvrages en Serrurerie von 1767 ein derartiges Schloss ab, das nach der Griffform des zugehörigen Schlüssels zu Anfang des 18. Jahrhunderts hergestellt sein wird (Abbild. 10). Nach Lamour wurden auch noch zu seiner Zeit solche

2) Auch beiden Meisterstücken der Gürtler, den Gürtelbeschlägen, finden wir eine ähnliche Erscheinung. 
Schlösser, die damals den sonderbaren Namen serrures à la moderne führten, angefertigt. Der Oberteil des Mittelstückes und die beiden Säulen bilden den Fallriegel, der, in einem Scharnier laufend (vergl. den Querschnitt), am Deckel der Truhe befestigt wurde. Zwischen den Säulen stehen Johannes der Täufer und Moses, von gotischen Spitzbaldachinen überdacht. Johannes weist auf das Kreuzeslamm über ihnen hin, das ebenfalls von einem Baldachin überragt wird. Unter dem Lamm ist auf einer besonderen Platte das Kreuz mit Marterwerkzeugen und Totenschädel angebracht. Wahrscheinlich verdeckte diese Platte das Schlüsselloch, das stets auf ähnliche Weise gesichert war. Durch den Druck auf eine Feder, die nur dem Besitzer des Schlosses bekannt war, sprang die Platte auf. Lamour verrät das Geheimnis seines Schlosses nicht. Rings um das Mittelstück sind Füllungen mit gotischen Masswerkornamenten u. s. w. angebracht. Im 15. Jahrhundert pflegten diese Schlösser nicht selten mit zahlreichen Heiligenfiguren oder auch biblischen Scenen geschmückt zu sein. Beliebt war besonders die Darstellung der Kreuzigung. Eines der schönsten Schlösser dieser Art stellt das Jüngste Gericht dar. ${ }^{1}$ ) - Auch der bei Lamour abgebildete zugehörige Schlüssel, der übrigens mit den. alten gotischen Schlüsseln in der Form wenig gemein hat, ist besonders kunstvoll gearbeitet. Der Griff zeigt in der Mitte eine Rosette, die von Masswerkornamenten umgeben ist, als Verbindung mit dem Rohr dient ein kapitälartiges Ornament. Der Bart ist mit vierzehn Einstrichen versehen. Bei anderen Schlüsseln war der Bart ausser mit diesen Zähnen auch noch mit zahlreichen Durchbrechungen versehen, denen natürlich in der Schlüsselhülse Führungen von gleichem Querschnitt entsprechen mussten. Nach den Mitteilungen Réaumurs

1) Abbildung in La collection Spitzer, Tafelband 11, Serrurerie p1. 1. betrug die geringste Anzahl der Durchbrechungen 7 , sie konnten aber bei den Bewerbern, die kein besonderes-Vorrecht, wie etwa die Söhne von Meistern, besassen, bis auf 21 erhöht werden. Gewöhnlich pflegte man, wenn mehrere Gesellen zugleich sich bewarben, jedem eine Durchbrechung mehr, wie seinem Vorgänger, zu geben. Die Arbeit an einem solchen Schlosse dauerte 1-2 Jahre. Da das Ganze nur darauf hinaus kam, möglichst von der Bewerbung um das Meisterrecht abzuschrecken, so wurden nach Réaumur durch eine Bestimmung vom 20. Juli 1699 andere, leichtere Meisterstücke den Gesellen auferlegt.

Auch sonst lebten in den ersten Jahrzehnten der Regierung Ludwigs XIV. (1643-1715) ältere Formen neben den neuen weiter fort. Noch lange erhielt sich, besonders bei kleineren Arbeiten, Schlossbeschlägen u.s. w., die Ornamentik, welche in der ersten Hälfte des 17. Jahrhunderts in der Schmiedekunst geherrscht hatte. Es scheint, dass die Ursache dieser Fortdauer älterer Formen besonders einem Werke zuzuschreiben ist, das auch

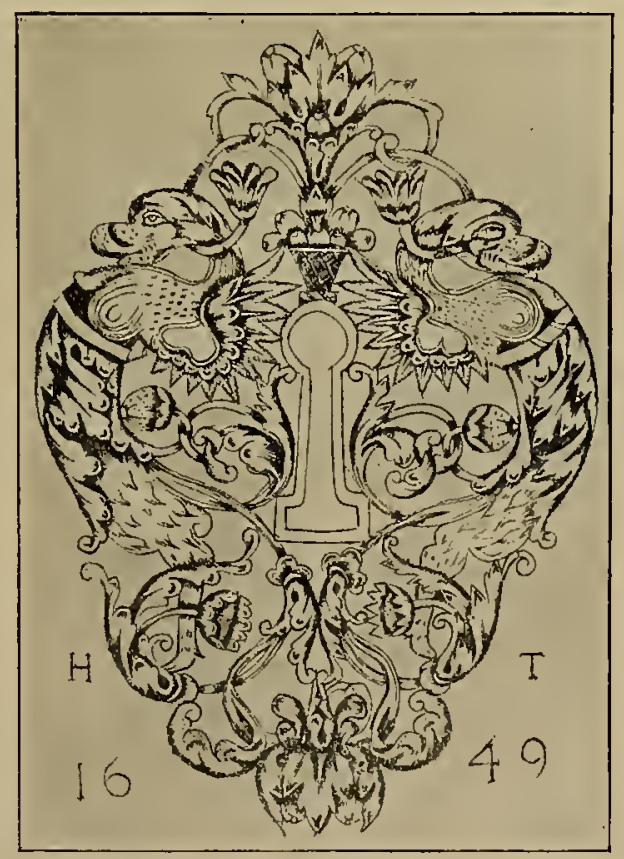

Abb.11. Schlüsselschild. Stich, bez. H T 1649. 
noch bis tief ins 18 . Jahrhundert hinein sich eines hohen Ansehens bei den französischen Schlossern erfreute, nämlich dem Schlosserbuch des Mathurin Jousse, mit französischem Titel: „La fidelle ouuerture de l'art de Serrurier", welches zu La Flèche an der Loire 1627 erschien. ${ }^{1}$ ) Das Buch ist von Félibien in seinen "Principes de l'architecture“ 1697 benutzt groteske Kompositionen, aus Figuren und Pflanzenmotiven gebildet.

Ganz denselben Charakter tragen nun auch eine Reihe von Stichen des 17. Jahrhunderts, wenn auch im einzelnen kleine Abwandlungen stattgefunden haben. Sie sind zumeist von ziemlich roher und ungelenker Strichführung, welche die schwere Hand des Schlossers, die mehr an die

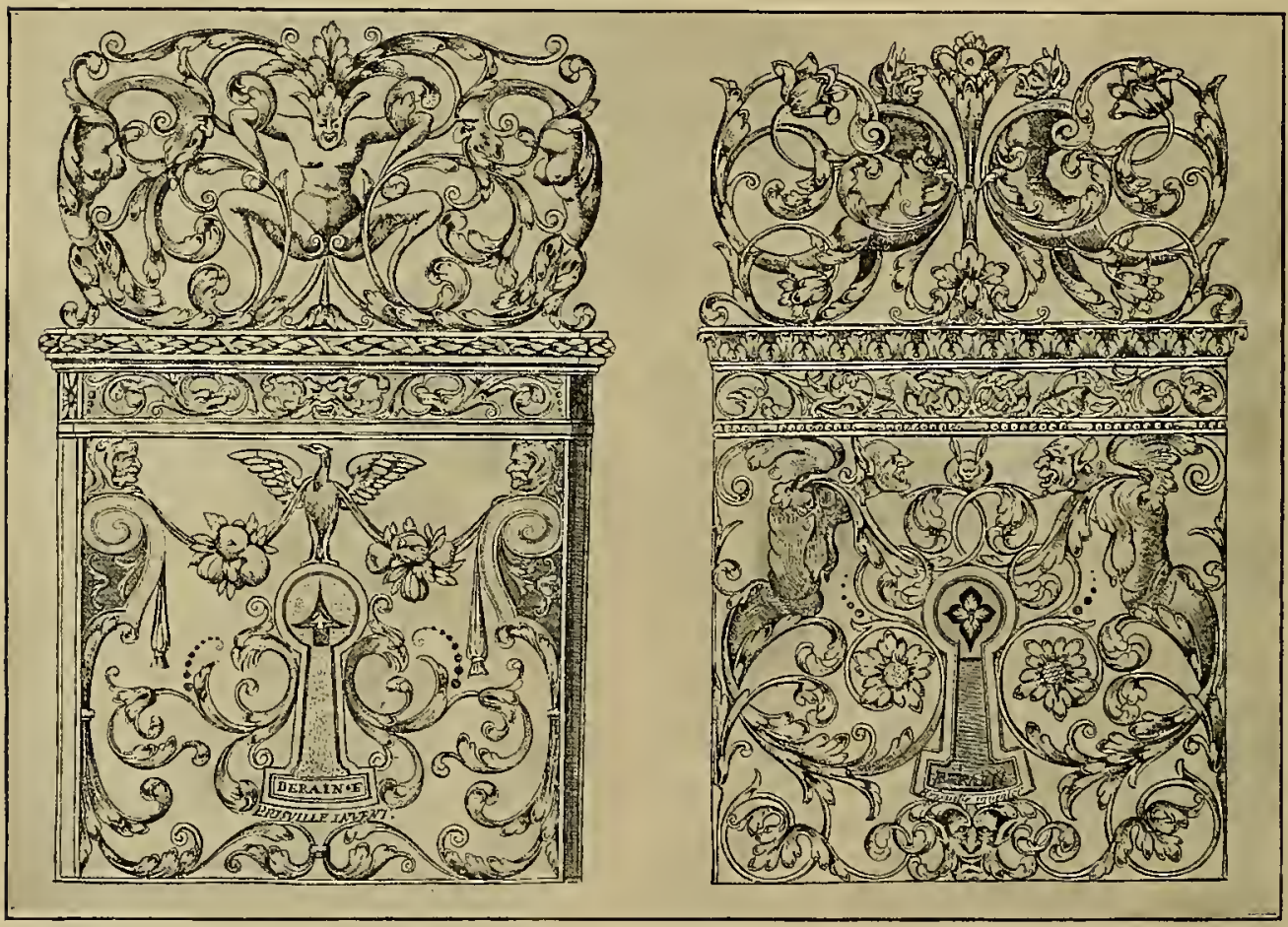

Abb. 12.

Abb. 13.

Schlossbleche aus dem Schlosserbuche von H. Brisville.

und wird sowohl im Schlosserbuch von Duhamel du Monceau, wie in dem vorhin genannten Werke Lamours erwähnt. Der grösste Teil der Abbildungen im Buch Jousses stellt Schlüssel, Schlüsselschilder und Schlossbleche mit gravierten Dekorationen dar. Die Ornamentik zeigt

1) Neudrucke: La fidelle ouverture de l'art du serrurier composée par Mathurin lousse. H. Destailleurs. Paris 1874 , und Reproduction of illustrations of ornamental metal-work forming l'art du serrurier par Mathurin Jousse by W. Griggs 1889 .
Arbeit mit dem Hammer als mit dem Grabstichel gewohnt ist, verraten. Auch direkte Abreibungen von ausgeführten Arbeiten kommen vor.

Ein grosser Teil derselben ist datiert und mit Meisternamen versehen. Unter den Arbeiten, welche den ersten Jahrzehnten der Regierungszeit Ludwigs XIV. angehören, sind die Stiche des Nicolas Prunier, Nicolas d'Jardins, Andre le Provancal, Didier Fion, Gaspar Mazelin und Denis Loche zu nennen. Ein Schlüsselschild mit der Bezeichnung H. T. 1649 
stellt die Abbildung 11 dar. Es ist mit einer um das Schlüsselloch sich gruppierenden, den Grund ausfüllenden Komposition versehen: zwei mit dem Rücken einander zugekehrte Chimären, die nach unten in akanthusartige, mit Blumen geschmückte Blattranken von lappiger Bildung auslaufen, ganz ähnlich, wie auch Jousse seine Schlüsselschilder zu dekorieren pflegte. Auch die mit Mathurin le Breton ${ }^{1}$ ) ohne $\mathrm{Da}$ tum bezeichneten Stiche gehören hierher, ebenso eine grössere Folge von Stichen, herausgegeben von Loriot 1658 unter dem Titel: „Differents portraitz pour les Serruriers nouuellement inventez par moy Aubert Loriot" und das „Liure Youueau Pour l'Art de Serrurier Inuenté par Jean de Rembeur et Nico. las Seigneurie $\mathrm{Pa}$ ris $1668^{\circ " . ~ S i e ~ e n t h a l-~}$ ten Entwürfe für gravierte Schlossbleche, Schlüsselschilder, Anschlagplatten fürThürgriffe und beliebig zu verwertende ornamen-

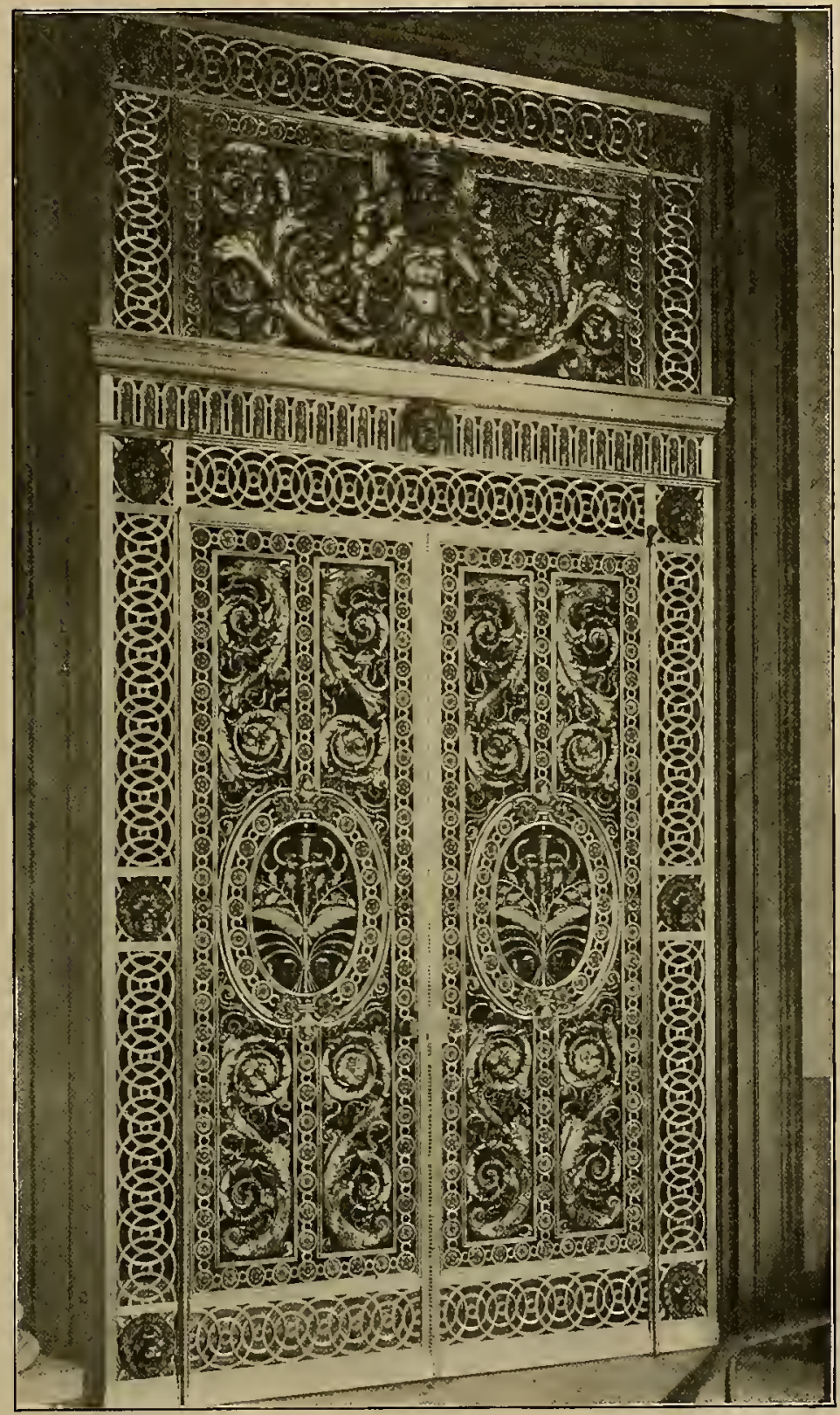

Abb. 14.

Portal aus dem Schlosse Maisons-sur-Seine im Louvre zu Paris. tale Friese. Ein Schloss im South Kensing. ton Museum in London (No. 2065-1855) ${ }^{2}$ )

1) Vielleicht identisch mit dem noch später zu erwähnenden Schlosser.

2) Abgeb. in Ornamental 1ronwork. B. Quaritch, London 1898, pl. 23. ist mit Gravierungen geschmückt, die mit den Stichen des Rembeur und Seigneurie sehr verwandt sind. Besonders die linkische Haltung der aus Blüten herauswachsenden Halbfiguren, deren Locken zu regelmässigen Spiralen aufgerollt sind, zeigen eine unverkennbare Aehnlichkeit mit den Figuren 


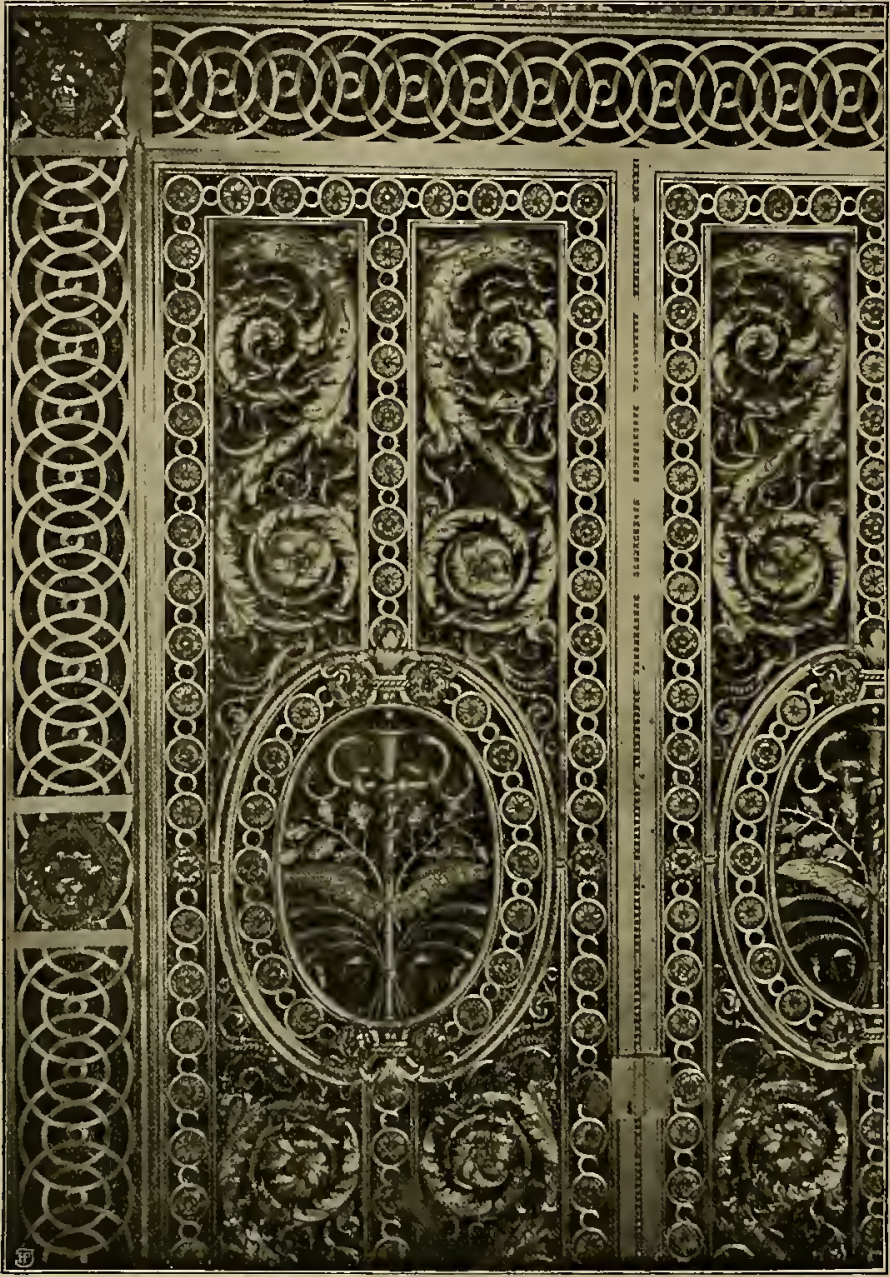

Abb. 15. Teil des in Abb. 14 dargestellten Portals. sind. Das Porträt Brivilles von Ladame ist mit der Jahreszahl 1663 versehen, wodurch auch dieZeit der übrigen Stiche bestimmt ist. Das Büchlein enthält neben rein ornamentalen Zeichnun. gen Entwürfe für gravierte Schlossbleche (Abbild. 12), Schlüsselschilder, Schlüssel, Thürgriffe, Beschlagplatten und Gitter. Der groteske Formenkreis des Jousse und seiner Nachfolger tritt bei Brisville in einem moderneren, künstlerisch vollkommeneren Gewande auf. Das Laubwerk in Form des antiken Akanthus ist weicher und eleganter gezeichnet, die Linienführung fliessender, die grotesken Figuren zeigen die volle Beherrschung der menschlichen und tierischen Körperformen.

Neben den Nachklängen einer älteren Formensprache enthalten die Entwürfe Brisvilles aber auch Anlehnungen der Stiche. Sonst sind ausgeführte Arbeiten dieser Art kaum erhalten.

Demselben Formenkreise gehört auch das Vorlagewerk des Hugues Brisville ${ }^{1}$ ), eines Schlossermeisters in Paris, von 1663 an, das alle genannten Arbeiten sowohl in der künstlerischen Erfindung wie zeichnerischen Ausführung übertrifft. Es besteht mit Einschluss des hübschen Titelbildes, des Porträts Brisvilles, und der Widmung an den Grand Audancier de France Mr. Longuet aus 17 Tafeln, von denen 12 von Jean Bérain, 2 von G. Ladame gestochen

1) Neudruck: Quaritch, B., Hugues Briseville. London 1888. an jüngere Formen, nämlich an die Ornamentik, wie sie in den beiden Hauptwerken der Schmiedekunst aus dem Anfange der Regierungszeit Ludwigs XIV. niedergelegt ist. Es sind das zwei Portale, welche sich jetzt am Eingang zur Apollogalerie und zum Saal der antiken Bronzen im Louvre zu Paris befinden (Abbild. 14-16). Ursprünglich im Schlosse Maisons-sur-Seine bei St. Germain-enLaye aufgestellt, wurden sie während der Revolution arg mitgenommen. Unter der Leitung des Percier und Fontaine, der führenden Architekten zur Zeit des ersten Kaiserreiches, wurden sie vom Schlosser Varin wiederhergestellt, nachdem dieser 
sich und seine Gehilfen für die schwierige Arbeit besonders geschult hatte. Die Portale sind blank gefeilt und poliert und zeigen eine solche Feinheit der Ausführung und Formvollendung, wie sie nur die besten Bronzearbeiten bieten.
Das Schloss Maisons wurde 1642 bis 1651 für den Präsidenten des Parlaments zu Paris, René de Longueil, erbaut. Es ist das Hauptwerk des Architekten François Mansart, zugleich das vornehm. ste Denkmal jener um die Mitte des

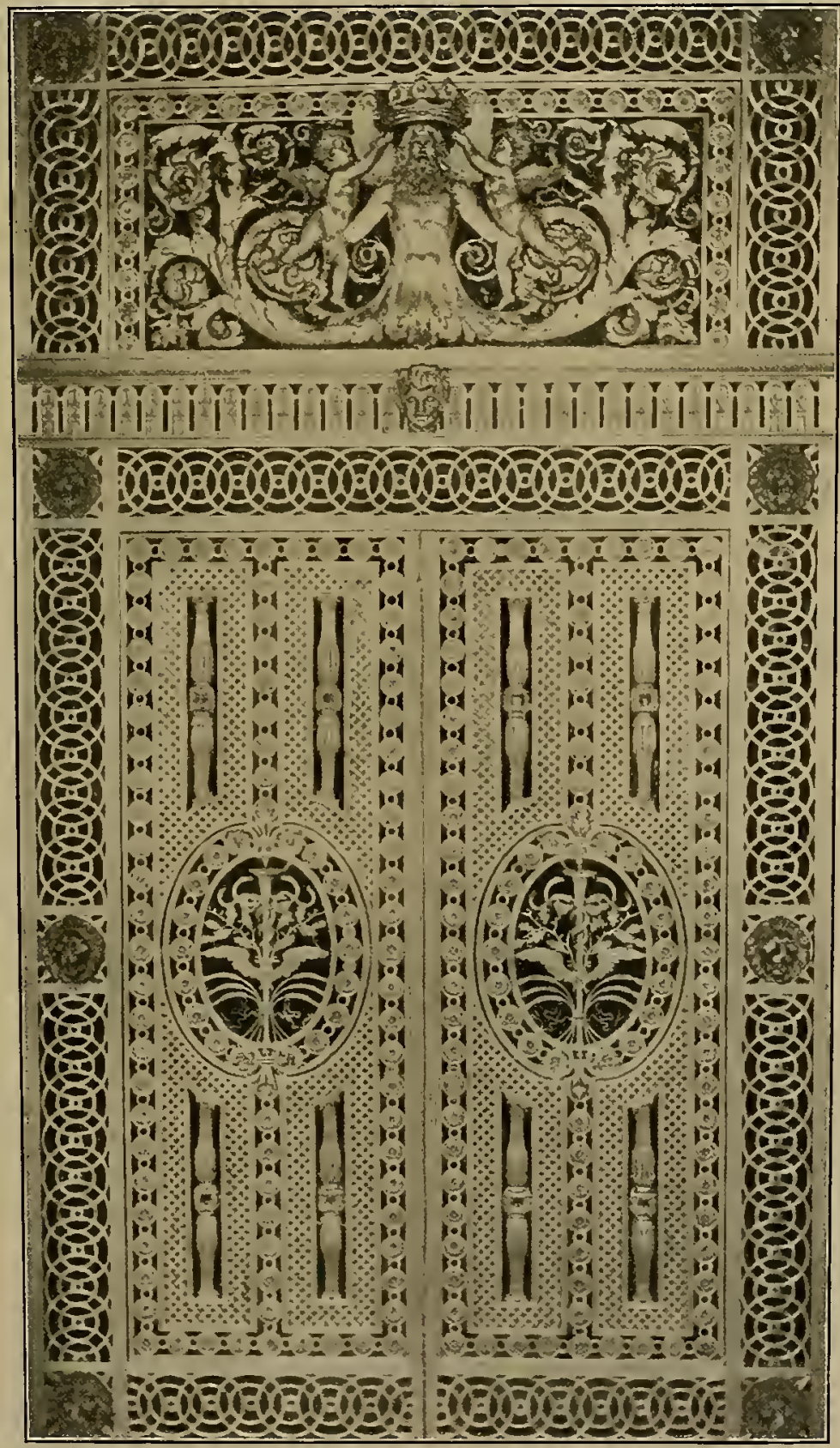

Abb. 16. Portal aus dem Schlosse Maisons-sur-Seine im Louvre zu Paris. 


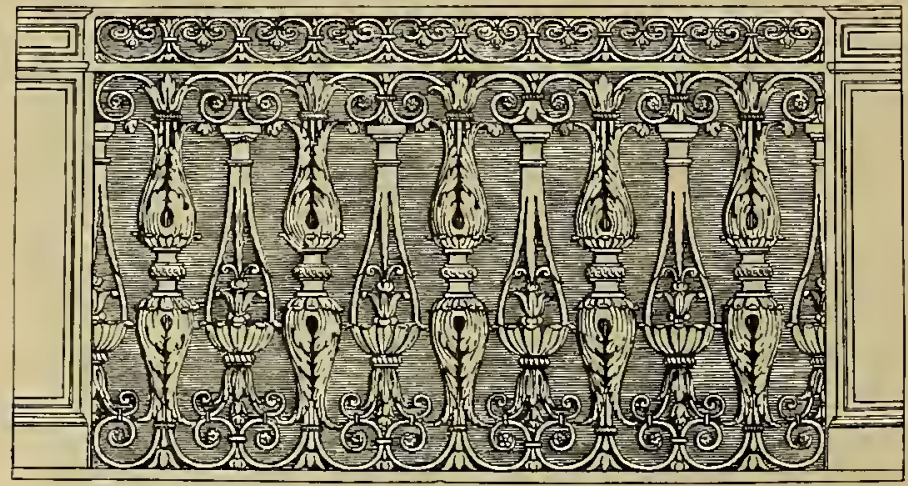

Abb. 17. Balustrade nach einem Stiche von J. Marot.

die oberen Ranken endigen in Adlerköpfe. Die Oberlichtfüllung wird von einer figürlichen Komposition eingenommen: einer bärtigen geflügelten Gestalt, welche nach unten in Akanthusranken, die sich seitlich verästeln, ausläuft, setzen zwei aus Blüten heraussteigende Knaben eine Krone auf. Als Umrahmung der Thür und des Oberlichtes dient ein aus

17. Jahrhunderts sich geltend machenden klassicistischen Richtung, die auf die reine, klare Formensprache der Antike zurückzugehen sich bemühte, und deren Entstehung man an den Stichen eines Philippon, Stella, Errard u. a. verfolgen kann. Ein Hauptvertreter dieser antikisierenden Tendenzen war auch der Architekt Jean Marot, auf den die beiden Gitterthore von Maisons zurückzuführen sind. Wir besitzen von Jean Marot ausser einer grossen Anzahl von Entwürfen schmiedeeiserner Thore, Oberlichtgitter und Balustraden auch den Stich einer Thür, die dem Portal der Apollogalerie sehr ähnlich, aber nicht identisch damit ist und die Bezeichnung trägt: „Porte de fer du vestibule du Chasteau de Maisons. Jean Marot fecit". Vielleicht ist es die Abbildung eines anderen Portales, das als Gegenstück zu dem noch erhaltenen gedient hat. Auch Marots sonstige Stiche mit Gitterwerken verraten grosse Verwandtschaft mit den Portalen von Maisons. Das Portal der Apollogalerie zeichnet sich vor allen anderen durch besonders reichen Schmuck aus. Jede Thürfüllung ist in ein mittleres ovales und in vier längliche Felder geteilt, die von einem aus Rosetten gebildeten Ornamentbande eingerahmt sind. Das Oval in der Mitte nimmt ein Merkurstab mit Aehren und Eichenzweigen ein; die schmalen Felder sind mit spiralig aufgerolltem Akanthuswerk ausgefüllt, durch welches sich Schlangen ringeln; sich überschneidenden Kreisen gebildetes Ornament, durch acht in bestimmten Zwischenräumen angebrachte Löwenköpfe belebt. Auf den Friesstreifen unterhalb des Oberlichtes ist ein Satyrkopf aufgesetzt. Ganz ähnlich ist das zweite Portal gestaltet (Abbild. 16), nur dass die schmalen Felder auf den Thürflügeln eine andere Ornamentik zeigen: zierlich ausgebildete $\mathrm{Ba}$ lüster innerhalb eines Flechtwerkrahmens. Die strenge regelmässige Gliederung der Flächen, der in gleichmässig gerundeten Spiralen sich entwickelnde Akanthus, die Verbindung menschlicher Figuren mit demselben in grotesker Art und andere Motive lassen den Einfluss antiker Monumente deutlich erkennen. Die Datierung dieser beiden Prachtwerke, fast der einzigen Denkmäler aus dem Gebiete der Kleinkünste, die jene antikisierende Kunstrichtung hinterlassen hat, wird schon durch die angeführte Zeit der Erbauung des Schlosses gegeben. Ausserdem weisen aber auch die verwandten, zeitlich bestimmten Ornamentstiche des A. Pierretz und anderer auf die Mitte des 17. Jahrhunderts als die Zeit der Entstehung dieser Arbeiten hin.

Die Stiche Jean Marots mit Vorlagen für Schmiedearbeit zeigen eine ähnliche Ornamentik, wie die Portale von Maison. Zum Teil sind seine Entwürfe etwas kalt und trocken, oder sie ermüden durch die langweilige Teilung der Flächen in regelmässige geometrische Figuren. Am glück- 
lichsten sind noch die Geländer komponiert, in denen die Balüster der Steinschranken in lockeres Stabwerk aufgelöst erscheinen. (Abbild. 9 u. 19.)

Die Gitterthore von Maisons-sur-Seine bedeuten indessen, ebenso wie die Ornamentstiche Jean Marots, für die Geschichte der Schmiedekunst nur eine vorübergehende Episode. Von weitgehendem Einfluss auf die Entwickelung der Schmiedekunst konnten sie schon deswegen nicht sein, weil die Ornamentik derselben in ihrer sauber ciselierten Ausführung mehr für die Gusstechnik als für Schmiedearbeit berechnet scheint.

Dagegen sollte ein anderer Bau, nämlich das Schloss zu Versailles für dieWeiterbildung der Schmiedekunst von höchster Bedeutung werden, indem nicht nur zum ersten Male hier die Schmiedearbeit in einem Umfange, wie nie zuvor bei einem Profanbau, herangezogen wurde, sondern auch bei der vorbildlichen Bedeutung, welche das Versailler Schloss in der Kunstentwickelung des übrigen Europas erlangen sollte, die hier auftretende ausgedehnte Beteiligung der Schmiedekunst an der Ausschmückung von Bauwerken weitgehende Nachahmung in allen Ländern fand. Leider ist von den überaus zahlreichen Eisenarbeiten, welche diesen Riesenbau schmückten und seine äussere Erscheinung wesentlich beeinflussten, fast nichts mehr erhalten geblieben. Wir sind fast allein auf die Stiche eines Silvestre, Lepautre, Rigaud u. a. angewiesen, wenn wir uns ein Bild von ihnen verschaffen wollen. Eine zweite reichlich fliessende Quelle bilden die von Jules Guiffrey herausgegebenen Comptes des bâtiments, die ausführlichen Rechnungsbücher über die königlichen Bauten, welche auf einen ganz kolossalen Verbrauch des Schmiedeeisens in künstlerischer Form bei diesem gewaltigen Bauwerke schliessen lassen.

Schon der Bau Ludwig XIII. (begonnen 1624) vom Architekten Lemercier besass einen wirkungsvollen Schmuck von Schmiedewerken. Auf den Stichen des Israel Silvestre von 1664 zieht sich rings um das ganze Schloss in der Höhe des zweiten Stockwerks ein fortlaufender vergoldeter Balkon, der auch über die Mauer hinweggeht, welche die beiden Flügel des Schlosses verbindet. $\mathrm{Er}$ diente auf diese Weise auch dazu, die Räume des Obergeschosses miteinander in Zusammenhang zu bringen. Die den Hof abschliessende Mauer öffnet sich in sieben rundbogigen Arkaden, welche mit Gittern versehen waren, bei denen nach dem Berichte der Mademoiselle de Scudéry "Gold und Grün in gutem Einklange standen." Das Schloss, dessen Dächer fast ganz vergoldet und mit Vasen und anderen Ornamenten von blauer Farbe geschmückt waren, und dessen Mauern aus roten Ziegeln und weissen Hausteinen bestanden, gewährte infolgedessen ein sehr farbenreiches Aussehen. ${ }^{1}$ ) Nach beiden

$\left.{ }^{1}\right)$ Vgl. Dussieux, L., Le château de Versailles. 1. S. 19.

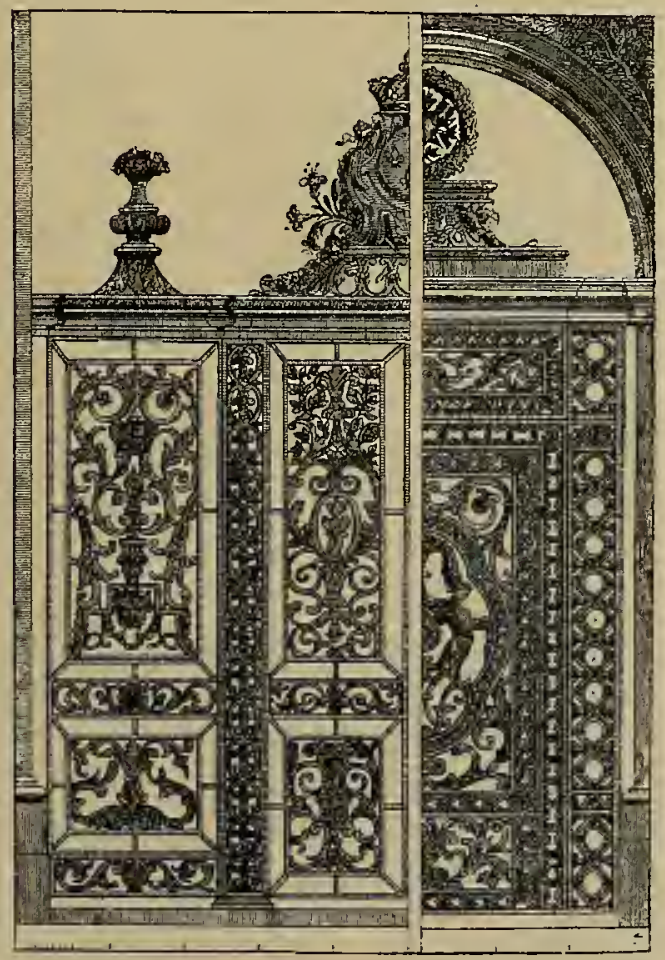

Abb. 18. Gitterthore aus dem Schlosserbuche von J. Lepautre. 


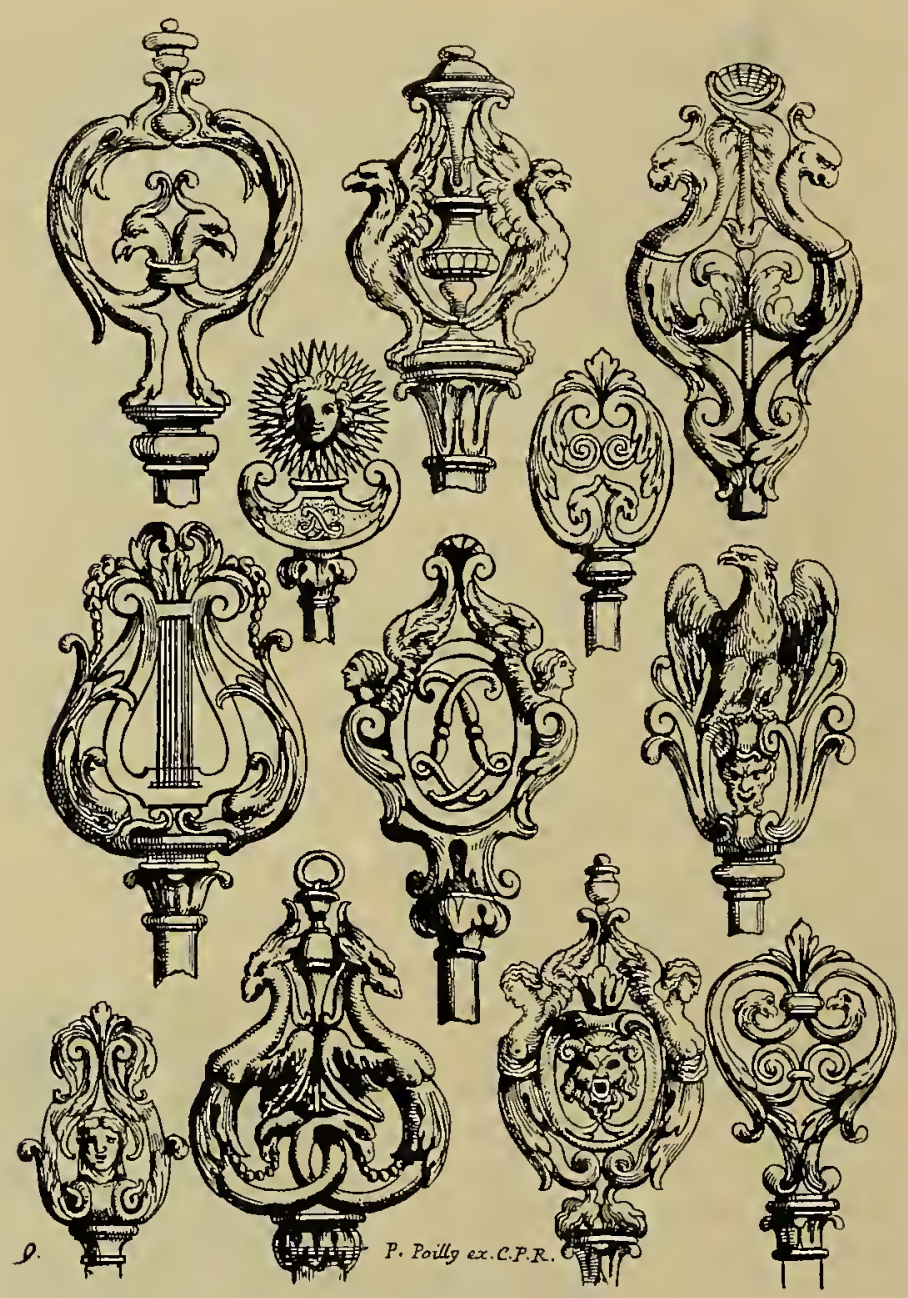

Abb. 19. Schlüsselgriffe aus dem Schlosserbuche von Pierretz le Jeune.

Schlosses sich gruppieren, der letzte führt direkt zu den Wohngemächern des Königs selbst. Ein Stich Silvestres von 1674 zeigt die neue Anlage, bei der die beiden ersten Höfe, die Avant-cour (oder cour des Ministres) und die Cour Royale durch Gitter abgeschlossen sind. Diese Gitter werden gegliedert durch Steinpfeiler mit bekrönenden Vasen, die in bestimmten Zwischenräumen nebeneinander gesetzt sind; dazwischen sind die ziemlich einfach gebildeten Eisengitter eingeschaltet. Die Endigungen der Stäbe sind wellenartig gebogen. Die. Portale bestehen ebenfalls aus einer Vereinigung von Mauerwerk und Eisenstäben. Die reichen Bekrönungen scheinen aus Stein gehauen gewesen zu sein. Das Gitter, welches die Avantcour im Kreisbogen abschloss, nahm dieselbe Stellung ein, wie das Gitter, welches sich noch

Gartenseiten hin zeigen die Stiche lange Gitter, durch Steinpilaster gegliedert.

Der verhältnismässig kleine Bau seines Vorgängers genügte Ludwig XIV. nicht. Er brauchte ein Schloss, gross genug, den ganzen Adel seines Reiches $\mathrm{zu}$ beherbergen und so in beständiger Obhut zu halten. Im Jahre 1662 beginnt Louis Levau den Umbau, dessen Leitung er bis zu seinem Tode im Jahre 1670 behält. Das Schloss erhielt in dieser Zeit schon im wesentlichen die Anlage, die es noch heute hat: in der Hauptaxe drei immer kleiner werdende Höfe, um welche die Gebäulichkeiten des heute dort befindet. Die Cour Royale, dem jetzt ein Abschlussgitter fehlt, wurde von der Avant-cour durch ein in gerader Linie sich zwischen den beiden Höfen hinziehendes Gitter getrennt, welches sich zwischen den Säulen der Front der beiden die Cour Royale seitlich begrenzenden Gebäuden fortsetzte und im weiteren Verlauf die rechts und links von der Cour Royale befindlichen kleineren Höfe, der Cour des Princes und der Cour de la Chapelle, abschloss. Die Cour Royale schmückten ebenso wie die dritte kleinste in der Hauptaxe des Schlosses liegende Cour de Marbre vergoldete Balkone. 
Die Cour de marbre trug damals ausserdem in den beiden inneren Winkeln des Hofes eine ungewöhnliche, aus Schmiedeeisen gebildete Dekoration, nämlich zwei grosse, über ein Stockwerk hohe Volièren, welche 1671 von den Schlossern Mathurin le Breton und Christophe Maugin hergestellt und von Goy vergoldet wurden. Für jede Volière wurde 5600 livres gezahlt, nach heutigem Gelde etwa 25000 frcs. Mathurin le Breton ist vielleicht derselbe Schlosser, von dem die erwähnte Stichfolge stammt (Seite 21). Die Volièren finden sich auf den Stichen Lepautres dargestellt, in denen die sechs Tage währenden Festlichkeiten verewigt sind, welche der König 1674 nach der Un. terwerfung der Franche Comté in Versailles veranstaltete. Am ersten Tage fand eine Aufführung der Oper "Alceste“ von Quinault und Lulli in der als Theater hergerichteten Cour de marbre statt. Der Stich Lepautres vom Jahre 1676 zeigt ausser den Balkonen und beiden Volièren im Hintergrunde drei schmiedeeisernePortale. Der hier dargestellte Stich (Abbild. 23) stellt das Fest des 4. Tages dar, an welchem abends in der Cour de marbre soupiert wurde. In der Mitte erhob sich eine grosse Lichtersäule.

Im Jahre 1776 wurde Jules-Hardouin Mansart die Oberleitung der Bauarbeiten übertragen. Schon die Stiche Silvestres von 1682 und 1684 zeigen bedeutende Veränderungen in Bezug auf die die Höfe des Schlosses zierenden Eisenarbeiten. Die Volièren fehlen vollständig. An die Stelle der durch Steinpfeiler gegliederten Abschlussgitter der beiden Höfe sind neue getreten, bei denen die Steinpfeiler durch Eisenpilaster mit reichem Schmuckwerk: Sonnenmasken, Lyren, Kronen u. s. w. ersetzt, und auch die Thore ganz aus Eisen gebildet sind. Das Gitter, welches die Avant-cour abschliesst, behielt den Umfang und die Anordnung

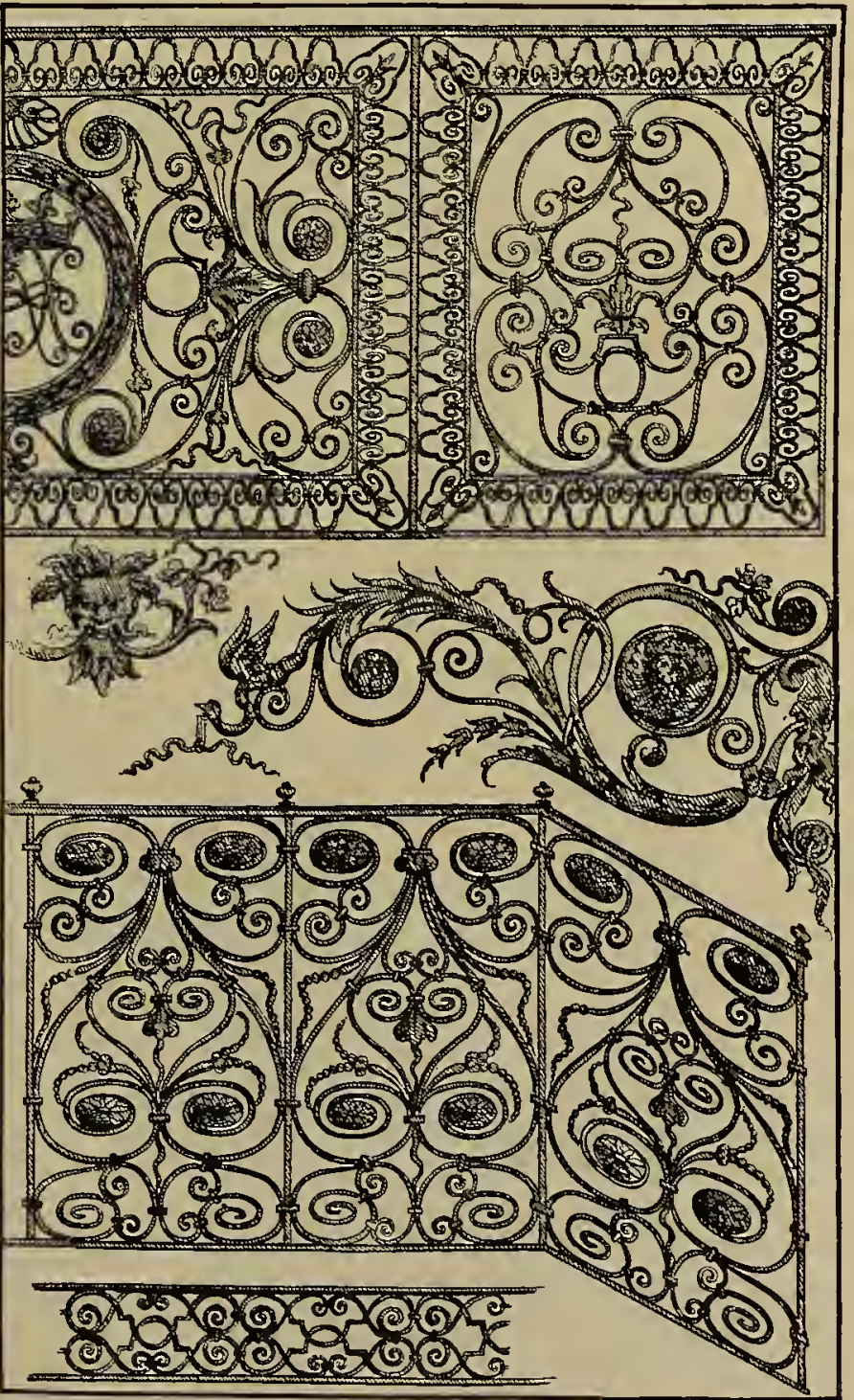

Abb. 20. Vorlagen für Schlosserarbeiten von M. Hasté. 
des ersten Gitters bei. Es schmückt noch heute den Vorhof, aber nicht mehr in seiner ursprünglichen Gestalt. Da es in den Schreckenszeiten der Revolution stark beschädigt worden war, wurde es zur Zeit des ersten Kaiserreiches unter der Leitung des damaligen Architekten vollständig das umfangreiche Gitter, welches früher die Cour Royale von der Avant-cour trennte. Dieses um 1680 errichtete Gitter befand sich nicht genau an derselben Stelle, wie das ältere durch Steinpfeiler gegliederte Gitter. Es trat vielmehr in der Mitte, entsprechend dem

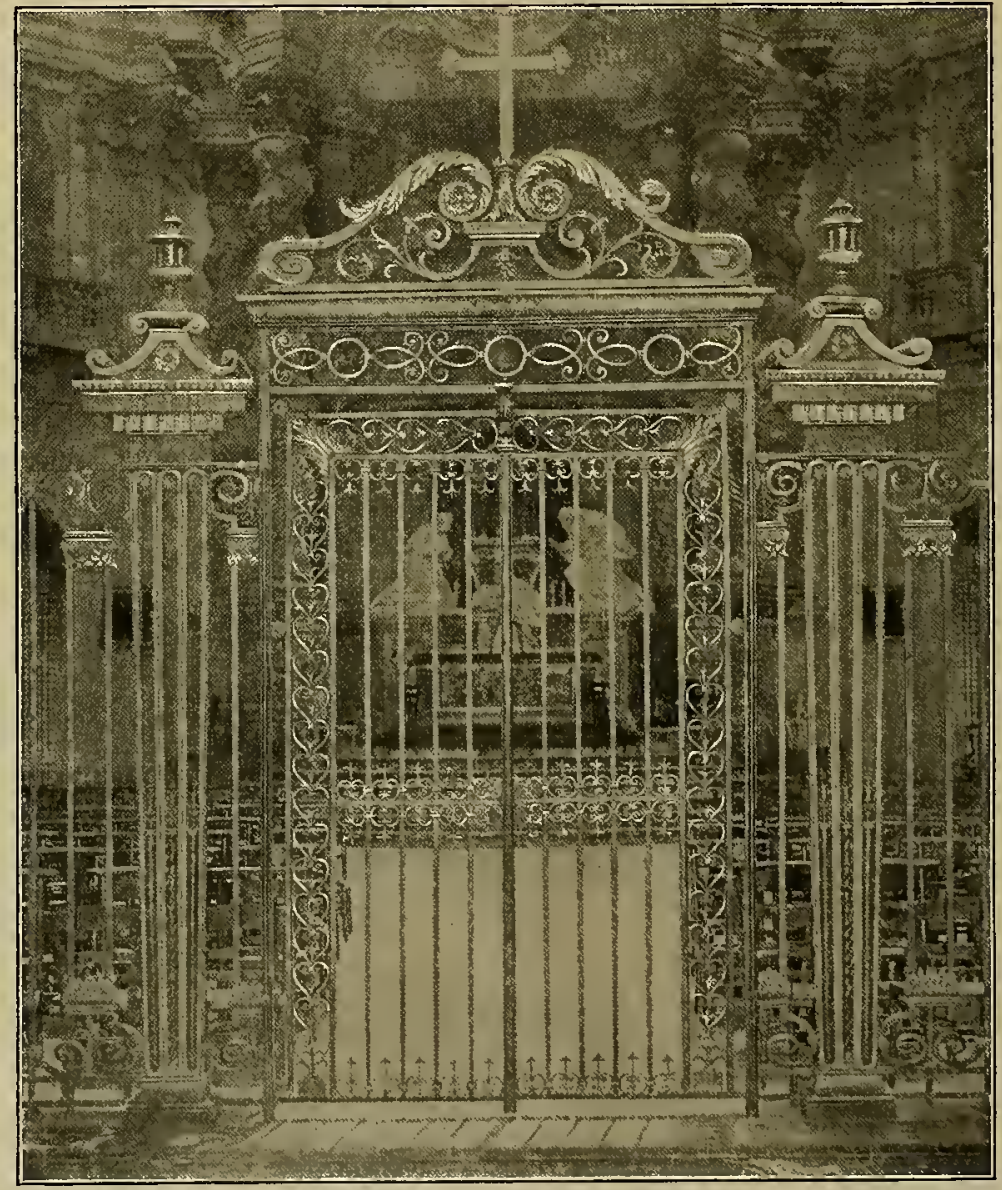

Abb. 21. Chorgitter in Val de Grâce zu Paris.

des Schlosses Dufour wiederhergestellt und zwar mit starker Abweichung von der ursprünglichen Form des Portals. ${ }^{1}$ ) Eine weitere Ausbesserung fand 1879 statt. ${ }^{2}$ ) Den jetzigen Zustand veranschaulicht die Abbildung 25. Dagegen fehlt jetzt

1) Vgl. Bury, Modèles de serrurerie. Paris. Seite 8.

2) Siehe: Dussieux, L., Le château de Versailles. 1, S. 98. Anmerk. 4.
Gitter der Avant-cour, bogenförmig vor. Sein Eingang war ungefähr an dem Platz, wo heute die 1834 errichtete Reiterstatue Ludwigs XIV. steht. Das ganz aus Eisen gebildete Gitter war nur durch zwei steinerne, mit Skulpturen geschmückte Schilderhäuser unterbrochen. Zwischen den Säulenreihen der Front der beiden Seitengebäude der Cour Royale sich hinziehend, fand das Gitter rechts und 


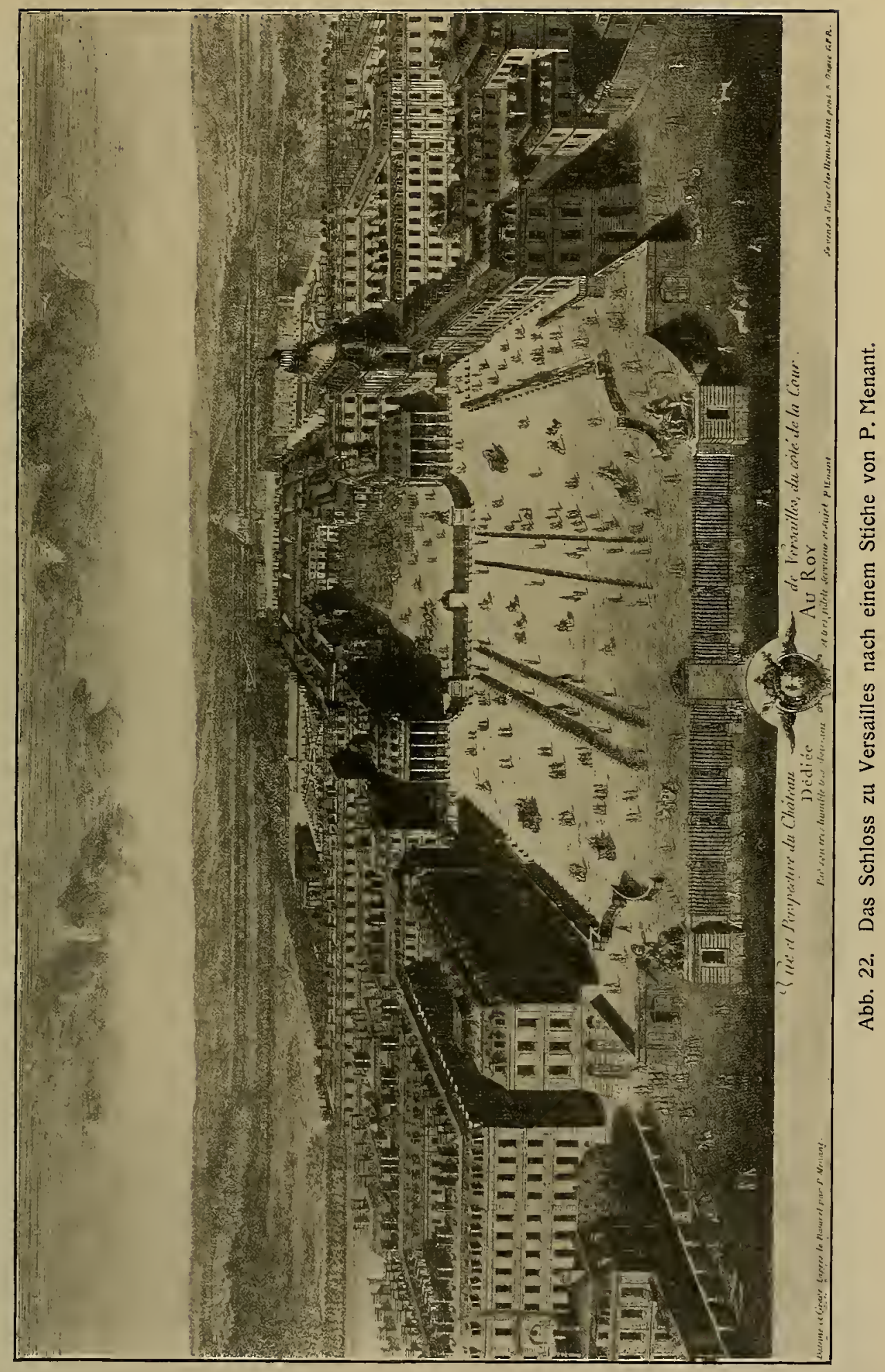


links seine Fortsetzung in den Gittern, welche einerseits die Cour de la Chapelle und die jetzige rue des Réservoires und andererseits die Cour des Princes und die jetzige Rue Gambetta abschlossen; jedes dieser vier Gitter war mit einem besonderen Thor versehen. (Abb. 22.)

Diese ganz eausgedehnte Gitteranlage wurde am 6. Oktober 1789 von den Scharen der entzügelten Volksmassen, welche die
Kasernen dienen, waren mit ähnlich gestalteten Gittern versehen.

Berücksichtigt man, dass alle diese umfangreichen Gitterwerke, sowie die Balkone im Schmuck reicher Vergoldung prangten, so wird man begreifen, dass besonders durch das Fehlen des grossen Hauptgitters vor der Cour Royale der Eindruck des ganzen Baues erheblich beeinträchtigt wird. Erst durch dieses Gitter erhielt

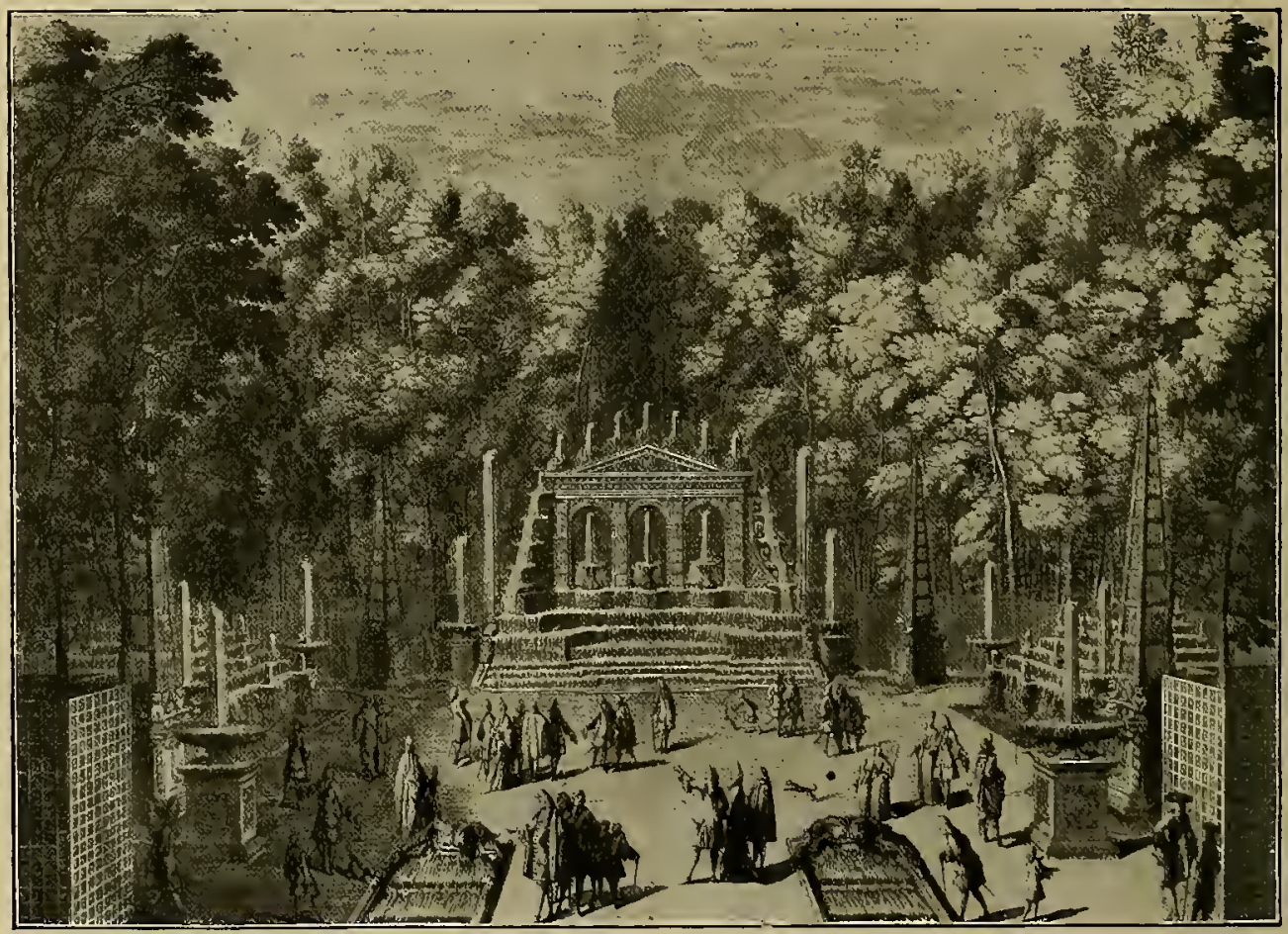

Abb. 24. Bosquet de l'arc de triomphe im Park von Versailles nach einer von M. Baqoy gestochenen Zeichnung von F. Delamonce, 1714.

königliche Familie zwangen, Versailles zu verlassen und sich nach Paris zu begeben, zerstört. Die als Lanzen gestalteten Eisenstäbe wurden in ihrer Hand zur Waffe, auf denen die Köpfe der ermordeten Leibgardisten im Zuge vorangetragen wurden.

Auch die gegenüber dem Schloss auf dem Place d'armes errichteten und zur ganzen Anlage in Beziehung gesetzten Flügelbauten, die, als Grande und Petite Ecurie von Mansard 1679-1682 errichtet, jetzt als die gewaltige Anlage die nötige Teilung, wurde die jetzt unerträglich grosse Tiefenausdehnung wohlthätig unterbrochen.

Rechnet man die in ihrer Anordnung zur Schlossanlage gehörige Place d'armes dazu, so gliedert sich das ganze Bauwerk in der Richtung der Hauptaxe in vier immer enger werdende Höfe, welche nur ein allmähliches Annähern an den eigentlichen Wohnsitz des Monarchen gestatteten. Während das Gitter vor der AvantCour von jedem Wagen passiert werden 


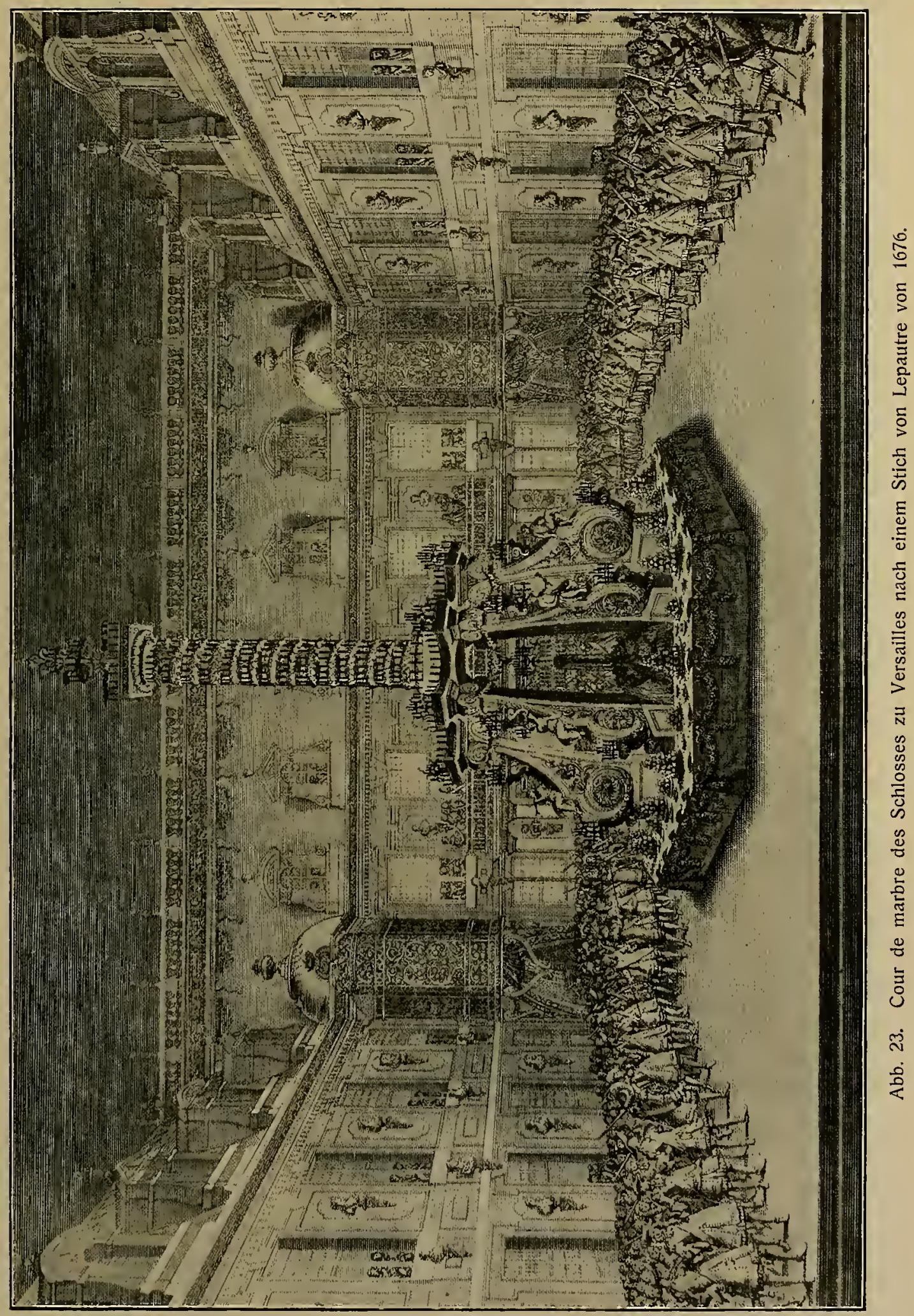




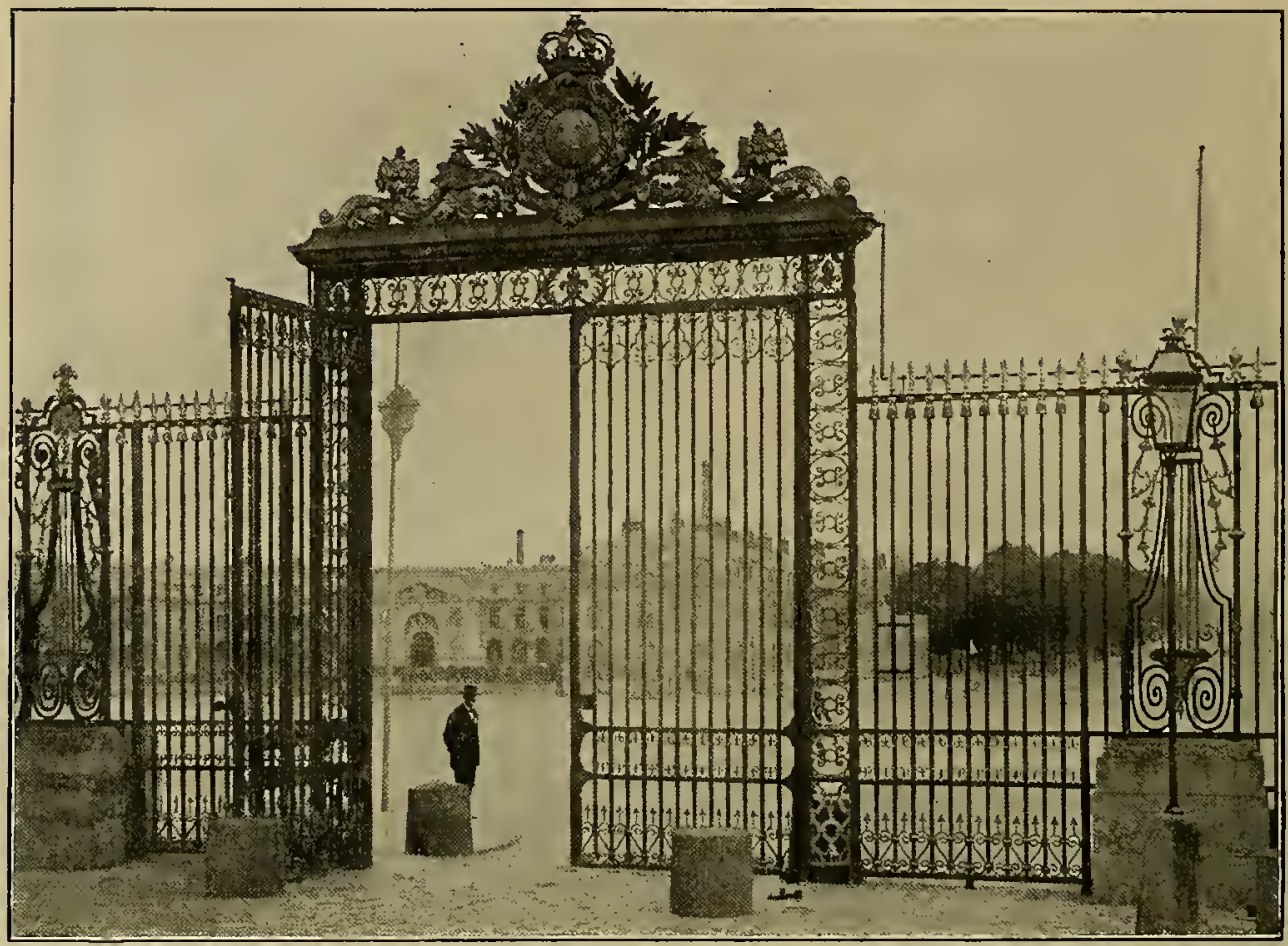

Abb. 25. Gitter der Avant-cour des Schlosses von Versailles (jetziger Zustand).

durfte, öfnete sich das grosse Gitter vor der Cour Royale nur den Karossen derjenigen, welche die Honneurs du Louvre besassen, eine Ehre, die den königlichen Prinzen, den Marschällen Frankreichs und den Gesandten der fremden Staaten vorbehalten waren; die übrigen Besucher mussten vorher aussteigen und sich in Sänften in das Schloss tragen lassen. Zur Zeit Ludwigs XVI. wurde das Hauptthor erst gegen $11^{1} / 2$ Uhr morgens, der Zeit des Levers des Königs, geöffnet. ${ }^{1}$ ) - Unwillkürlich wird man an jene altägyptischen Tempel erinnert, bei denen auch eine Anzahl Vorhöfe, die allmählich auf die Nähe der Gottheit vorbereiteten, zu dem weiter zurückliegenden Heiligtum führten.

Aber nicht nur die äussere Erscheinung des Schlosses erhielt durch solche kunstvollen Schmiedewerke eine bedeutende

1) Vgl. d'Hézecques, Souvenirs d' un page de la cour de Louis XVI., S. 135.
Erhöhung, auch im Innern waren zahlreiche Eisenarbeiten, Portale, Geländer, Balustraden u. s. w. angebracht, die ebenfalls zumeist verschwunden sind. So war z. B. das Vestibül der beiden Haupttreppen, des escalier des ambassadeurs und des escalier de la reine, von schönen Gitterthoren abgeschlossen.

Von der umfangreichen Verwendung schmiedeeiserner Arbeiten im Park lässt sich kaum noch eine Vorstellung gewinnen. Von Gittern und Portalen zur Abgrenzung einzelner Teile des Parks, vor Grotten und sonstigen Bauten, von Balustraden um Fontänen u. dgl., ferner von jenen aus Eisen und Holz errichteten Laubengängen und Architekturen muss sehr weitgehender Gebrauch gemacht worden sein. Einzelnes lässt sich noch aus Stichen und sonstigen Mitteilungen ungefähr rekonstruieren. Nur weniges hat sich, wie das Eingangsgitter zum grossen Gemüsegarten, noch erhalten. Manches ist schon zu Ludwigs XIV. Zeit entfernt 
worden, wie die reich geschmückten Portale, welche die drei Arkaden der Grotte der Thetis abschlossen. Sie waren 1666 von Mathurin le Breton (sieheS. 21 1. 27) ausgeführt und von Goy vergoldet worden. Die Grotte wurde schon 1686 zerstört, als Mansart den Nordflügel des Schlosses erbaute.

Eine der grossartigsten Schöpfungen der Schmiedekunst im Park war der grosse Triumphbogen, der den Hauptschmuck des Bosquet de l'Arc de Triomphe bildete (Abbild.24). Drei grosse Fontänen zierten den Vordergrund der theatralisch sich abstufenden, von Heckenmauern eingefassten Anlage. Eine Marmorterrasse führte dann zum Vorplatz; hier standen vier schmiedeeiserne durchbrochene Obelisken, in welchen Wasserstrahlen emporsprangen. Rechts und links an den Seiten befanden sich büffetartige Aufbauten, ebenfalls aus Schmiedeeisen gebildet. Im Hintergrunde endlich erhob sich auf mehreren Stufen der Triumphbogen, sich in drei Arkaden öffnend, von einem Giebel bekrönt. Das Giebelfeld nahm eine symmetrische Komposition mit dem königlichen Wappen in der Mitte ein. Auch die übrigen Teile der Architektur des Triumphbogens, der stufenförmige Unterbau, sowie die erwähnten Büffets und Obelisken waren mit mannigfaltigen schmiedeeisernen und vergoldeten Ornamenten geschmückt. Delobel, von B rüning, Schmiedekunst. dem auch ein grosser Teil der Balkone des Schlosses, die Portale des Vestibüls der Gesandtentreppe, sowie andere Schmiedearbeiten herrühren, war der Verfertiger dieser grossartigen Eisenwerke, die von 1677-83 etwa hergestellt wurden. „Wahrlich,“ sagt Blondel, „es ist unmöglich, wenn man es nicht gesehen hat, sich den wunderbaren Eindruck vorzustellen, welchen diese Dekoration hervorruft; die Kunst scheint hier den höchsten Gipfel erreicht zu haben und die Natur neidisch mit ihr um den Vorrang zu streiten." 1801 wurde die ganze Anlage zerstört.

Wie in Versailles, so spielte auch bei den anderen unter Ludwig XIV. errichteten Schlössern das Eisen in der äusseren und inneren Deko. ration eine grosse Rolle. Auch hier lassen allein die Comptes des bâtiments ahnen, welche Massen kunstvoller

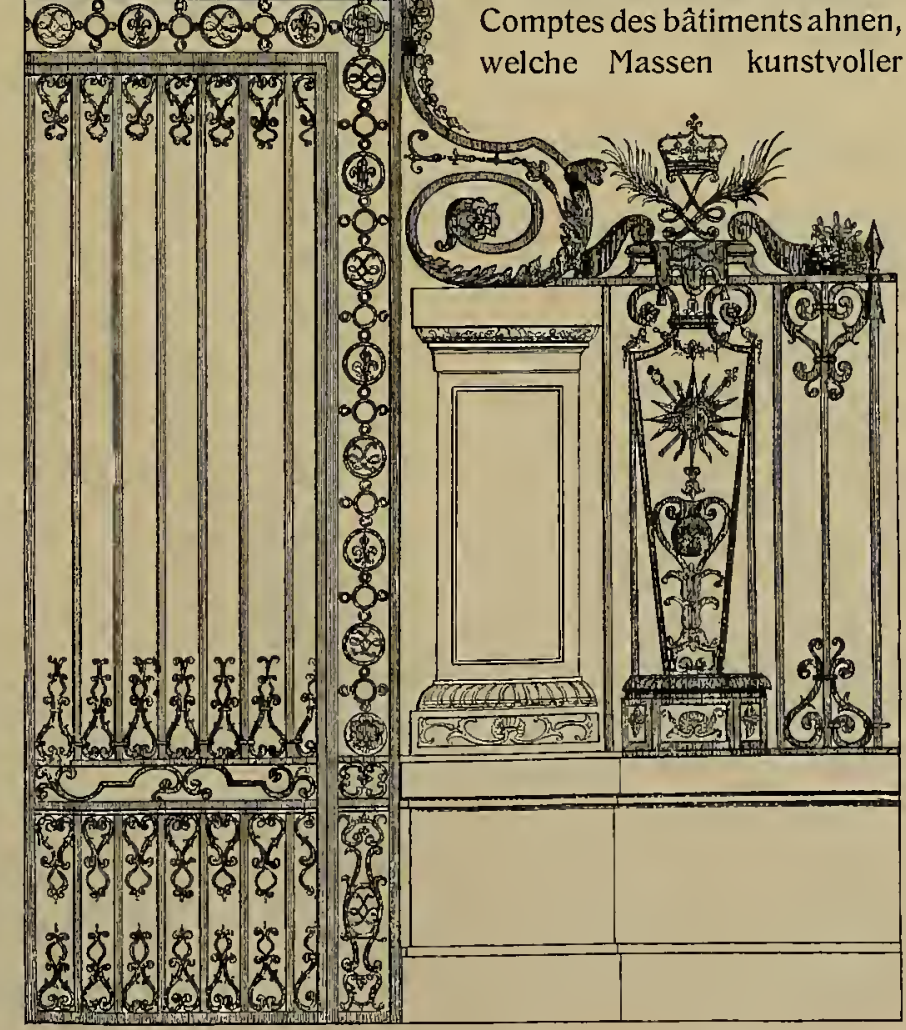

Abb.26. Stich mit dem Portal des Gitters der Cour-Royale(Versailles). 


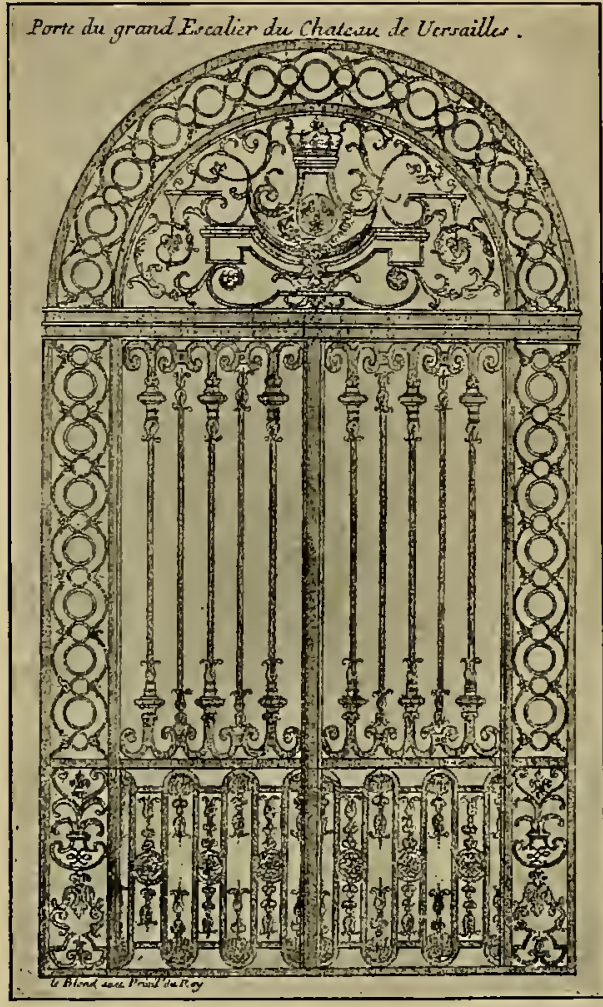

Abb. 27. Stich mit dem Portal an der grossen Treppe im Schloss zu Versailles.

Schmiedearbeit zu Grunde gegangen sind. Aehnlich wie in Versailles hatte auch das Schloss zu Sceaux ein doppeltes Vorhofgitter, das Schloss Choisy, Clagny, St. Cloud, St. Germain u. a. zierten ebenfalls ausgedehnte Gitterwerke. Besonders geschmackvolle Schmiedearbeiten befanden sich in Marly, einem Schlösschen in einem ganz von Hügeln eingeschlossenen, versteckten Thale, wo Ludwig XIV., wenn er des lauten Treibens in Versailles müde war, sich mit wenigen Günstlingen auf einige Tage zurückzuziehen pflegte. Abgesehen von einem schlichten Vorhofgitter war das Schloss selbst von einer schönen Balustrade umgeben, welche zwischen marmornen Sphinxen angebracht war. Auch die Fontānen und Wasserbecken des Parks waren von hübschen schmiedeeisernen Umfriedigungen eingeschlossen. ${ }^{1}$ )

1) Siehe: Guillaumot, A. A., Château de Marly-le-Roi. Paris 1865.
Aehnlich wie die Vorhöfe und Parks der Schlösser pflegte man auch die Chöre und Seitenkapellen der Kirchen mit grossen Gittern abzugrenzen, eine Sitte, die bis dahin in grösserem Umfange nur, wie erwähnt, in Spanien geübt worden war. Eines der frühesten Beispiele eines derartigen Chorgitters ist das der Abteikirche Val de Grâce zu Paris, welches 1666 von den Schlossern Jean Demouchy und Sébastien Mathérion hergestellt wurde (Abbild. 21). Ausserdem aber fand das Schmiedeeisen auch in der Form von Kanzelgittern, Kommuniongittern, d. h. niedrigen Balustraden vor dem Altar, an die die Gläubigen zum Empfange des Abendmahls herantraten, ferner als Kronleuchter, Kandelaber, Lesepulte u. s. w. reiche Verwendung, während in den Schlössern diese Geräte zumeist aus Bronze oder auch aus Edelmetall bestanden.

Leider sind fast alle diese zahllosen Schmiedearbeiten, welche Versailles und die anderen Schlösser Ludwigs XIV. und des französischen Adels schmückten, verschwunden. Wir können uns indessen, wie gesagt, aus den Ornamentstichen jener Zeit eine annähernde Vorstellung von ihrem Aussehen verschaffen. Für die in dem Zeitraume von 1660 bis etwa 1690 entstandenen Werke geben uns unter anderem die Stiche des Jean Lepautre, Pierretz le Jeune und Michel Hasté einen Anhalt.

Wohl noch in die sechziger lahre ist das Livre de serrurerie von Jean Lepautre, gestochen von Jacques Lepautre, zu setzen. Jean Lepautre (1617-1682), der fruchtbarste Ornamentstecher jener Zeit, ein Mitarbeiter und künstlerischer Gesinnungsgenosse Lebruns, giebt hier auf 12 Blättern Entwürfe von ungleichem Charakter für Gitter, Portale, Balustraden, Wandarme, Kaminböcke, Thürklopfer, Schlüssel und Schlüsselschilder. Seine grossen Gitter und Thore zeigen zum Teil einfache Bildung, die in einem schlichten Nebeneinanderreihen von Stäben quadratischen Querschnitts besteht. Nur an den Enden der Stäbe wird 
der Zwischenraum zwischen je zwei Stäben wie beim Chorgitter von Val de Grâce mit einem kleinen spitzenartigen Ornament gefüllt. Eine reiche Ausgestaltung erfahren nur die Bekrönungen der Portale, die mit Wappen, Monogrammen, dicken Akanthusspiralen und oft auch mit Figuren geziert sind. Andere Gitterthore besitzen eine mannigfaltigere Formgebung. Die gewöhnlich in ein grösseres oberes und ein kleineres unteres Feld zerfallenden Thürflügel sind mit symmetrischen Kompositionen gefüllt, welche aus Stabwerk, das sich meist in rundlichen Linien bewegt, in Verbindung mit üppigen Akanthusranken besteht (Abbild. 18). Ein der Tischlerei entnommenes Motiv ist die Einfassung der Füllungen durch Stabwerk, welches einen Holzrahmen mit auf Gehrung geschnittenen Ecken nachahmt. Es entsteht dadurch fast eine perspektivische Wirkung, indem die Füllungen scheinbar zurücktreten. Die Balkongitter sind ähnlich diesen Füllungen gebildet. Die Wandarme bestehen aus grossen Akanthus- spiralen, welche in Halbfiguren als Träger der Aushängeschilder auswachsen. Die Entwürfe für Kaminböcke, Thürklopfer und Schlüsselschilder sind mit Akanthus, schweren dicken Guirlanden, Masken, Figuren, Trophäen und Emblemen reichlich ausgestattet; in Treibarbeit und Eisenschnitt ausführbar, enthalten sie in ihrer Formgebung nichts, was sie von Arbeiten in Gussmetall unterscheiden könnte. Jedenfalls wird auch ein grosser Teil derselben für Bronzeguss bestimmt gewesen sein.

Stark beeinflusst von Lepautre ist das ebenfalls aus 12 Tafeln bestehende Schlosserbuch des Pierretz le Jeune, das ungefähr derselben Zeit angehören dürfte. Seine Entwürfe für Klopfer, Riegel, Schlüsselschilder und Schlüssel (Abbild. 19) sind von ähnlichem Formenreichtum, wie die gleichen Arbeiten seines Vorbildes. In schroffem Gegensatz zu der in diesen Gegenständen niedergelegten Fülle von Motiven stehen dagegen die Zeichnungen für Balkone und Treppengeländer, welche aus beinahe schmucklosen Stäben be-

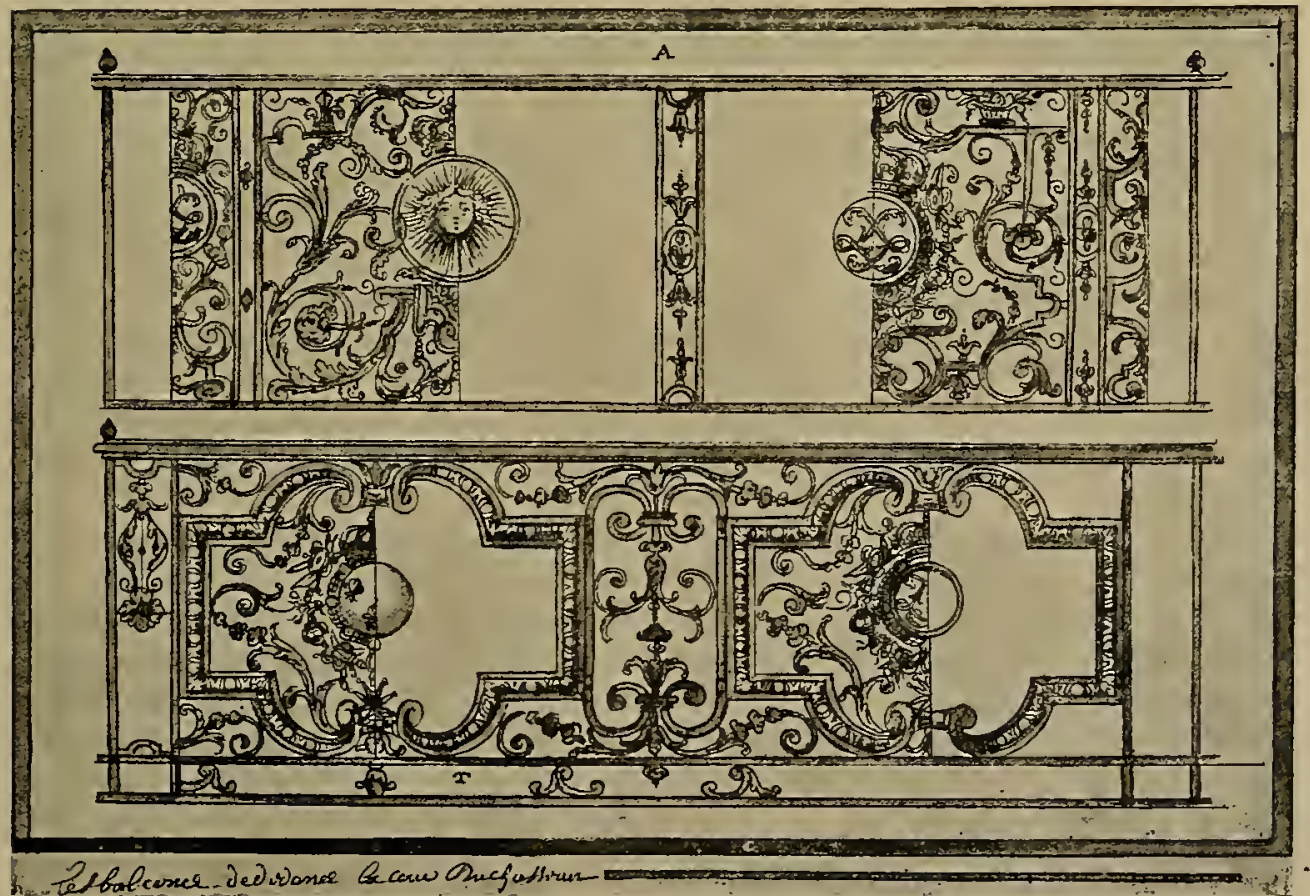

Abb. 28. Entwurf für die Balkongitter des Schlosses zu Versailles. 


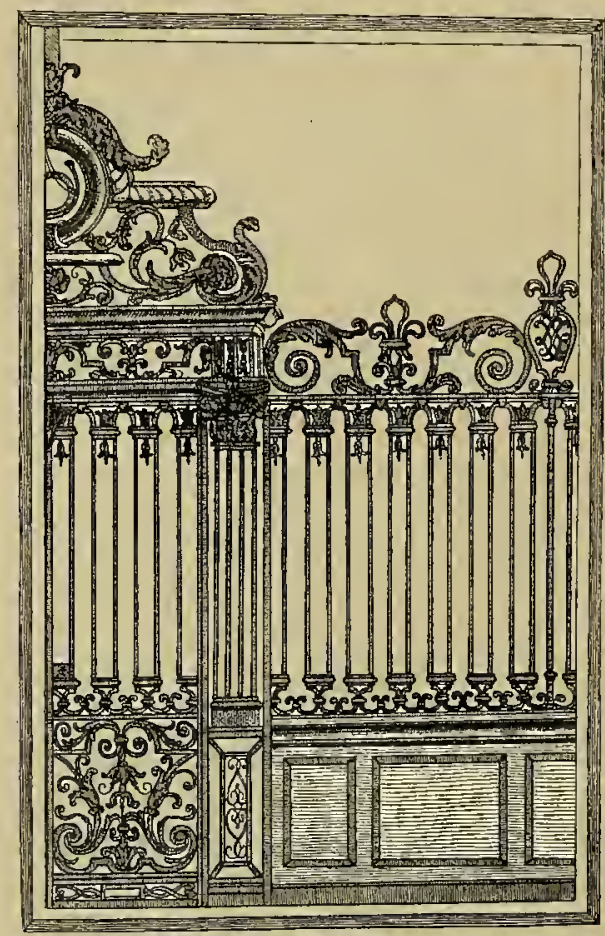

Abb. 29. Stich mit dem Chorgitter von St. Eustache zu Paris.

stehen, die in regelmässigen Bogenlinien gẹzogen sind, eine Formgebung, die an die unter Ludwig XIII. übliche Gitterbildung erinnert. Ein auch dort beliebtes Ziermotiv, von dem Pierretz häufig Gebrauch macht, ist der wellig gebogene Stab als freie Endigung.

Dem Formenkreise, der bei Lepautre und Pierretz le Jeune erscheint, gehören auch 6 Blatt mit Schmiedearbeiten an, welche von dem Pariser Schlossermeister Michel Hast é dem Architekten de Lespine gewidmet sind. Da die Widmung, welche über dem auf dem ersten Blatte dar̀gestellten Portale angebracht ist, uns über die künstlerische Urheberschaft dieser Vorlageblätter Aufschluss giebt, so möge sie unverkürzt hier folgen: „A Monsieur de l'Espine Architecte des Bastimens du Roy. Monsieur ll est bien raisonnable, que ces Ouurages soint honorez de vostre Nom puis qu'ils ont eu l'honneur de vostre aprobation come vous estes le sage Architecte qui a esleué les Bastimens considerables dans lesquels iay executé ces desseins sous vos ordres, c'est vous rendre ce, qui vous appartient que de vous les Consacrer vous leur auez donné l'Estre, et lon peut dire que vous en estes le Pere et le premier Mobile: et que c'est a vous que le public en sera plus obligé qu'a moy qui feray gloire de me dire toute ma vie Monsieur Vostre tres humble et tres obligé seruiteur Mic. Hasté M. Serurier a Paris." Aus diesen Worten geht nicht nur hervor, dass die in den herausgegebenen Stichen dargestellten Schlosserarbeiten für die Bauten de Lespines ausgeführt worden sind, sondern man darf wohl auch daraus entnehmen, dass der ursprüngliche Entwurf oder wenigstens die Skizzen zu allen diesen Gitterwerken u. s. w. von de Lespine herrühren. Die ungeschickte ängstliche Zeichnung der Stiche spricht ebenfalls dafür, dass Hasté mehr Handwerker als entwerfender Künstler war. Die dargestellten Arbeiten, Gitterthore, Treppengeländer, Wandarme, Wandleuchter und Kaminböcke sind zumeist im Stile Lepautres gehalten (Abbild. 20).

Wahrscheinlich ist Hasté auch eine zweite unbezeichnete Folge von 6 Blatt zuzuschreiben, welche bei demselben Verleger (F. Poilly rue St. Jacques à l'image H. Benoist) erschienen ist, wie die bezeichneten Stiche. Dass diese Folge nicht den Namen des Hasté trägt, kann kein Hinderungsgrund sein, sie auf ihn zurückzuführen, da auch die erste Folge, abgesehen von der Unterschrift der Widmung, keine weitere Bezeichnung des Verfassers enthält. Auch diese Entwürfe stehen den Stichen des Lepautre und Pierretz sehr nahe und gehören ungefähr in dieselbe Zeit. Die Gitter zeigen eine besondere Bildung, insofern bei mehreren die Stäbe durch breite Bunde zu je zweien vereinigt sind, wodurch die Eintönigkeit der nebeneinander gereihten parallelen Stäbe angenehm unterbrochen wird. Das erste Blatt stellt die Hälften zweier Chorgitter dar, von denen das eine eine sehr grosse Verwandtschaft mit dem noch zu erwähnenden Chorgitter von St. Eustache be- 
sitzt (Abbild. 29). Auf dem zweiten Blatt ist dagegen unverkennbar das Chorgitter von Val de Grâce abgebildet (Abbild. 21). Auch bei diesem Gitter ist die Monotonie, welche leicht durch das Aneinanderreihen gleichartiger Stäbe entsteht, geschickt aufgehoben, indem je zwei Stäbe zu einer Art von Pilaster verbunden sind. Eine etwas starre architektonische Bildung weisen die Eisenpfeiler zu beiden Seiten des Portals auf, welche kannelierte, von Vasen bekrönte Steinpfeiler nachahmen.

Auch drei weitere Folgen, jede zu 6 Blatt, untereinander sehr verwandt, gehen vielleicht auf denselben Hasté zurück. Alle drei tragen die Bezeichnung: Chez NDe Poilly rue St. Jacques à la belle Image, ausserdem sind sämtliche 18 Blätter von 5-6 dünnen enggestellten Linien eingerahmt. Die eine derselben giebt auf 5 Tafeln einen Teil der grossen Gitterwerke des Schlosses zu Versailles, das 6. Blatt enthält das schon erwähnte Chorgitter von St. Eustache, sämtliche Blätter besitzen diesbezügliche Unterschriften. Die zweite Folge giebt Treppen- geländer und Balkone, die dritte Thürklopfer, Schlüsselschilder, Riegel, Kaminböcke und Wandarme (Abbild. 30), alles dem Stile der Versailler Arbeiten nahe verwandt. Alle drei Folgen müssen etwa zwischen 1680 und 1690 erschienen sein. Für ihre Zuteilung an Hasté spricht auch der Umstand, dass ein Schlosser Namens Michel Hasté am Versailler Schloss beschäftigt war. In den Comptes des bâtiments wird seit 1676 ein Schlosser Hasté erwähnt, der Arbeiten für Clagny, Fontainebleau, St. Germain und Versailles ausführte; von 1679 bis 1686 wird von einem Michel Hasté l'aisné gesprochen, der für Versailles, Marly und Noisy arbeitete. Seit 1685 erscheint auch ein Michel Hasté le jeune unter den für Versailles thätigen Schlossern. Möglicherweise ist der ältere Hasté, der anfangs nur bei seinem Zunamen genannt wird, der Verfasser der genannten Ornamentstichfolgen, in denen er neben ausgeführten, zum Teil von ihm selbst geschmiedeten Arbeiten auch einige Entwürfe eigener Erfindung abgebildet haben mag.

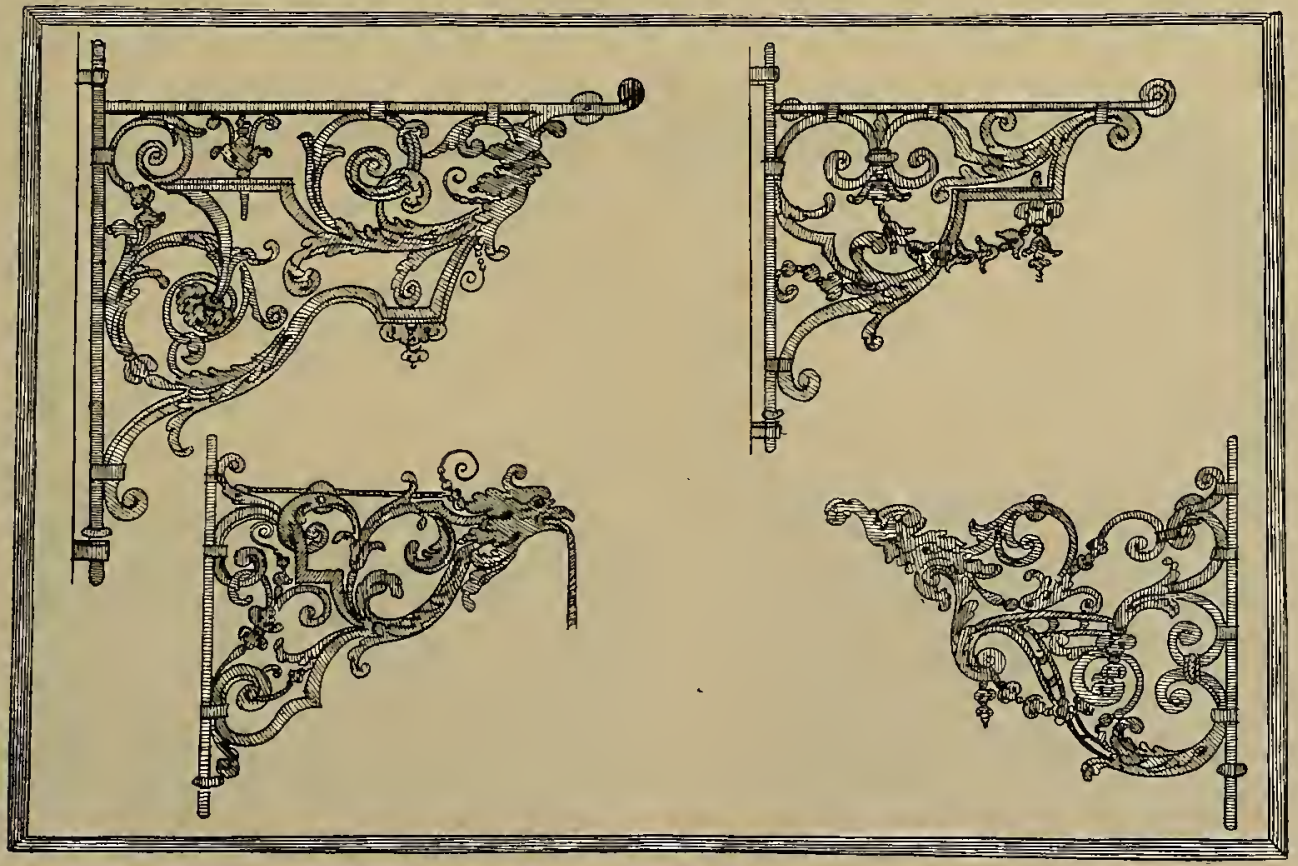

Abb. 30. Wandarme nach einem Stiche von M. Hasté. 
Ausser den angeführten 5 Tafeln mit Stichen von Versailler Gitterwerken sind auch bei le Blond 10 Blatt mit Versailler Schmiedearbeiten erschienen, welche zum Teil die dem Hasté zugeschriebenen Stiche ergänzen. $\mathrm{Da}$ die meisten dieser Gitter nicht mehr vorhanden sind, die wenigen noch erhaltenen zum Teil, wie das Gitter des Vorhofes, nicht mehr ihre ursprüngliche Gestalt bewahrt haben, so geben uns diese Stiche im Verein mit denen von Silvestre und Rigaud den einzigen authentischen Anhalt zur Feststellung der Form jener Gitterwerke. Sie stellen die Hauptteile der Gitter der beiden grossen Höfe und deren Portale, der Stallungen, zwei Thore des Vestibüls der grossen Treppe, das Abschlussgitter der Kapelle und mehrere Balkone dar. Davon sind die Portale der Haupttreppe 1677-79 von Delobel, die Gitter der Höfe und Stallungen von Delobel, Luchet, Hasté und Gilles Fordrin in den Jahren 1679 und 1680 geschaffen worden.

Gegenüber den zum Teil etwas überladenen, an den überquellenden Formenaufwand Lebruns erinnernden Entwürfen von Lepautre und Pierretz zeichnen sich alle diese Arbeiten durch ziemliche Einfachheit aus, was vielleicht der massvollen, zurückhaltenden Ornamentkunst Mansarts zuzuschreiben ist. Die Gitter bestehen aus einem Spalier von Stäben in Lanzenform, welche in bestimmten Entfernungen von pilasterartigen, den früheren Steinpfeilern entsprechenden $\mathrm{Zwi}$ schensätzen unterbrochen sind. Beim Gitter der Cour Royale wechselt jedesmal ein lanzenförmiger Stab mit einem Stabe $a b$, der in eine heraldische Lilie, das Wappenzeichen der Bourbonen, endigt (Abbild. 26). Die Pilaster sind mit beziehungsreichen Emblemen ausgestattet: die der Avantcour zeigen als Hauptschmuck eine grosse Lyra, darunter die Maske des Sonnengottes, beides ein Hinweis auf Phöbus Apollo, mit welchem Ludwig XIV. sich gern in stolzer Selbstgefälligkeit vergleichen liess (Abbild. 25). Nach oben laufen sie in die drei bourbonischen Lilien aus. Die Pilaster des grossen Gitters vor del Cour Royale tragen in der Mitte eine grosse Sonnenmaske. Als Krönung ist auf einer Art von Sockel, von dem ein Behang herunterfällt, das von einer Krone überragte Monogramm des Königs, das

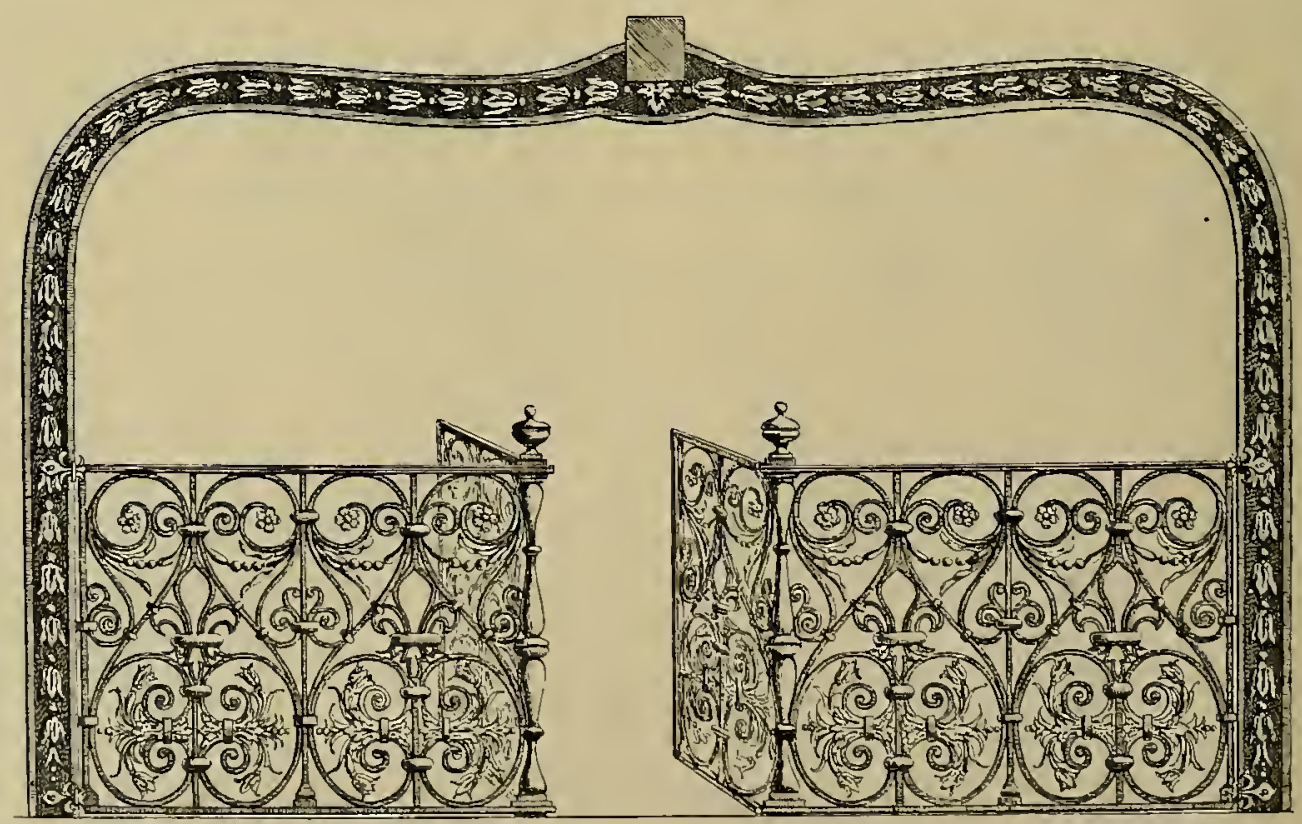

Abb. 31. Gitter, abgebildet in einer Handschrift von Barras de la Penne, 1698. 
Doppel-L, zwischen Füllhörnern und Palmzweigen angebracht. Die Pilaster des Gitters der Petite-Ecurie enthalten Peitschen, Striegel und ähnliche auf die Bestim. mung des Gebäudes hinweisende Abzeichen, die der Grande-Ecurie Degen u. dgl., was wohl auf die dort wohnenden $\mathrm{Pa}$ gen hindeuten soll. Die Eingangsthore sind ähnlich wie das Portal des Chorgitters von Val de Grâce aus schlichten Stäben gebildet, zwischen denen oben und unten sowie zu beiden Seiten des Querstabes kleine Füllornamente in Form einer Lyra und ähnliches eingesetzt sind. Den Hauptzierrat des Portals bildet der Aufsatz, das von einer Krone überdachte Wappen oder Monogramm des Königs,
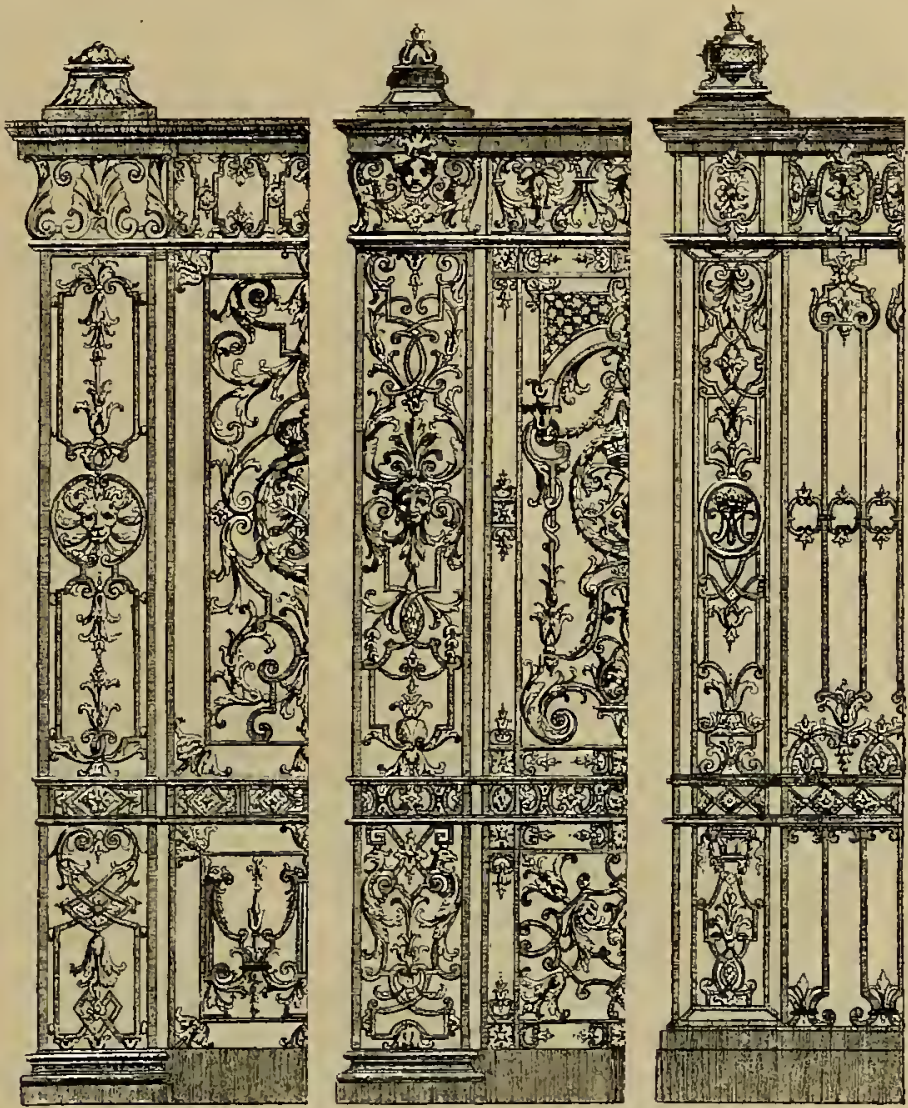

Abb. 32. Gitter nach einem Stiche von J. Bérain. umgeben von grossen S-förmigen Voluten, Akanthusranken u. s. w. Zu beiden Seiten des Portals der Cour Royale be. finden sich noch zwei niedrigere Steinpfeiler, auf welche das Thor sich vermittels zweier grossen Eisenvoluten gleichsam wie auf Krücken stützt.

Reicher in ihrer Bildung sind die von Rundbogen abgeschlossenen Portale der grossen Treppe. Die Umrahmung der hier (Abbild. 27) dargesteliten Gitterthür besteht aus einem Friesstreifen, der sich aus Kreisen zusammensetzt. Das Oberlicht enthält auf einem aus Stäben gebildeten Sockel das Wappen des Königs. Bei den Thürflügeln laufen die Stäbe nicht durch beide Felder hindurch, sondern jedes Feld zeigt eine für sich abgesonderte Komposition. Im oberen Felde sind jedesmal die paarigen und unpaarigen Stäbe gleichartig gebildet, sämtliche aber untereinander oben und

unten verbunden. Im unteren Felde sind die Stäbe paarweise zusammengefasst und diese Paare durch Querleisten und Rosetten vereinigt. Die Balkone gliedern sich in schmalere und breitere $\mathrm{Ab}$ schnitte, die von einer Komposition gefüllt sind, welche das königliche Wappen, das Doppel-L oder die Sonnenmaske zum Mittelpunkte hat. Diese Embleme ruhen gewöhnlich auf elnem aus Stäben gebildeten Sockel mit oder ohne Behang, seitlich sind sie von Akanthusspiralen umgeben. Bei anderen Balkonen schliesst sich ein mit einem Eierstab geschmückter breiter Rahmen um das Centrum. Ausser den angeführten Stichen befindet sich noch eine Federzeichnung von mehreren Balkonen der Cour de Marbre im Musée des arts décoratifs zu Paris (Abbild. 28).

Dem Formenkreis, wie er in den Stichen der angeführten Meister und in 

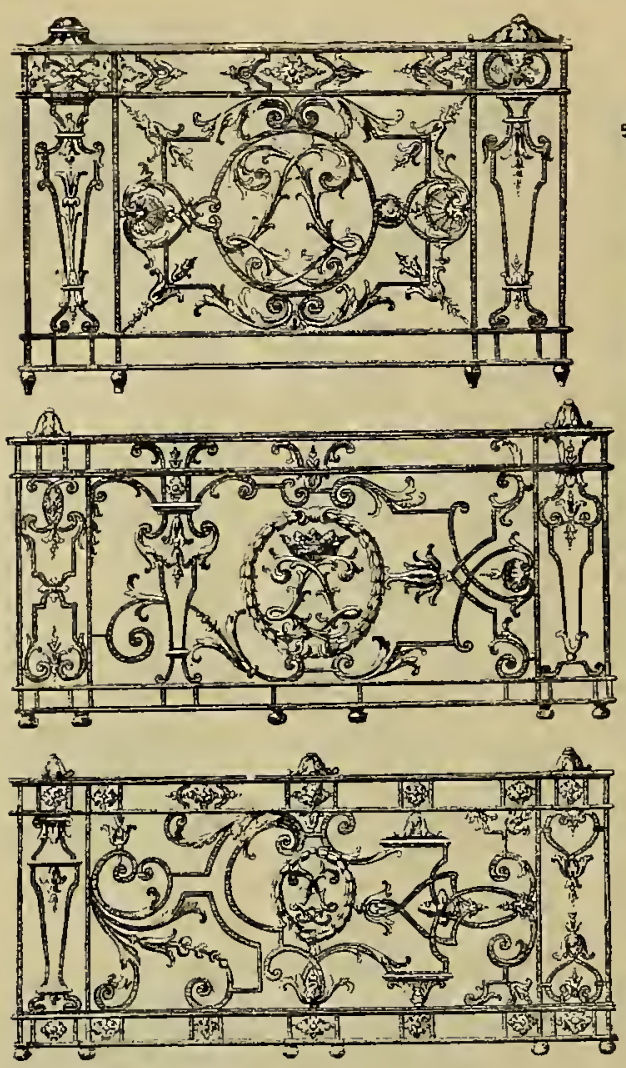

Abb. 33. Gitter nach einem Stiche von J. Bérain.

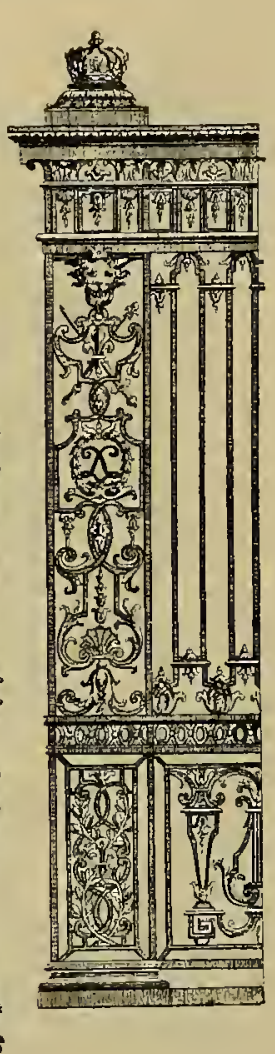

wissermassen zu dem das Gitter tragenden Sockel die Fortsetzung bildet. Dieser muss, nach seiner Gliederung in Rahmen und Füllung zu urteilen, aus Holz bestanden haben. Die Stäbe des oberen Feldes sind durch Bunde zu Paaren vereinigt. Die Bekrönung des Portals zeigt den aus den Versailler Thoren bekannten Aufsatz. Das Gitter ist ebenfalls mit einem besonderen fortlaufenden, niedrigen Aufsatz versehen (Abbild. 29).

Auch die formprächtigen Chorgitter von St. Sulpice und von St. Denis, welches letztere in seiner Gestaltung an das Chorgitter von Val de Grâce anklingt, aber sehr viel reicher ausgeschmückt ist, sind uns durch Stiche des Nicolas Guérard und Nic. Bonnard bekannt. den Versailler Arbeiten ausgebildet erscheint, gehören noch mehrere grosse Gitter an, die als Chor- oder Kapellenabschlüsse gedient haben. Einzelne derselben haben sich noch erhalten, wie das Gitter einer Kapelle in der Kathedrale zu Dijon, dessen Bekrönung lebhaft an den Aufsatz des Portals auf dem ersten Blatt der Stichfolge des Hasté mit der Widmung an de Lespine erinnert. Die Gestalt anderer, nicht mehr vorhandener, ist wenigstens in Stichen aufbewahrt. So stellt das letzte Blatt der dem Michel Hasté zugeschriebenen Folge mit Gitterwerken von Versailles das Chorgitter von St. Eustache in Paris dar, das um dieselbe Zeit wie die Versailler Arbeiten entstanden sein muss. Die Flügel der von korinthischem Pilaster flankierten Thür enthalten in ihrem unteren Felde eine symmetrische Akanthuskomposition, die in ihrer raumfüllenden Eigenschaft ge-
Wie aus diesen und den anderen angeführten Beispièlen ersichtlich ist, wurden diese Gitter, welche den Chor sowohl von vorn, als auch an den Seiten gegen den Chorumgang hin abzusperren pflegten, nicht nur in neue Kirchen, sondern auch in die alten mittelalterlichen Kathedralen hineingebaut, ohne dass man irgendwelche stilkritische Bedenken dabei gehabt hätte.

Als Nachzügler einer älteren Stilrichtung, als die zuletzt vorgeführten Arbeiten vertreten, kann man zwei in Marseille thätige Künstler, den Pierre und Jean Gautier, betrachten, von denen der erstere sich als königlichen Schlossermeister im Schiffsarsenal zu Marseille bezeichnet. Pierre Gautier hat ein Büchlein mit Stichen nach seinen ausgeführten Arbeiten, im ganzen 16 Blatt, 1685 herausgegeben. Daneben existiren noch 6 Tafeln mit der Bezeichnung J. G., von denen eine die Jahreszahl 1688 trägt. Es sind Gitter, 
Kaminböcke, ein Wandarm und eine Laterne. Die Stiche beider, die sich nur wenig voneinander unterscheiden, zeigen zum Teil noch eine Hinneigung $\mathrm{zu}$ den
Schmiedearbeiten der Zeit Ludwigs XIIl., was vielleicht mit der grossen Entfernung des Ortes ihrer Thätigkeit von der Hauptstadt in Verbindung $\mathrm{zu}$ bringen ist. Be-

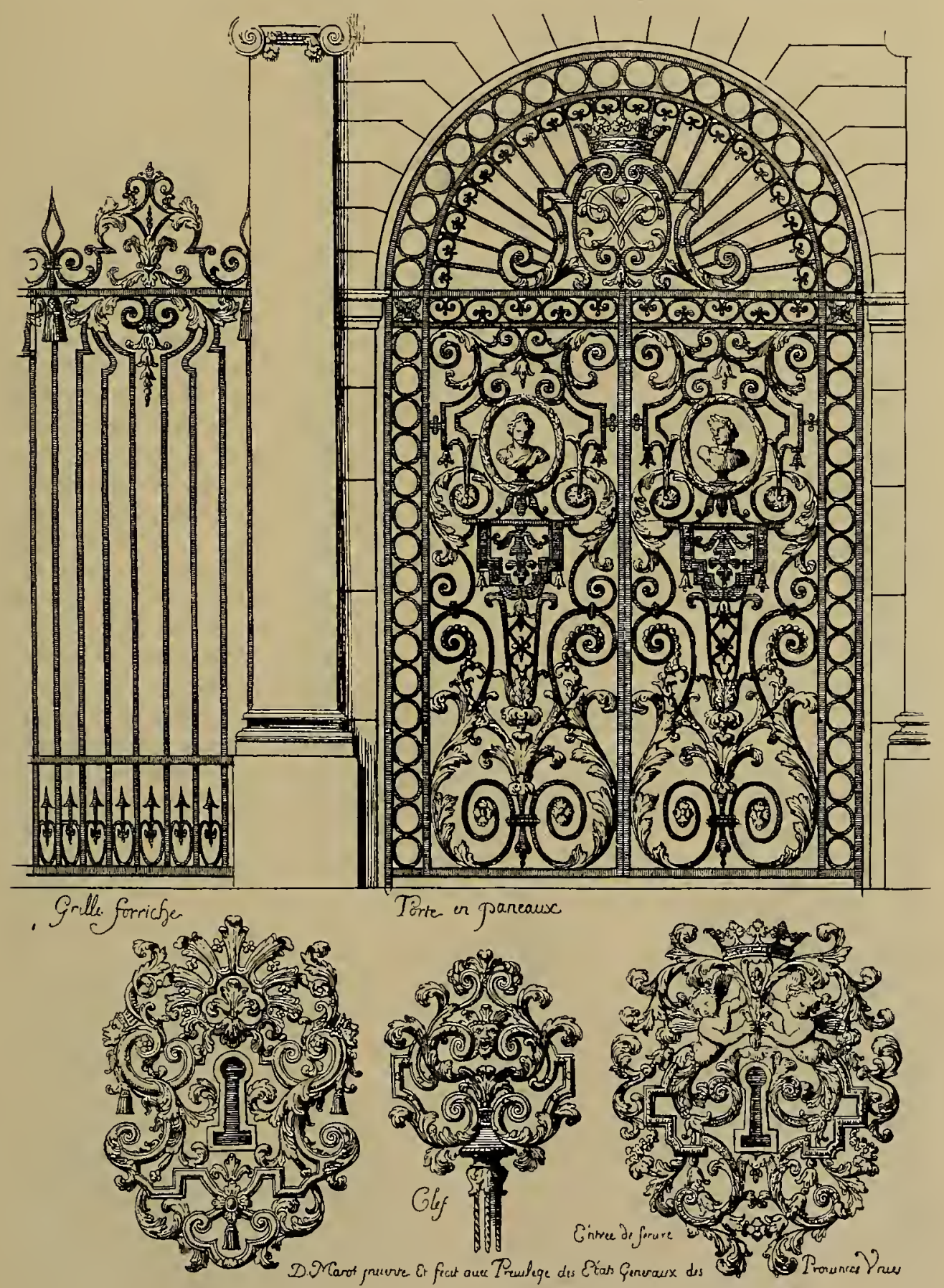

Abb. 34. Entwürfe für Schmiedearbeiten von D. Marot. 
sonders fällt die häufige Verwendung des Motivs der bourbonischen Lilien in verschiedenen Massstäben auf. Daneben spielt die Akanthusranke in regelmässig gezogenen vollrunden Spiralen von einer etwas flauen, marklosen Zeichnung eine grosse Rolle; auch natürliche Pflanzen, Aehren, Tulpen und andere Blumen kommen vor. Die Linienführung des Stab. werks besitzt in ihrer Hinneigung zu rundlichen Formen einen weichlichen Charakter. Gebrochene Linien treten bei Jean Gautier nur in bescheidenem Masse auf, bei Pierre fehlen sie völlig. Ein Teil der Arbeiten fand vielleicht auf den Prunkschiffen des Königs Verwendung. Ein Manuskript von Barras de la Penne vom Jahre 1698 enthält die Darstellung eines Gitters von der Galeere Ludwigs XIV., welches genau dieselbe Zeichnung zeigt, wie ein Stich des Pierre Gautier (Abb. 31).

Mit dem Jahre 1690 etwa tritt die französische Schmiedekunst zugleich mit den übrigen dekorativen Künsten in die Gefolgschaft der Kunst eines der bedeutendsten schöpferischen Geister auf dem Gebiete der Ornamentik, nämlich des Jean Bérain. Auch in Deutschland steht die Schmiedekunst in den folgenden Jahrzehnten durchaus im Zeichen dieses

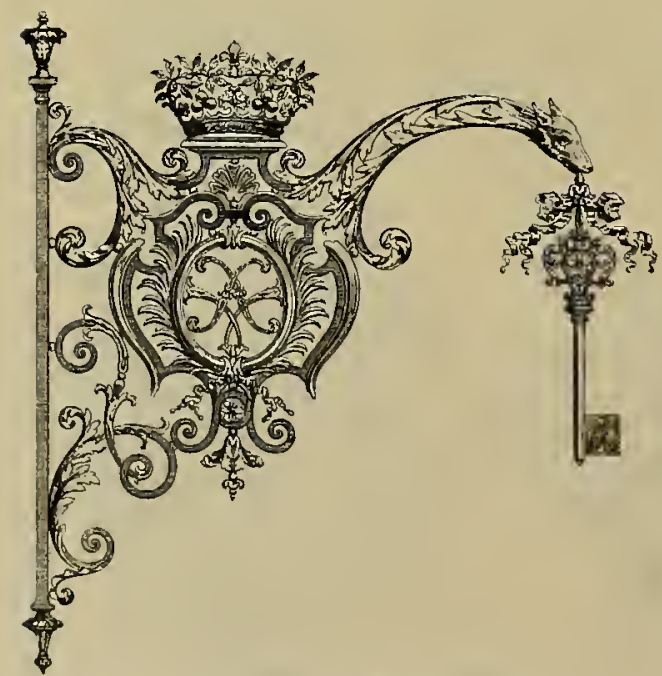

Abb. 35. Wandarm nach einem Stiche von S. Vallée.
Künstlers. Um jedoch die Bedeutung Bérains für die Schmiedekunst ganz zu verstehen, bedarf es eines kurzen Rückblicks auf das, was bisher geschaffen worden war.

Jean Marots Entwürfe für Schmiedearbeiten hatten keine weitere Verbreitung gefunden. Indessen war doch der Eindruck, den die grossartigen Portale von Maisons-sur-Seine auf die Zeitgenossen ausübten, so gross, dass noch lange einzelne Motive der in denselben angewandten Ornamentik weiterlebten. Daviler bezeichnet in seinem Cours d'Architecture von 1691 ausdrücklich die Gitterthore von Maisons neben den Versaillern als die schönsten Eisenportale. Den neuen Aufgaben gegenüber, die dann Versailles und die anderen gleichzeitig erbauten Schlösser an die Schmiedekunst stellten, zeigte man sich, was die künstlerische Erfindung angeht, zum Teil noch nicht ganz gewachsen. Vielfach kehrte man zu den Motiven aus der Zeit Ludwigs XIIl. zurück. Die neuen Entwürfe, wie z. B. die Gitterthore von Versailles oder von Val de Grâce, sind ziemlich dürftige und trockene Leistungen, reicheren Kompositionen fehlt die Eleganz der Linienführung; die Pflanzenornamentik, die in der Form des Akanthus auftritt, überwiegt vielfach noch zu sehr. Vor allem aber fehlt es der Schmiedekunst noch an einem einheitlichen Formenkreis, der sämtliche in ihren Bereich fallende Arbeiten gleichmässig umfasst. Diesen Mangel zeigen besonders die Schlosserbücher des Lepautre und Pierretz; während die Gitterbildung sich vielfach mit rein linearen Motiven begnügt, sind die Thürklopfer, Schlüsselschilder, Wandarme u. s. w. mit mannigfaltigem figürlichen und pflanzlichen Dekor ausgestattet.

Schon einmal ist Bérain uns in der Geschichte der Schmiedekunst begegnet. 16 Tafeln des um 1663 veröffentlichten Schlosserbuches von Brisville wurden von seiner Hand graviert, nachdem er selbst 1659 eine Folge von Ornamentstichen zum Gebrauch für Büchsenmacher in 
Paris herausgegeben hatte. Was von seinem Wirken vorher liegt, ist uns unbekannt. Wir wissen nur, dass er wahrscheinlich im Jahre 1637 zu Saint-Mihiel in Lothringen geboren wurde und mit seinem älteren Bruder Claude, der auch Graveur war, schon früh nach Paris gekommen sein muss. 1671 erscheint er zum ersten Male in den Comptes des bâtiments als Stecher zweier Tafeln mit Ornamenten der von Lebrun dekorierten Apollogalerie. Aber nicht nur als geschickter Stecher, sondern auch als erfindungsreicher Künstler muss er sich bewährt haben, denn drei Jahre später wird er zum „dessinateur de la chambre et du cabinet du roj" ernannt, mit dem beson. deren Auftrage, für das Theater und sonstige Festlichkeiten Dekorationen und Kostüme zu entwerfen. Im Jahre 1679 erhält er als besondere Auszeichnung eine Wohnung im Louvre, die er

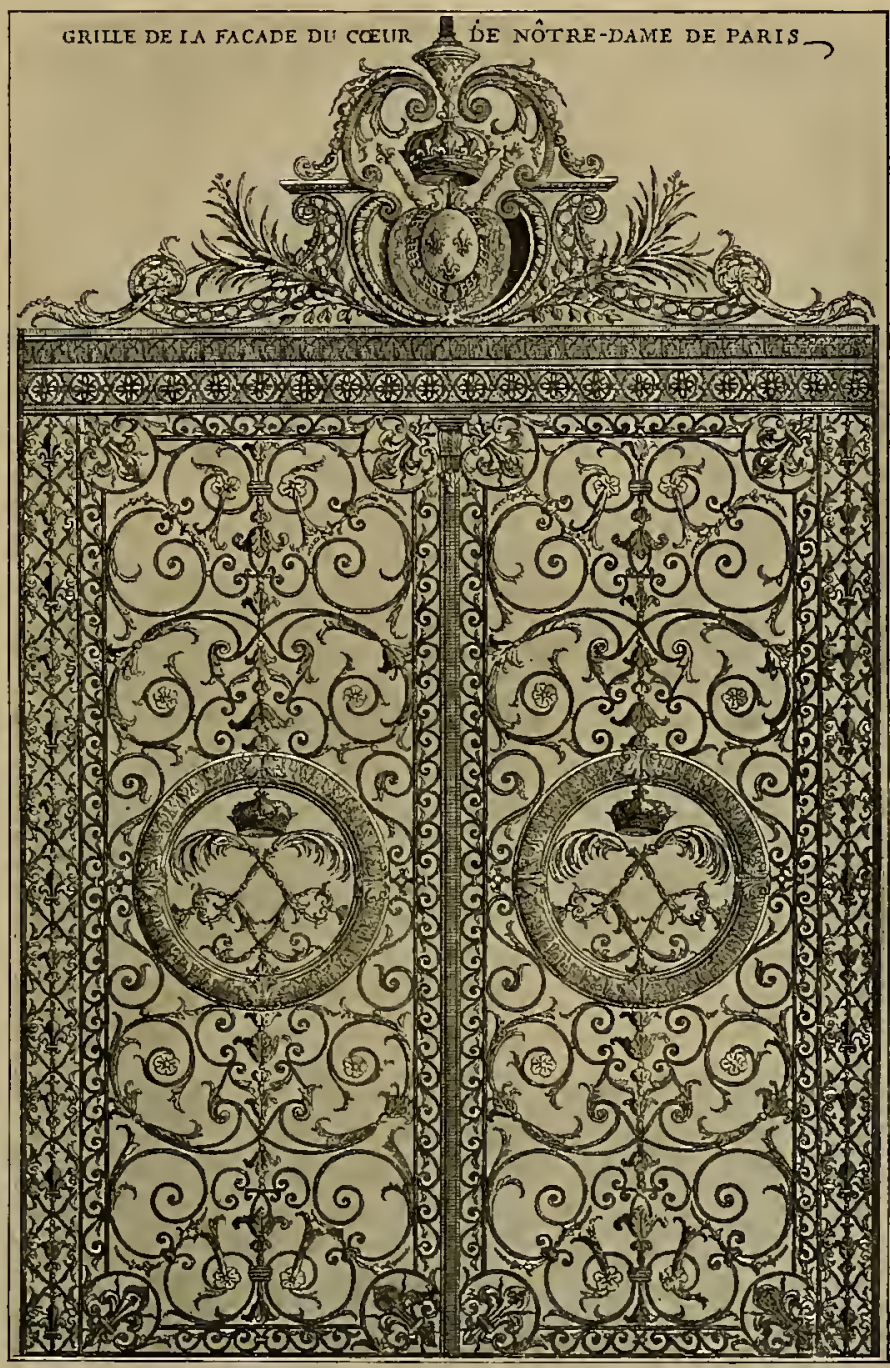

Abb. 36. Portal des Chorgitters von Notre Dame zu Paris nach einem Stiche des Nic. Bonnard. bis $\mathrm{zu}$ seinem $1711 \mathrm{er}$.

folgten Tode innebehielt. Der grösste Teil der Entwürfe Bérains ist erst nach seinem Tode durch Thuret in Stichen von Lepautre, Dolivar und D. Marot veröffentlicht worden. Sie bieten grosse ornamentale, für Wandmalerei und Wandteppiche bestimmte Flächendekorationen, sog. Grotesken, d. h. rechteckige Felder ausfüllende Kompositionen mit phantastischen Architekturen nebst eingestellten Figuren u. ähnl., ferner Entwürfe für Decken, Kamine, Möbel, Beleuchtungsgerät, für Gartenanlagen, Gitter u. s. w.
An Vorlagen für Schmiedearbeiten sind 5 Tafeln vorhanden, welche die Bezeichnung tragen: J. Berain delin. aux Galleries du Louvre. ${ }^{1}$ ) Schon aus der Beifügung aux Galleries du Louvre erhellt, dass sie nicht vor 1679 gezeichnet sein können. Von den genannten Tafeln enthalten vier Zeich. nungen zu grossen Gittern und Balkonen,

1) Neudruck der Stiche für Schmiedeeisen in: 100 Planches principales de l'oeuvre complet de Jean Bérain. Paris, A. Quantin. Ueber Bérain vgl. Revue des arts décoratifs Bd. VI. S. 1 ff. 


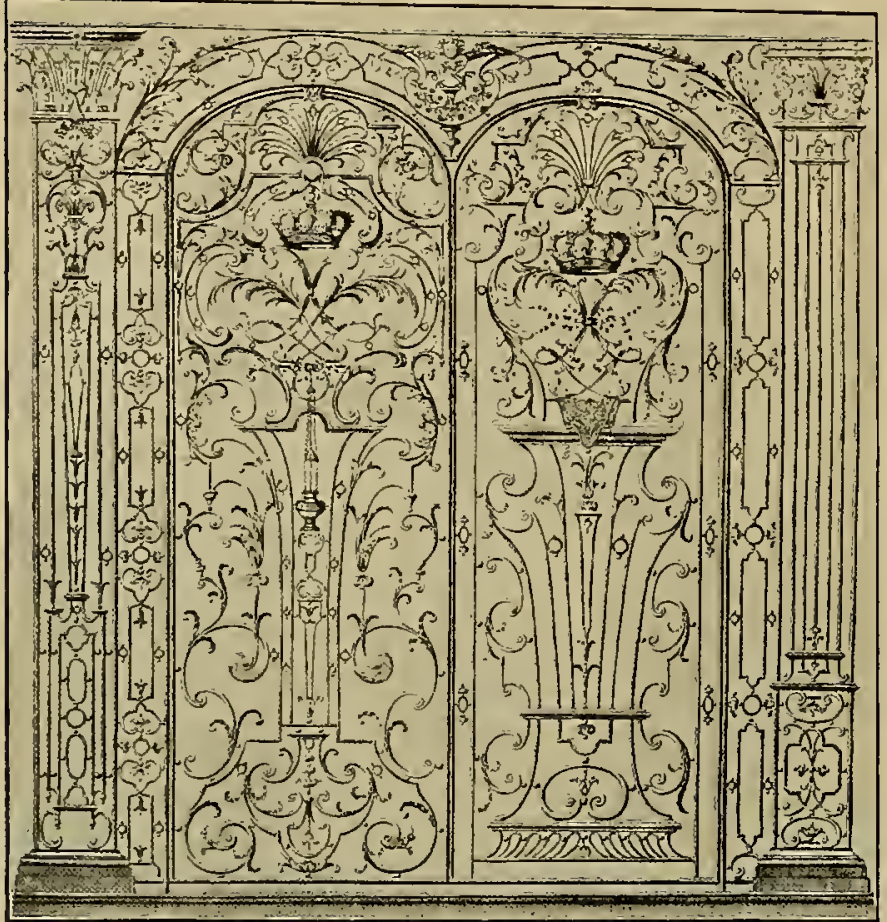

Abb. 37. Portal aus dem Schlosserbuch von L. Fordrin.

deutenden Anteil an der Komposition und Ornamentik der Eisenarbeiten besass. Dass dieses Hervortreten des Stabwerkes und das Zurückweichen des Akanthus einen Fort. schritt für die Schmiede. kunst bedeutet, braucht wohl nicht besonders betont zu werden. Als gelegentlicher Schmuck erscheinen neben diesen Hauptelementen der Bérainschen Eisenornamen. tik Rosetten, kleine Palmetten, die königlichen Embleme: Scepter, Krone, die Lilie u. s. w., sowie vereinzelt Masken und Tier. köpfe, ferner jenes für die Dekoration des 18. Jahr. hunderts so charakteristische Gittermuster mit kleinen Rosetten oder Blüten auf den Schnitt. die fünfte Friese und Kapitäle, bei denen die architektonischen Formen in leicittes Stab- und Laubwerk in Verbindung mit Masken, Wappen, Namenszügen aufgelöst sind.

Das Gerüst aller dieser Eisenkompositionen bildet ein festes Stabwerk von bestimmter, leicht fasslicher Linienführung. Die Linienzüge setzen sich aus abwechselnd geraden und gebogenen Stäben zusammen, die Endigungen der Bogenlinien sind in der Regel volutenartig aufgerollt. Dieses Stabwerk ist belebt durch Blattwerk von akanthusartiger Bildung, das die Biegungen und Voluten begleitet oder auch wohl einhüllt. Bezeichnend ist es, dass das Laubwerk nicht selbständig als Ranke auftritt, sondern nur als Begleitung des Stabwerkes erscheint, ein wesentlicher Unterschied gegen die bisherige Verwendung des Akanthus, der als besondere sich entwickelnde Ranke in den Entwürfen der früheren Ornamentstecher, vor allem bei Jean Marot, einen so be-

punkten der Bänder, dessen Ursprung wohl in dem Lattenwerk der Laubengänge in den Gärten der damaligen Zeit zu suchen ist (Abbild. 32 u. 33).

Die Entwürfe Bérains für Schmiedewerk bilden gewissermassen die reinste Abstraktion seines Stiles, dem die deutschen Ornamentstecher, welche ihn zu Anfang des 18. Jahrhunderts aufnahmen und weiterbildeten, den bezeichnenden Namen "Laub- und Bandelwerk" gaben. Wie hier, so bilden auch in seinen Flächenornamenten die gebrochenen, abwechselnd geraden und gebogenen Linien des dort als Bänder erscheinenden Stabwerks im Verein mit dem schmückenden Laubwerk die charakteristischen Merkmale des ihm eigentümlichen Stils. Indem Bérain an die Stelle der etwas schwülstigen Akanthusranken des italienischen Barocks, wie sie in Lebruns und Lepautres Werken vorherrschen, die klaren Linien seines Bandwerks setzt, greift er auf ähnliche Ornamentformen der deutschen Renaissance 
zurück. Denn die Verwandtschaft der Bandornamente Bérains mit Rollwerkoder Maureskenmotiven des 16. Jahrhunderts - als beliebiges Beispiel mögen die 1579 in Nürnberg vom Maler Georg Wechter herausgegebenen Entwürfe für Goldschmiede erwähnt sein — ist bei eingehendem Vergleich nicht zu verkennen.

Die gewaltige Einwirkung, welche Bérain auf die Formgebung der Schmiedekunst, und zwar, wie es scheint, weniger in Frankreich als in Deutschland, während eines halben Jahrhunderts ausüben sollte, liegt nicht so sehr in den wenigen für die Schmiedekunst entworfenen Zeichnungen, als vielmehr in dem grossen $\mathrm{Er}$ folge begründet, den sein Stil überhaupt davon trug, indem er eine leichte Anwendung auf die verschiedensten Gebiete des Kunstgewerbes gestattete. Was Bérain für Wanddekorationen, Kamine, Möbel erfand, übertrugen seine Nachfolger auf andere Gegenstände mit geringer Mühe.

Der bedeutendste unter diesen war der Sohn des Jean Marot, Daniel Marot, den die Aufhebung des Edikts von Nantes im Jahre 1685 zwang, nach Holland auszuwandern. Hier fand er günstige Aufnahme bei Wilhelm von Oranien, dem späteren Könige von England. Sein Werk kam 1712 zu Amsterdam heraus. ${ }^{1}$ ) Zuletzt begegnet uns sein Name auf den Illustrationen zu einer jüdischen Bibel, welche die Inschrift tragen: Daniel Marot, invenit et fecit 1718. ${ }^{2}$ ) Marots Stil ist stark durch Bérains Laub-und Bandelwerk beeinflusst. Vielfach erscheinen seine Stiche nur als eine erweiterte Anwendung der Bérainschen Formen, die freilich bei ihm schon infolge der reicheren Verwendung des Akanthus schwerer erscheinen. Vielfach geht er auch auf den massigen Pomp Lepautres zurück. Für die Schlosser hat er eine Folge von 6 Blatt entworfen, welche die Aufschrift trägt: „Nouveau Liure de Serrurerie Inuenté et Grauée Par D. Marot

1) Neudrucke im: Ornamentwerk des Daniel Marot. Berlin, E. Wasmuth 1892.

2) Bérard, A., Catalogue de toutes les estampes qui forment l'oeuvre de Daniel Marot. Bruxelles 1865 . S. 5 .

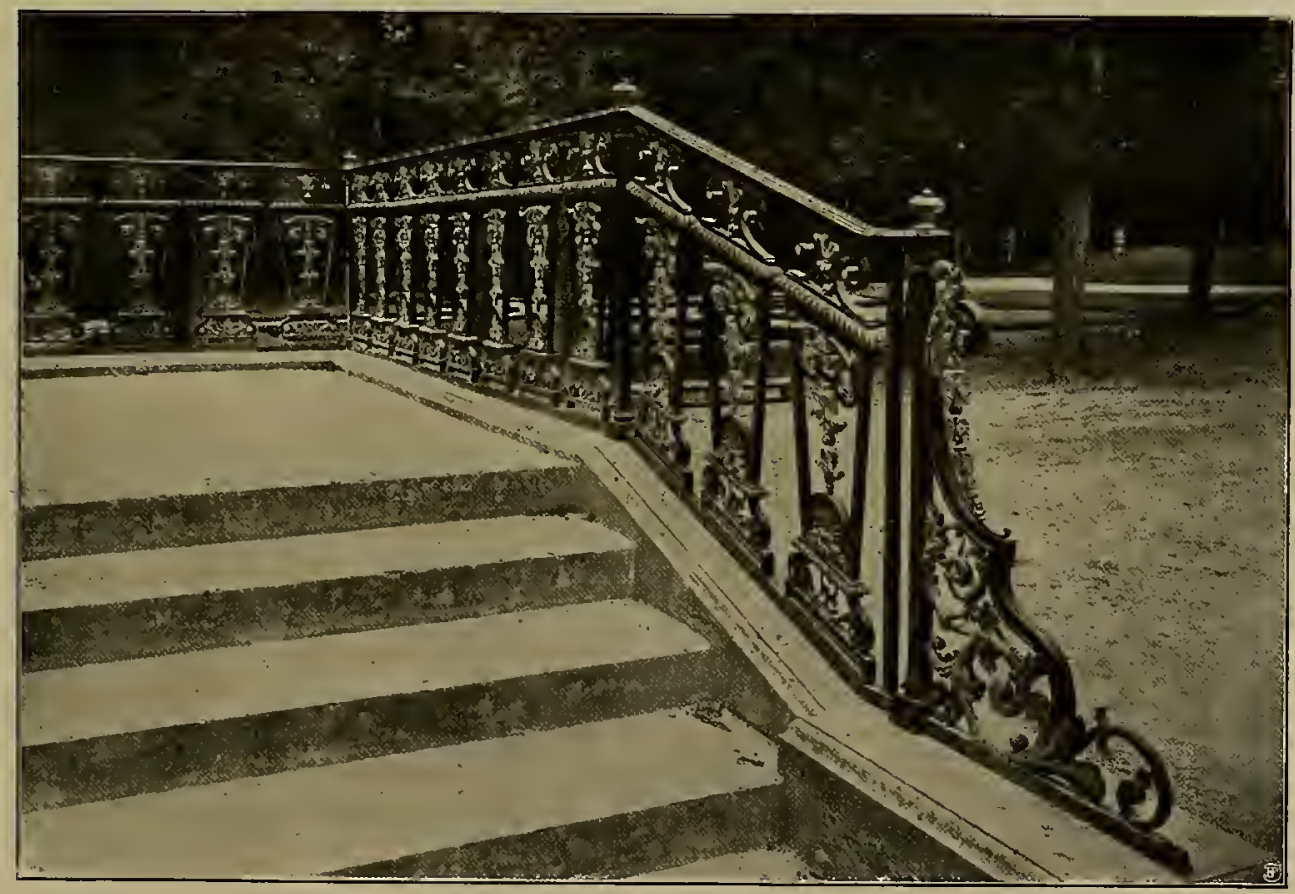

Abb. 38. Geländer am Schloss Grand Trianon. 


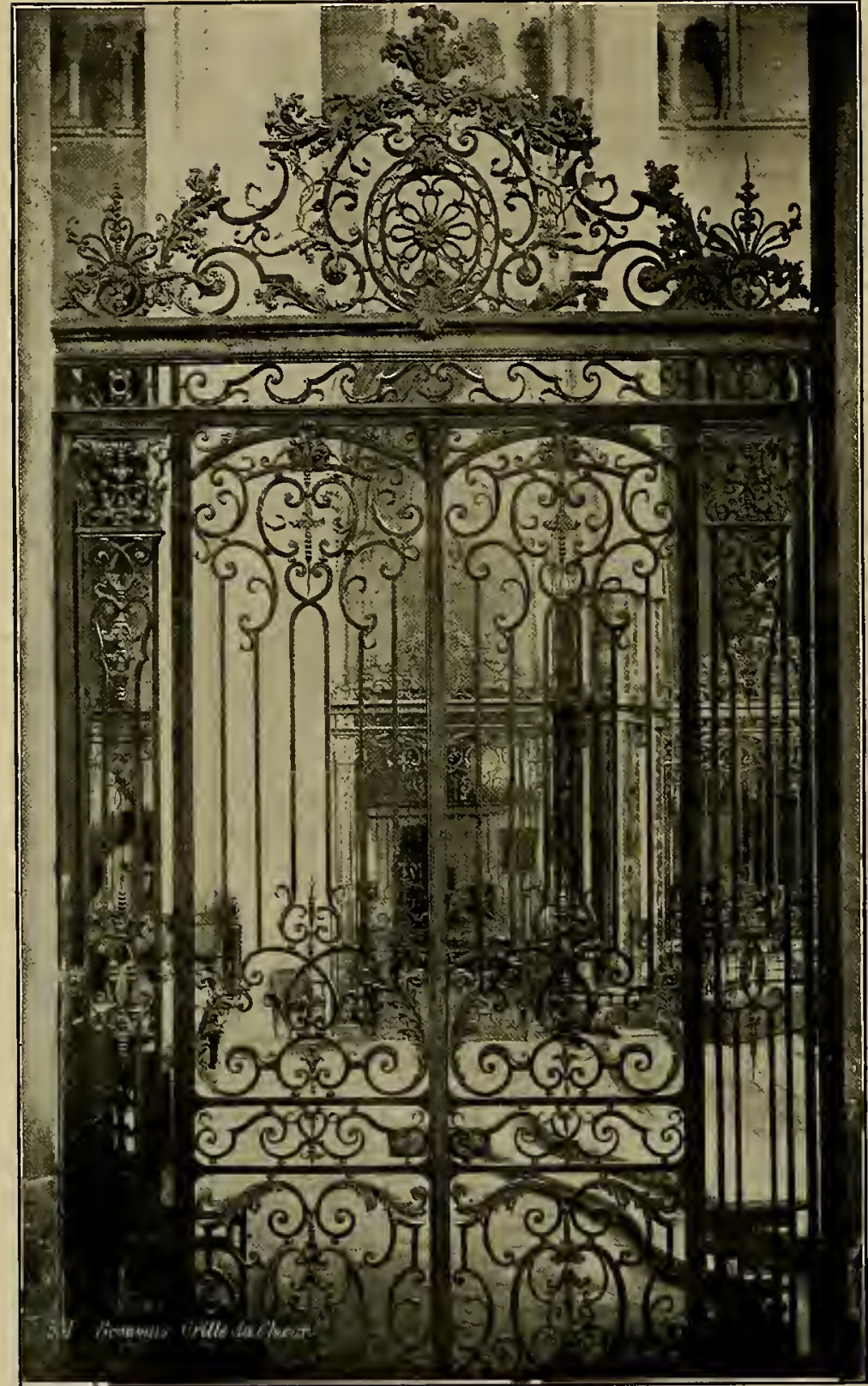

Abb. 39. Chorgitter der Kathedrale zu Beauvais.

Balkone, dessen Mitte ein Monogramm einnimmt, liesse sich ohne weiteres in die Reihe der Balkone der Cour de Marbre setzen. Was von seinen Arbeiten in England, was in den Niederlanden oder anderswo ausgeführt worden ist, vermag ich nicht zu entscheiden.

Aehnlich wie bei Bérain ist auch Marots Einfluss auf die Schmiedekunst nicht nur in der bescheidenen $\mathrm{Zahl}$ seiner Entwürfe für Eisenarbeiten be. grenzt, bedeutend wichtiger für die Entwicklung des Formenkreises der Schmiedekunst besondersinDeutschland war die durch ihn erfolgte weitere Ausbildung und Festlegung des Laub- und Bandelwerkstils überhaupt.

Unter den Ornament - Stechern, welcheausschliesslich auf dem Gebiete des Schmiedeeisens thätig

Architecte de Sa Majesté Britanicque fait aux Preuilege des États Generaux des Provinces Unies ce vend à la Haye chez L'auteur." Sie enthält Portale, Gitter, Treppengeländer, Balkone, Schlüsselschilder und Schlüsselgriffe (Abbild. 34). Mehrere Entwürfe zeigen deutliche Anklänge an die Versailler Arbeiten. Einer der waren, das Ornamentkapital Bérains weiter auszunutzen und die Laub- und Bandelwerkformen, die ihr Vorbild in Gitterwerken niedergelegt hatte, auch auf alle anderen in den Bereich der Schmiedekunst fallenden Gegenstände, Schlösser, Schlüssel, Beschläge, Klopfer, Geräte u. s. w. zu übertragen, hat sich besondere Verdienste 
S. Vallée erworben, der nicht nur Balkone, sondern auch Chorpulte, Kronleuchter, grosse Kandelaber für die Osterkerze, Wandarme (Abbild. 35), Schlüsselgriffe entwarf. Zum Teil sind seine Linien schon weicher und geschmeidiger, als die Bérains. Eine Ergänzung dazu bilden die Stiche des Nicolas Guérard mit Chorund Kommuniongittern, Thürklopfern und Schlüsselschildern.

Uebrigens scheint Bérains Einfluss auf die französische Schmiedekunst nur wenige Jahrzehnte gedauert zu haben, soweit sich das bei dem fast gänzlichen Mangel an erhaltenen Schmiedearbeiten jener Zeit beurteilen lässt. Schon gegen Ende der Regierung Ludwigs XIV. tauchen neue künstlerische Kräfte auf, die von den strengeren Formen Bérains allmählich $\mathrm{zu}$ dem bewegteren freieren Linienfluss des Rokoko hinüberführen. Siestehen auf jener vermittelnden Kunststufe, die man mit dem Namen Régence zu bezeichnen pflegt.

Der führende Geist unter ihnen war Robert de Cotte, damals "der erste Architekt des Königs", von dem die berühmten, leider nur noch in Stichen des Nic. Bonnard erhaltenen Chorgitter der Notre DameKirche in Paris ent. worfen wurden. Ludwig XI1l. hatte 1638 ein Gelübde gethan, zuEhren der Gottesmutter den Hauptaltar der Kathedrale neu aufzubauen. Erst 1699 dachte sein Nachfolger daran, das Versprechen des Vaters zu erfüllen. $\mathrm{Er}$ übertrug Jules-Hardouin Mansart die Ausführung der
Aufgabe. Die begonnenen Arbeiten wurden aber plötzlich wieder abgebrochen und erst 1708 nach dem Tode Mansarts unter Leitung de Cottes wieder aufgenommen, der den ganzen Chor samt Gestühl und Gitter im Geschmack der damaligen Zeit ohne historische Aengstlichkeit neu errichtete. In der Architecture française von Jacques François Blondel, die 1752 erschien, sind Pläne und Ansichten des Chors (Livre IV, No. IIl, pl. II u. ff.) enthalten, woraus die Stellung der einzelnen Gitter ersichtlich ist. Ausser dem Hauptportale am Eingang des Chores befanden sich auf der Mitte der Langseiten zwei kleinere Thüren.' Die Seiten des Chores

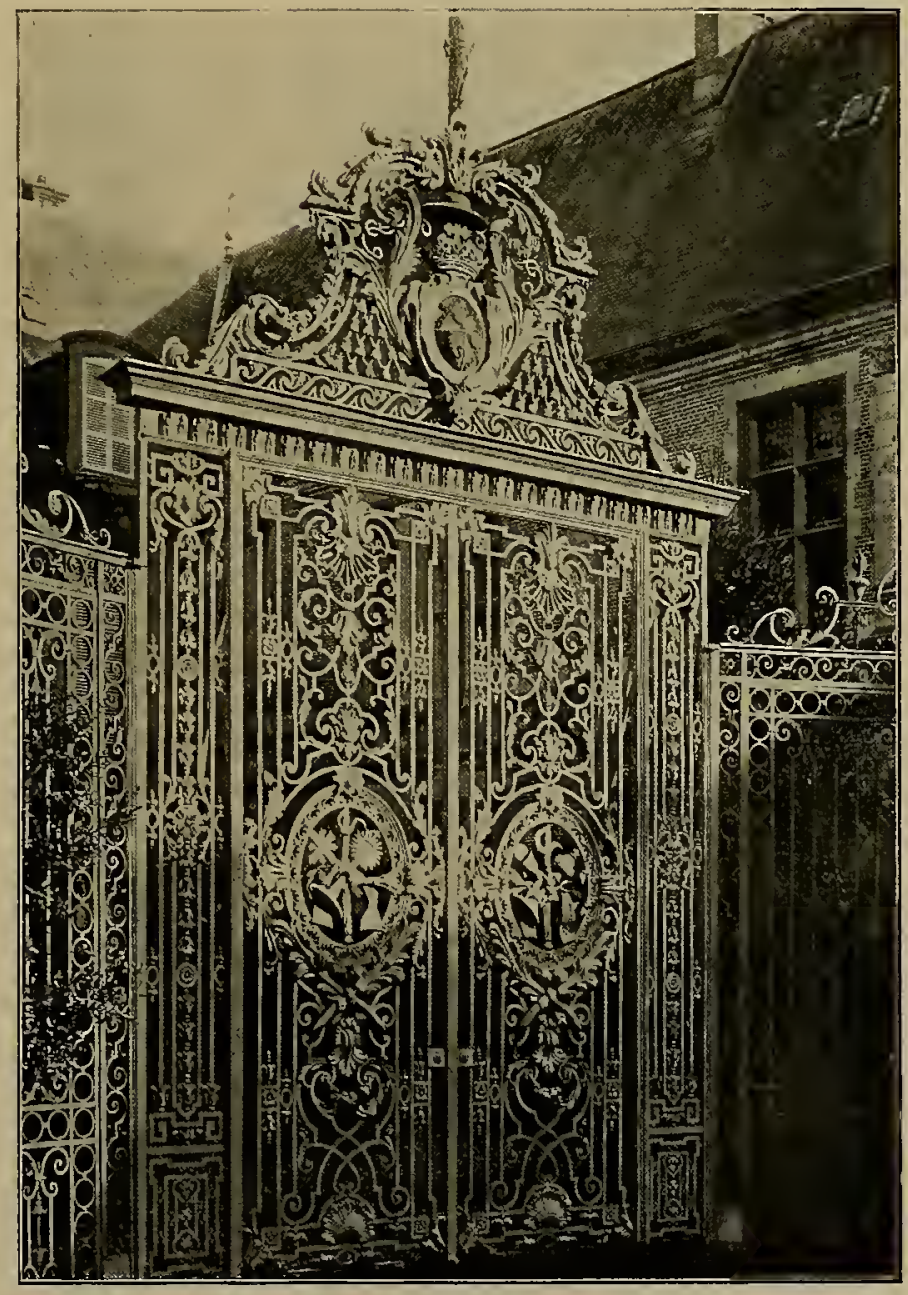

Abb. 40. Gitter im Garten des erzbischöflichen Palais zu Sens. 
nach dem Umgang hin waren durch sechs Gitter abgeschlossen. An der Ausführung der von Robert de Cotte entworfenen, reich vergoldeten Schmiedewerke hatten mehrere Schlosser gearbeitet, das Hauptportal verfertigte François Caffin, die beiden Seitenthüren Louis Fordrin (Foudrain), die Abschlussgitter Nicolas Parent,

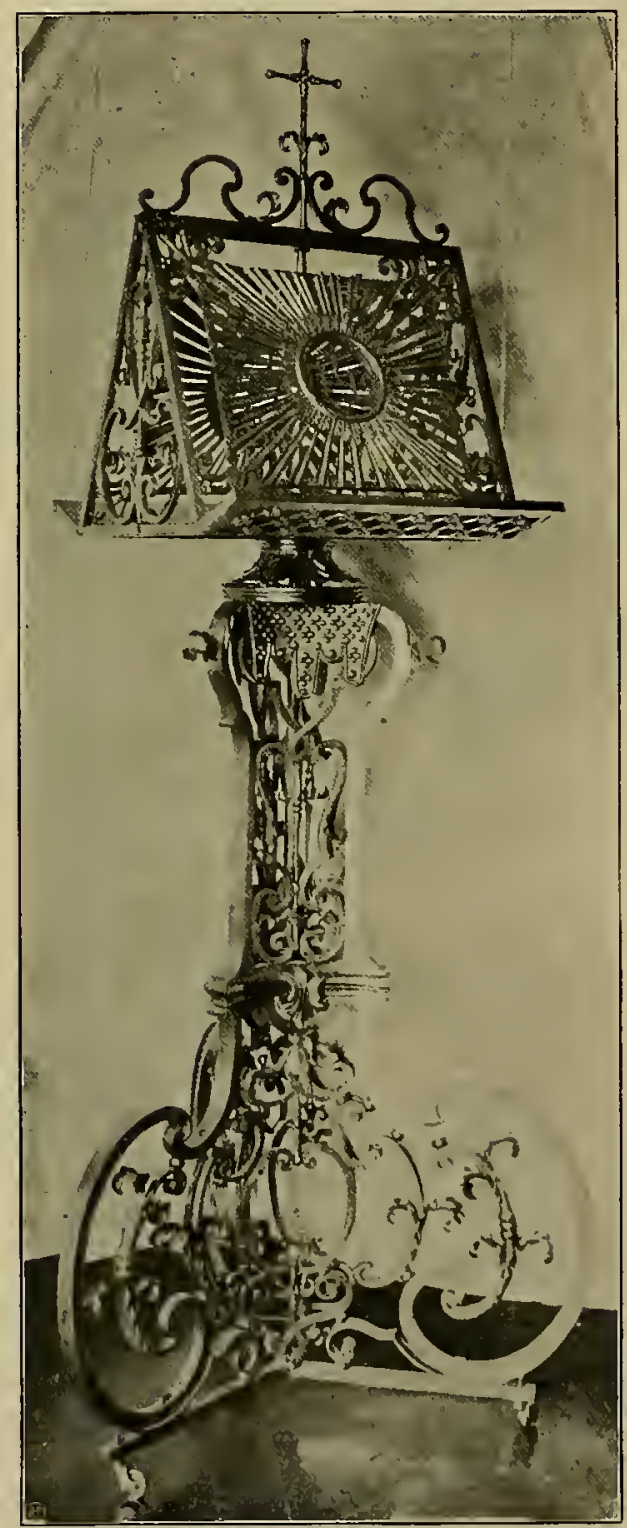

Abb. 41.

Chorpult in der Sammlung Secq des Tournelles.
Jacques Petit und Richard. ${ }^{1}$ ) 1714 war die ganze Anlage vollendet. Zur Zeit der Revolution wurden die Gitter zerstört (1793).

Gegenüber der strenger gefügten bisherigen Linienkompositionen herrscht jetzt eine leichte Gefälligkeit. Die Stäbe schwingen sich in rundlich geschweiften Linien, jede gerade Richtung ist vermieden. Das Akanthuslaub, welches das Stabwerk verziert, ist von dünner, zierlicher Bildung. Die Mitte der Flügel des Eingangsthores (Abbild. 36) nimmt ein grosses rundes Medaillon mit einem gekrönten Doppel-L ein, der Rahmen ist mit breiten Akanthusblättern geziert. Die ganze Füllung umgiebt ein Wellenband, die vier Ecken sind mit grossen Lilien geschmückt. Elegant geschwungene Voluten mit dem königlichen Wappen in der Mitte bilden den Aufsatz. Die Seitenthüren und Abschlussgitter sind ähnlich gestaltet.

Einer der bei der Herstellung der Gitter von Notre Dame thätigen Schlosser besass auch bedeutende künstlerische Talente, nämlich Louis Fordrin, der uns ein ziemlich umfangreiches Foliowerk mit Entwürfen für Schmiedearbeiten hinterlassen hat. Das Privileg dazu ist 1723 ausgestelit. Dafür, dass der Verfasser dieses Nouveau Livre de Serrurerie identisch ist mit dem bei den soeben erwähnten Gittern Robert de Cottes beschäftigten Schlosser, spricht der Umstand, dass ein Teil der Entwürfe Anlehnungen an die Gitterwerke der Pariser Kathedrale verraten, wie z. B. der Stich mit der Unterschrift: Porte pour une choeur d'église. Fordrin nennt sich im Titel "Maitre serrurier ordinaire des bâtiments du roy et de ses monnaies". Er scheint einer Schlosserfamilie zu entstammen. Ausser seinem Namen, der seit 1703 in den Comptes des bâtiments auftritt, werden ebendort noch seit 1686 ein Gilles, Alexis, François und eine Witwe Jean Fordrin erwähnt.

1) Vgl. Nouveau Livre de Serrurerie par Louis Fordrin. A. Calavas. Paris. Einleitung S. 2. (Neudruck.) 
Neben Kompositionen, deren schön geschweifte Linienzüge an Robert de Cottes Formgebung erinnert, weist ein grosser Teil der veröffentlichten Arbeiten auf ein den Gittern von Yotre Dame um zwanzig Jahre vorausliegendes Ornamentwerk hin, nämlich das Schlosserbuch des Jean Tijou von 1693, dessen für England hochbedeutsame Thätigkeit noch zu würdigen sein wird. Fordrin benutzte nicht nur das Titelblatt des Werkes von Tijou in seinem Schlosserbuche von neuem, sondern er gab auch eine Neuauflage des Tijouschen Buches heraus, die noch in mehreren Exemplaren vorhanden ist. In einigen derselben tragen die Stiche die Bezeichnung Tijou inv. et del. (von Tijou erfunden und gezeichnet), in anderen ist dagegen statt dessen L. Fordrin exc. (von L. Fordrin herausgegeben) eingesetzt, der Name Tijous also vollständig unterdrückt. Auf Tijous Ornamentik weist in den Stichen Fordrins der in reichem Umfange verwandte Akanthus hin, der freilich in einer zierlicher und dünner gezeichneten Gestalt auftritt als bei Tijou, ferner die in Akanthusranken auswachsenden Tierköpfe und phantastischen Masken und die gebrochenen Linien der Stäbe. Auch die eigentümlichen langen Blätter in Lanzettform mit gewellten Kanten finden sich ebensowohl bei Tijou wie bei Fordrin. Besonders die Treppengeländer und Balkone sind in dieser älteren Manier entworfen.

Trotz dieser Anlehnung an Tijou und de Cotte ist Fordrin eine reiche schöpferische Phantasie nicht abzusprechen. Vielmehr erfreut er durch seine mannig. faltigen Gitterkompositionen, die zum Teil ganz neue, wirkungsvolle und grosszügige Motive enthalten. Er liebt es besonders, die Rahmen seiner Gitterwerke mit einer grossen Komposition in Fãcher- oder Palmettenform oder in Gestalt einer ovalen Rosette zu füllen, oder er bildet das Stabwerk seiner Thürflügel als eine Art von grossem Sockel, auf dem das Monogramm des Königs oder anderes steht, ähnlich wie Daniel Marot, mit dem er sich

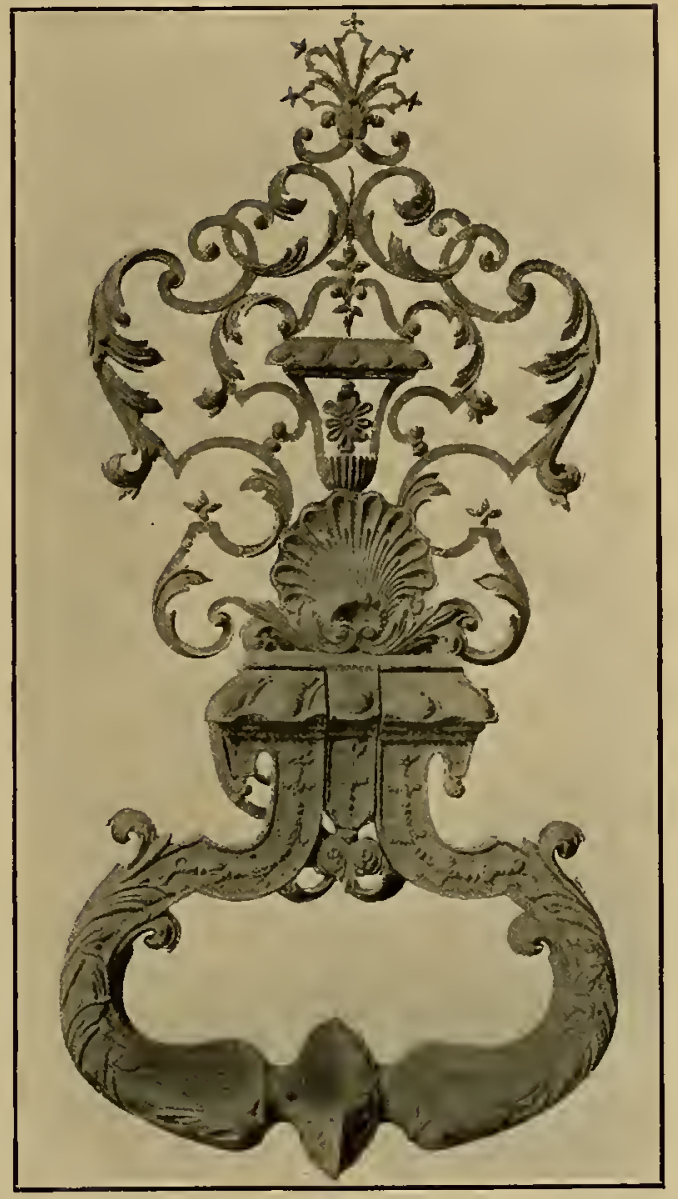

Abb. 42. Klopfer an der Ecole Saint-François de Sales zu Dijon.

auch zuweilen berührt, es gethan (Abb. 37). Jedenfalls gehört Fordrin zu den hervorragendsten Ornamentstechern, welche die Geschichte der Schmiedekunst aufzuweisen hat.

Fragt man nach erhaltenen Schmiedearbeiten aus der Spätzeit Ludwigs XIV. und aus der Régence, so erhält man nur eine dürftige Antwort. Ein aus Balüstern gebildetes Geländer befindet sich noch an der Nordseite des Schlösschens Grand Trianon, das Ludwig für die Frau von Maintenon durch Mansart in den Jahren 1687 und 1688 erbauen liess. Die Balustrade, welche einen terassenartigen Ausbau und die von demselben hinabführende Treppe einfasst, ist 
von dem bereits genannten (S. 48) Alexis Fordrin hergestellt worden (Abb. 38).

Die schon erwähnten (S. 34), zu Anfang des 18. Jahrhunderts errichteten Gitterwerke von Marly, die schönen Balustradengitter, welche zwischen Marmorgruppen von Sphinxen und spielenden Putten das Schloss einrahmten, und die Umfriedigungen der Teiche und Fontänen des Parkes sind uns dagegen nur aus Abbildungen noch bekannt.

Etwas besser sieht es mit den kirchlichen Schmiedearbeiten aus. Hier sind zunächst

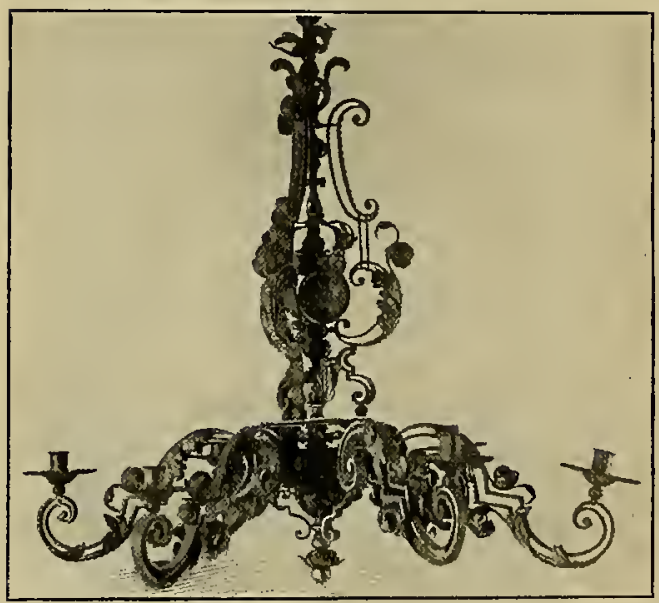

Abb. 43. Kronleuchter im Musée de Cluny zu Paris.

das durch besonders kunstvolle Arbeit sich auszeichnende Chorgitter von St. Ouen zu Rouen und das einfachere, aber gefällige Chorgitter der Kathedrale zu Beauvais zu nennen (Abb. 39). Der geschmeidige leichte Linienfluss des Stabwerks weist sie dem Kreise der Arbeiten de Cottes und Fordrins zu. Etwas später als diese beiden Werke scheint das herrliche Portal zu sein, welches jetzt den Hof des erzbischöflichen Palais in Sens (Abbild. 40) abschliesst. Während die Gesamtkomposition noch im Geschmack Bérains gehalten ist, zeigen einzelne Ornamente schon starke Anklänge an das Muschelwerk des Rokoko. Die ovalen Felder in der Mitte eines jeden Thürflügels enthalten kirchliche Embleme, Kreuz und Monstranz, sowie Kelch und
Ciborium mit Trauben und Aehren, In Aufsatz sind die Troddeln des Kardinalshutes hübsch dekorativ verwendet worden.

Von schmiedeeisernen Chorpulten, die, nach den Stichen Vallées zu schliessen, damals beliebt gewesen sein müssen, haben sich noch mehrere erhalten. Wohl das schönste besitzt Mr. Secq des Tournelles, Eigentümer einer wertvollen Sammlung alter Schmiedearbeiten. Die geneigten Flächen des Pultes sind mit dem strahlenumflossenen Monogramm Christi geschmückt (Abbild. 41). Einer der sehr seltenen schmiedeeisernen Kronleuchter befindet sich im Musée de Cluny zu Paris (Abbild. 43). Er erinnert an einen ähnlichen Entwurf Bérains für einen Kronleuchter, bei dem auch das Mittelstück die Gestalt einer Kugel mit den drei bourbonischen Lilien und der Krone hat. Als Beispiel einer Schlosserarbeit kleineren Massstabes mag der Thürklopfer der Ecole Saint-François de Sales, rue de la vannerie in Dijon dienen (Abbild. 42). Während bei diesem Klopfer und den verwandten Entwürfen der Ornamentstecher die Anschlagplatte den Hauptschmuck trägt, der Klopfring in der bescheidenen Form des Bügels auftritt, gab es daneben auch Klopfer mit figürlichem Schmuck, bei dessen Herstellung die Kunst des Eisenschneiders reiche Bethätigung fand.

Mehr, wie man gewöhnlich annimmt, muss auch vom Gusseisen zu künstlerischen Zwecken damals Gebrauch gemacht worden sein. Nach einer Mitteilung Davilers in seinem Cours d'Architecture vorl 1691 kannte man zu seiner Zeit eine Art von schmiedbarem Eisenguss, der eine Bearbeitung mit dem Meissel und der Feile gestattete - wie er behauptet, ein Geheimnis, das, nachdem es verloren gegangen, seit einigen Jahren wieder entdeckt worden sei. In diesem Eisenguss wurden Balkone, Treppengeländer, Chorgitter und verschiedene Werkzeuge hergestellt. Als Beispiele führt Daviler Balustraden im Schloss zu Meudon, sowie ein Treppengeländer im Hause des Intendanten Pelletier auf der rue de la Cou- 
ture Saint-Catherine zu Paris an, das nach einer Zeichnung von Bullet hergestellt sei. Wahrscheinlich ist in derselben Technik die auf Girardon (1630 bis 1715) zurückgeführte Reiterstatuette Ludwigs XIV. im Besitz des Herrn Lefrançois zu Rouen ausgeführt worden, welche auf den letzten Pariser Weltausstellungen weitesten Kreisen bekannt geworden ist. Das Kostüm des Königs, der in der Tracht des römischen Im- perators erscheint, ist ebenso wie der Sattel und das Zaumzeug des Pferdes mit Goldlinien und Goldornamenten tauschiert. Das Eisen ist blank gefeilt. Schon in Führern durch Paris aus dem 18. Jahrhundert wird die Statuette wiederholt genannt. Sie befand sich ursprünglich in der Sammlung des Maximilien Titon du Tillet, des Generaldirektors der königlichen Waffenfabriken und Magazine. 


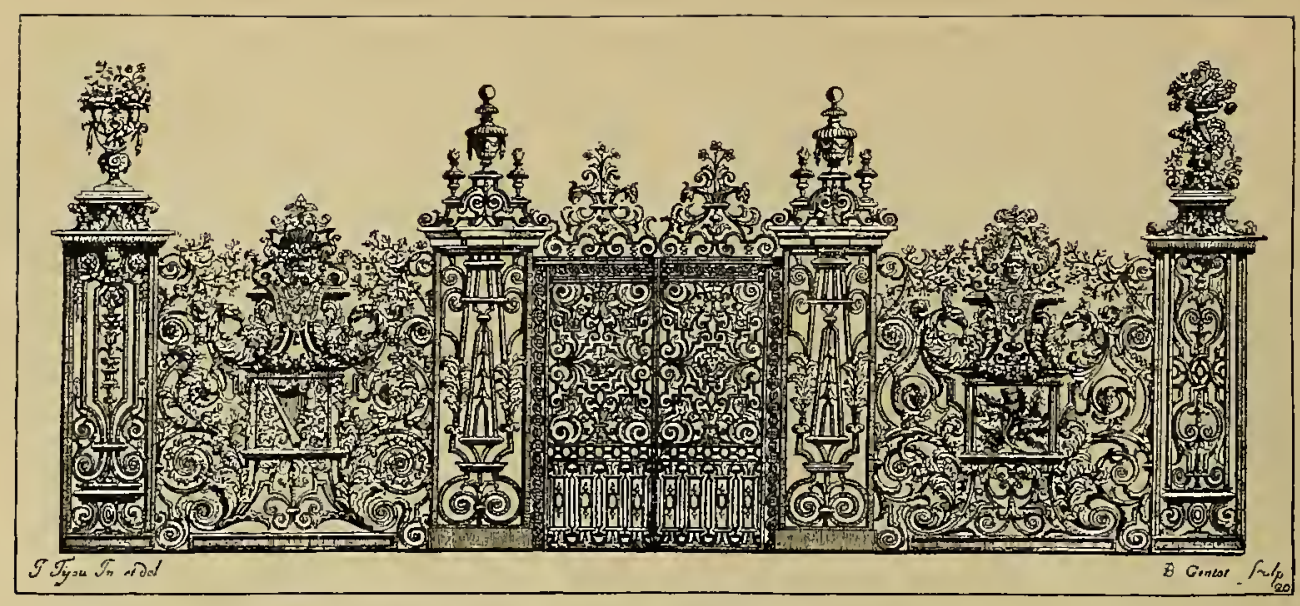

Abb. 44. Gitter im Park von Hampton Court nach einem Stiche von S. Tijou.

\section{Die Schmiedekunst in England nach der Restauration.}

[: Nach hoher Blüte im Mittelalter war die Schmiedekunst im 16. und 17. Jahrhundert in England zu handwerksmässigem Betriebe ohne künstlerische Befruchtung herabgesunken. Wie aus den erhaltenen Schmiedearbeiten jener Zeit ersichtlich ist, beschränkte man sich auf einfache Nutzformen ohne reicheren Zierrat. Erst gegen Ende des 17. Jahrhunderts erfolgte ein neuer Aufschwung der Schmiedekunst. Sein Höhepunkt fällt zusammen mit der Regierung des Oraniers Wilhelm Ill. (1688-1702). Was an dieser erneuten Blüte der englischen Schmiedekunst besonders merkwürdig ist, das ist der Umstand, dass sie durch die Thätigkeit eines einzigen Mannes, nämlich des Franzosen Jean Tijou, herbeigeführt wurde.

Man vermutet, dass Christopher Wren, der führende englische Architekt in der zweiten Hälfte des 17. Jahrhunderts, der "Schöpfer des modernen Londons", Jean Tijou nach England gezogen habe. Die Hauptwerke Tijous sind wenigstens für Bauten Wrens ausgeführt worden. Von 1689-1700 arbeitete er für das königliche Schloss Hampton Court, das damals von Wren erweitert wurde, von 1693-1711 wird er in den Baurechnungen der St. Paulskirche in London, dem Hauptwerk Wrens, erwähnt. Auch für die Architekten Talman und John Vanbrugh hat Tijou Schmiedearbeiten entworfen und vielleicht auch selbst ausgeführt. Die Hauptquelle zur Erkenntnis seiner Kunst bildet ein von ihm selbst herausgegebenes Werk mit französischem und englischem Titel. Derselbe lautet in der Uebersetzung: „Neues Vorlagewerk, entworfen und gezelchnet von Jean Tijou, mit mancherlei Arten von Eisenarbeiten wie Thoren, Bekrönungen, Treppengeländern, Füllungen u. s. w., von denen der grösste Teil für das kōnigliche Schloss zu Hampton Court und die Häuser mehrerer Personen von Rang in diesern Königreiche ausgeführt worden sind. Alles zum Nutzen derienigen, welche das Eisen mit Vollendung und Kunst bearbeiten wollen. Verkäuflich beim Autor London 1693“. ${ }^{\text {) }}$ ) Der Titel steht auf einem Vorhange, vor dem mehrere Männer mit einem Teil einer kunstvoll geschmiedeten Bekrönung beschäftigt

1) Neudruck: Starkie Gardner. A new booke of drawings by John Tijou. London 1890. 
sind. $\operatorname{lm}$ oberen Teil des Stiches führt Merkur der Athene, welche umgeben von den Musen verschiedener Künste auf einer Wolke erscheint, eine Gitterfüllung vor. Im Hintergrunde sieht man in einer Höhle Cyklopen bei der Schmiedearbeit. (Abbild. 1.) Das Bild ist entworfen und gezeichnet von Louis Laguerre, dem Schwiegersohne Tijous, graviert von P. Van Somer, einem in Amsterdam gebürtigen Stecher. Die übrigen 19 Tafeln sind von Van der Banck, P. P. Bouche und Van der Gucht, sämtlich niederländischer Herkunft, gestochen worden. Sie enthalten ausser den im Titel genannten Gegenständen Wandarme, Schlüsselschilder und Schlüsselgriffe.

Die Formensprache Tijous ist ziemlich schwülstig und weitschweifig. $\mathrm{Er}$ macht sehr reiche Verwendung vom Akanthus, der bei ihm stark ins Kraut geschossen ist und eine breite lappige Bildung zeigt.
So entsteht der Eindruck einer üppigen Vegetation, in der eine reiche Tierwelt sich tummelt. Die bei Fordrin erwähnten lanzettförmigen Blätter mit gewellten Kanten scheinen bei Tijou zum ersten Male in Anwendung gekommen zu sein. Der Einfluss der Versailler Arbeiten lässt sich deutlich verfolgen (vgl. Abb. 45), ebenso scheinen die Portale von Maisons eine nachhaltige Einwirkung auf Tijous Formgebung ausgeübt zu haben. Auch Motive der zwischen den Arbeiten von Maisons und Versailles liegenden Schmiedewerke kommen vor - so zeigen z. B. mehrere der auf Tafel 18 dargestellten Entwürfe starke Anklänge an Brisville - sodass seine Ornamentik fast wie ein gedrängter Auszug der französischen Schmiedekunst von 1650-1690 erscheint.

Die Bestimmung eines grossen Teils der in seinen Werken enthaltenen Eisenarbeiten lässt sich noch nachweisen.
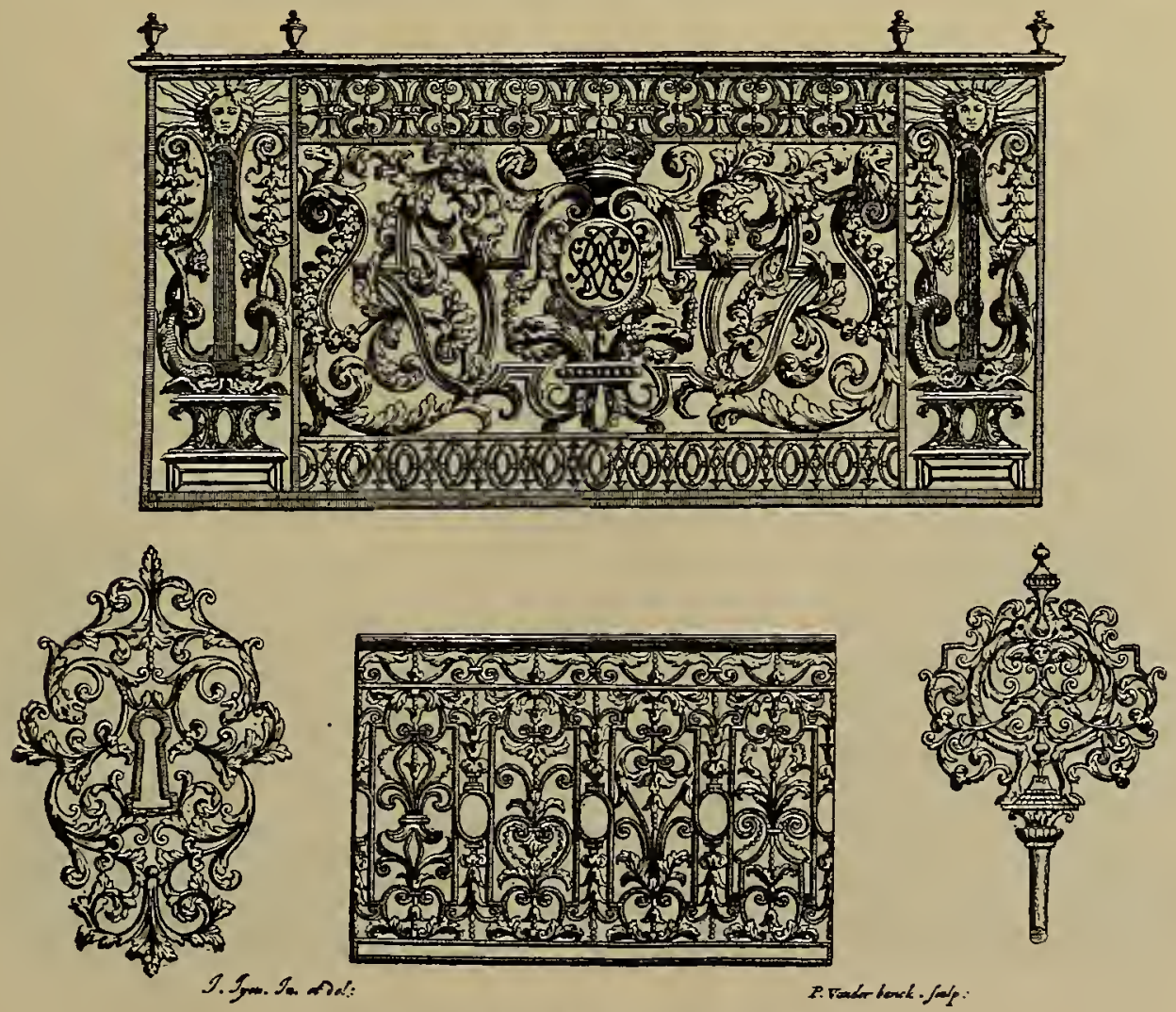

Abb. 45. Stich aus Jean Tijous Schlosserbuch. 
Auf den Tafeln 2, 4, 12, 16, 19 und 20 sind Schmiedewerke dargestellt, welche für Hampton Court ausgeführt worden sind. Auf der Tafel 20 (Abbild. 44) ist ein Teil des berühmten Gitters aus dem Park von Hampton Court dargestellt. Zwölf der Füllungen haben sich noch samt den einfassenden Pilastern erhalten, das Portal in der Mitte dagegen fehit. Sie sind nach London geschafft worden und von da auf das South Kensington Museum und auf verschiedene Städte, Edinburgh, Dublin, Nottingham, Wolverhampton, Sheffield u. s. w. verteilt. Den Mittelpunkt jeder Füllung bilden Zeichen des englischen Königswappens, die Harfe, Distel, Rose, ferner heraldische Lilien, das Monogramm des Königs u. s. w. Die Masken darüber, welche den Abschluss der Füllungen nach oben bilden, sind nochmals auf den Tafeln 12 und 16 in grösserem Massstabe wiedergegeben, sowohl die Maske der noch vorhandenen Füllung in der Abbildung 46, wie die auf den beiden Füllungen des Stiches. Tafel 6-10 enthalten Arbeiten, welche für Chatsworth ausgeführt worden sind, darunter ein Balkon mit dem Wappen des Herzogs von Devonshire (drei Hirschköpfe); Tafel 17 führt die Gitter des Hofgartens zu Burleigh vor, die genau so ausgeführt worden sind, was nicht auf alle Stiche zutrifft. Ein Treppenbalüster auf der Tafel 18 ist in der Bibliothek des Trinity College zu Cambridge, welche auch von Wren gebaut wurde, als Motiv für ein Geländer verwandt worden. Die Schmiedearbeiten dieses Geländers wurden von dem Londoner Schlosser Patridge angefertigt, der in den Rechnungen der Bibliothek aus den Jahren 1691 und 1692 auftritt. An den Schmiedewerken zu Hampton Court dürfte der Schlosser Huntington Shaw zu Nottingham beschäftigt gewesen sein. Bei der gewaltigen Anzahl von Schmiedewerken, die auf Tijou

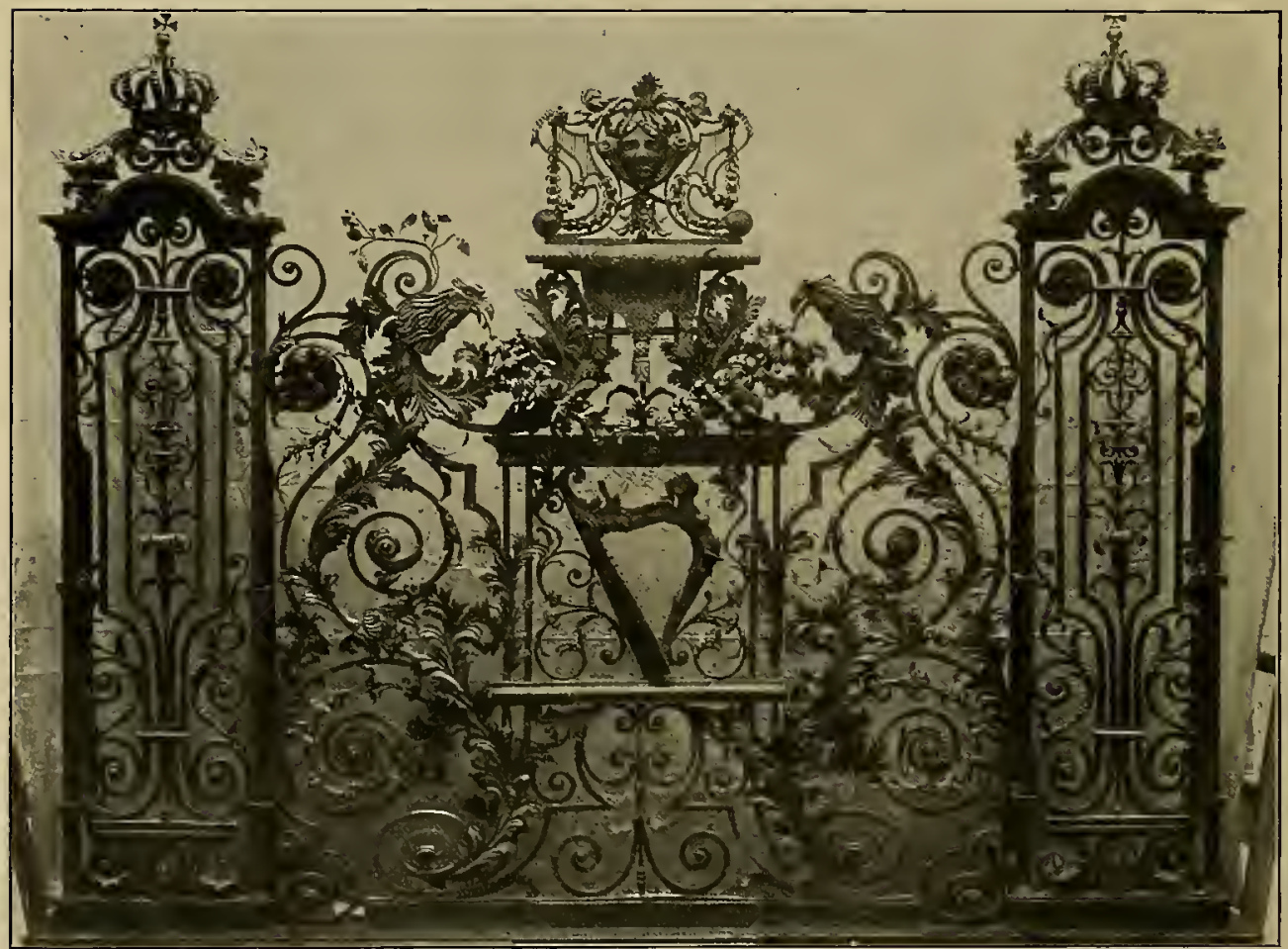

Abb. 46. Teil eines Gitters aus dem Park von Hampton Court im South Kensington Museum zu London (vgl. Abb. 44). 
zurück zu führen sind, wird nur ein kleiner Teil von seiner eignen Hand ausgeführt worden sein.

Wohl die bedeutend. sten Arbeiten seiner späteren Zeit sind die Gitter der St. Paulskirche zu London, welche zwischen 1693 und 1711 entstanden sind, also nicht in seinem Vorlagewerk abgebildet sein können. Besonders stattliche Gitter schliessen die Seitenschiffe zu beiden Seiten des Chors $a b .{ }^{1}$ ) Die Stäbe der oberen Hälfte des Gitters sind $\mathrm{zu} \mathrm{Pi-}$ lasterreihen zusammengefasst. Die Thüren sind von kannellierten korinthischen Pilastern flankiert. Die Spitzen der reichen Bekrönung bilden flammende Vasen. Ebenfalls die Westminster-Abtei besitzt Arbeiten im Stile Tijous.

Auch ausserhalb Londons scheint Tijou eine reicheThätigkeit entfaltet

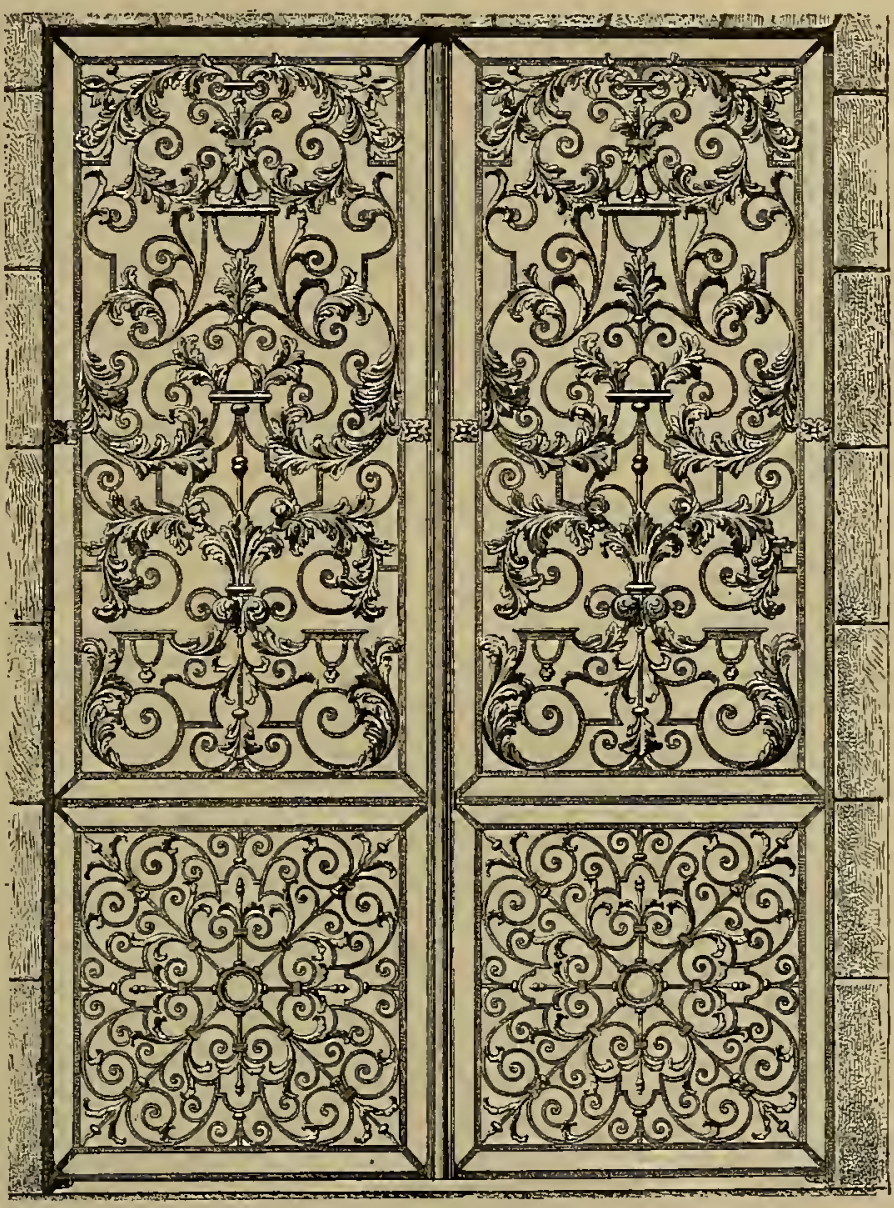

Abb. 47. Gitterthür an der "Clarendon Press" zu Oxford. zu haben. So sind noch

Werke seiner Formensprache in Hampstead, Old Langthon, Hall in Essex, Lincoln, Carshalton, Beverley, Oxford u.s.w. vorhanden (Abb. 47 u. 48). Ein besonders prächtiges Werk ist das Portal von All Souls in Oxford. ") Alle diese Beispiele zeigen den für Tijou so charakteristischen breitlappigen Akanthus in reicher Verwendung.

Zahlreiche andere englische Gitter der ersten Hälfte des 18. Jahrhunderts sind mit weniger reichhaltigem Laubwerk aus-

1) Abbildung in: Ebbets, D.J., Examples of decorative wrought ironwork. London 1879, pl. 10.

2) Vgl. Bloemfield, R. A history of RenaisSance Architecture in England. London 1897 Il, S. 388 u. f. gestattet und lassen das Stabwerk mehr hervortreten, eine Beschränkung, die allerdings den eigentümlichen Charakter der Ornamentik Tijous verwischt, aber aus praktischen Gründen Anerkennung verdient. Indessen lassen auch in dieser Abwandlung die meisten derselben ihre Herkunft von diesem so fruchtbaren Meister deutlich erkennen.

Von Kleinarbeiten jener Zeit ist eine im Berliner Kunstgewerbemuseum aufbewahrte Eisenkassette ( $K$ 4455) zu erwähnen mit rotem Sammetbezug und Bronzebeschlägen, auf die durchbrochene Eisenornamente aufgesetzt sind. Sie trägt das Monogramm Wilhelms IIl. und seiner Gemahlin Maria und soll aus dem Nach- 
lass der 1694 gestorbenen Königin stammen. Der sehr zierlich gearbeitete Schlüssel zeigt besonders starke Anklänge an die Formensprache Tijous. Aehnliche Schlüssel mit Wappen und Monogrammen englischer Aristokraten haben sich noch zahlreich erhaiten. Auch sonst findet man eine gleiche Verbindung von Eisen und Messing bei englischen Schlössern, indem der eiserne Schlosskasten in einen durchbrochenen Mantel von graviertem Messing eingehüllt ist. ${ }^{1}$ )

Ein sprechendes Zeugnis für die lange Lebensdauer der Tijouschen Formen giebt das Architekturwerk: "The City and Country Builders and Workmans Treasury of Designs" von Battey Langley London

1) Abgebildet in Quaritch, B., Ornamental 1ronwork. London 1898, pl. $11 \mathrm{u}$. ff.
1740, in welchem auf den Tafeln 179 bis 186 Nachstiche aus Tijous Schlosserbuch als Vorlagen für Eisenarbeiten vorgeführt werden. Sie sind von Thomas Langley gestochen. Die Tafeln 179 und 180 enthalten die Bezeichnung: Batty Langley Invent(or) 1739 , enthüllen aiso ein ähnliches Plagiat, wie Fordrin es begangen.

Der Stil Tijous wurde in gewissem Sinne Englands nationaler Eisenstil. Das Rokoko fand kaum Aufnahme in der englischen Schmiedekunst. Die dürftige Erfindung eines Taylor und anderer im Empiregeschmack können keinen Anspruch auf Kunst erheben. So stirbt denn mit dem Ausklingen der Formen Tijous auch die Schmiedekunst Englands allmählich wieder $a b$.

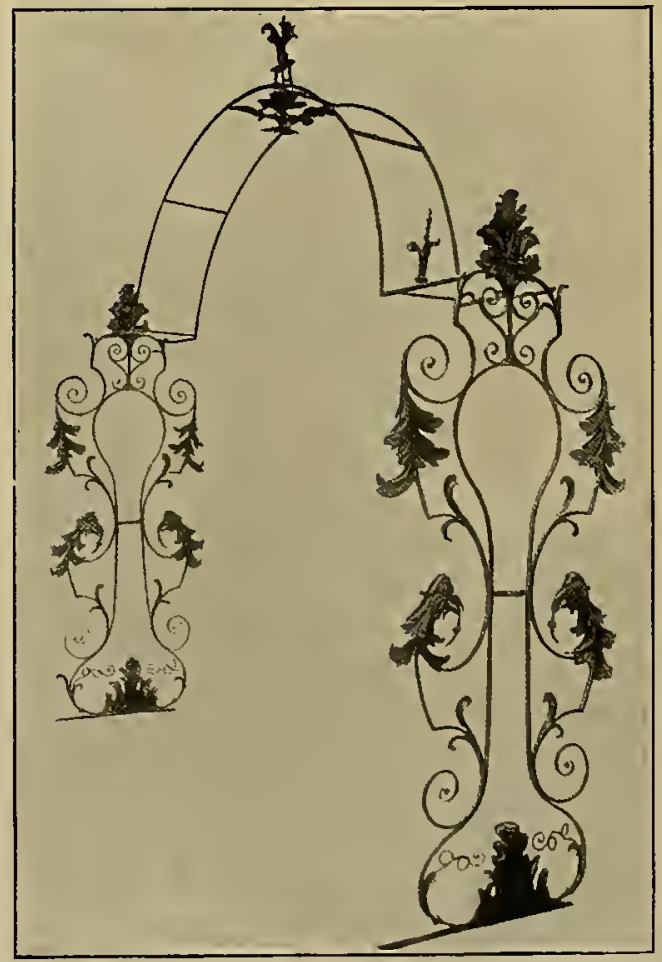

Abb. 48. Gestell aus der Pfarrkirche von Newcastle-under-Lyne, Staffordshire, im South Kensington Museum zu London. 


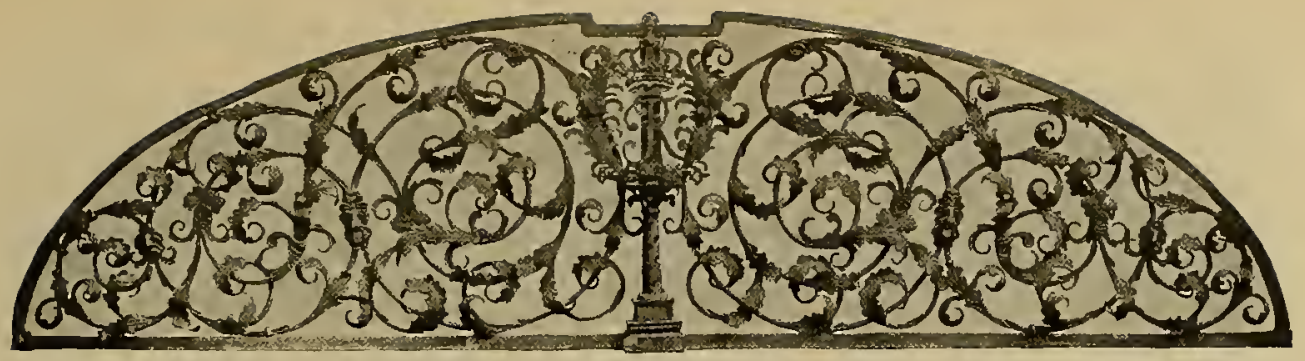

Abb. 49. Oberlichtgitter im Kunstgewerbemuseum zu Berlin.

\section{Die deutsche Schmiedekunst von der Mitte des 17. bis zum Anfange des 18. Jahrhunderts.}

Der Krieg, der durch drei Jahrzehnte hindurch Deutschlands Gauen durchtobt, hatte auch den herrlichen Kunstbau, den man mit dem Namen "Deutsche Renaissance" zu bezeichnen pflegt, arg verwüstet. Wo Hunger und Not aus den Fenstern schauen, hat die Kunst keine Heimstätte. Wohl verkündeten die Friedensboten des Jahres 1648 den Anfang einer besseren Zeit. Aber es ist leichter zu zerstören, als aufzubauen. Es bedurfte vieler Jahrzehnte, bis die Wunden, die der Krieg geschlagen, wieder geheilt waren.

Wir dürfen daher auch für die erste Hälfte des 17. Jahrhunderts, in der die französische Schmiedekunst sich so glänzend bethätigte, von Deutschlands Schmiedekunst nur wenig erwarten. Man hatte notwendigere Dinge $z u$ thun, als Paläste und Kirchen $\mathrm{zu}$ erbauen und mit kostbaren Gitterwerken zu schmücken. Wo man Gelegenheit hatte, ein Gitter oder ein Schloss zu schaffen, knüpfte man an die Werke der Väter wieder an. Erst langsam und allmählich machten neue Formen sich geltend.

Im Gitterwerk behielt man zunächst die Form bei, welche sich etwa um die Mitte des 16. Jahrhunderts ausgebildet hatte. Man setzte das Gitter aus Rundstäben zusammen, welche sich mannigfach verschlangen. Dort wo zwei Stäbe sich begegneten, wurde der eine durch- bohrt, der andere durch die so entstandene Oeffnung durchgeschoben. So entstand ein Gitter, das Festigkeit und Leichtigkeit zugleich besass. Die verschlungenen Rundstäbe bilden nun entweder rein lineare Motive, die an die Schnörkel der Kalligraphen des 16. Jahrhunderts erinnern, oder sie haben eine mehr naturalistische Gestaltung, indem z. B. die ganze Komposition einer Gitterfüllung als eine grosse, aus einer Vase herauswachsende Pflanze aufgefasst wird, deren Zweige sich in regelmässig gezogenen Spiralen nach den Seiten ausbreiten und mit ihren Blättern, Blüten und Früchten die Fläche füllen. Diese pflanzenartige Bildung des Gitters ist wohl älter als die rein geometrische. Sie geht offenbar auf das Rankenwerk der Kleinmeister, eines Aldegrevers, der Beham u. a. zurück. Ein sehr beliebter Schmuck dieses Renaissancegitters in seinen beiden Formen ist die Spindelblume. Ein spindelförmig gewundener Draht bildet das Mittelstück, um welches dünne gebogene Rundstäbe oder schmale schilfförmige Blätter im Kreise angeordnet sind. Das Ganze stellt eine Phantasieblume mit Fruchtknoten, Staubfäden, Blüten- oder Kelchblättern dar. Die Spindelblumen kommen als Schmuck der durchschobenen Rundstäbe innerhalb des Gitters vor, oder sie dienen als freie Endigungen und sind dann zumeist nicht senkrecht gestellt, sondern nach aussen 
geneigt, wie von ihrer eigenen Schwere herabgezogen ( $\mathrm{Abb}$. 50). Die ganze $\mathrm{Zu}$ sammensetzung des Gitters bringt es mit sich, dass man immer nur verhältnismässig kleine Füllungen herstellt, aus denen dann wieder grössere Gitter gebildet werden.

Die schönsten Renaissancegitter des 16. Jahrhunderts sind die, welche zu Umfriedigungen freistehender Grabdenkmäler verwandt wurden. Besonders stattliche Gitter umgeben z. B. das Grab. mal der Königin Anna im Dom zu Prag, das Grabdenkmal Maximilians I. in der Hofkirche zu Innsbruck (Abb.50), die Grabstätte der Fugger in der Ulrichskirche zu Augsburg, das Denkmal des Kurfürsten Moritz zu Freiberg in Sachsen u. a. Während bei diesen und manchen anderen Gittern die Zeit ihrer Entstehung urkundlich oder durch andere Umstände festzulegen ist, giebt es dagegen viele hundert Gitter dieses Typus, deren Herstellungszeit sich nicht mehr mit Sicherheit bestimmen lässt, zumal wenn sie aus ihrer ursprünglichen Umgebung herausgerissen und in irgend einem Museum unterge- bracht sind. Stilistisch lässt sich nur in seltenen Fällen ein sicherer Anhalt gewinnen, ob ein solches Gitter aus der ersten oder der zweiten Hälfte des 17. Jahrhunderts stammt.

Eines der wenigen Gitter, welche sich mit Bestimmtheit als Arbeiten der zweiten Hälfte des 17. Jahrhunderts nachweisen lassen, ist das Gitter, welches den St. Floriansbrunnen, der inschriftlich 1687 errichtet wurde, auf dem Marktplatz zu Salzburg ziert (Abb.52). Die acht Selten desselben, welche auf einem steinernen Unterbau befestigt sind, zeigen im wesentlichen lineare Motive. Die Enden der Rundstäbe laufen in kleine herzförmige Blättchen oder Hufeisen aus. Die Ecken, sowie der geschweifte herumlaufende Aufsatz sind mit Spindelblumen geschmückt. Ausserdem sind noch aus Blech geschnittene Wappen und Figuren, Einhörner, Engelsköpfe und mehrmals wiederkehrend ein drachentötender St. Georg und St. Martin, wie er dem Bettler die Hälfte seines Mantels schenkt, angefügt. Die Innenzeichnung ist bei diesen Blechzierraten durch Bemalung gegeben.

Nach hartem Kampfe

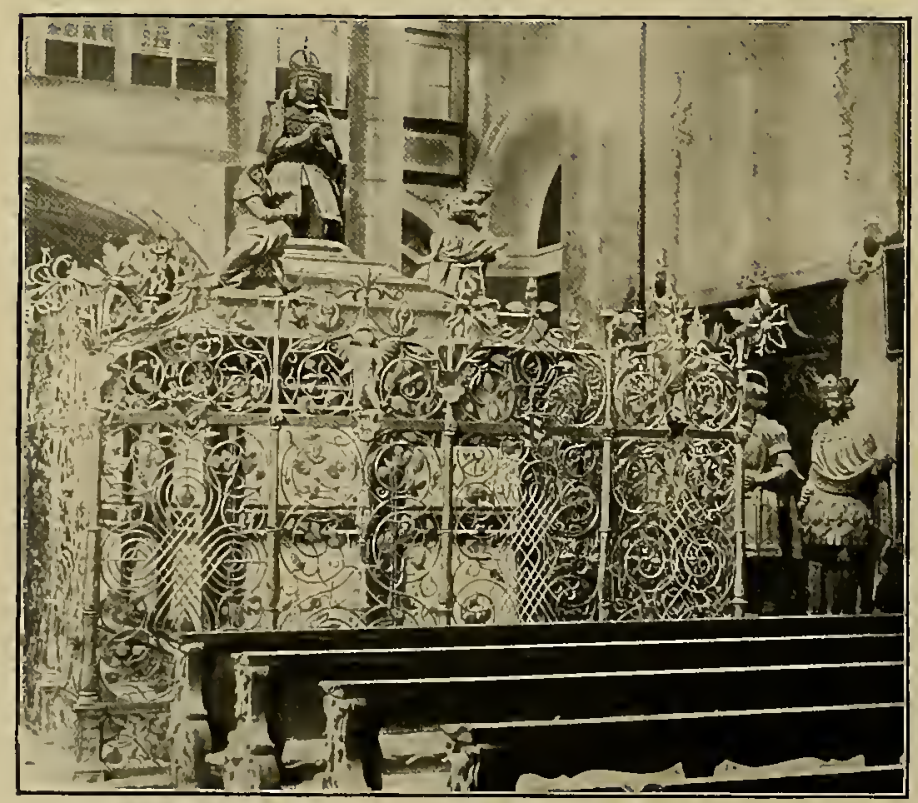

Abb. 50. Umfriedigungsgitter des Maximiliansgrabes in der Hofkirche zu Innsbruck, um 1570. mit dem Stadtschlosser Wolf Hapacher, der die Ausführung des Gitters als sein gutes Recht betrachtete, hatte der Rat der Stadt dem Schlosser Wolf Guggenberger die Arbeit übergeben. Als das Werk, das Guggenberger nach eigenem Entwurfe fertig stellte, vollendet war, wurde es zur öffentlichen Besichtigung auf dem Tanzboden des Rathauses aufgestellt und der ganze Rat der Stadt kam herzu, um die Arbeit zu prüfen. Man war so zufrieden damit, dass man statt der ausgemachten 10 Pfennige für das Pfund Eisen 12 Pfennige be- 


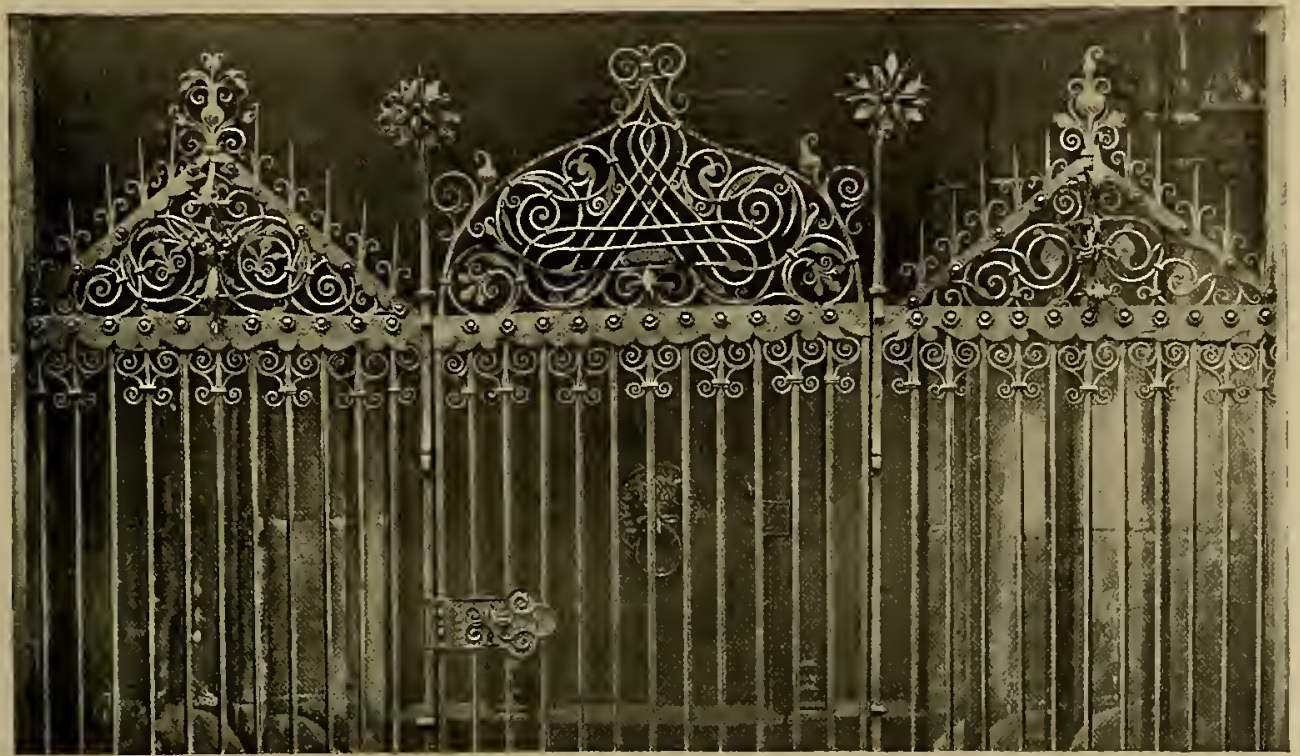

Abb. 51. Gitter an der Lorenzkirche in Nürnberg, bez. 1649.

willigte. So erhielt denn Guggenberger für das 982 Pfund schwere Gitter 49 fl. 24 Pf., dazu $1 \mathrm{fl}$. Trinkgeld für den Gesellen. Das Gitter wurde bemalt und zwar die Stäbe grün, die Rosetten und Bunde golden, die Wappen u. S. w. in ihren natürlichen Farben. Der Maler verlangte $40 \mathrm{fl}$. dafür, er erhielt aber nur 28; erst als er noch die Engelsköpfe vergoldete, bekam er noch 14 fl. dazu.

Weitere datierte Gitter dieser Art sind z. B. ein Gitter in der Benediktinerkirche zu Lambach von 1662'1), ein Glockenstuhl, zu Wien in Privatbesitz befindlich, mit dem Datum 1666 (Abbild. 53), das Umfassungsgitter der Boseschen Grabkapelle in der Marienkirche zu Zwickau vom Jahre $1678^{\circ}$ ), ein Weihkerzenständer im South Kensington Museum zu London (Inv. Nr. 1217-1872) mit der Jahreszahl $1696^{3}$ ) und als eine der spätesten Arbeiten

1) Abgeb. in Ortwein, Deutsche Renaissance in Oesterreich, Bd. Il. Leipzig 1887. Tafel 28 und 29.

2) Abgeb. in Ortwein, Deutsche Renaissance, Bd. Ill, Leipzig 1876-78. Zwickau. Tafel 14 und 15 .

3) Abbildung in Quaritch, B., Ornamental Ironwork. London 1898, pl. 40. dieser Art ein Kirchhofkreuz aus Lauingen, zur Zeit im bayerischen Nationalmuseum zu München, welches die Jahreszahl 1726 trägt. ${ }^{4}$ ) Bei dem Glockenstuhl und dem Weihkerzenträger bilden ebenso wie beim Grabkreuz in der angegebenen Art verzierte und verschlungene Rundstäbe den Hauptschmuck des Geräts. Auch bei anderen Gegenständen, Wandarmen, Beleuchtungskörpern u. s. w. wird die Ornamentik mit Gittermotiven bestritten. Dieses Fortleben der Formen des Gitters aus dem 16. Jahrhundert bis ins 18. Jahrhundert darf man also nicht nur für das Gitter im eigentlichen Sinne annehmen, sondern auch für alle anderen Gegenstände, die ihre wesentlichste Dekoration dem Gitterwerk entlehnen.

Neben dieser älteren Form des Renaissancegitters mit glatten Rundstäben tritt zu Anfang des 17. Jahrhunderts eine neue Bildung auf, die ebenfalls bis ins dritte Jahrzehnt des 18. Jahrhunderts hinein weiterlebte. Das Rundeisen mit Durchzügen in schön gezogenen Spiralen und kalligraphischen Verschnörkelungen wird

4) Hefner-Alteneck, J.H. von, Eisenwerke. Frankfurt a. M. 1885 . Bd. II, Tafel 84. 


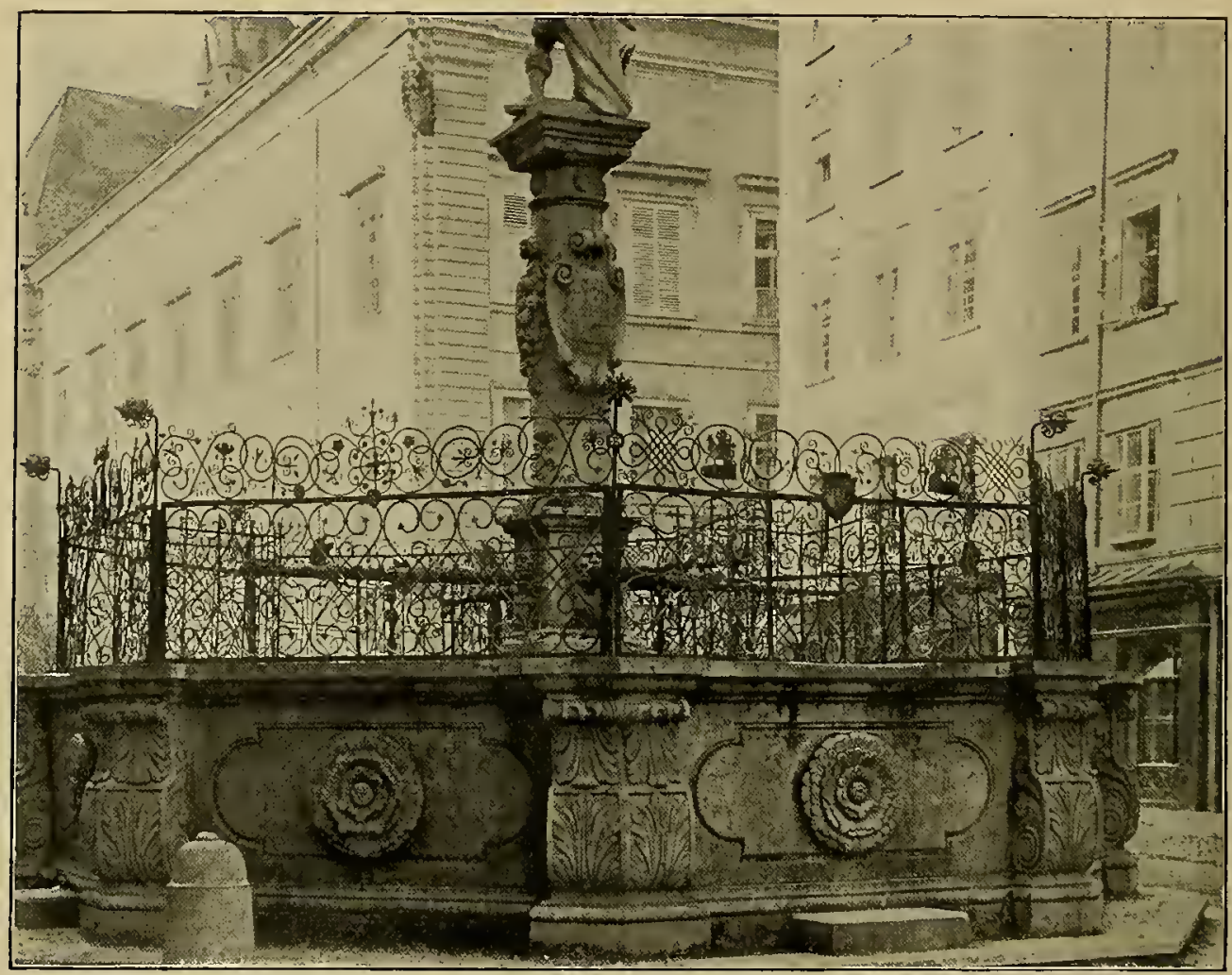

Abb. 52. Gitter des St. Floriansbrunnen zu Salzburg.

beibehalten. Dort aber, wo sich mehrere Stäbe abzweigen, also an den Schweissstellen, wird die Verbindungsstelle durch gravierte oder vielmehr eingehauene Ornamente, welche zumeist pflanzenartige Formen darstellen, verziert. An anderen Stellen wachsen die Stäbe zu grösseren phantastischen Gebilden, Greifen und ähnlichem aus, die ebenfalls mit eigenartiger Innenzeichnung versehen sind. Häufig erinnern die eingehauenen Ornamente in ihren weichlichen, verschwommenen Zügen an die Formen des Ohrmuschelornamentes. Eines der frühesten Beispiele dieser Art von Gitterwerk stellt ein Grabkreuz auf dem Friedhofe zu Altdorf bei Nürnberg von 1614 dar. ${ }^{1}$ ) Wohl eines der spätesten ist das Gitter der alten

1) Die Schmiedekunst nach Originalen des XV.-XV1II. Jahrhunderts. Berlin, E. Wasmuth, 1887. Tafel 41.
Kapelle in Regensburg vom Jahre 1726.") Sie lassen sich in allen Gegenden Deutschlands von Zürich bis Königsberg und Schleswig nachweisen. Ein besonders schönes Gitter dieses Typus bildet den Abschluss einer Gruft in der Georgskirche am Hradschin in Prag (Abbild. 54). Die Lambrequins der Steinumrahmung sprechen für eine Entstehung des Gitters im Anfange des 18. Jahrhunderts.

Während hier und bei ähnlichen Arbeiten der Rundstab noch zum grössten Teil seine glatte Form beibehalten hat, sind bei anderen Werken die Stäbe flach geschmiedet und völlig mit eingeschlagenen Ornamenten bedeckt, wie bei dem "schönen Brunnen“ in Ne isse (Abbild. 55). Auf einer Steinbrüstung erhebt sich eine

2) Roeper und Bösch, Geschmiedete Gitter des XVl.--XV1II. Jahrhunderts aus Süddeutschland. München. Tafel 35 und 36. 
cylindrische Eisenlaube mit einem Kuppeldach. Die geschlossene Laube ist hier an die Stelle der früher üblichen, auf Pfeilern emporgehobenen Baldachine getreten. Der Brunnen wurde von dem Konsul Kaspar Naar gestiftet und 1686 vollendet. Die mittlere Bandschiene trägt die Inschrift „Ao 1686 aus Belieben eines loblichen Magistrates machte mich Wilhelm Helleweg Zeugwarter." Unter Zeugwarter ist jedenfalls einer zu verstehen, dem die Aufsicht über das städtische Zeughaus oblag. Helleweg war also wahrscheinlich zugleich Schlosser und Büchsenmacher.

Auch der im bayerischen Yationalmuseum zu München aufbewahrte Zunftpokal in Gestalt eines grossen Schlüssels vom Jahre 1680 (Abbild. 56), der aus einer Zunftstube der Schlosser in Unterfranken stammt, zeigt eine verwandte Ornamentik. An den Bügeln, welche vom Griff zum Rohr überführen, sind acht Figürchen angebracht, von denen vier die Abzeichen der Gewerke tragen, welche zu der Zunft gehörten, nämlich Schlüssel, Büchse, Winde und Uhr. Auch als Aushängezeichen wurden ähnliche grosse Schlüssel angefertigt.

Der flächenhafte Charakter, den das Stabwerk in der Umgestaltung, wie es z. B. bei dem Brunnen zu Neisse auftritt, angenommen hat, gestattete auch eine leichte Uebertragung dieser Ornamentik auf Beschläge, Thürklopfer, Schlossbleche u. a. Die meisten dieser Arbeiten sind allerdings roh und unerfreulich. Sie sind mehr oder weniger eine Vergröberung und Entartung der Formen des 16. Jahrhunderts. Auch hier lässt sich die Entstehungszeit der erhaltenen Schmiedewerke nur dann bestimmen, wenn die betreffenden Stücke auf irgend eine Art datiert sind. So ist die Zeit der hübschen Griffe und Schlüsselschilder an den Sakristeischränken der Kirche zu Obermarchthal in Bayern durch die an den Schränken angebrachte Jahreszahl 1672 festgelegt.

Ueberhaupt aber sind Beschläge und kunstvoll gearbeitete Schlösser seit der Mitte des 17. Jahrhunderts seltener geworden. Die Sitte, die Thüren und Kastenmöbel mit breiten Bändern und reich ausgebildeten Schlössern und Griffen auszustatten, die sich in Süddeutschland länger als in Norddeutschland bis ins 17. Jahrhundert erhalten hatte, ist jetzt fast ganz verschwunden. Nur bei der Truhe wird in einzelnen Gegenden, wie Westfalen und den Marschen der Niederelbe, der die ganze Oberfläche überspinnende Eisenbeschlag beibehalten ( $\mathrm{Ab}$ bild. 57). Das Schloss wird jetzt zumeist völlig im Holzwerk verborgen, nach aussen tritt es fast nur in dürftigen, meist aus Messing gearbeiteten Schlüsselschildern in die Erscheinung. Jedoch sorgten die Satzungen der Zünfte, welche als Meisterstück in der Regel ein kunstvolles Schloss verlangten, dass das Schloss noch immer mit einem gewissen Reichtum von Orna-

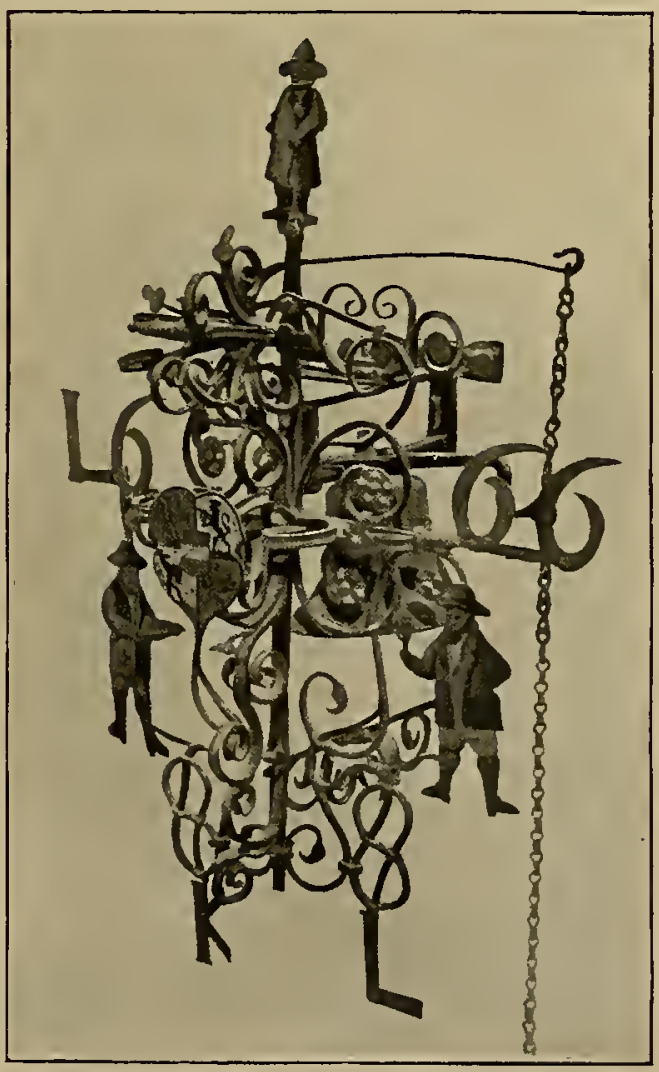

Abb. 53. Glockengestell, bez. 1666 (Wien, Privatbesitz). 


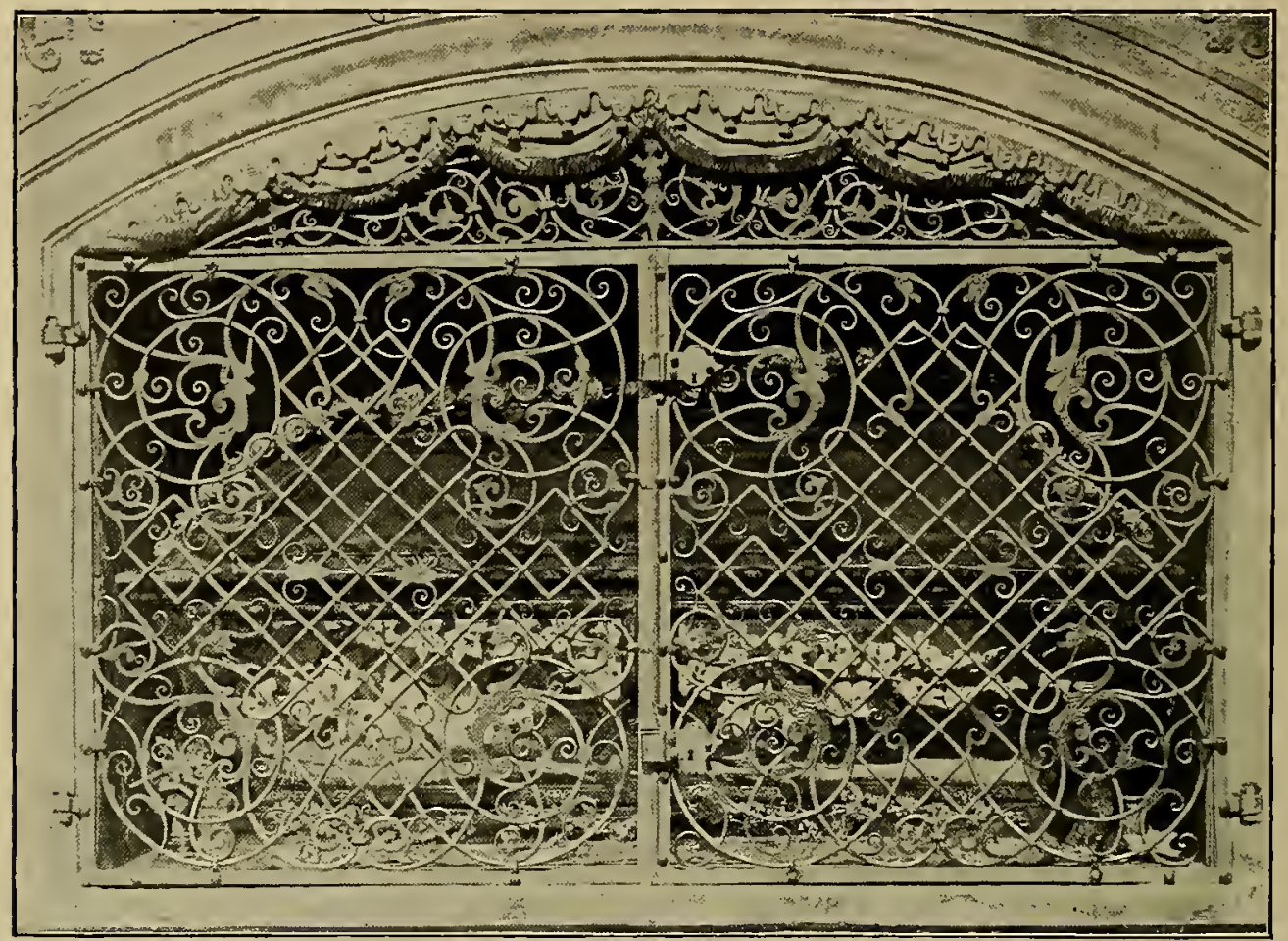

Abb. 54. Gitter in der Georgskirche zu Prag.

menten versehen wird. Der Hauptwert bei diesen als Meisterstücke gearbeiteten Vorhänge- und Kastenschlössern wurde freilich weniger auf den äusseren Schmuck, als auf den kunstvollen Verschlussmechanismus gelegt, indem die Besatzung der Schlüssel und Schlösser sehr kompliziert gestaltet wurde.

In den letzten Jahrzehnten des 17. Jahrhunderts erfolgte dann eine weitere Veränderung des Renaissancegitters durch Aufnahme des Akanthus, oder wenigstens akanthusartiger Blattformen. Das Gerüst des Gitters besteht auch jetzt noch aus glatten Rundeisen in regelmässigen Spiralen. Durchschiebungen kommen allerdings nur selten noch vor, zumeist werden die Stäbe, wenn sie sich begegnen, übereinander hergeführt. Die Endigungen bestehen regelmässig aus akanthusartig geschnittenen länglichen Blättern, welche, die Bewegung der Spirale fortsetzend, sich nach innen biegen. Masken, die in ähnliches Laubwerk auswachsen und kleine Halbfiguren in Blattkelchen beleben das Rankenwerk. Auch hier werden die Stäbe nicht selten mit eingehauenen Ornamenten versehen (Abbild. 49 und 62).

Von den zahlreichen noch vorhande. nen Gitterwerken in diesem Geschmack ist vielleicht das merkwürdigste eine $10 \mathrm{~m}$ hohe Gartenpyramide im Besitz des Museums für Kunst und Gewerbe in Hamburg. $\left.{ }^{1}\right)$ Es ist eines der wenigen erhaltenen Beispiele dieser Art der Verwendung des Eisens in der Gartenarchitektur, welche, wie schon bei der Besprechung der Gitterwerke im Park zu Versailles erwähnt wurde, nicht selten gewesen sein muss. Im dortigen Bosquet de l'arc de triomphe waren ähnliche Pyramiden aus Eisen aufgestellt (vgl. die Abb. 24). Die Hamburger Pyramide schmückte ehemals den Garten des reichen Kaufmanns Wil-

1) Vgl. Brinckmann, 1., Das hamburgische Museum für Kunst und Gewerbe. Leipzig 1894. S. 793. 
helm von Hertoghe zu Billwärder bei Hamburg. Sie bildete den Endpunkt einer auf perspektivische Wirkung berechneten grossen Anlage.

Die dem Gitterwerk dieses Stiles entsprechenden Kleinarbeiten, Beschläge, Schlösser, Schlüssel, Klopfer u. s. w. verwenden den Akanthus in getriebener (Abb. 58), gravierter, geschmiedeter oder geschnittener Form. Bei den gravierten Arbeiten ist der Grund zwischen den Akanthusranken häufig blau angelassen. Gewöhnlich pflegt die ganze Fläche mit verschlungenen Akanthusranken, die sich zu Spiralen aufrollen und mit Masken und Halbfiguren wie beim Gitterwerk geziert sind, gefüllt zu sein. Bei den umfangreichen Kastenschlössern ist sowohl die Schlossdecke wie die Anschlagplatte, mit der der Schlosskasten auf der Thür befestigt wird, mit Akanthusranken verziert. Der Umriss der Anschlagplatte folgt den geschweiften Linien des Akanthus (vgl. die Abbild.58). Zuweilen findet man die getriebene und gravierte Arbeit an einem Stück vereinigt. Z. B. ist bei einem Schloss des Kunstgewerbe - Museums zu Berlin (lnv. Nr. 68, $458 \mathrm{ab})$ die Anschlag. platte mit graviertem Akanthus auf blauangelassenem Grunde geschmückt, der Schlosskasten aber ist mit durchbrochenen, getriebenen Akanthusranken aus Messingblech versehen, welche sich vom blauen Grunde der Schlossdecke wirkungsvoll abheben
Die Schlüssel sind zumeist einfach gebildet, doch kommen auch sehr reich verzierte Beispiele vor, an denen der Eisenschneider seine Kunst hat zeigen wollen. So besitzt das Berliner Kunstgewerbemuseum einen zierlichen, überaus kunstvoll gearbeiteten Schlüssel, der als Hauptschlüssel des Jagdschlosses Grunewald gedient haben soll. Der Griff enthält in einer von Palmzweigen und zwei Adlern umgebenen und von der preussischen Krone überragten Kartusche das Monogramm Friedrich Wilhelms I. (1713 bis

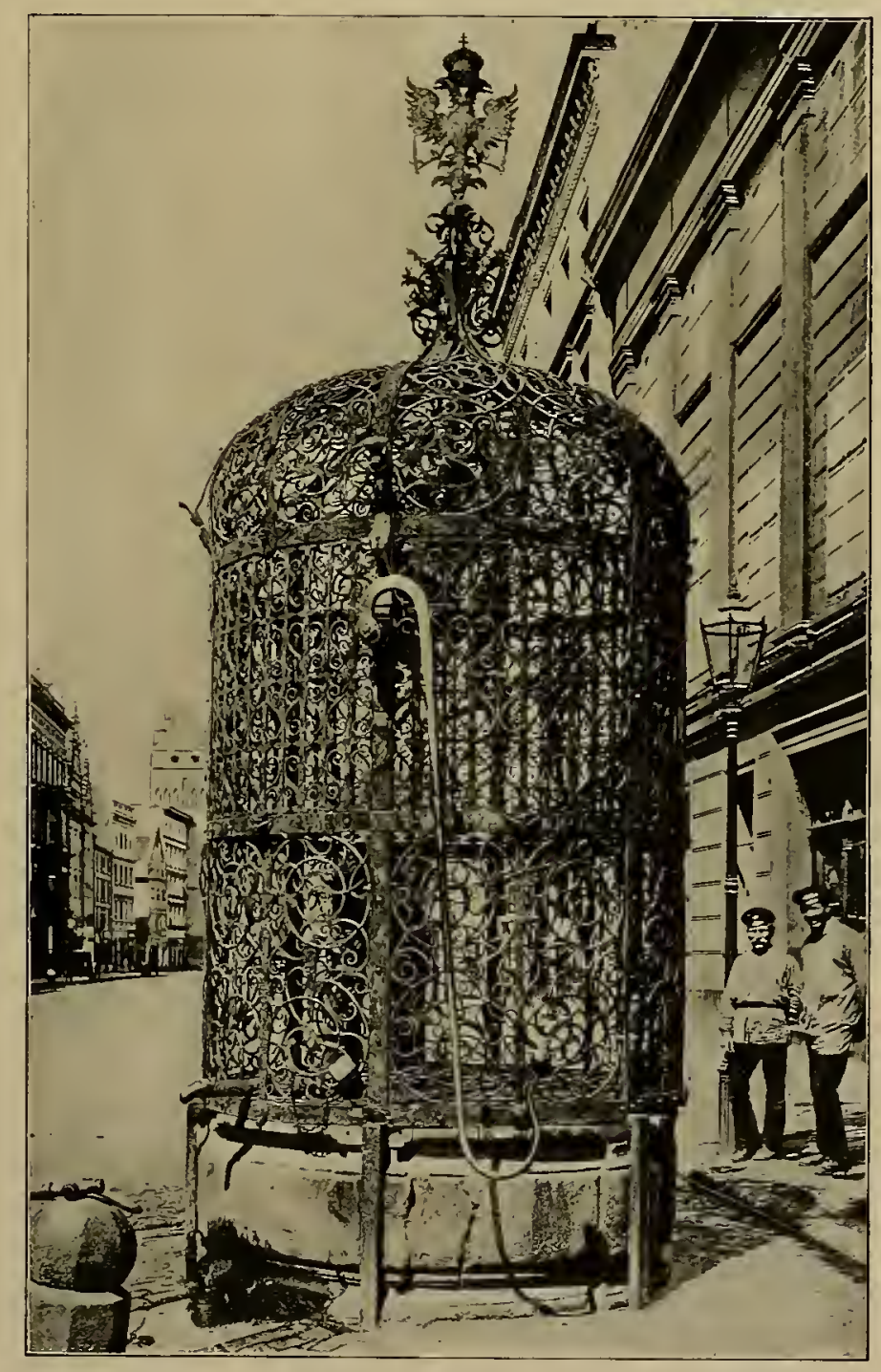

Abb. 55. Der schöne Brunnen in Neisse, 1686. 


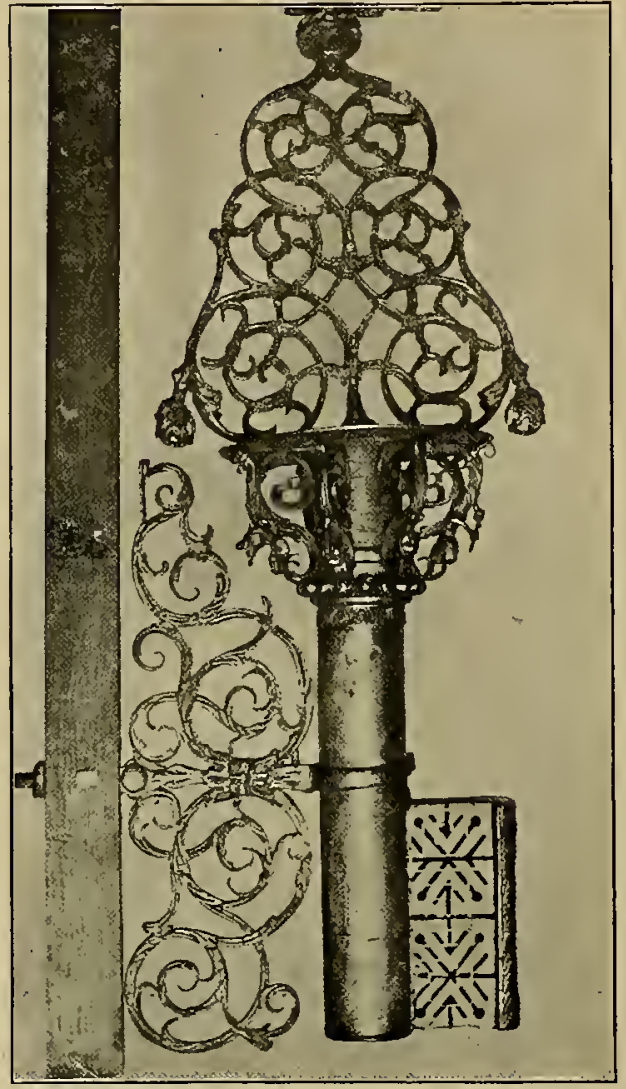

Abb. 56. Zunftpokal im bayerischen Nationalmuseum zu München.

1740). Das durchbrochene Rohr und der Bart sind mit geschnittenen und gravierten Akanthusblättern und Ranken in feinster Arbeit ausgestattet. (Abbild. 59). Von sonstigen Arbeiten dieses Stiles verdient noch eine im South Kensington Museum in London aufbewahrte Eisenkassette (Inv. Nr. 4255-1856) vom Jahre 1716, deren Deckel mit durchbrochenen und getriebenen Akanthusranken geschmückt ist, besondere Erwähnung. ${ }^{1}$ )

Vorlagen für Schlossbleche, Anschlagplatten, Schlüsselschilder und Thürklopfer enthält das von Joh. Christ. Weigel in Augsburg verlegte: „Reiss - Büchlein Heinrich Oelckers Pürger und Hoff-

1) Abgeb. in Quaritch, B., Ornamental lronwork pl. 43 น. 44.
Schlossers in Spremberg. Gebürtig in Buxtehude. Gelernt in Hamburg Anno $1710^{*}$. Es ist meines Wissens das früheste deutsche Ornamentstichwerk für Schlosserarbeiten überhaupt, eine interessante Thatsache, die zum Teil das lange Fortleben älterer Formen in der deutschen Schmiedekunst erklärt. Die Akanthusspiralen sind auch hier mit Tierköpfen, menschlichen Masken und Halbflguren durchsetzt. Besonders beachtenswert ist die Tafel mit Klopfern (Abbild. 60). Links ist die Hälfte eines Klopfers in Bügelform dargestellt, aus dessen Seite eine menschliche Büste herauswächst. Dann folgt ein Klopfer in Gestalt eines Seepferdes mit Akanthusblättern statt der Flossen. Ganz merkwürdig ist der dritte Thürklopfer, der eine weibliche Halbfigur darstellt; über ihren Kopf beugt sich ein Adler, der seine Krallen um ihren Leib gelegt hat - nichts anderes als eine sonderbare Entstellung einer bekannten antiken Gruppe, welche den Raub des Ganymedes durch den Adler des Jupiter darstelit. Aehnliche Klopfer besitzt auch das Kunstgewerbemuseum zu Berlin, sowie Sförnig geschwungene Klopfer in Gestalt von Delphinen mit einer Kugel im Maul und einen bügelförmigen mit seitlicher Menschenbüste, über welche ein Adlerkopf sich neigt.

Eine besondere Gruppe von Schmiedewerken für sich bilden die perspekti$v$ ischen Gitter, welche besonders in der Schweiz und im südlichen Deutschland seit der Mitte des 17. Jahrhunderts in Aufnahme kamen. Eines der frühesten ist das Chorgitter im Dom zu Luzern, das in den Jahren 1641-1644 von dem Stadtschlosser zu Konstanz Johann Reifell angefertigt worden ist. Von demselben rühren auch möglicherweise die perspektivischen Gitter im Dom zu Konstanz her. Andere befinden sich zu Kostel in Mähren, in der wälschen Kapelle des Collegium Clementinum zu Prag, in der Vincenzkirche zu Breslau u. s. w.

Ein besonders stattliches Gitter dieser Art ist das Chorgitter der Kirche Maria- 
Einsiedeln in der Schweiz (Abbild. 61). Es wurde bei Gelegenheit des Neubaues des Chores unter dem Fürstabt Augustin II. von Reding von dem Klosterbruder Vincenz Nussbaumer von Aegeri und seinen Gesellen in dem Zeitraum von 1675-1684 geschmiedet. ${ }^{1}$ ) 1798 wollte der Führer des französischen Revolutionsheeres dasselbe ausbrechen und nach Paris schaffen lassen. Es kam aber zum Glück nicht dazu.

Die Bildung dieses Gitters ist nun sehr absonderlich. Es besteht aus drei grossen Portalaufbauten, welche durch rechteckige Gitterteile miteinander verbunden sind. Das mittlere Portal ist mit einer Flügelthür, die beiden seitlichen sind mit einfachen Thüren versehen. Alle drei sind so komponiert, als sähe man in lange, von einem Tonnengewölbe bedeckte Galerien hinein. Dabei liegen aber sämtliche Eisenteile, aus welchen das Gitter besteht, in einer Fläche. Die Seitenwände dieser Scheingalerien sind von Pilastern eingefasst; ober- und unterhalb dieser Pilaster befinden sich Reihen kleiner Balüster, welche sich in perspektivischer Linienführung durch das ganze Gitter hindurchziehen. Die Gewölbe sind aus sich überschneidenden Flacheisen gebildet, auf deren Kreuzungspunkte Rosetten aufgesetzt sind. Die Füllungen der Thüren, die Zwischensätze zwischen den Portalen, sowie die Bekrönungen zeigen die schön geschwungenen Spiralen der Renaissancegitter der zweiten Form mit eingehauenem Ornament. Jedes Portal trägt ausserdern in der Mitte noch einen Aufsatz mit drei tulpenartigen Blumen. Die Oberlichte der Thü-

1) Vgl. Kuhn, P.A., Der jetzige Stiftsbau Maria. Einsiedeln. Einsiedeln 1883. S. 32. ren enthalten in der Mitte das Zeichen Jesus, auf den Seiten die Namen Maria und Joseph in einer den übrigen Ornamenten des Stabwerks entsprechenden Gestaltung. Ungefähr in gleicher Höhe damit ist auf den die Portale verbindenden Gitterteilen das Wappen des Fürstabtes angebracht.

Ein perspektivisches Gitter in den Formen des durch den Akanthus bereicherten Renaissancegitters befindet sich in der St. Ulrichskirche zu Augsburg (Abbild. 62). Es schliesst gleich hinter dem Eingange den Kirchenraum ab. Derartige Abschlussgitter kommen in süddeutschen Kirchen häufiger vor, sie sind wohl aus rein praktischen Gesichtspunkten entstanden. Man wollte die Kirche abschliessen und doch den Gläubigen Gelegenheit geben, zu allen Stunden des Tages in dem so gebildeten Vorraum ihre Andacht angesichts des Altars zu verrichten.

Das Gitter, welches 1712 entstanden ist, ist in einen Holzrahmen eingelassen, der in den Formen der damaligen Schrankarchitektur gehalten ist. Getragen wird er von einem Sockel mit verkröpften Füllungen, korinthische Pilaster trennen die einzelnen Gitterteile, und ein reich profiliertes Gesims mit verkröpftem Gebälk, bekrönt von Akanthusvoluten mit

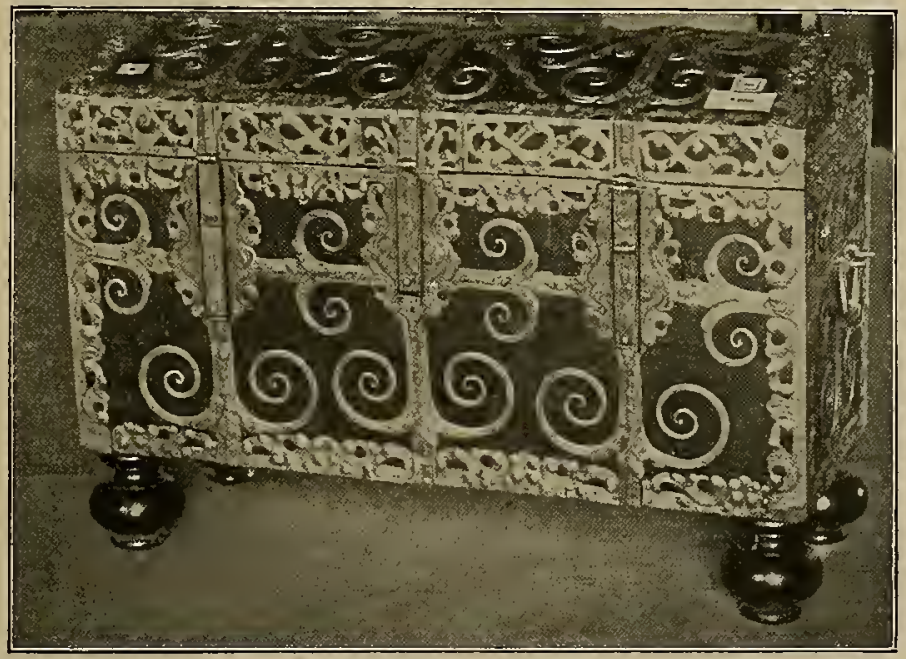

Abb. 57. Truhe (Kunst- und Industrieausstellung zu Kopenhagen 1879). 


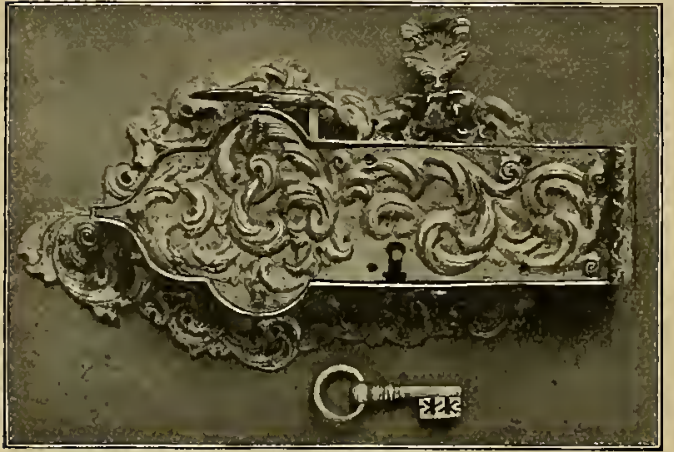

Abb. 58. Schloss im Kunstgewerbemuseum zu Berlin.

Kartuschen und kleinen Engeln, bildet den oberen Abschluss. Aehnlich wie beim Chorgitter von Maria-Einsiedeln ist die Thür in der Mitte, abgesehen von den beiden unteren Füllungen, die als Fortsetzungen des Holzsockels gedacht sind, so komponiert, als sähe man in einen langen, rund gewölbten Laubengang oder eine Galerie hinein. Die scheinbar das Ende des Ganges abschliessende Thür ist aus Rundeisen mit Akanthus gebildet, ähnlich sind auch die übrigen Füllungen gestaltet. Die Seitenwände des Scheinganges sind mit Balüstern aus Bandeisen besetzt. Auch die an die Mittelthür sich rechts und links anschliessenden Gitterteile sind als zurückweichend dargestellt. Die dann folgenden Fenster erwecken die Vorstellung, als lägen sie tief zwischen dicken Mauern. Im übrigen ist der Versuch, das Auge irre zu führen, so misslungen wie nur etwas, denn die Täuschung wird leicht durch den für das Auge in einer Fläche liegenden Holzsockel aufgehoben, während die geschweiften Linien des Gesimses wohl den Anschein des Zurückweichens erwecken könnten; trotzdem ist aber die Wirkung des Ganzen nicht unschön.

Wenn diese perspektivischen Gitter auch in der Ornamentik noch zum grossen Teil die Formen des Renaissancegitters in seinen verschiedenen Umbildungen bewahrt haben, so ist doch ihre Komposition schon im Sinne einer neuen Kunst gestaltet. Denn die Fläche des Gitters nicht als Raumabschluss, sondern als Raumerweiterung zu behandeln, ist ein Gedanke, der ganz dem Geiste des Barocks angehört. Ist doch die Scheinperspektive eines der vornehmsten Mittel, mit welchem die Architektur des Barocks zu wirken pflegte. Mit grossartigem $\mathrm{Er}$ folge hatte sie Lorenzo Bernini bei der Scala Regia des Vatikans angewandt, indem er die beiden Seitenmauern der Treppe allmählich sich nähern liess und so den Eindruck einer viel grösseren Länge der Treppe hervorrief, als dieselbe in Wirklichkeit besitzt. Auf mannigfache Weise wurde auch sonst von diesem effektvollen Mittel Gebrauch gemacht: durch kulissenartig vorgeschobene Säulen oder gemalte Architekturteile eine grössere Tiefe und Ausdehnung vorgetäuscht, die Höhe einer Kirche oder eines Saales durch perspektivische Deckenmalerei über die Wirklichkeit hinaus für den Anblick vergrössert u. dgl. mehr. Etwas Aehnliches beabsichtigte man auch mit diesen perspektivischen Gittern.

Die Annahme, dass diese eigentümliche Gitterbildung zuerst bei Oberlichtgittern in Anwendung gebracht $\operatorname{sei}^{1}$ ), lässt sich meines Wissens durch kein Beispiel belegen. Eher könnte man daran denken, dass die perspektivischen Gitter zuerst in der Gartenarchitektur aufgekommen seien. Hier pflegte man gern an das Ende grösserer einheitlicher gärtneri-

1) Minkus, F., Flächendekoration und Perspektive. Kunstgewerbeblatt. Neue Folge IX. S. 40.

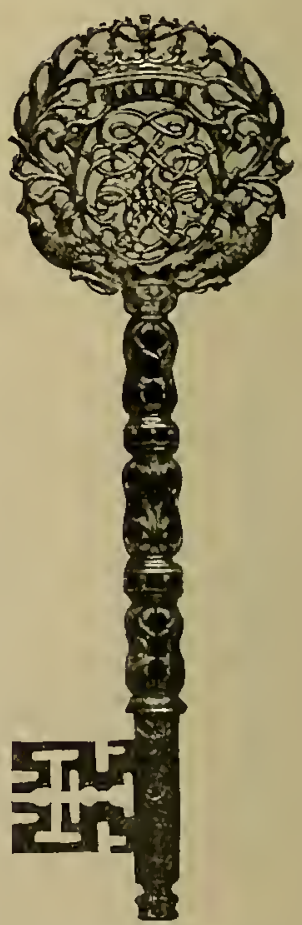

Abb.59. Schlüssel im Kunstgewerbe. museum zu Berlin. 
scher Anlagen Architekturen zu setzen, sog. Berceaux, aus Eisen und Holz konstruiert. Man konnte nun leicht auf den Gedanken kommen, an die Stelle solcher wirklichen Raumbauten bei Anlagen, welche nur auf die Fernwirkung berechnet waren, Scheinarchitekturen zu setzen, da sie doch denselben Zweck erfüliten. Besonders am Ende laubengangartiger Alleen

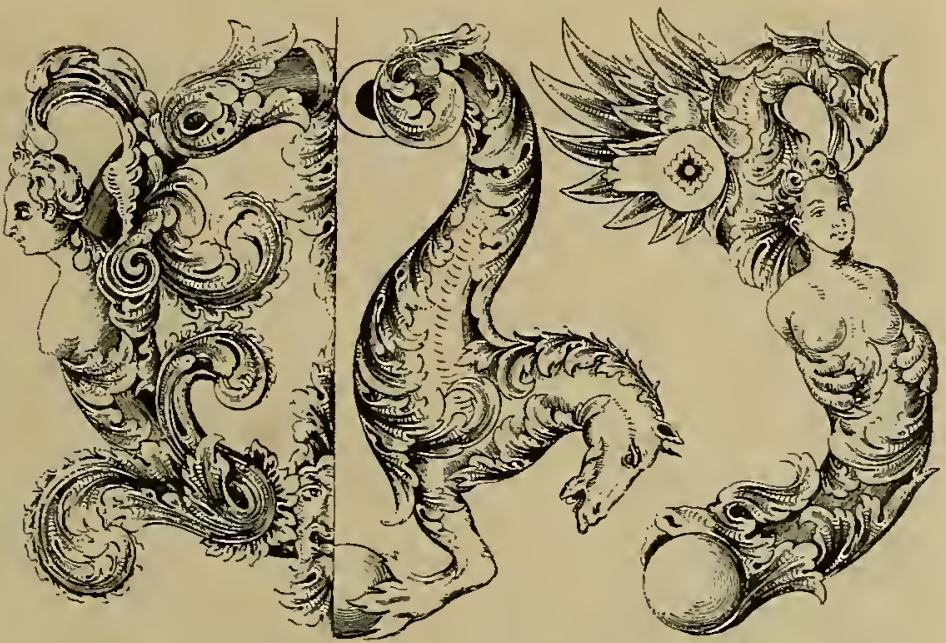

Abb. 60. Thürklopfer aus dem Schlosserbuche von H. Oelcker. würde solch perspektivisches Gitter gut am Platze gewesen sein, indem es einerseits ein gutes Bild gab, andererseits aber auch sicheren Abschluss nach aussen hin bot. Ein solches Gitter hat sich z. B. noch im Park der Favorita in Wien, des heutigen Theresianums, das unter Karl Vl. angelegt wurde, erhalten. Es schliesst den Park nach dem Gemüsegarten ab. Das Portal ahmt einen langen Weinlaubengang nach, und zwar so geschickt, dass man von einem bestimmten Punkte aus wohl getäuscht werden kann.

Mag das perspektivische Gitter bei solcher Anwendung in weiträumigen Parks als Abschluss langer Alleen u. dgl. eine gewisse Berechtigung haben, indem es die natüriiche Perspektive eines solchen langen Ganges fortsetzt und so in dem Besitzer des Gartens das angenehme Gefühl einer bedeutenden Raumerweiterung seines Grundstücks schafft, so ist seine Ueberführung in geschlossene Räume nicht glücklich zu nennen, weil die beabsichtigte lllusion hier durch die nahe hinter dem Gitter befindlichen Gegenstände bald aufgehoben wird.

Nur wenige Namen kunstreicher Schlosser und Eisenschneider jener Zeit sind der Nachwelt überliefert worden. Unter den Nürnbergischen Eisenkünstlern aus der zweiten Hälfte des 17. Jahrhunderts, von denen uns Doppelmayr in seiner "Historischen Nachricht von den Nürnbergischen Mathematicis und Künstlern. Nürnberg 1730 " berichtet, zeichnet er zwei besonders aus, indem er ihre Hauptwerke in Stichen darstellt, es sind Bartholomäus Hoppert, und der auch sonst rühmlichst bekannte Gottfried Leygebe.

Hoppert wurde 1648 im Markgrafentum Ansbach geboren. Nach überstandener Lehrzeit hatte er sich auf die Wanderschaft begeben und vieler Herren Länder besucht: Holland, England, Frankreich, Dänemark und Schweden. In Paris arbeitete er auch für Ludwig XIV.; 1677 liess er sich dauernd in Nürnberg nieder. Als Meisterstück verfertigte er hier eine kunstvolle grosse Eisenkassette mit Ornamenten in getriebener Arbeit, welche zum Preise von 1000 Thalern als Geschenk für Kaiser Leopold 1. angekauft wurde. Das Schloss war unter einem liegenden Löwen verborgen. Die Ornamentik verrät französischen Einfluss. Von seinen sonstigen Arbeiten wissen wir, dass er sich besonders auf die Herstellung kunstvoller Schlösser verstand. Er starb 1715.

Einen ungleich klangvolleren Namen hat Gottfried Leygebe ${ }^{1}$ ) sich er-

1) Ueber Leygebe vgl. Ernst Friedländer, Gottfr , ed Leygebe, Zeitschrift für Numismatik 


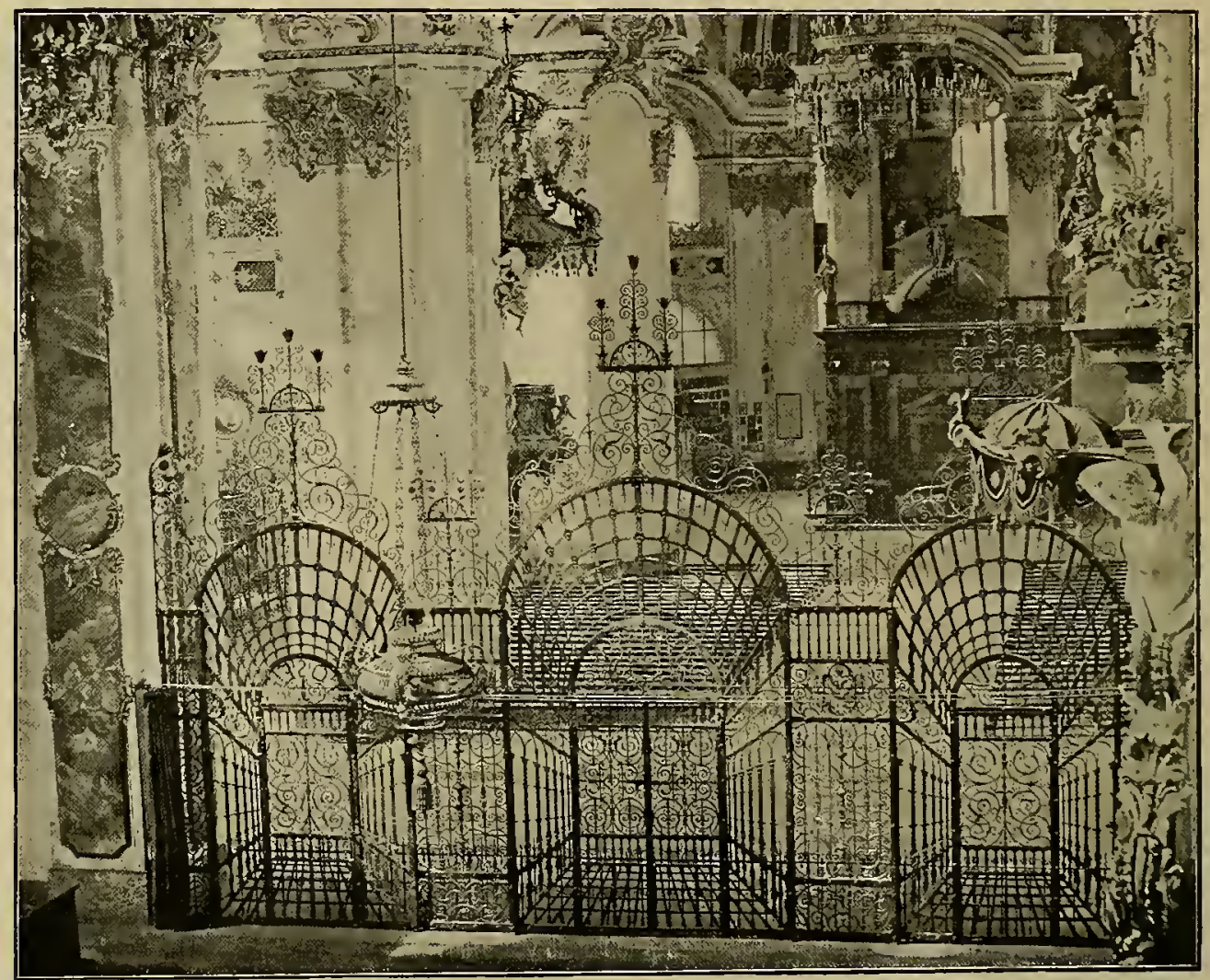

Abb. 61. Chorgitter der Stiftskirche Maria-Einsiedeln.

worben, der 1630 zu Freistadt in Schlesien geboren wurde. Seine künstlerische Erziehung erhielt er in Nürnberg, wo er seit 1645 lebte und das Schwertfegerhandwerk erlernte. Schon früh zeigte er eine besondere Kunstfertigkeit in der Herstellung geschnittener Eisenzierrate. Seine Degengefässe, Hirschfängergriffe, Pistolenbeschläge $u$. s. w. mit in Eisen geschnittenen Jagden, Reitern, Kriegswaffen 11. dgl. machten ihn bald bekannt. Im Besitz des Fürsten Reuss zu Gera befindet sich noch eine Arbeit aus seiner Nürnberger Zeit, ein Stichblatt mit Degenknopf in Gestalt eines antiken Reiters, welches die Jahreszahl 1655 trägt. Durch diese Arbeiten gelangte er allmählich zu solcher Meisterschaft, dass er sogar statuarische Kunstwerke in dieser schwierig-

Bd. XIII und Paul Seidel, Der grosse Kurfürst in der Plastik seiner Zeit. HohenzollernJahrbuch 1898. sten aller Handfertigkeiten auszuführen unternahm. In den Jahren 1660-1662 schnitt er aus einem Eisenblock die Reiterstatuette des Kaisers Leopold 1., die sich jetzt im Schloss Rosenborg zu Kopenhagen befindet, und um dieselbe Zeit ein anderes Bildwerk, welches den König Karl Il. von England zu Pferde als St. Georg darstellt. Leygebe brachte dieses Stück nach Berlin, wo es der Grosse Kurfürst für 600 Thaler ankaufte und 1667 als Geschenk an den Kurfürsten von Sachsen nach Dresden sandte. Hier befindet es sich noch heute im Grünen Gewölbe. Die Bemühungen des Kurfürsten, Leygebe in seinen Dienst zu ziehen, blieben erfolglos, da Leygebe damals "noch nicht gesonnen gewest, in grosser Herren Diensten zu stehen". Indessen übernahm er einen Auftrag des Kurfürsten, einen Degen herzustellen, auf dem die Bildnisse der oranischen Prinzen und des Kurfürsten, 
jedes wie ein Pfennig gross, in Eisen geschnitten waren. Leygebe führte denselben in Nürnberg aus und sandte ihn dann auf Geheiss Friedrich Wilhelms nach Kleve. Auf einer Reise nach Frankfurt, wohin man ihn zur Ausführung einer Arbeit gerufen hatte, kommt Leygebe dann zum zweiten Male nach Berlin, ohne jedoch zu wissen, dass der Kurfürst ihn ebenfalls für einen neuen Auftrag dahin beschieden hatte. Noch an demselben Abend, an dem er eingetroffen, wird ihm mitgeteilt, dass der Kurfürst ihn am anderen Tage zu sprechen wünsche. Obschon Leygebe andere Verpflichtungen hatte, konnte er doch den dringenden Wünschen des Kurfürsten, der eilige Aufträge für ihn hatte, nicht widerstehen.

Der längere Aufenthalt in Berlin, der durch diese Arbeiten und den Umstand, dass die Bezahlung derselben sich lange hinzögerte, veranlasst wurde, hatte zur Folge, dass Leygebe sich endlich entschloss, dauernd dazubleiben. Der Grosse Kurfürst überreichte ihm persönlich die vom 6. April 1668 datierte
Bestallung als Münzeisenschneider. Als Gehalt wurden ihm 400 Thaler, sowie freie Wohnung in der Münze zugesprochen; ein bestimmtes Quantum Holz und Roggen, das er verlangt hatte, wurde ihm nicht bewilligt. Leygebe verpflichtete sich dafür, alle verlangten Münzstempel zu schneiden, Medaillen zu verfertigen und sonstige Arbeiten in Wachs oder Thon zu modellieren. Es scheint, dass Leygebe anfangs bei seinen Kollegen in der Münze keine günstige Aufnahme gefunden und sich deshalb beim Kurfürsten beklagt hat. Denn wir besitzen noch ein Schreiben Friedrich Wilhelms an den Geh. Rat, Oberhofmarschall und Amtskammerpräsidenten Raban von Canstein, in weichem er unter besonderer Anerkennung der künstlerischen Leistungen Leygebes befiehit, denselben bei der ihm erteilten Bestallung zu schützen und in der Münze die Verfügung zu thun, „dass sie sich darnach gehorsambst achten sollen". Die Wohnung in der Münze hat Leygebe freilich nie erhalten, und ebenso wenig wurde ihm je sein Gehalt voll

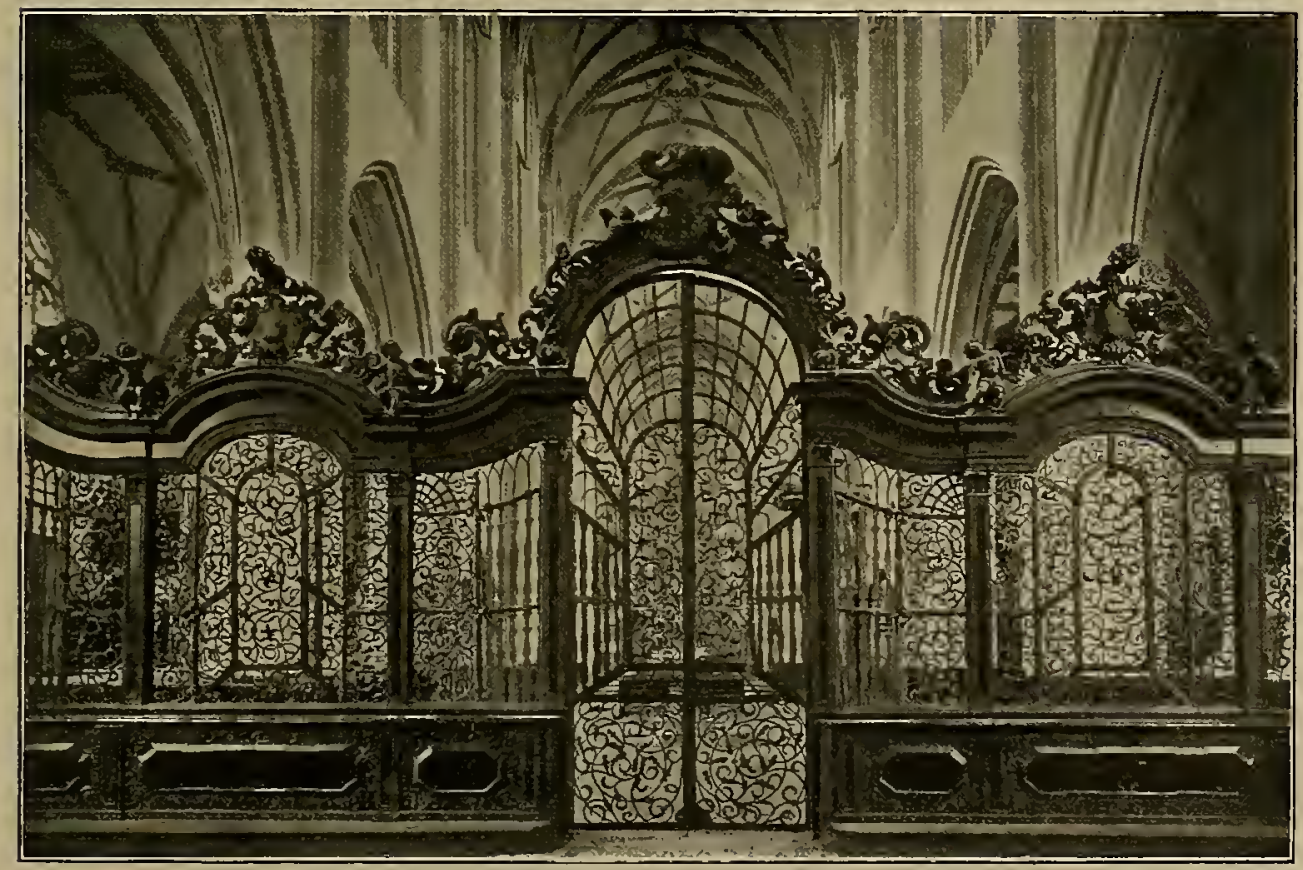

Abb. 62. Gitter in der St. Ulrichskirche zul Augsburg. 


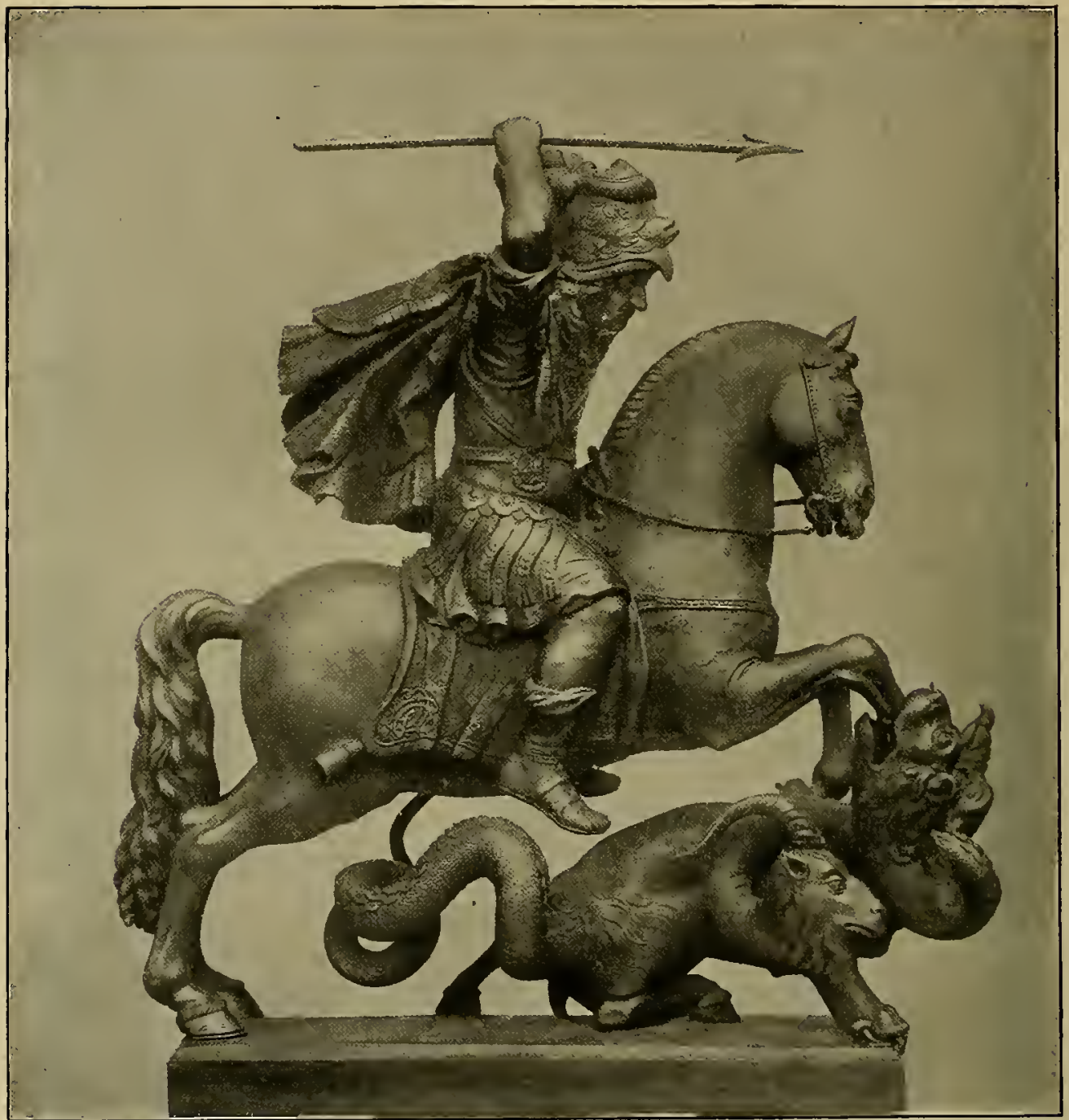

Abb. 63. Der grosse Kurfürst, in Eisen geschnitten von G. Leygebe (Berlin, Neues Museum).

ausbezahlt, so dass er sein ganzes Leben hindurch mit Nahrungssorgen zu kämpfen hatte und seine Familie bei seinem 1683 erfolgten Tode in dürftigen Verhältnissen zurückliess.

Das Hauptwerk Leygebes in geschnittener Eisenarbeit während seiner Berliner Zeit ist die im Neuen Museum zu Berlin aufbewahrte, $29 \mathrm{~cm}$ hohe Statuette des Grossen Kurfürsten zu Pferde, wie er als St. Georg einen dreiköpfigen Drachen tötet (Abbild. 63). Man darf sich über diese für uns befremdliche Maskerade nicht verwundern. Solche allegorischen
Verkleidungen lagen im Geschmack der damaligen Zeit. Auch Schlüter stellt ja den Grossen Kurfürsten auf der langen Brücke nicht in der Tracht der damaligen Zeit, sondern im Kostüm des römischen Imperators dar, der über seine gedemütigten Feinde triumphiert. In der Statuette Leygebes wird er ebenfalls als glorreicher Held gefeiert, der sein Land von allem Unheil, das der dreissigjährige Krieg und seine Folgen über dasselbe gebracht, mit starker Hand befreit. Leygebe vollendete das schwierige Werk nach einer mühseligen Arbeit 
von 3 Jahren 1680, ruinierte aber, wie er selbst klagt, seine Gesundheit dabei.

Von sonstigen in Eisen geschnittenen Arbeiten Leygebes hat sich noch ausser einem kleinen Relief mit der Austreibung des Heliodor im Yeuen Museum eine kleine Kapsel im Berliner Kunstgewerbemuseum erhalten. Dieselbe stellt auf den beiden Aussenseiten in einem Rahmen von Blattkränzen die vier Elemente in Gestalt von Putten mit Drachen, Delphin, Adler, Füllhorn und anderen Attributen dar und zwar auf der einen Seite vier, auf der anderen drei Elemente. Im Innern ist auf der einen Hälfte in gepunzter Manier das strahlenumflossene Haupt Christi auf einer Korkziehersäule zwischen zwei Blumenranken dargestellt, auf der anderen Hälfte befindet sich wieder ein Reliefbild: ein geflügelter Knabe steht vor einer Staffelei und malt nach einem Bilde, das ein auf einer Erhöhung rechts neben ihm stehender Putte ihm vorhält, eine Mondsichel. Links von der Staffelei steht ein dritter Knabe und hält einen Totenkopf empor. Die Darstellung umschliesst eine fortlaufende, vom Rande sich nach innen neigende Reihe abwechselnd goldener und silberner Blätter. Auch andere Teile des Bildes, die Körper der Putten u. s. w. sind mit Gold und Silber plattiert. Am Boden rechts steht auf einem Buche das Monogramm Gottfried Leygebes.

Auch sonst entwickelte Leygebe neben seiner Berufsarbeit in der Münze eine höchst mannigfaltige Thätigkeit. $\mathrm{Er}$ gab den Söhnen des Kurfürsten Unterricht im Zeichnen, für die Kurfürstin und den Prinzen Ludwig entwarf er Fahnen für ihre Regimenter und verfertigte Siegel und Petschafte für die ganze kurfürstliche Familie. Für die Glashütten des Kurfürsten stellte er Formen für Verzie- rungen der Gläser her, für die Geschützgiessereien modellierte er allerlei Ornamente zum Schmucke der Kanonen, Wappen, das Bildnis des Kurfürsten und sonstigen Zierrat. Ferner arbeitete er ein kunstvolles Schachspiel aus Gold und Silber, sowie für den Kurfürsten mit Silber eingelegte Schnallen. Auch grössere Aufträge traten an ihn heran. Im Hohenzollernmuseum zu Berlin befindet sich noch ein grosses Bronzemedaillon des Kurfürsten, welches ursprünglich den Marmorsaal des Stadtschlosses zu Potsdam schmücken sollte. Gegen Ende seines Lebens modellierte er eine Statue seines Gönners in Lebensgrösse. Sie sollte als Probe dienen; der Kurfürst beabsichtigte nämlich, sämtliche Mitglieder seines Hauses in gleichem Massstabe in Erz giessen zu lassen.

Auf Leygebe wird auch von Kugler (Königl. Kunstkammer in Berlin S. 248) ein im Berliner Kunstgewerbemuseum aufbewahrter kleiner Schwertknauf (K 5525) mit der Darstellung des Kampfes der Lapithen und Kentauren zurückgeführt. Man nahm an, dass er nach einem ebenfalls dort befindlichen Bronzeknauf in Eisen geschnitten sei. Ein genaues Gegenstück dazu wurde 1901 auf der Auktion Habich in Kassel für ungefähr 7000 Mk. verkauft. Schon der Umstand, dass zwei vollständig gleiche Exemplare vorhanden sind, macht stutzig, vergleicht man aber den Berliner Knopf mit dem Bronzeknauf genauer, so ergeben sich, abgesehen von sonstigen Merkmalen, so viele Uebereinstimmungen in Einzelheiten, dass man den Eisenknopf für einen ciselierten Nachguss des Bronzeoriginals halten muss. Wir haben also hier wieder einen jener ciselierten Eisengüsse vor uns, von dem Daviler in seinem Cours d'Architecture berichtet (vgl. S. 50).

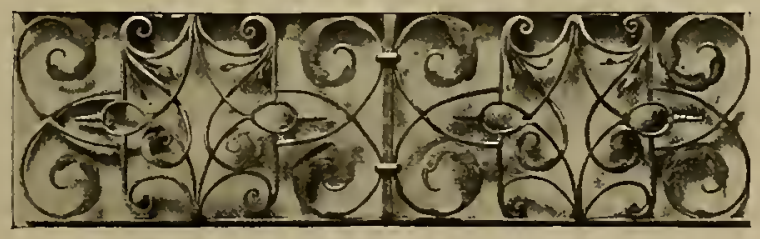

Abb. 64. Gitter im Bayerischen Gewerbemuseum zu Nürnberg. 


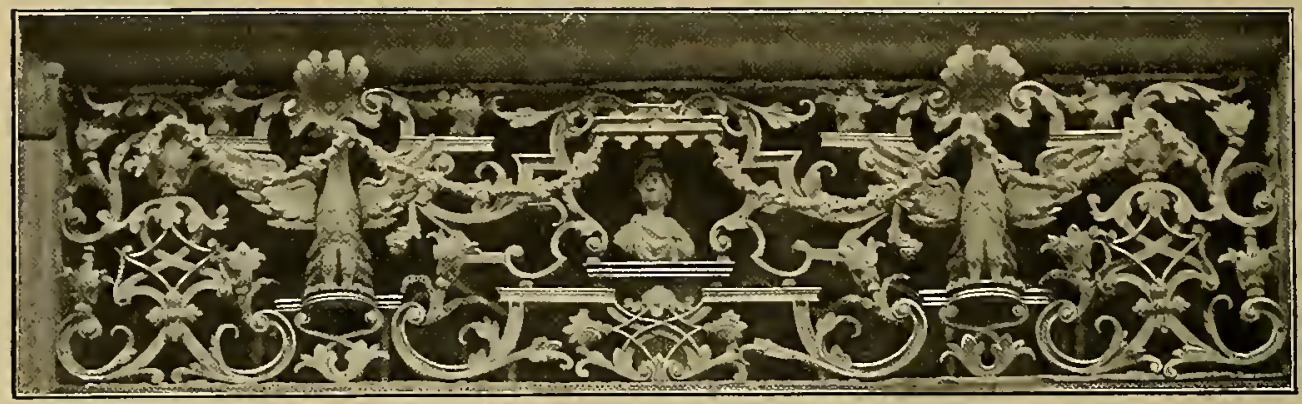

Abb. 65. Oberlichtgitter an einem Hause in Zürich.

\section{Das Laub- und Bandelwerk in der deutschen Schmiedekunst.}

Einer der frühesten Versuche, den französischen Formen Eingang in die deutsche Schmiedekunst zu verschaffen, stellt, abgesehen von der erwähnten, nur in einer dürftigen Abbildung erhaltenen Kassette des Bartholomäus Hoppert, das Chorgitter in der Kirche zu Obermarchthal in Bayern dar. ${ }^{1}$ ) Das Gitter zeigt eine Mișchung von französischen Ornamenten und deutschen Renaissanceformen. Wir wissen, dass Abt Yikolaus den Riss zu diesem Gitter 1688 durch einen Herrn Locher aus UIm in Paris bestellen liess. Ausgeführt wurde es durch den Klosterschlosser Hans Rieger von Obermarchthal. Die Vereinigung deutscher und französischer Motive erklärt sich wohl daraus, dass Rieger den Pariser Entwurf selbständig verändert hat.

Mit Ausnahme solcher vereinzelten Vorläufer lässt sich eine entscheidende Wendung der deutschen Schmiedekunst nach Frankreich hin erst im 18. Jahrhundert feststellen. Besondere Verdienste um die Einführung der neuen Formen des Laub- und Bandelwerks, die damals ja in Frankreich in Mode waren, erwarb sich der Verleger Johann Christoph Weigel in Nürnberg, der in der Zeit von 1710--1725

1) Abgeb. in Kick, W., Barock, Rokoko und Louis XVI. aus Schwaben und der Schweiz. Stuttgart. Tafel 4. eine grosse Anzahl von Stichfolgen mit Vorlagen für Schmiedewerke herausgab. Das früheste Schlosserbuch, das von Oelcker, war noch unberührt von französischem Einfluss. Neben den alten Akanthusformen erscheinen die gebrochenen Bänder zuerst, wenn auch noch' schüchtern, in dem Schlosserbuch des Schlossergesellen Christian von der Heyden aus Gross-Zerbst, dessen Entwürfe im übrigen sich an die Formen Oelckers anlehnen.

Völlig ausgeprägt zeigt sich dann das Laub- und Bandelwerk in einer Folge Wejgels mit dem Titel „Neues Bändel Werck Büchlein vor Schlosser auffgezeichnet. Erster Theil" mit der Verlagsnummer 140; die Tafeln sind von ungelenker Hand gestochen und dürftig in der Erfindung. Vielleicht als Fortsetzung dieser Folge ist ein anderes, ebenfalls anonymes Werkchen anzusehen, das den Titel führt: „Des vor Schlosser aufgezeichnete neuen BandelWercks anderer Theil jedes Stuck gehalbirt von einen Schlosser in Nürnberg Nr. 203“. Unter dem Titel, der zwischen den Hälften zweier Klopfer angebracht ist, steht der Zusatz: „Weil einige Schlosser davor geachtet, der Erste Theil des Bandel Wercks sey nicht alles zu hauen und zu treiben. nur zum ättern (ätzen?), so ist ja jeden frey in diesen und Ersten Theil alles zu vergrössern, zu erweitern vieles auszulassen, und nach seinen gefallen zu 
richten", eine interessante Erklärung, wie der Verleger seine Stiche benutzt wissen wollte. Die Tafeln dieser Folge enthalten Vorlagen zu Wandarmen, zu einem Grabkreuz, zu "Wagen Stützen in Apothecken", "Kohl Pfannen zu Caffe", Balustraden, Gitterthoren, Bekrönungen u. s. w. (Abbild. 66). Mehrere Gitterentwürfe verraten deutliche Entlehnungen von Bérain. Auch die Stiche dieser Folge sind mässig und trocken. Reicher, findlicher Klopfer mit reich geschmückter Anschlagplatte (Abbild. 67).

Auch der bekannte Architekt Paul Decker veröffentlichte bei dem Nürnberger Kupferstecher Hieronymus Bölmann ein Büchlein mit Schlossblechen, Schlüsseln, Riegeln, Klopfern u. dgl. von flotter Zeichnung, aber ungleichmässigem Charakter und mit teilweise starker Anlehnung an die Ornamentik französischer Stecher; es scheint indessen keine grosse Anaber nicht viel besser sind die Entwürfe einer von Christoph Weigel jun. herausgegebenen Folge, benannt: "Neu inventirtes Schlosser - Reiss Buch gezeichnet von einem Schlosser in Nürnberg", in dem die Formen des Laub- und Bandelwerks durch eingefügte Halbfiguren, Büsten, Tiere, Baldachine u. dgl. belebt sind, ähnlich wie Marot sie in seinen Vorlagen anwendet, freilich ohne die elegante Linienführung des französischen Meisters. Recht hausbacken und langweilig nimmt sich z. B. die Frau aus, welche auf der Volute eines grossen Klopfers sitzt und einen Schlüssel in der Hand hält. Verwandt damit ist das ebenfalls wenig bedeutende "Neu inventirte Schlosser Büchlein gezeichnet durch Hein. rich GottfriedFörster Schlosser Gesell von Leipzig“, von dem ä́lteren Weigel verlegt. Dem Formenkreis dieserStiche entspricht ungefähr ein im Germanischen $\mathrm{Mu}$ seum zu Nürnberg be-

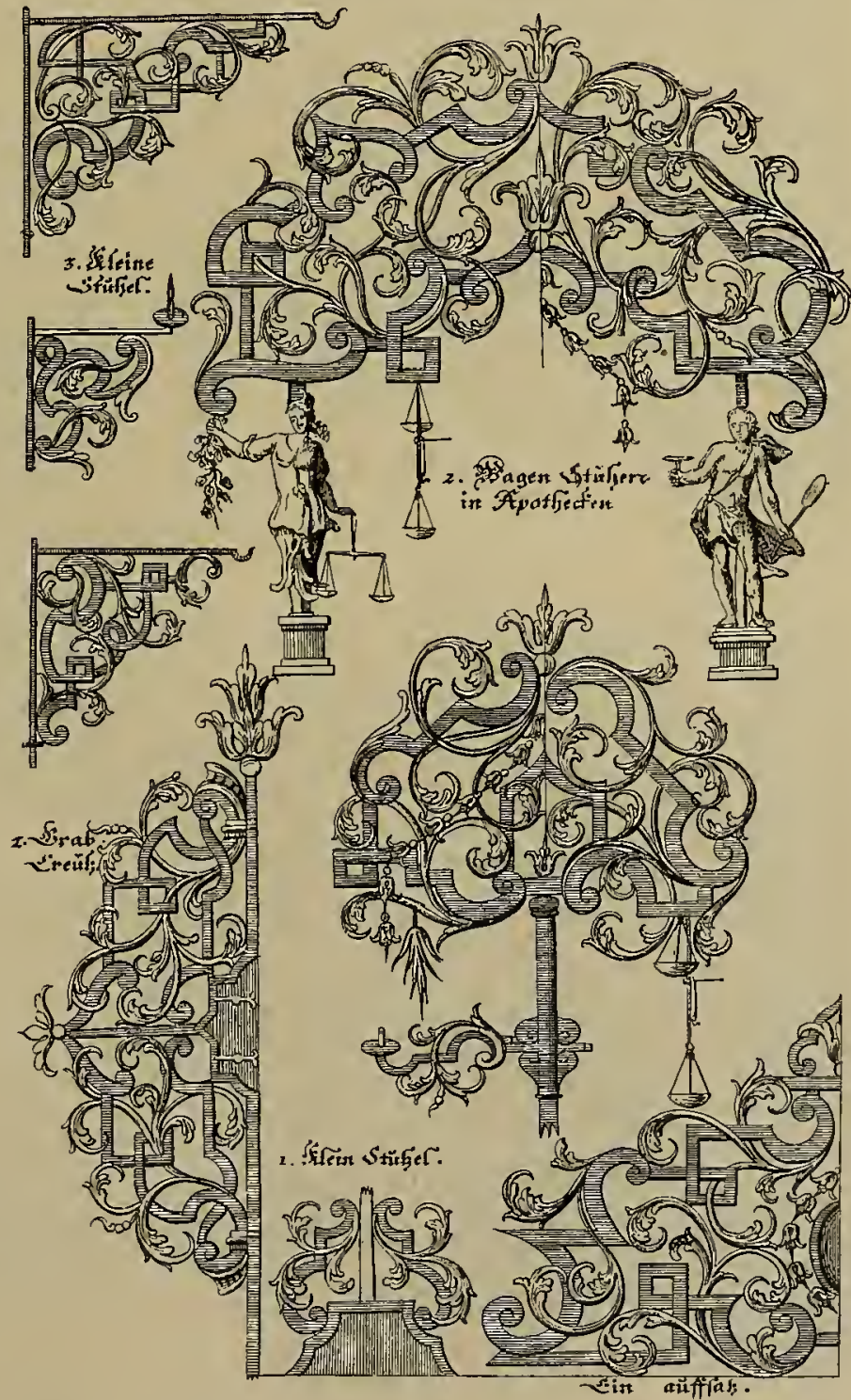

Abb. 66. Entwürfe für Schmiedearbeiten aus einer bei J. C. Weigel in Nürnberg erschienenen Ornamentstichfolge. 


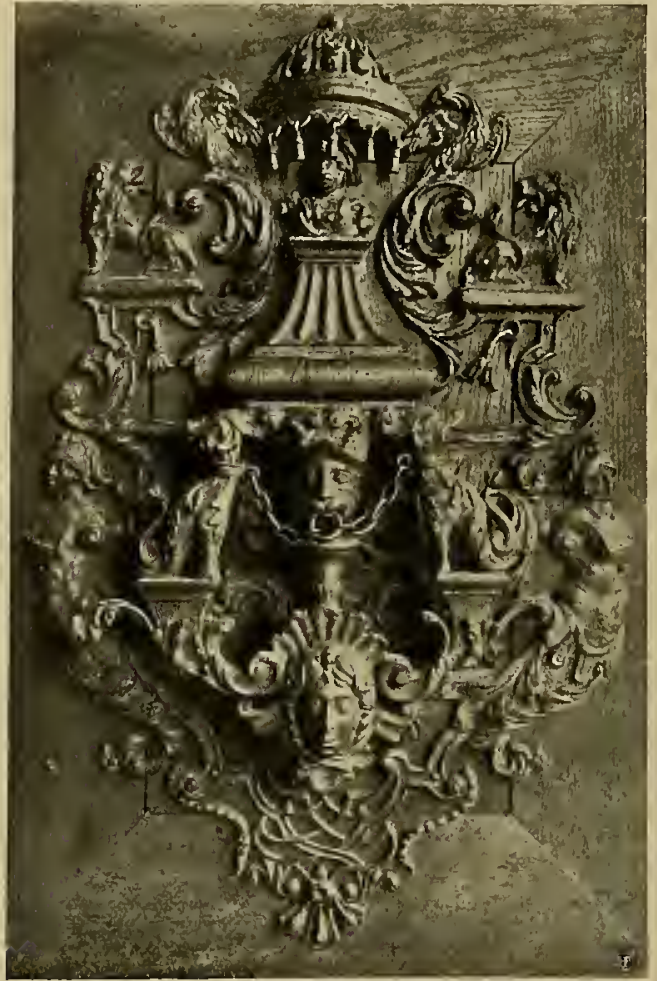

Abb. 67. Thürklopfer im Germanischen Museum zu Nürnberg.

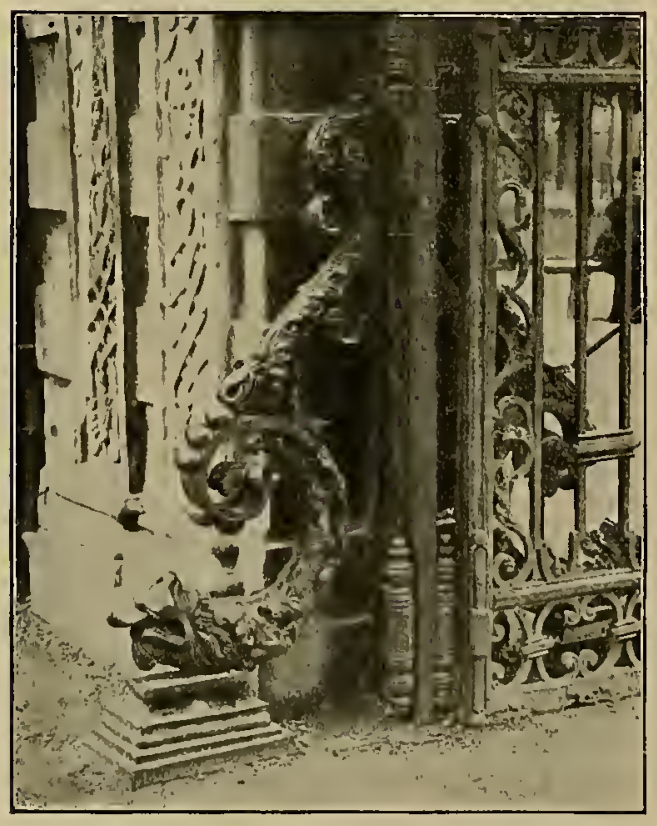

Abb. 68. Stütze an einem Portal des Belvedere zu Wien. wendung gefunden $\mathrm{zu}$ haben. Ebenso zeigen auch die in seiner "Civilbaukunst" gelegentlich abgebildeten Gitter auffällige Anklänge an die Schmiedearbeiten, die Daviler in seinem Cours d'Architecture vorführt. Ueberhaupt scheint Decker einer ausgedehnten Verwendung von Schmiedewerken in der Architektur ferngestanden zu haben. Sein „Fürstlicher Baumeister" bringt nur in der „Perspek-

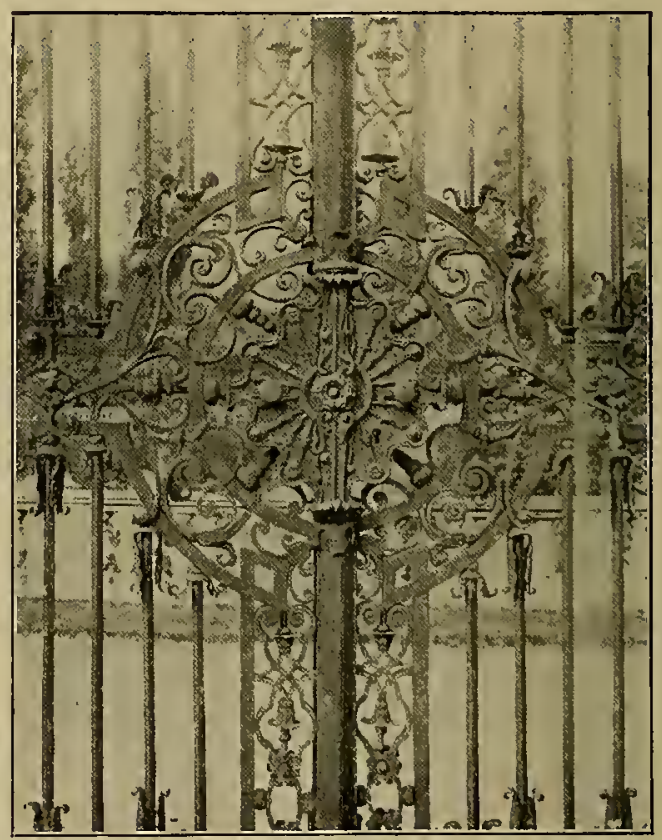

Abb. 69. Mittelteil eines Portals des Belvedere zu Wien.

tive des fürstlichen Schlosses zu Christian Erlang " ein grosses Vorhofgitter; hier und da kommen auch einige Parkgitter vor.

Interessant sind die Gitterentwürfe 10 . hann Jakob Schüblers, die ebenfalls bei Weigel und bei Johann Trautner in Nürnberg herauskamen. Sie zeigen eine lebendig bewegte Linienführung von selbständiger Erfindung, die schon stark zum Rokoko hinneigt. Ebenso eigenwillig und absonderlich sind die durch eigentümliche spitzwinkelige Linienzüge sich kennzeichnenden Entwürfe von Christian Fried. rich Rudolph in Augsburg. Die Vorlagen beider scheinen indessen wenig benutzt worden zu sein. 


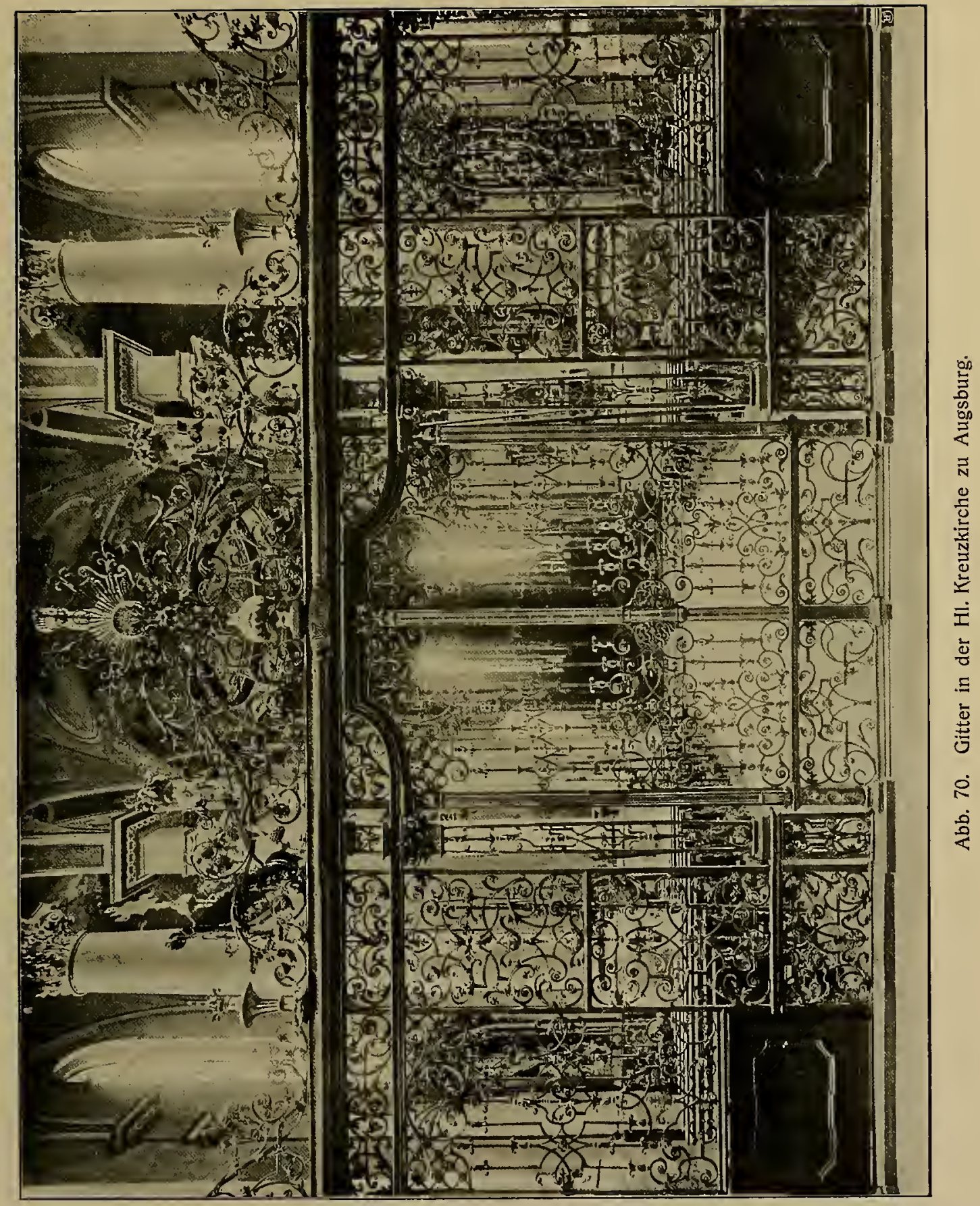


Auch sonst hat Augsburg an Ornamentstichen für die Schmiedekunst beigesteuert. So gab Gottfried Hartmann, Schlossergesell aus Breslau, nacheinander mehrere Folgen zum Teil mit denselben Tafeln bei verschiedenen Verlegern, bei Kaspar Rad, bei Hieronymus Martin Oster-

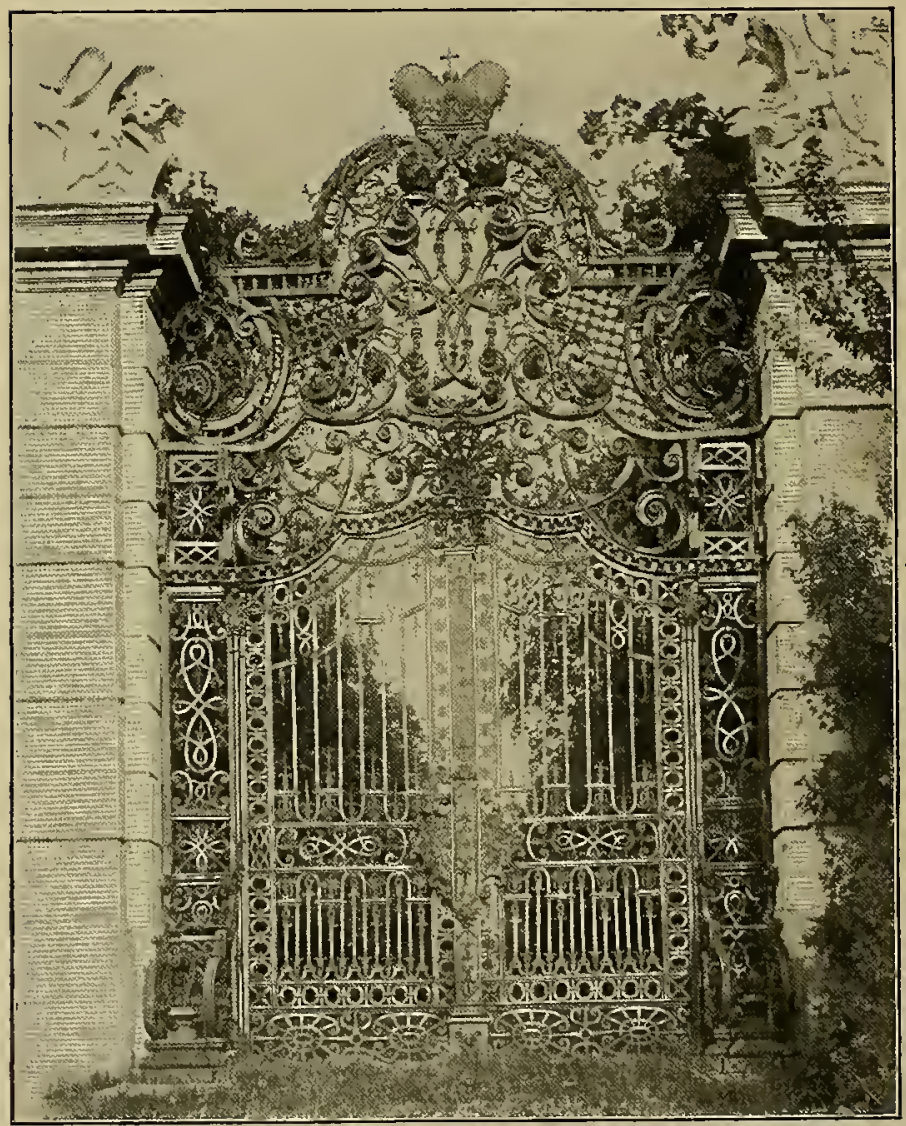

Abb. 71. Gitterthor des Schlosses Schlosshof. hl. Kreuz in Augsburg (Abbild. 70). Besonders gut gelungen ist die Gitterbildung des Portals. Die Bekrönung enthält als Mittelstück eine Vase, aus der nach den Seiten Weinreben und Aehren, als Symbole des Weines und Brotes im Abendmahl, wachsen. Unterhalb der Vase steht auf dem Thürgesims die Jahreszahl 1744. Ausserdem trägt das Gitter die Namen des Stadtschlos. sermeisters Johann Michael Hoch und seines Gesellen Joh. Georg Rummel, des Herausgebers des Schlosserbuches, dem wohl der Löwenanteil an der Herstellung des Gitters zufiel, da er sonst wohl nicht genannt sein würde. Nach Fertigstellung des Gitters, dessen Arbeit drei Jahre dauerte, erhielt Rummel auf Grund dieser hervorragenden Leistung das Meisterrecht unter den Augsburger Schlossern. ${ }^{1}$ ) Der Stich stimmt mit dem Gitter im grossen und ganzen überein, nur die Bekrönung weicht $a b$.

Eines der besten Vorlagewerke dieser Zeit ist das "Neu inventierte Schlosser Reiss - Buch gezejchnet von Frantz tag und 1736 bei Joh. Andr. Steisslinger heraus. Während seine Entwürfe, die in der reichen Verwendung des Akanthus auf ältere Vorbilder zurückgreifen, wenig bedeutend sind, erfreut dagegen Johann Georg Rummel, der ein Schlosserbuch bei Joh. Georg Hertel in Augsburg herausgab, durch einige selbständig erfundene, hübsche Entwürfe, von denen einer sich sogar, wenigstens in teilweiser Ausführung, nachweisen lässt. Es ist das Abschlussgitter des Langhauses der Kirche zum
Leopold Schmittner Schlossergesell". Schmittner, der 1703 in Wien geboren wurde und zuerst das Schmiedehandwerk erlernte, wurde später Kupferstecher. 1732 wird er als civis academicus der Universität bezeichnet, zu deren korporativem Verbande damals auch die Künstler gehörten. Er stach unter anderen Porträts von Mitgliedern der kaiserlichen Familie

1) Vgl. Kempf, A., Alt-Augsburg. Berlin 1898. S. 15. 


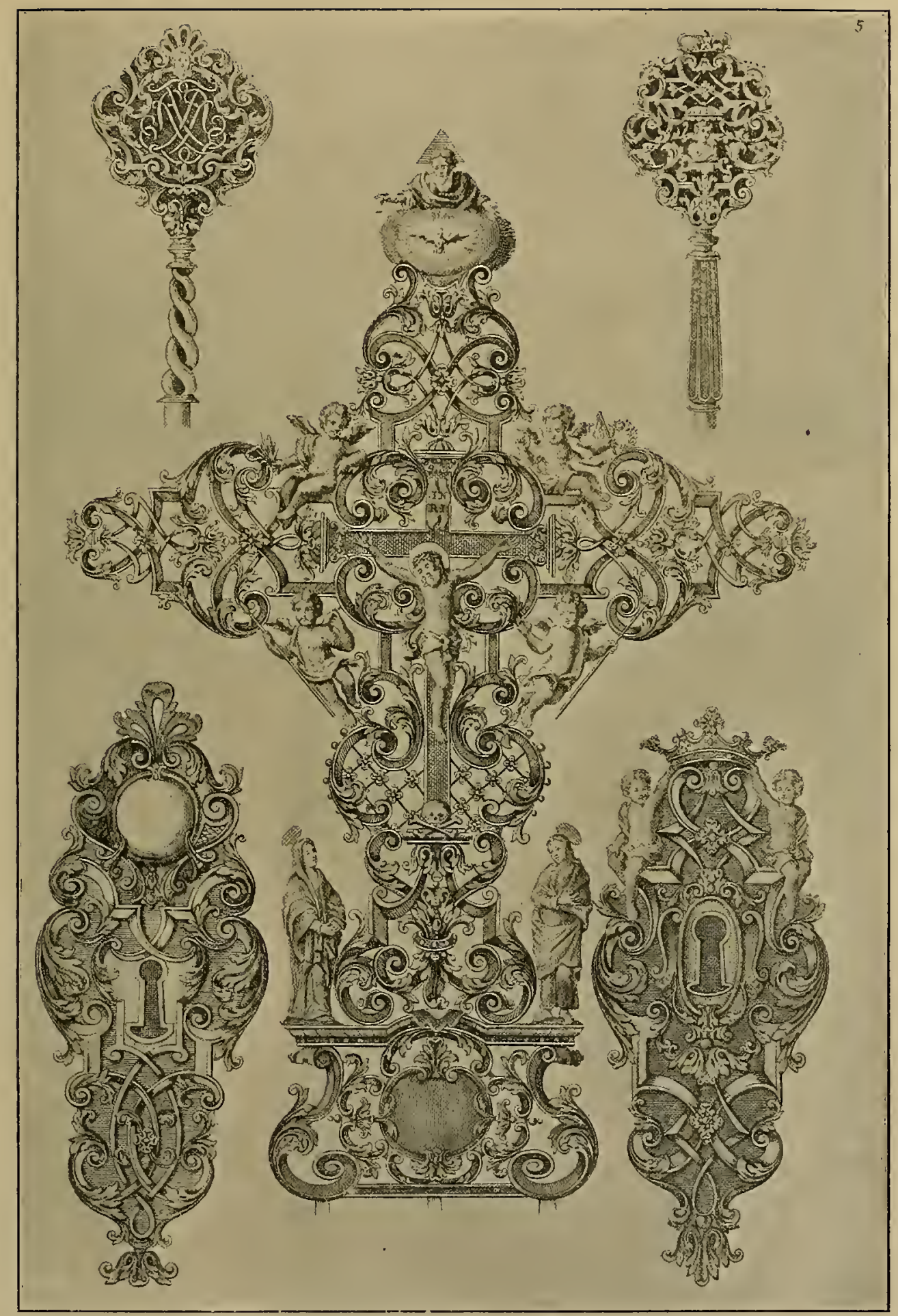

Abj. 72. Schmiedearbeiten, gestochen von F. L. Schmittner. 


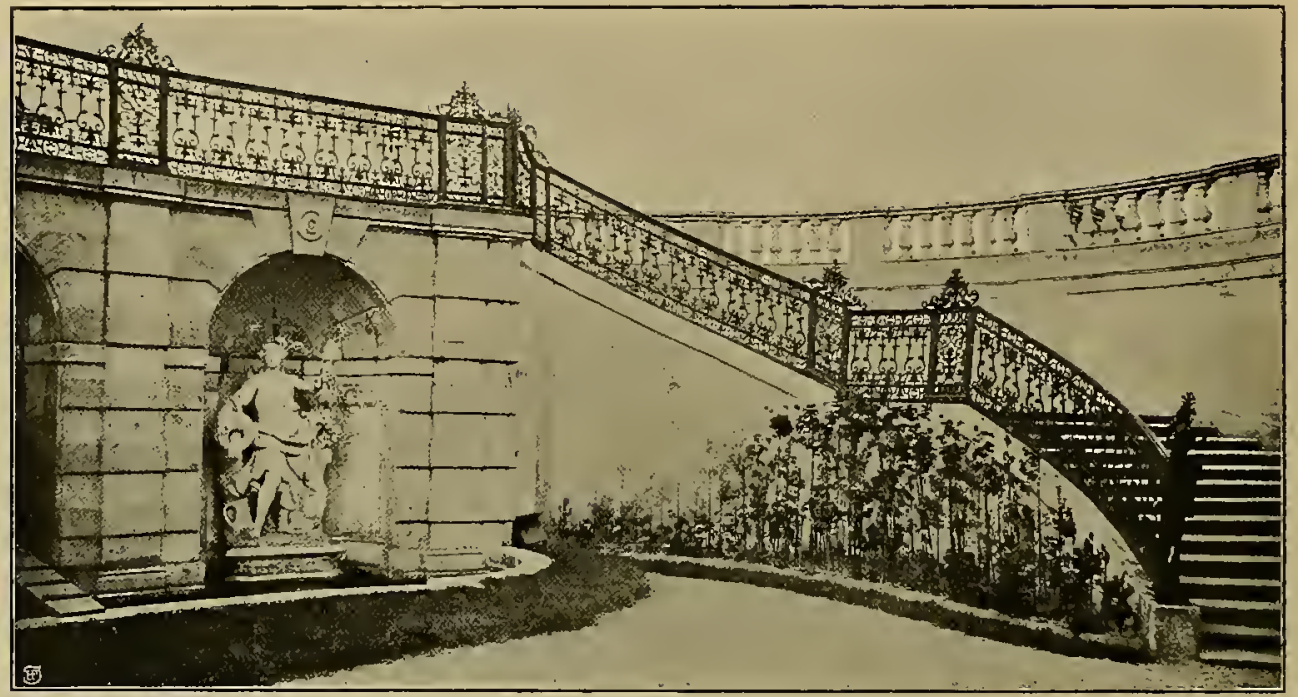

Abb. 73. Geländer im Schlosse Schlosshof.

und religiöse Darstellungen. Er starb 1761. Die 7 Tafeln seines Schlosserbuches zeigen ein flott und sicher gezeichnetes und gut komponiertes Laubund Bandelwerk, bereichert durch allerlei figürliche Zuthaten, gewappnete Halbfiguren, Büsten, Adler, Wappenschilder u. s. w. Sie geben sowohl Thürbeschläge, Schlösser u. dgl., sowie Gitter. Auch ein vortreffliches perspektivisches Gitter befindet sich darunter, das sehr stark an das Meidlingerthor in Schönbrunn erinnert; besonders die Seitenteile des Portals in Gestalt von rundbogigen Nischen mit eingestellten Vasen sind bei beiden sehr ähnlich. Auch die übrigen Arbeiten sind ganz im Stile der noch vorhandenen Wiener Schlosserarbeiten jener Zeit gehalten (Abbild. 72). Schmittner ist offenbar von Marot sehr beeinflusst, dessen Formenwelt überhaupt bei den deutschen Schmieden gute Aufnahme fand. Mög. licherweise ist aber auch Schmittner, wie vielleicht manch anderer seiner Genossen, nicht der Erfinder der Arbeiten, die er in seinen Stichen uns vorführt, sondern er wiederholt nur zum Teil oder ganz schon ausgeführte, von anderen entworfene Schmiedewerke. ${ }^{1}$ )

1) Ueber Schmittner vgl. llg, A., der Schlos-
An Reichtum der erhaltenen Schmiedearbeiten im Laub- und Bandelwerkgeschmack lässt sich wohl kaum eine andere Stadt mit Wien vergleichen. Ueberhaupt ist die Schmiedekunst dieser Zeit in den österreichischen Ländern noch sehr gut vertreten. ${ }^{2}$ ) In Wien und Umgegend weisen besonders die prächtigen Paläste und Sommerresidenzen, welche in der 1. Hälfte des 18. Jahr. hunderts von einem Joh. Bernh. Fischer von Erlach, Joh. Lukas von Hildebrand und anderen erbaut wurden, eine grosse Zahl stattlicher Schmiedearbeiten dieses Stiles auf. Was diese Arbeiten vor den französischen Schmiedewerken auszeichnet, ist nicht so sehr die Zeichnung und Komposition, die wohl zuweilen die sichere Eleganz und Schönheit der französischen Vorbilder vermissen lassen, als vielmehr ihre hervorragende technische Ausführung. Während das Stabwerk in Frankreich meist aus Quadrat- oder Flacheisen gebildet ist, haben die Stäbe hier verschiedene Querschnittprofile, die Endigun-

ser und Kupferstecher F. L. Schmittner, in den Mitteilungen des $K$. $K$. österreich. Museums für Kunst und Industrie 1886/7, S. $489 \mathrm{ff}$.

2) Vgl. Ilg und Kabdebo, Wiener Schmiedewerk des 17. und 18. Jahrhunderts. Dresden 1883. 
gen sind gewöhnlich zu starken Schnecken aufgerollt. Auch sonst zeichnen sich die deutschen Arbeiten durch mannigfaltige plastische Bildung aus.

$\mathrm{Zu}$ den Hauptwerken der Wiener Schlosserkunst gehören die Schmiedearbeiten, welche das Lustschloss Belvedere schmücken, das für den Prinzen Eugen von Savoyen durch den Hofarchitekten Joh. Lukas von Hildebrand (geb. zu Genua 1668, gest. in Wien 1745) in den Jahren 1693-1724 erbaut wurde. Der Garten hat neun prachtvolle Gitterthore, von denen drei zu den Strassen führen, welche das Gebäude umgeben, sechs aber einzelne Teile des Gartens im Innern von einander trennen. Die urwüchsige derbe Kraft, welche die deutschen Arbeiten vor den französischen auszeichnet, offenbart 'sich besonders in den Streben eines der Gartenthore. Sie endigen in einen massiv geschmiedeten Löwenkopf, bei den beschränkten technischen Hilfsmitteln der damaligen Zeit eine ganz gewaltige Leistung. (Abb. 68).

Sehr verwandt mit den Gitterthoren des Belvedere sind die Schmiedewerke, die für ein anderes Lustschloss des Prinzen Eugen von Savoyen hergestellt wurden, nämlich für das SchlossSchlosshof an der March, das ebenfalls von Hildebrand um 1728 erbaut wurde. Der Haupteingang ist von drei schmiedeeisernen Portalen abgeschlossen, einem mittleren grösseren und zwei seitlichen kleineren, welche ähnlich wie beim Belvedere von mächtigen steinernen, mit reichem figür- lichem Schmuck versehenen Pfeilern flankiert werden. Schon diese schwere architektonische Einrahmung musste zu kräftigen mannigfaltigen Formen führen. Auch hier sind die Portale von mächtigen eisernen Streben gestützt. Das Schloss ist nicht als besonderer Teil aufgesetzt, sondern ebenso wie bei den Portalen des Belvedere (Abb. 69) als ein der Komposition des Ganzen sich unterordnender Schmuckteil behandelt und in centraler Anordnung um den Mittelpilaster, der die Fuge zwischen den beiden Thorflügeln verdeckt, angebracht. Die Zusammenfassung je zweier Stäbe des Gitterwerks durch horizontale breite Bunde ist französischen Vorbildern entlehnt. Besonders gefällig wirkt der geschweifte obere

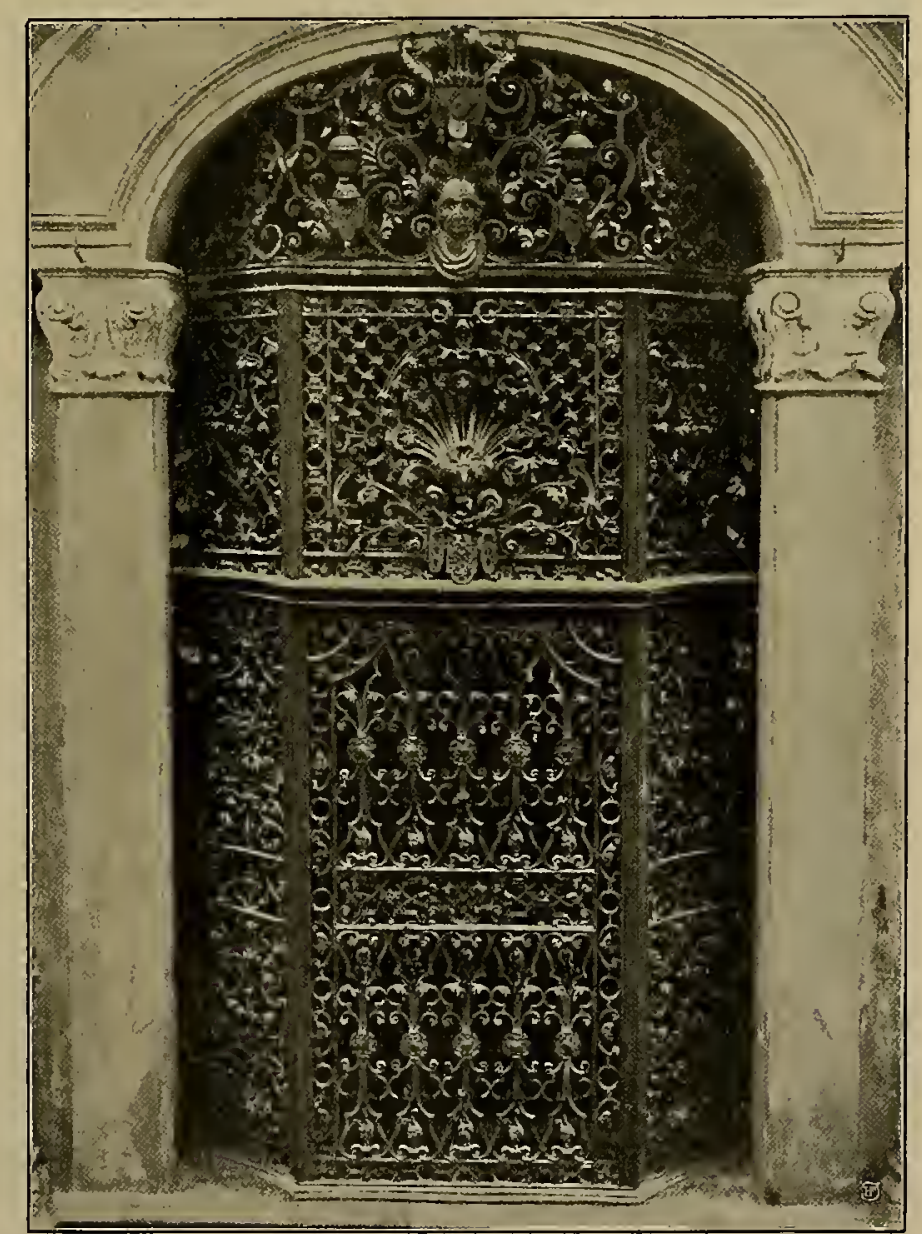

Abb. 74. Gitter der Johanniskapelle in Wien. 


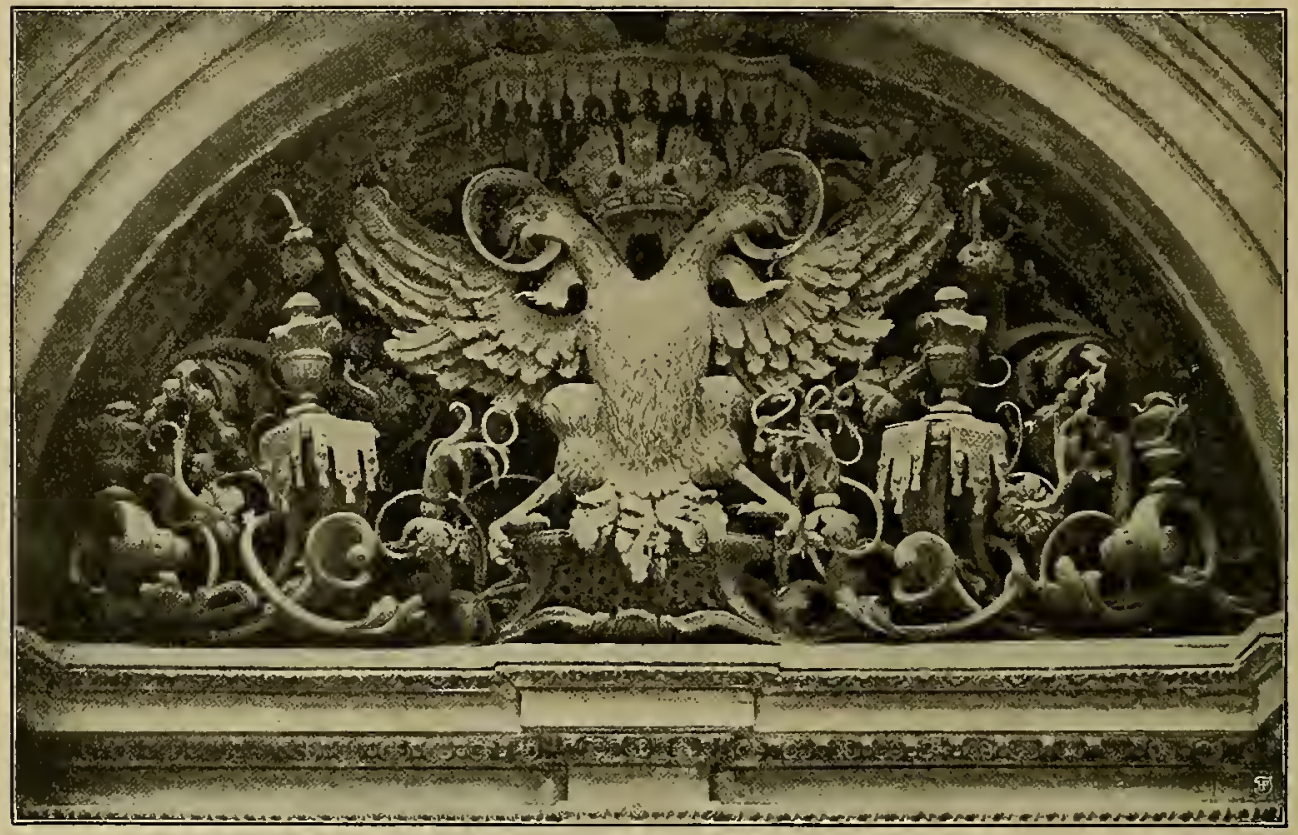

Abb. 75. Oberlichtgitter am Ministerium des Innern in Wien.

Abschluss der Thorflügel, der zu der stattlichen Bekrönung hinüberleitet. Die Mitte dieses Aufsatzes nimmt ein aus den Buchstaben $\mathrm{E}$ und $\mathrm{S}$ gebildetes Monogramm ein, von dem Herzogshut überdacht. Die Endigungen der Buchstaben rollen sich zu starken, schōn geformten Schnecken auf. (Abbild. 71). Man wird wohl nicht fehl gehen, wenn man Hildebrand selbst als den geistigen Urheber dieser grossartigen Gitterwerke, sowohl des Belvedere als von Schlosshof, bezeichnet. Wissen wir doch aus der Baugeschichte der Würzburger Residenz, dass er für das grosse Gitter des Ehrenhofes dieses Schlosses einen Entwurf angefertigt hat. Ein Schlosser aus Hollitsch soll die Schmiedearbeiten von Schlosshof verfertigt haben (Abbild. 73).

Auch der Schönbrunner Park, das Salesianerinnenkloster, die Stephanskirche in Wien haben schöne Gitter dieser Art. Wohl die schmuckvollsten unter allen befinden sich in der Johanneskapelle an der Donau. Das Kirchlein war von einem Wiener Bürger, namens Kirchlehner, 1744 dem Johannes von Nepo. muk gestiftet worden zum Gedächtnis an das gewaltige Hochwasser, welches im Frühjahre dieses Jahres die an der Donau gelegenen Stadtteile bedroht hatte. Die vier Gitter, welche das Portal und die Fenster zieren, sind jedoch älter; das eine von ihnen trägt das Datum 1738. Auch der auf demselben angebrachte Doppeladler mit dem Hauptländerwappen des kaiserlichen Hauses scheint auf eine ursprünglich andere Verwendung der Gitter hinzudeuten. Die Abbildung 74 stellt die obere Hälfte eines der Gitter dar.

In den Strassen der Stadt selbst, welche damals mit zahlreichen stattlichen Palästen und öffentlichen Gebäuden geschmückt wurden, konnte natürlich das Eisen nur bescheidenere Anwendung finden, als in den freigelegenen Lustschlössern mit ihren weiträumigen Gärten. Man beschränkte sich im grossen und ganzen auf Balkone und Oberlichtgitter. Diese Beschränkung führte aber dazu, dass man, besonders bei den Oberlichtgittern, auf diese naturgemäss wenig umfangreichen Arbeiten allen Schmuck konzentrierte, den man 
bei den grösseren Gitterwerken auf eine ausgedehntere Fläche verteilte. Dazu kam noch, dass die Oberlichtgitter einer kräftig ausladenden Bildung des Eisenwerkes schon deshalb bedurften, um sich gegen den umschliessenden, stark profilierten Steinrahmen zu behaupten und aus dem dunklen Hintergrunde herauszulösen. Man blieb bei der Konstruktion des Gitterwerkes also nicht in der Fläche, sondern liess einzelne Teile aus derselben herausspringen, sodass eine energische plastische Wirkung mit Licht und Schatten erzielt wurde. Eines der glänzendsten Beispiele derartiger Oberlichte befindet sich am Eingange des Ministeriums des Innern in der Wipplingerstrasse, des Gebäudes der ehemaligen böhmischen und österreichischen Hofkanzlei, welches von Fischer von Erlach errichtet wurde. (Abbild. 75). Der Doppeladler und die
Vasen sind in voller körperlicher Rundung aus Eisenblech getrieben, das Laubwerk und die reich ausgebildeten Voluten der Stäbe sind aus dem Vollen geschmiedet. Während bei den bisher vorgeführten Gittern, wie z. B. den Versaillern (vgl. Abb. 28), die Sockel mit Behängen stets in der Fläche dargestellt wurden, treten sie hier völlig plastisch heraus und dienen wie wirkliche Konsolen als Träger der Vasen, die auf ihnen stehen. Wegen ihrer kunstvollen Arbeit sind auch die Brüstungsgitter im Portikus des Schwarzenbergischen Sommerpalais besonders hervorzuheben. Den Entwurf dazu schreibt man Daniel Gran zu, der die malerische Ausstattung des Palastes ausführte.

Auch für Beschläge und Geräte im Laub und Bandelwerkstil lassen sich die besten Arbeiten auf dem Gebiete der österreichischen Monarchie nachweisen.

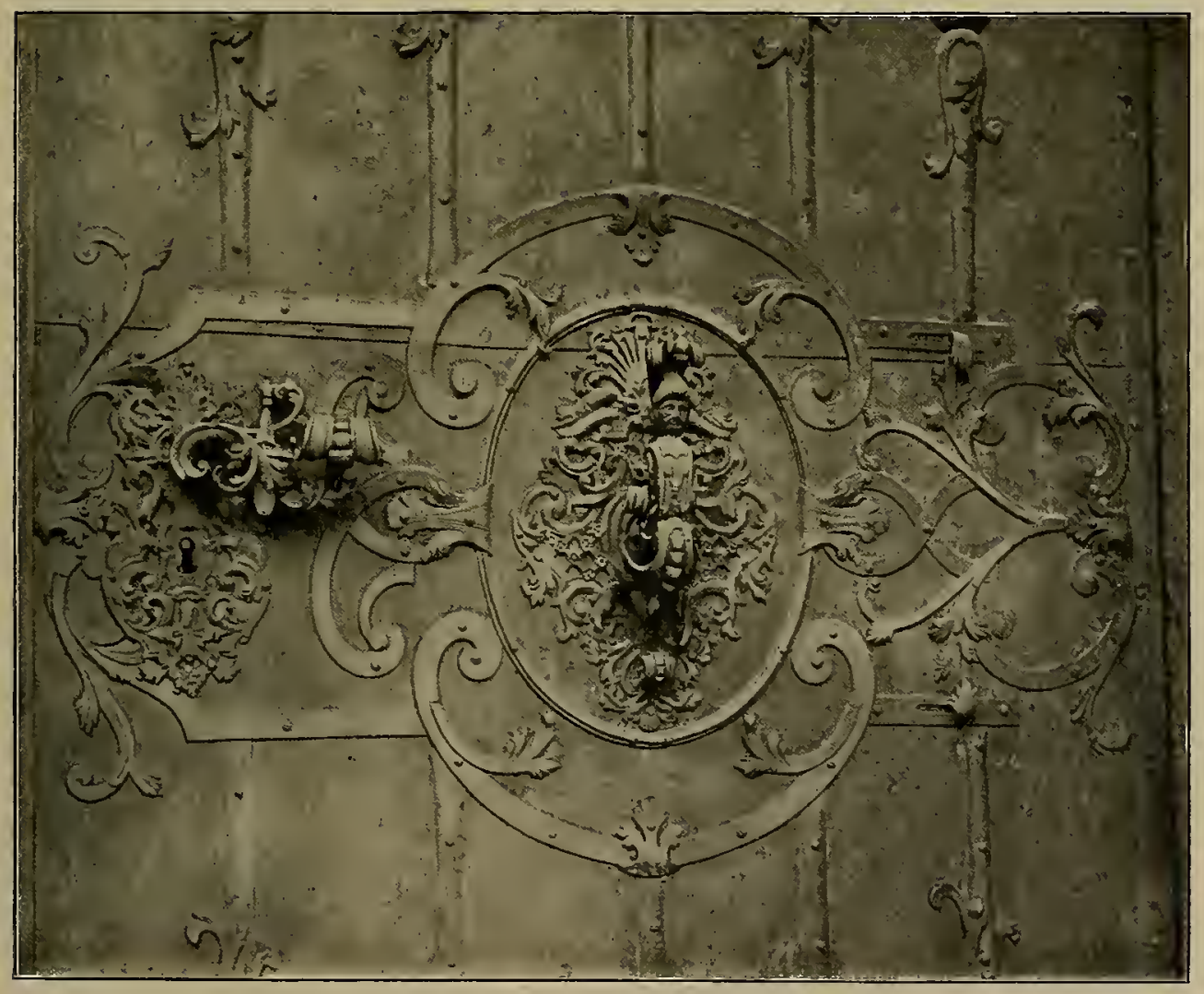

Abb. 76. Thürbeschlag an der Nikolaikirche zu Prag. 


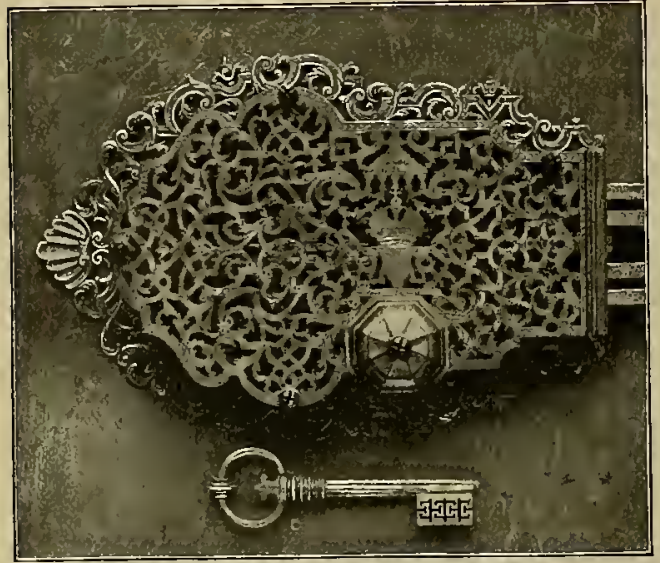

Abb. 77. Schloss im Kunstgewerbemuseum zu Berlin.

In Prag findet man mehrere sehr gute Beispiele eisenbeschlagener Thüren, welche sich in ihrer Gestalt von den Gitterthoren nur dadurch unterscheiden, dass das Stabwerk auf einem Grunde von Eisenblech befestigt ist. Bei der Thür der Thomaskirche ist die Form des perspektivischen Gitters gewählt worden. Als aussergewöhnlich schöne Arbeiten stellen sich das Schloss und der Klopfer der dortigen Nikolaikirche dar (Abbild.76). Schlüsselschild und Anschlagplatte bestehen aus durchbrochenem getriebenen Eisenblech, Drücker und Klopfer sind aus massiven Eisenstïcken geschmiedet und geschnitten. Besonders gefällig ist die Thürklinke gestaltet. Der schöngeschwungene, mit Laubwerk verzierte Stab versinnlicht in seiner Bewegung das Auf- und Abwärtsgehen des Drückers. Als Auflage für die Hand dient eine kräftig ausgebildete Volute. Schloss und Klopfer sind geradezu musterhafte Beispiele der Uebertragung des Laub- und Bandelwerks auf die Kleinarbeit.

Wahrscheinlich österreichischer Herkunft ist auch ein sehr kunstvoll gearbeitetes Kastenschloss im Kunstgewerbemuseum zu Berlin (lnv. Nr. 68, 492 ab). Die durchbrochene und gravierte Schlossdecke aus Messing stellt oberhalb der Messingkappe des Schlüsselgehäuses die Kaiserkrone auf einem Sockel mit Behang unter einem Baldachine dar. Durch die Oeffnung der Decke sieht man den künstlichen Mechanismus des mit vier Riegeln und einer schiessenden Falle versehenen Schlosses. Einzelne Teile des Mechanismus sind durch Gravierungen verziert. Der Umschweif (die Seitenwände) zeigt auf gepunztem Grunde fein graviertes Ornament. Das Schlossblech ist von einer durchbrochenen Borte aus Laub- und Bandelwerk in geschnittener Arbeit umgeben. (Abbild. 77).

Seltener sind Geräte, doch finden sich auch dafür einige gute Beispiele. Einen schmiedeeisernen Kandelaber im Stile der genannten Arbeiten, der sich in dem Schlosse Eisgrub befindet, stellt die $\mathrm{Ab}$ bildung 78 dar. Während hier der Schaft eine gelungene Auflösung des massiven Stammes des Holz - oder Bronze-Kandelabers in die durchbrochenen, aus Stabwerk gebildeten Formen des Schmiedeeisens zeigt, ist der schmiedeeiserne Kronleuchter des Landes-Museums in Graz eine geschickte Uebersetzung der sogenannten holländischen Messingkrone in die Sprache des Schmiedeeisens. Die grosse Messingkugel am unteren Ende des Schaftes ist hier durch grosse Akanthus.

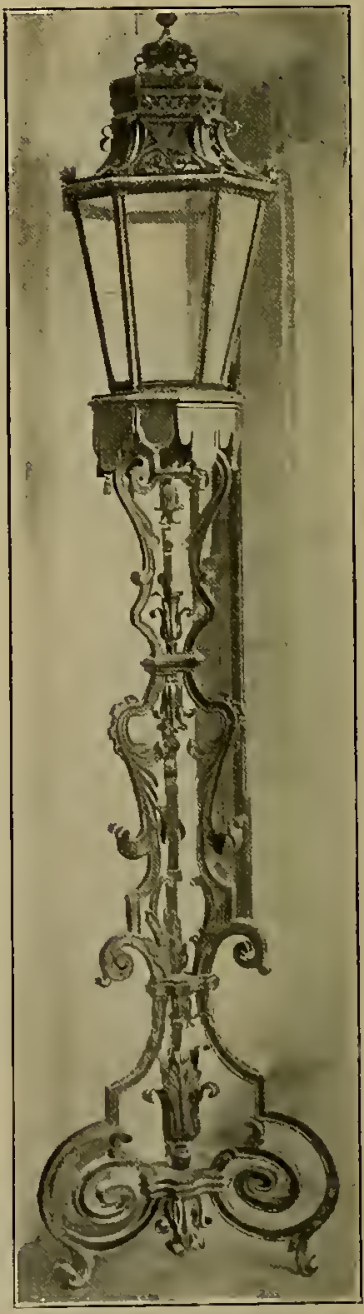

Abb. 78. Kandelaber im Schlosse Eisgrub. 


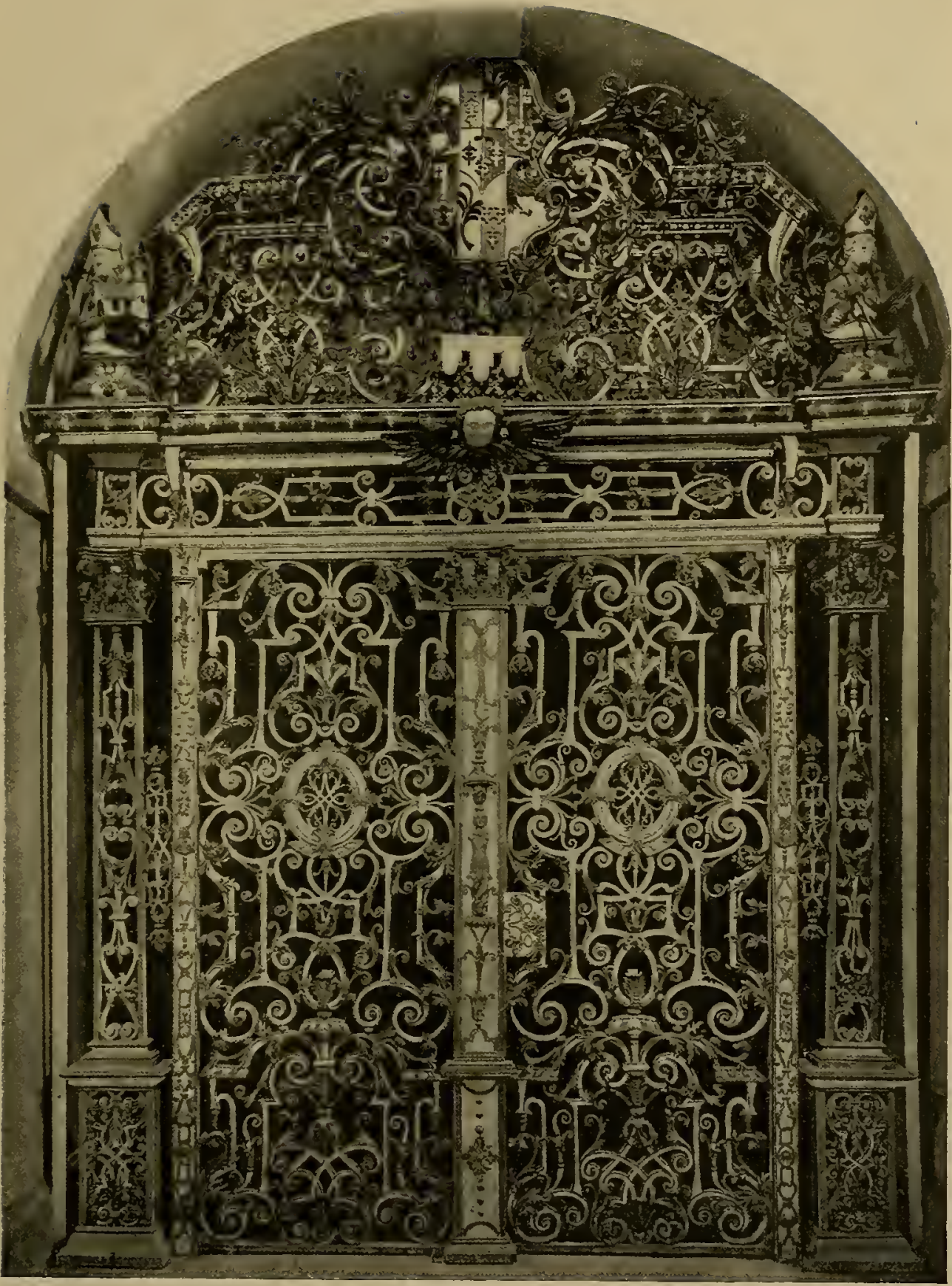

Abb. 79. Portal in der St. Emmeranskirche zu Regensburg. 
84 Brüning, Schmiedekunst: V. Das Laub-und Bandelwerk in der deutschen Schmiedekunst.

blätter dargestellt. Auch am oberen ihre Verbreitung durch das ganze deutsche Teil des Schaftes sind an die Stelle der Sprachgebiet. So befinden sich, um nur geschlossenen Knäufe und Kugeln durch- einige Beispiele anzuführen, Schmiedebrochene Formen getreten. (Abbild. 80).

Die österreichischen Länder sind zur Erkenntnis der Ausbildung des Laub- und Bandelwerks in der Schmiedekunst nur deshalb vor dem übrigen Deutschland bevorzugt worden, weil sich in ihnen dieser Eisenstil am glänzendsten entwickelte. $\mathrm{Er}$ hielt sich in Wien und Umgegend sogar bis in die zweite Hälfte des 18. Jahrhunderts hinein. $\mathrm{Im}$ übrigen fanden die Laub- und Bandelwerkformen werke dieser Art in Zürich (Abb. 65), in der St. Emmeranskirche zu Regensburg (Abb. 79); stattliche Thore besitzt der Römer zu Frankfurt a. M., ein Gitter mit reichem Aufsatz von 1725 schirmt das Grabmal des Ministers von Kraut in der Nikolaikirche zu Berlin. Um 1741 sind die Gitter entstanden, welche den Moltkestuhl in der Nikolaikirche zu Rostock schmücken, und auch der Dom zu Riga hat Schmiedearbeiten dieses Stiles aufzuweisen.

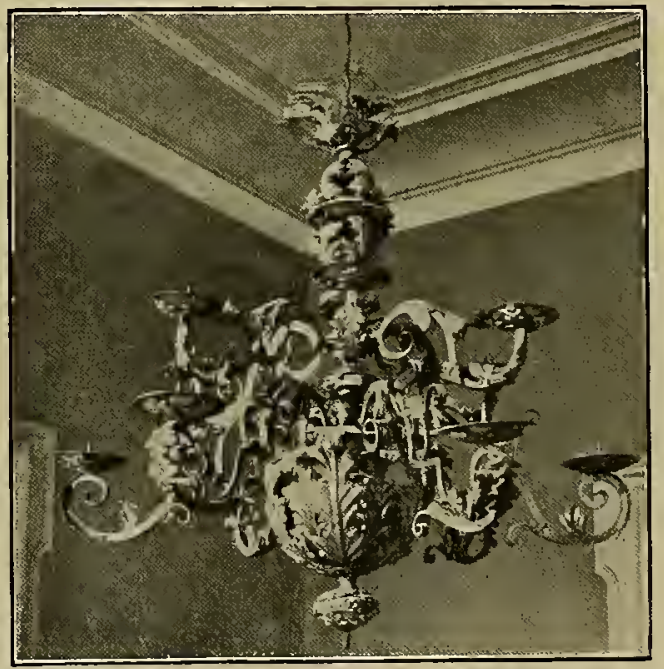

Abb. 80. Kronleuchter im Landesmuseum zu Graz. 


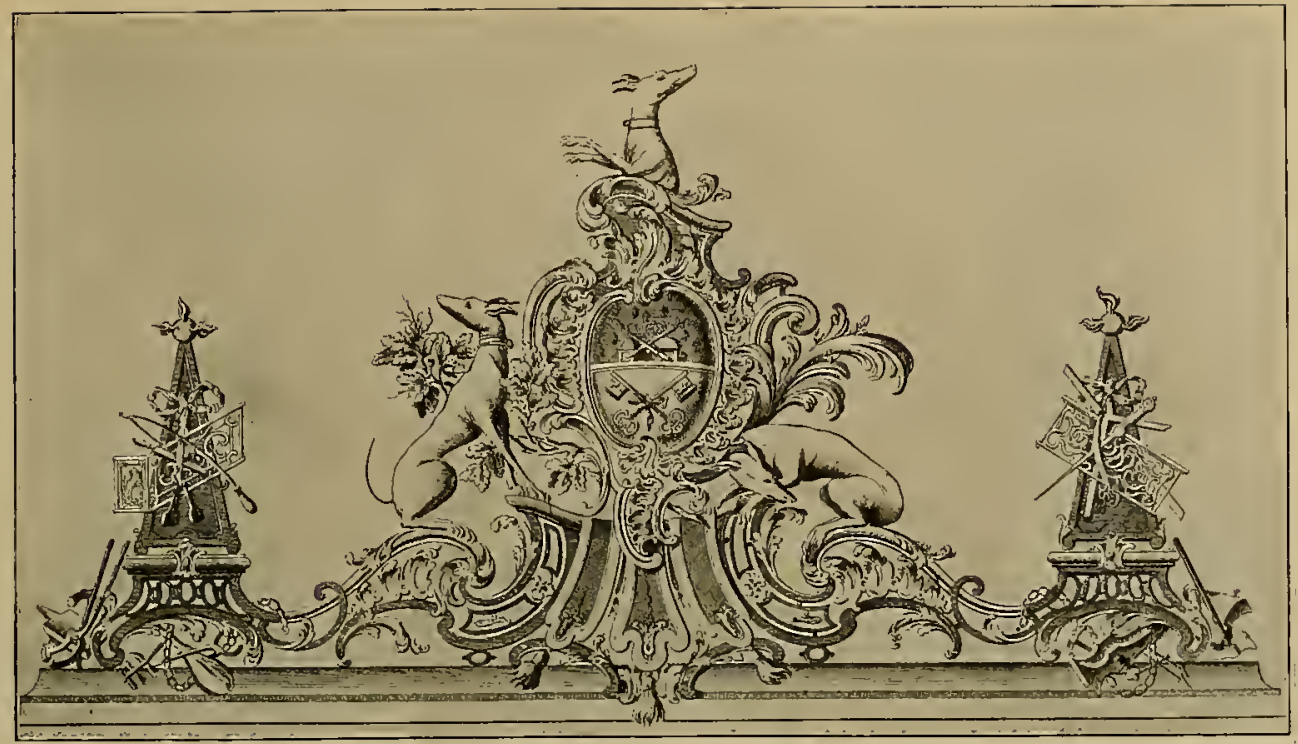

Abb. 81. Bekrönung (Lamour, Recueil des ouvr. en serrurerie).

\section{Die Schmiedekunst in Frankreich unter Ludwig XV. und Ludwig XVI.}

Die allmähliche Abwandlung der in gebrochenen Linien sich bewegenden, etwas strengen und schweren Formen des Schmiedeeisens der Zeit Ludwigs XIV. zu den gefälligen und geschmeidigen Linienzügen des Rokoko liess sich schon in den Arbeiten von Robert de Cotte und den Entwürfen Louis Fordrins verfolgen. Einen weiteren Schritt vorwärts bedeuten die in der Distribution des maisons de plaisance von Jacques François Blondel 1738 erschienenen Gitterentwürfe. (Abbild. 82). Das Stabwerk derselben zeichnet sich durch reizvolle Motive in weich gezogenen, geschweiften Linien aus; das massvoll beigefügte Laubwerk erinnert in seiner Bildung noch stark an den Akanthus des Louis XIV., ist aber dünner und zierlicher und von unbestimmter Zeichnung. Abgesehen von einigen schüchternen Andeutungen fehlt das eigentliche Ornament des Rokoko-Muschelwerks noch ganz, während es in den Wanddekorationen $\mathrm{u}$. a. desselben Werkes schon häufiger auftritt, ein weiterer Beleg für die in der Geschichte der Schmiedekunst so häufig auftretende Erscheinung, dass die Ornamentik des Schmiedeeisens immer erst langsam den allgemeinen Fortschritten der Kunst folgt. Blondel giebt auch einige Bemerkungen über die Anwendung des Schmiedeeisens. So empfiehlt er bei den das Stabgerüst des Gitters schmückenden Ornamenten Bronze oder Blei statt des Schmiedeeisens, weil die geschmiedeten Zierrate leicht die Kleider beschädigten. Für das Abschlussgitter des Vorhofes eines Schlosses schlägt er grün angestrichene Eisenstäbe mit Bronzeornamenten vor.

Aehnlich leicht und gefällig, ohne besonders reichen Ornamentschmuck, sind die Zeichnungen für Balkone u. dgl. von Babin. Die früheren Entwürfe dieses Stechers zeigen ebenso wie die Blondelschen Stiche ein ziemlich schlichtes Stabgerüst mit wenig akanthusartigem Blattwerk; auch jene schon von Tijou und Fordrin angewandten lanzettförmigen Blätter mit gewellten Kanten kommen vor. 
Seine späteren Arbeiten haben schon etwas Muschelwerk. Babin gab seine Vorlagen in sieben Heften zu je 10 Blatt heraus. Das sechste enthält Umrisszeichnungen von wappenhaltenden Figuren, wilden Männern und Tieren aller Art, die

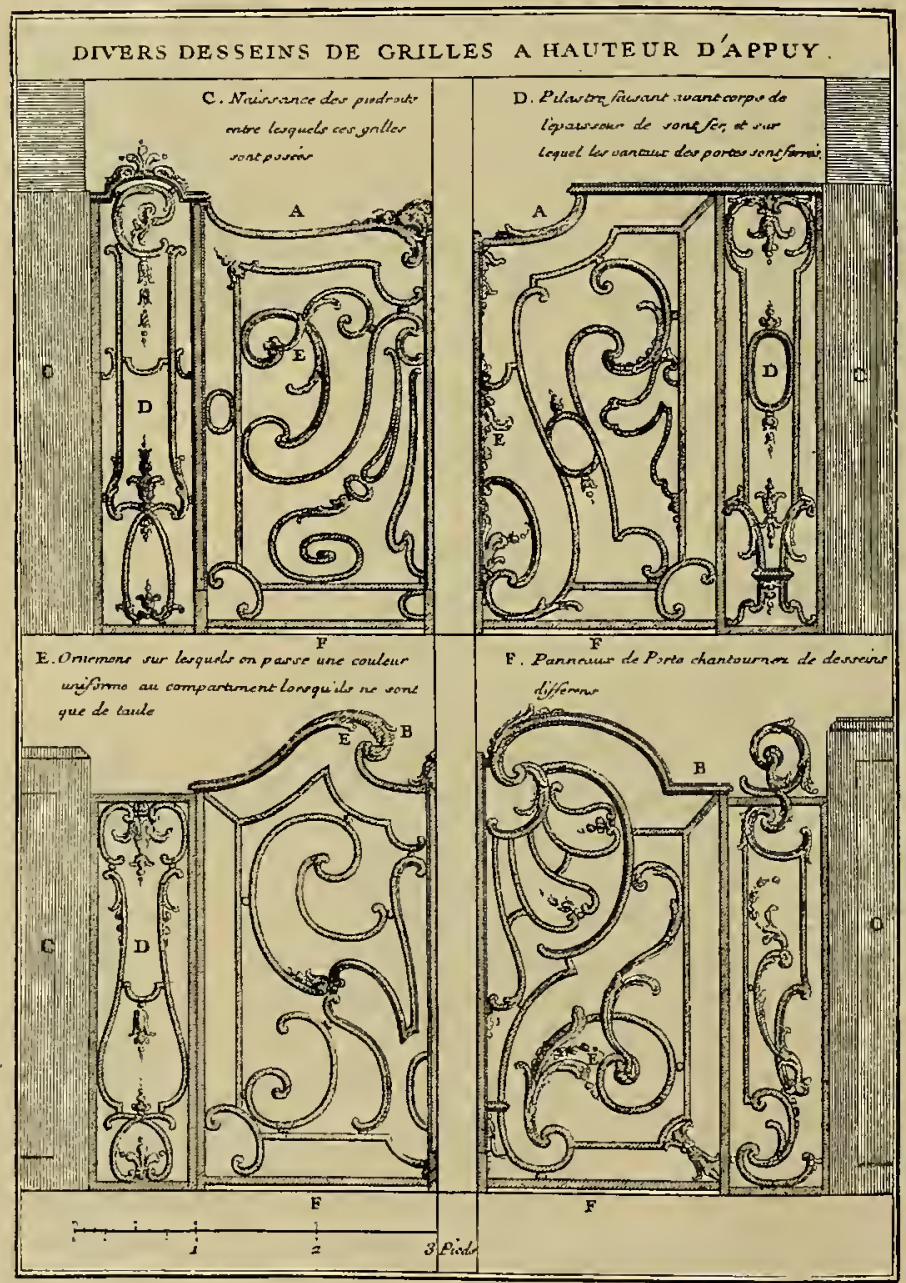

Abb. 82. Gitter (J. F. Blondel, Distribution des maisons de; plaisance II, pl. 55).

zumeist als Schmuck von Portalbekrönungen dienen. Bei ihrer häufigen Anwendung entsprachen solche Vorlagen durchaus den Bedürfnissen des Schlossers.

Das bedeutendste Schlosserbuch des Rokoko, das etwa um 1740 erschienen sein dürfte, ist das des Gabriel Huquier (1695-1772); es enthält 60 Tafeln, die in 10 Heften $\mathrm{zu}$ je 6 Blatt gegliedert sind. $\left.{ }^{1}\right)$ Die Entwürfe sind ausserordentlich flott und sicher gezeichnet und offenbaren grosse Erfindungskraft und reiche künstlerische Phantasie. Auch Huquier verwendet als Ornament noch den dünnen Akanthus wie Blondel, aber bei ihm wächst er zum Teil zu langen palmenartigen Schösslingen aus, die das schön geschwungene Stabwerk begleiten. Daneben kommen auch natürliche Blumen in sparsamer Verwendung vor. Vom Muschelwerk macht er in seinen Entwürfen für Schmiedeeisen auch noch wenig Gebrauch. Dagegen zeigen seine Schlüsselschilder $u$. dgl., die für Bronzeguss bestimmt sind, schon das ausgereifte Muschelwerk Meissonniers. Sehr lehrreich für die Kenntnis des Arbeitsfeldes der damaligen Schlosserkunst ist die Auswahl der Gegenstände. Neben Gittern aller Art, unter denen die grossen Gitter für Vorhöfe, Gärten und Kirchen von besonders graziöser Zeichnung und mannigfaltiger Erfindung sind (Abbild. 84), und Schlosszubehörsind auch verschiedene Geräte für kirchlichen Gebrauch, Beleuchtungskörper, Tische u.s. w. dargestellt. (Abbild.83.) Die letzte Tafel enthält eine Anweisung, wie man eine rechteckige Füllung vermittels eines Liniennetzes in eine schräg ansteigende (für Treppengeländer) ver-

1) Neudruck der Hälfte des Schlosserbuchs von Huquier: Entwürfe für Schmiedeeisen in Stil des Rokoko nach G. Huquier. 30 Lichtdrucke. Paul Schahl. Berlin 1889. 


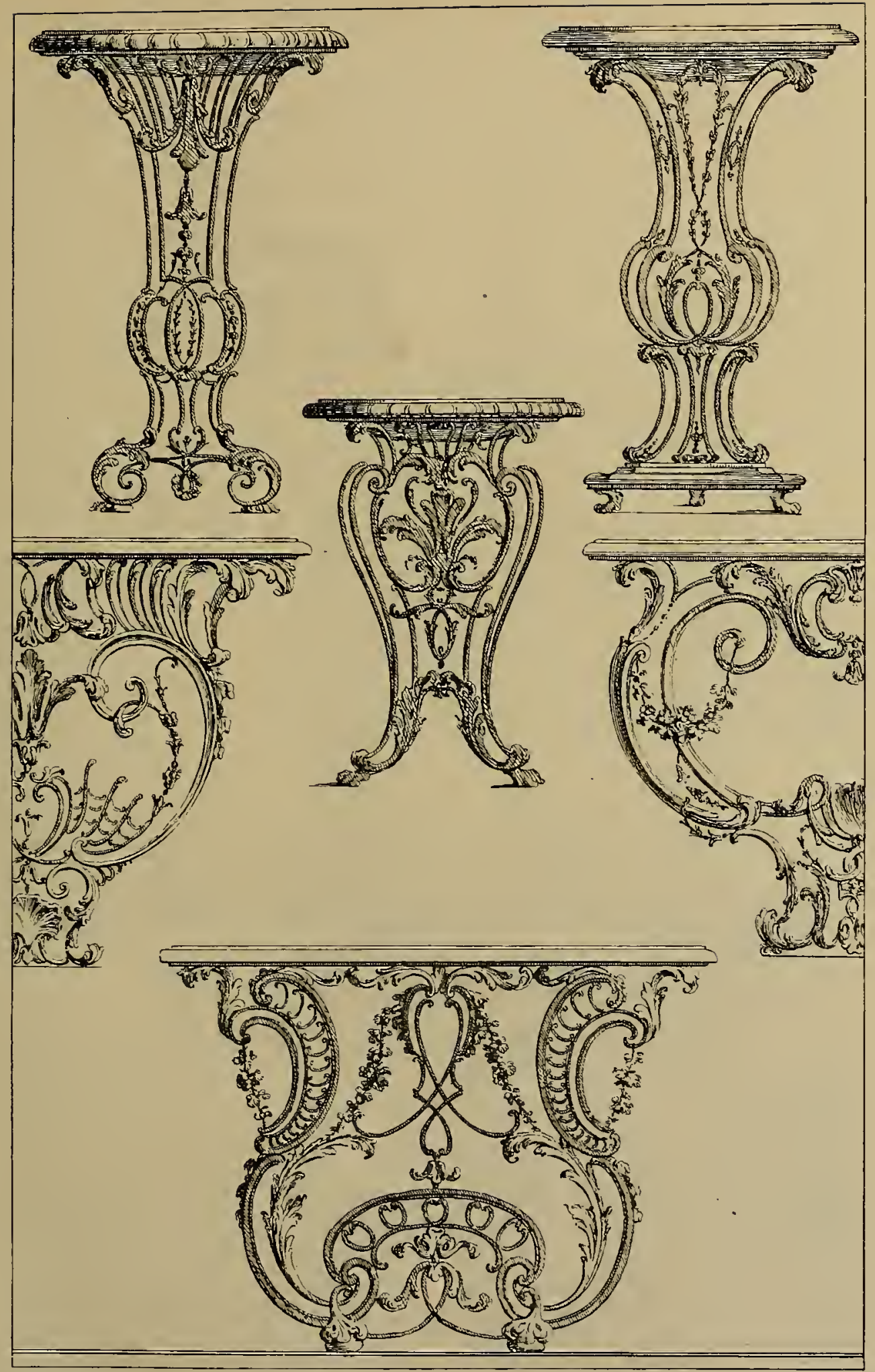

Abb. 83. Kohlenbeckenträger und Tische aus dem Schlosserbuche von G. Huquier. 


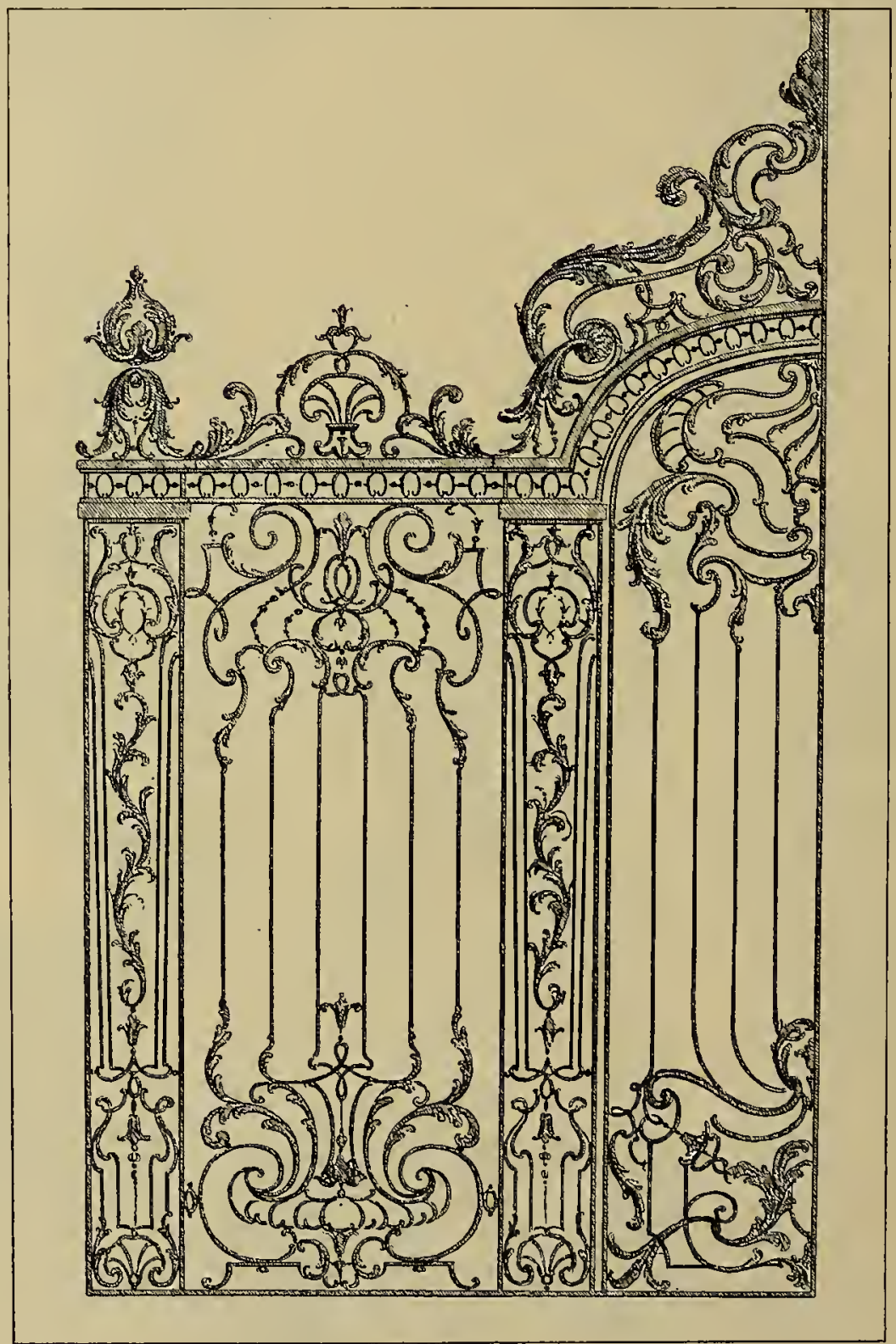

Abb. 84. Kirchengitter aus dem Schlosserbuche von G. Huquier.

wandeln kann. Huquier hat sich auf jedem Stich als der Erfinder der dargestellten Gegenstände bezeichnet. $\mathrm{Zu}$ einem Zweifel an der Wahrheit dieser Behauptung könnte man durch einige Tafeln des „Livre Nouveau d'Architecture par Mr. B . . . Architecte du Roy 1767" veranlasst werden, die Entwürfe aus dem
Schlosserbuche des Huquier enthalten, aber die Bezeichnung tragen: Oppenord inv. und Messonier inv. Da indessen auf denselben Tafeln auch mehrere stilistisch mit beiden Meistern unverträgliche $\mathrm{Ar}$ beiten aus dem noch zu nennenden Schlosserbuche von Fontaine dargestellt sind, so verlieren jene Bezeichnungen 
völlig ihren Wert. Allerdings verraten ja viele der in Huquiers Werk dargestellten Gegenstände grosse Verwandtschaft mit Oppenord sowohl wie Meissonnier. Aber diese erklärt sich leicht daraus, dass Huquier beinahe das ganze Werk Oppenords und Meissonniers, wie auch das von Gillot, Watteau und anderen gestochen hat. Die in dem Werk von Oppenord selbst enthaltenen Gitterentwürfe zeigen, wie.z. B. das Chorportal der Kathedrale zu Meaux, ganz andere, zum Teil noch ältere Formen, als die Arbeiten Huquiers. Es ist also an der Urheberschaft Huquiers wohl nicht zu zweifeln.

Ein reiferes, üppiges

Rokoko in stark beweg. ter Zeichnung mit aus. gebildetem Muschelwerk und reicher Verwendung figürlicher Zuthaten bietet das Schlosserbuch des erwähnten J.V. Fontaine, der sich „Königlichen Schlosserin derGobelinmanufaktur" nennt. Es enthält Wandarme, einen Lampenträger, einen Osterkerzenleuchter (Abbild. 86), ein Lesepult, ein Taufbecken und Aushängeschilder eines Uhrmachers. In einer anderen Ornamentstichfolge giebt er Bekrönungen für Schlossund Kirchengitter, in einer dritten Ornamente in natürlichem Massstabe zum Gebrauch für die Schlosser. Von dem Buche des Schlossers C. Michel, das 1750 erschien, liegt nur noch das Titelblatt mit zwei Wandarmen und zwei Konsoltischen vor, die gerade keine besonders hohe Vorstellung von dem Können ihres Schöpfers geben.
Durch grosszügige Motive mit kräftig betontem Stabwerk, das durch BlumenGuirlanden, Vasen und sonstige Attribute bereichert ist, zeichnen sich die zahlreichen Gitterentwürfe im Traité du beau essentiel dans les arts appliqués von C. E. Briseux aus dem Jahre 1752 und der L'art du bâtir des Maisons de campagne desselben Verfassers von 1761 aus. Ein Teil der in dem letzteren Werk enthaltenen Stiche mit Schmiedewerken trägt die Bezeichnung Bri (seux) inv. Bab(el) sc. Sämtliche Entwürfe zeigen grosse Verwandtschaft mit einer grösseren Anzahl von Stichen mit Gittern, die Babel selbst als seine

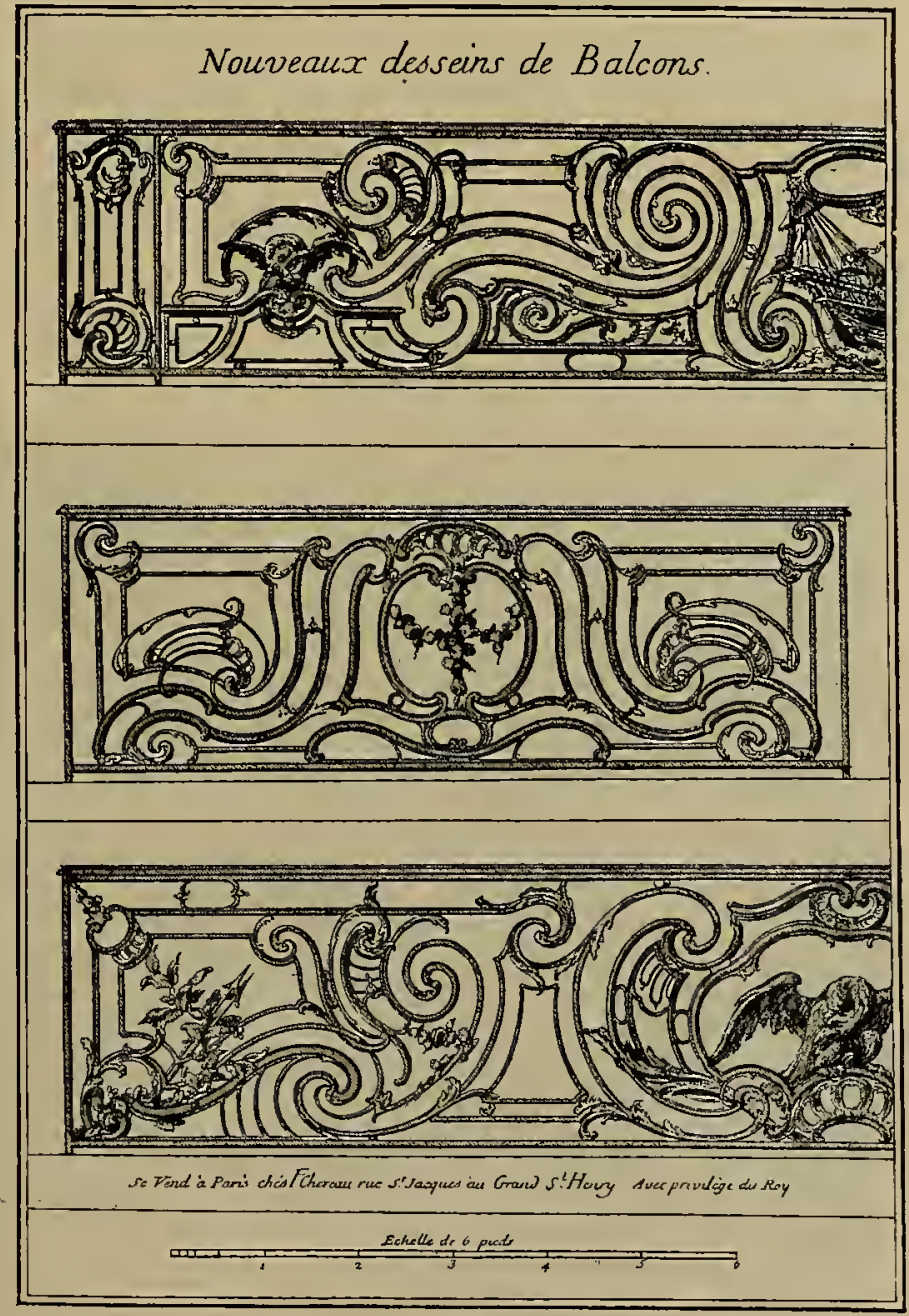

Abb. 85. Balkone, Stich von Babel. 


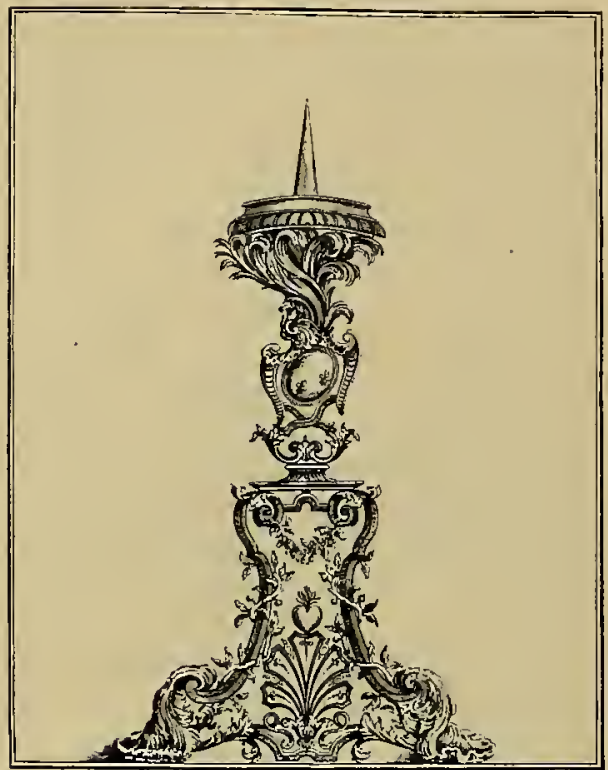

Abb. 86. Osterkerzenleuchter nach einem Stiche von J. V. Fontaine.

eigenen Erfindungen herausgab. ( $\mathrm{Ab}$ bild. 85). Es liegt also hier wohl ein ähnliches Verhältnis vor, wie zwischen
Oppenord und Huquier. Der Stecher Babel hat sich so in die Formenwelt des Briseux eingelebt, dass sie $z u$ seiner eigenen geworden ist. Einer der spätesten Stecher für Schmiedeeisen in Rokokoformen endlich ist Moreau, der unter anderen 1762 eine Sammlung von Entwürfen für Balkone und Treppengeländer veröffentlichte. Die Zeichnung seines Gitterwerkes ist unklar und wenig bedeutend.

Der höchste Triumph, den die Schlosserkunst unter Ludwig XV. feierte, knüpft sich an den Namen Jean Lamours, des Hofschlossers des Königs Stanislaus Leszczynski in Nancy, dessen Werk sich noch zum grössten Teil - ein seltenes Glück - fast unversehrt erhalten hat. Lamours Vater war Stadtschlosser in Nancy. Indessen sein Sohn (geb. 1698) begnügte sich nicht mit dem väterlichen Unterricht; schon als Vierzehnjährigen treffen wir ihn in Metz. Dann unternahm er zwei Reisen nach Paris, um sich in der Schlosserkunst und im Zeichnen weiter

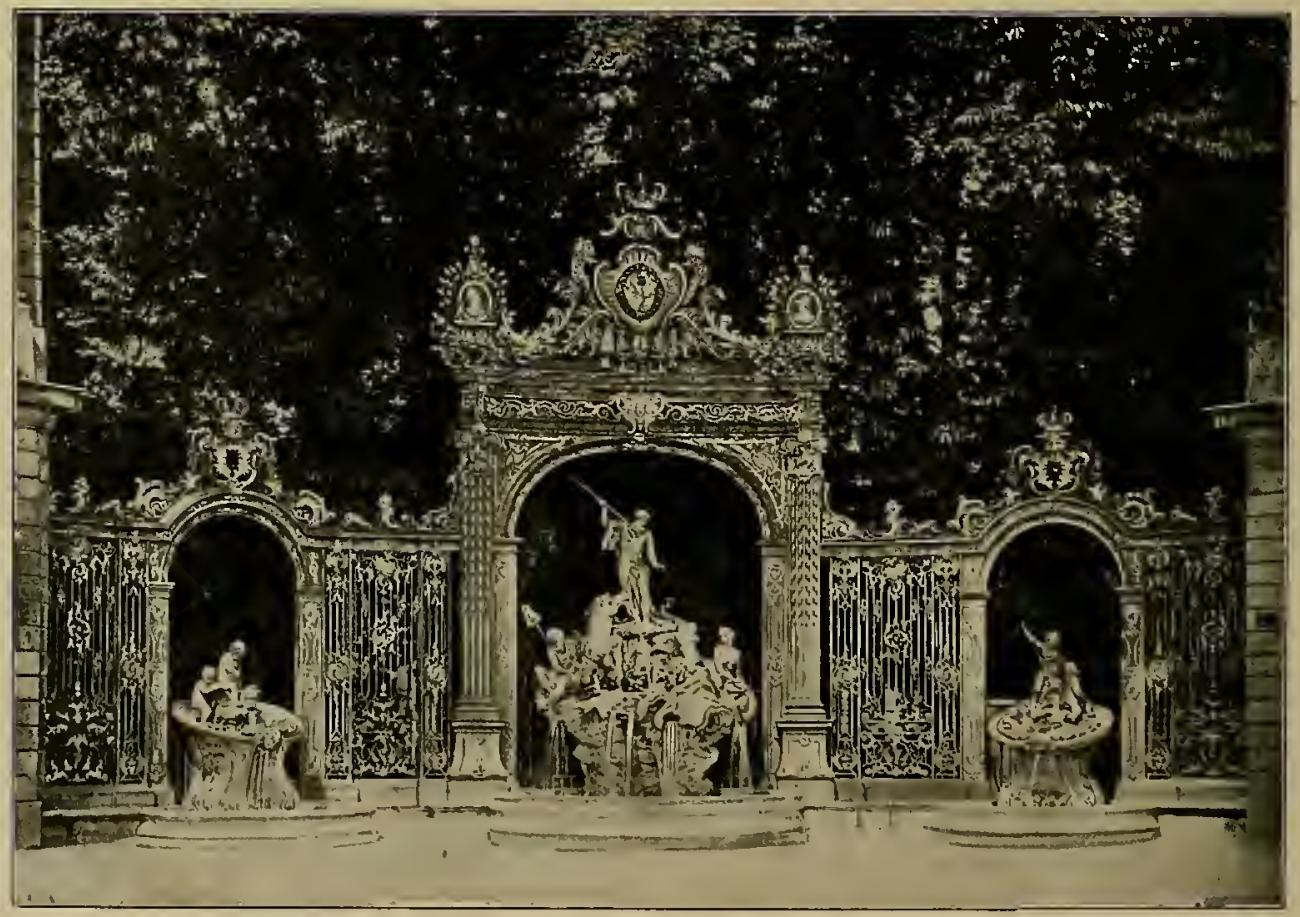

Abb. 87. Abschlussgitter des Place Stanislas in Nancy. 


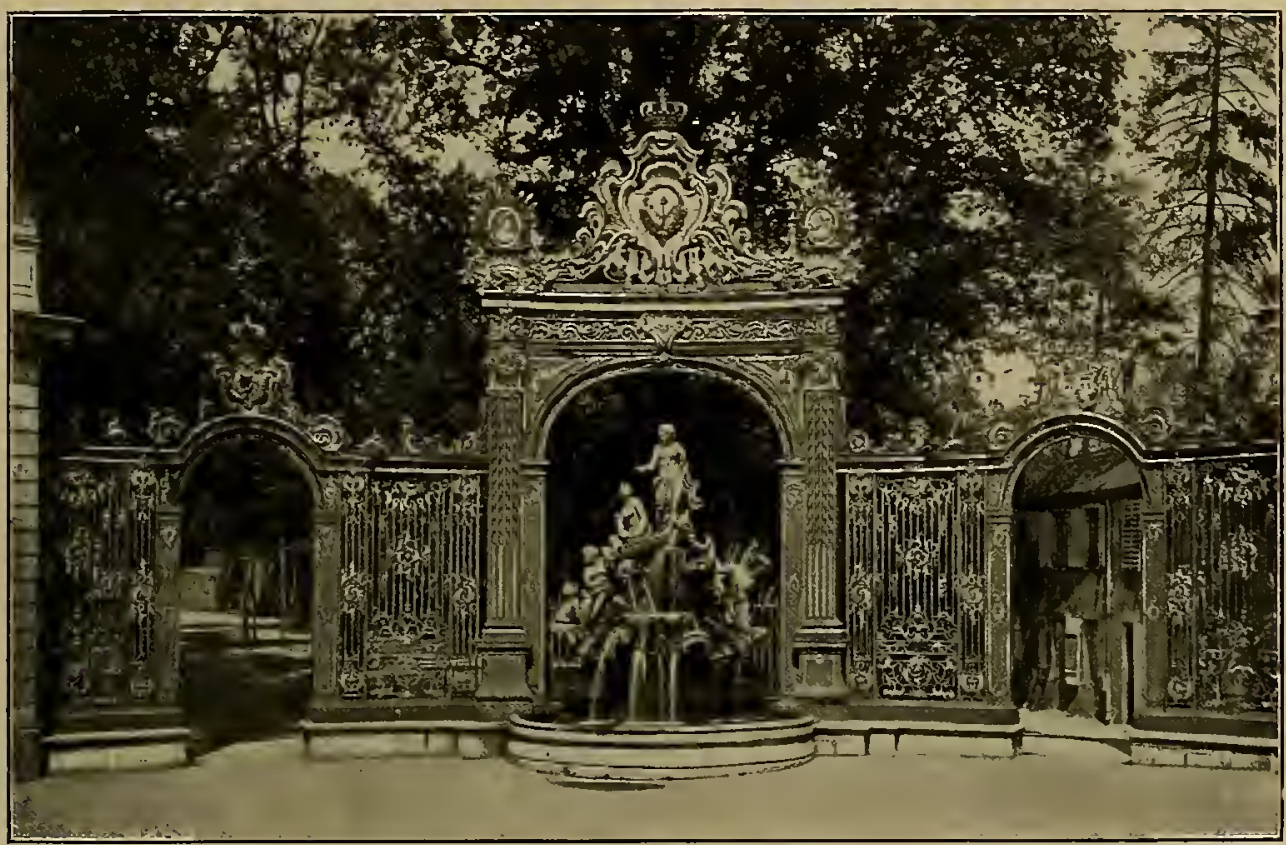

Abb. 88. Abschlussgitter des Place Stanislas zu Nancy.

auszubilden. Nach dem Tode des Vaters übernimmt Jean 1720 die Stelle des Stadtschlossers in Nancy. Unter anderem musste er auch die Verpflichtung eingehen, für die Instandhaltung der öffentlichen Laternen und der Glocken der Pfarrkirchen zu sorgen. An grösseren Schmiedearbeiten finden wir zuerst ein Gitter mit dem Stadtwappen in der Kirche Saint Epure erwähnt, für welches er 1728 eine Zahlung von 1150 Livres erhielt. Zwei Jahre später ist er mit den Vorbereitungen zu einem grossen Feuerwerk beschäftigt, welches beim Einzug des Herzogs Franz III. in Nancy abgebrannt werden sollte. ${ }^{1}$ )

$\mathrm{Zu}$ einer vollen Entfaltung seiner Talente gelangte er aber erst, als im Jahre 1737 auf Grund des Wiener Friedens Lothringen als selbständiges Herzogtum dem ehemaligen Polenkönig Stanislaus Leszczynski anheimfiel, nachdem dieser Fürst im polnischen Erbfolgekrieg zum zweiten Male seinen Thron verloren hatte. Seinen

1) Vgl. Cournault, C., Jean Lamour (Les artistes célèbres). Librairie d'art. Paris, D. Rouam. London, Gilbert Wood \& Co.

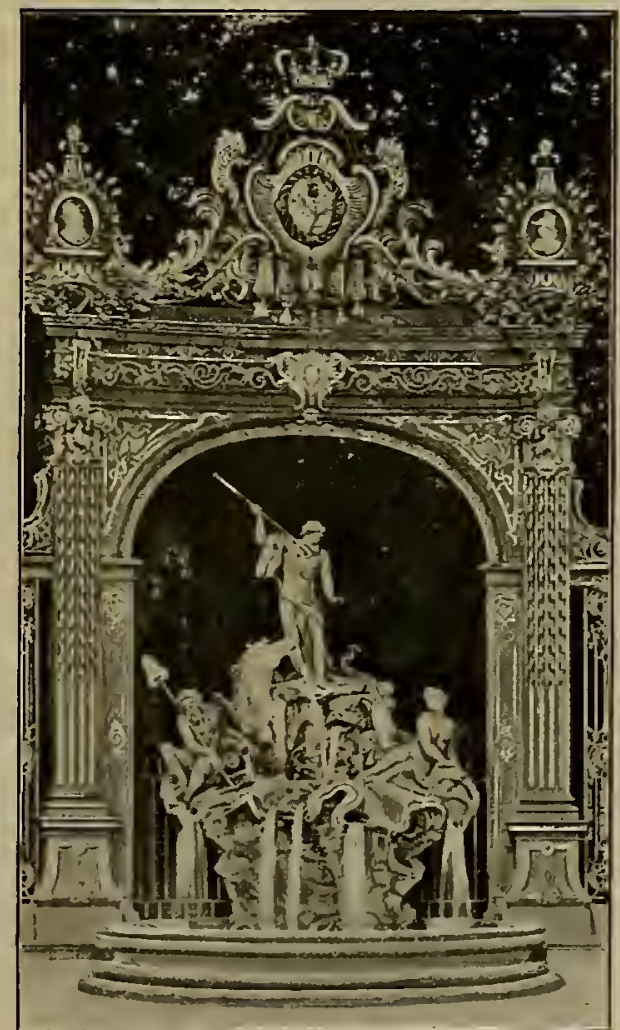

Abb. 89. Mittelteil des Abschlussgitters der Abb. 87. 


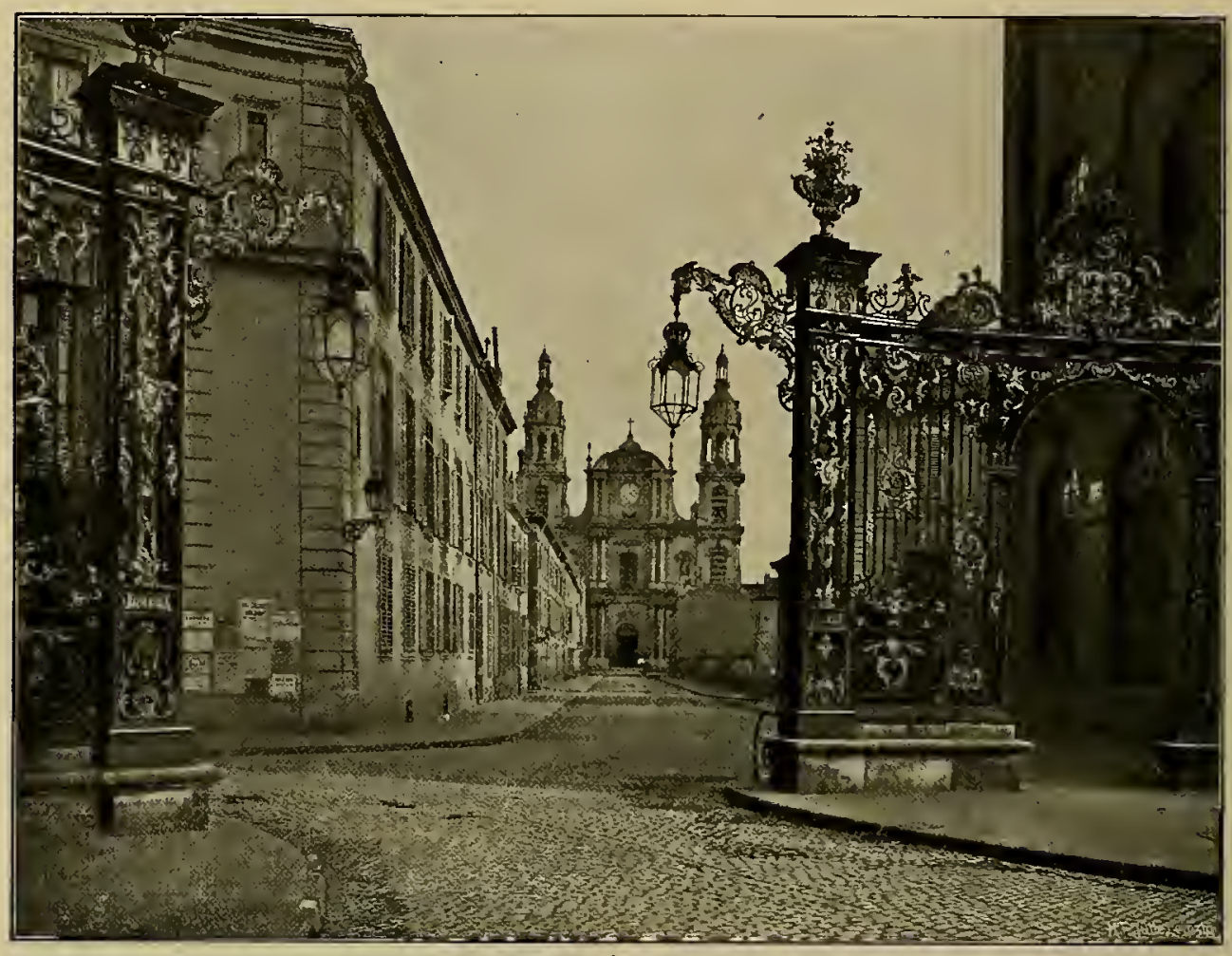

Abb. 90. Eingangsgitter zum Place Stanislas in Nancy.

politischen Ruhmesträumen entsagend, widmete der König sich hinfort in seinem neuen Wirkungskreise seinen wissenschaftlichen und künstlerischen Liebhabereien. Durch seinen Architekten Emmanuel Héré liess er in Nancy und an anderen Orten Lothringens eine grössere Anzahl Bauten errichten, in denen sich die Steinarchitektur mit den Schmiedearbeiten Lamours zu glücklicher harmonischer Wirkung vereinigte. Nancy wurde unter seiner Fürsorge eine Perle unter den französischen Städten.

Schon 1738 hatte Lamour Gelegenheit, dem Könige mit seiner Kunst zu dienen. Für die Grabkapelle, welche Stanislaus für sich und seine Gemahlin in Notre Dame de Bon Secours, der Hauptkirche Nancys, ausschmücken liess, verfertigte er ein schönes vergoldetes Gitter, das aber schon 1792 einem Kunsthändler in die Hände geriet. Ebenfalls fielen der Vernichtung anheim die Schmiedearbeiten, die er einige Jahre später für das von Héré erbaute Schloss Chanteheux bei Lunéville hergestellt hatte. Es ist uns aber wenigstens in der Abbildung in Lamours Werk, auf das noch näher einzugehen sein wird, das Treppengeländer erhalten, welches schon die ausgesprochenen Rokokoformen zeigt, wie sie in den späteren Arbeiten Lamours erscheinen. Lamour erzählt uns, dass dasselbe, als Ludwig XV. 1744 durch Nancy kam, die Bewunderung aller Kenner im Gefolge des Königs erweckt hätte. Dann folgen die für Commercy hergestellten Gitterwerke, von denen ebenfalls mehrere auf einer Kupfertafel des Lamourschen Werkes dargestellt sind. Sie zeichnen sich durch eine lebendige, graciöse Linienführung des Stabwerks aus, sind aber etwas gedrängt und überladen in den Ornamenten.

Unter den zahlreichen noch vorhandenen Arbeiten, die Lamour für Nancy 
selbst schuf, bilden die Schmiedewerke, welche den Place Royale (jetzt Place Stanislas) schmücken, den Höhepunkt. Hier gelangte nämlich das Schmiedeeisen in einer monumentalen Form zur Anwendung, wie nie vorher noch nachher in ähnlichem Massstabe. Der Platz bildet ein Rechteck von 124,44 m Länge und $106 \mathrm{~m}$ Breite und ist rings umher von Gebäuden umgeben. Die ganze Südseite ist vom Hôtel de ville eingenommen, das mit seinen gewaltigen Massen den Platz beherrscht. An den vier Ecken sind Oeffnungen zwischen den den Platz umgebenden Bauten gelassen, ausserdem münden an den beiden Schmalseiten Strassen ein. Diese sechs Zwischenräume sind nun von prächtigen schmiedeeisernen Aufbauten ausgefüllt, die dem Platz die zu einer künstlerischen Wirkung nötige Geschlossenheit geben. Die beiden Winkel des Platzes gegenüber dem Hôtel de ville nehmen zwei grosse triumphbogenartige $\mathrm{Ei}$ senbauten ein. Die übrigen vier Oeffnungen sämtlich Strassenmündungen - sind mit einfacheren, aber nicht minder kunstvollen portalartigen Anlagen abgeschlossen. Ausserdem schmücken die Gebäude schöne Laternenträger, sowie eine fortlaufende Reihe von prächtigen Balkonen. Das Hôtel de ville besitzt 14 Balkone, von denen der mittlere allein eine Länge von $19 \mathrm{~m}$ hat, die übrigen Gebäude haben zusammen 56 Balkone. Auch die in der Mitte des Platzes stehende Statue des Königs (früher Ludwigs $X V$.) umgiebt ein schmiedeeisernes
Gitter. Alles prangt in reicher Vergoldung, im 18. Jahrhundert zum Teil in verschieden getönten Goldfarben. Den ganzen Platz umrahmt also ein fortlaufender Kranz herrlicher, im Glanz der Sonne strahlender Schmiedewerke, vergleichbar einem kōstlichen Geschmeide am Halse einer schönen Frau.

Diese unvergleichliche Anlage ist zweifellos in ihren Grundzügen eine Schöpfung Emmanuel Hérés, welcher, indem er die Kunstfertigkeit Lamours zu würdigen verstand, diesem einen bedeutenden Anteil an der künstlerischen Ausschmückung des Platzes einräumte. Der Entwurf der Eisenarbeiten im einzelnen und ihre Ausführung geht indessen direkt auf Lamour zurück. Das Verhältnis beider zu einander wird klargelegt durch das Kupferwerk Hérés: Plans

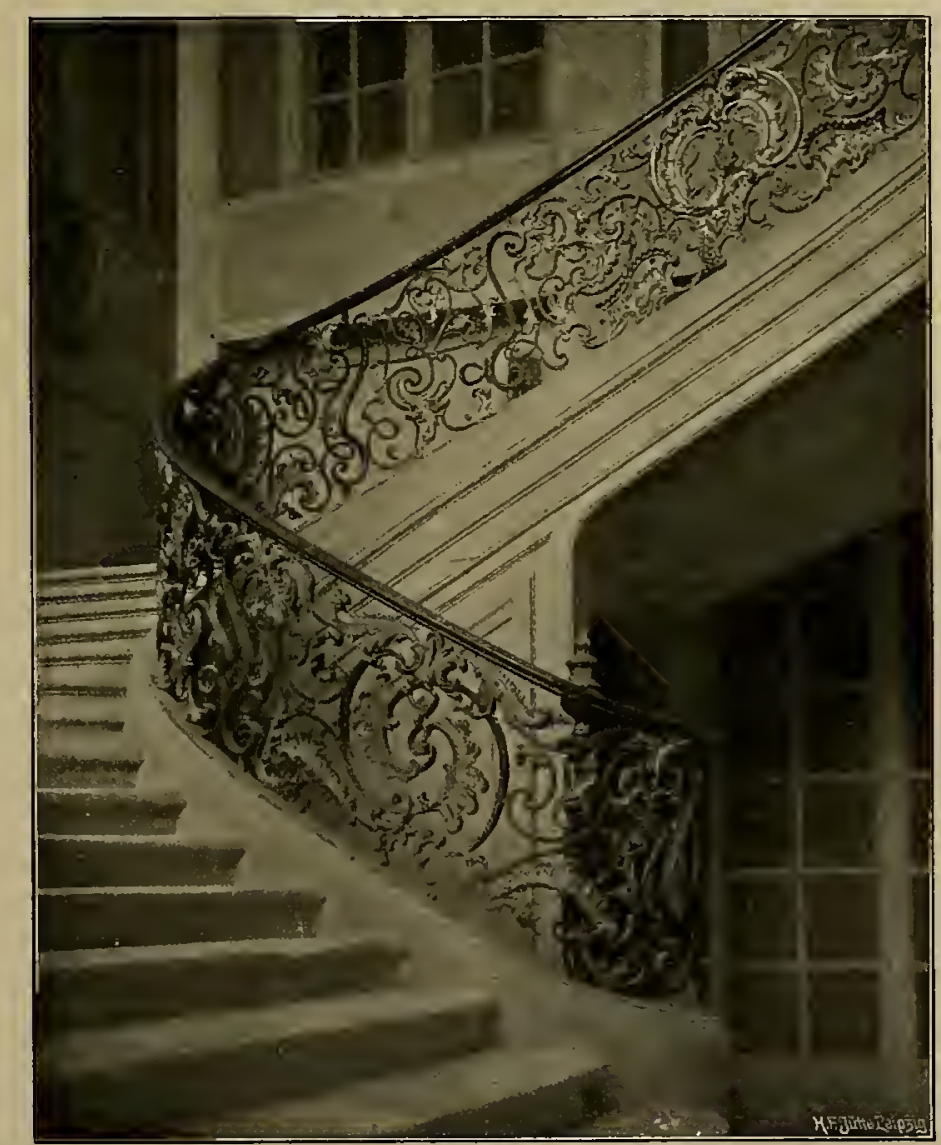

Abb. 91. Treppengeländer im Hôtel de ville zu Nancy. 


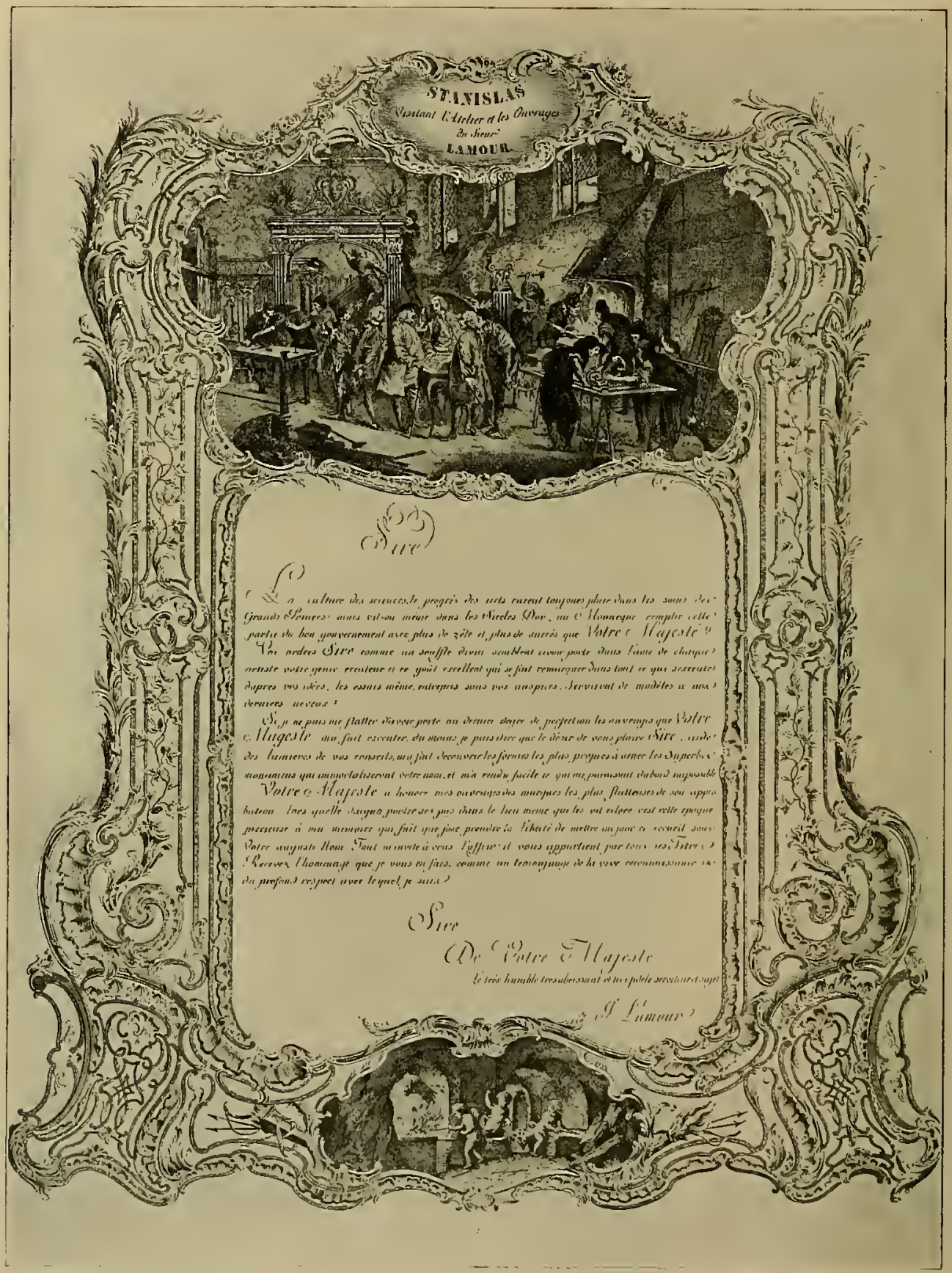

Abb. 92. Tafel mit der Widmung in "Lamour, Recueil des ouvrages en serrurerie".

et Elevations de la Place Royale de Nancy vom Jahre 1753, als die Schmiedewerke noch in Arbeit waren. Auf den Tafeln, welche den Platz darstellen, sind sämtliche sechs Lücken mit gleichen Triumphbogen ab. geschlossen, während doch bei der späteren Ausführung, wie schon erwähnt, vier eine ganz andere Gestalt erhieltelı. Ein besonderer Stich bringt dann die Abbildung eines der wirklich ausgeführten 
Abschlussgitter mit der Poseidongruppe; er trägt die Bezeichnung: Fait par J. Lamour Serrurier du Roy. Vergleicht man indessen diesen Entwurf mit der vorhandenen Anlage, so ergeben sich ver- schiedene Unterschiede. Die kleineren Felder unter den grossen Füllungen zu beiden Seiten der Nebenportale fehlen. Die Bekrönung der Hauptportale ist niedriger. Ausserdem hat dieser Vorent-

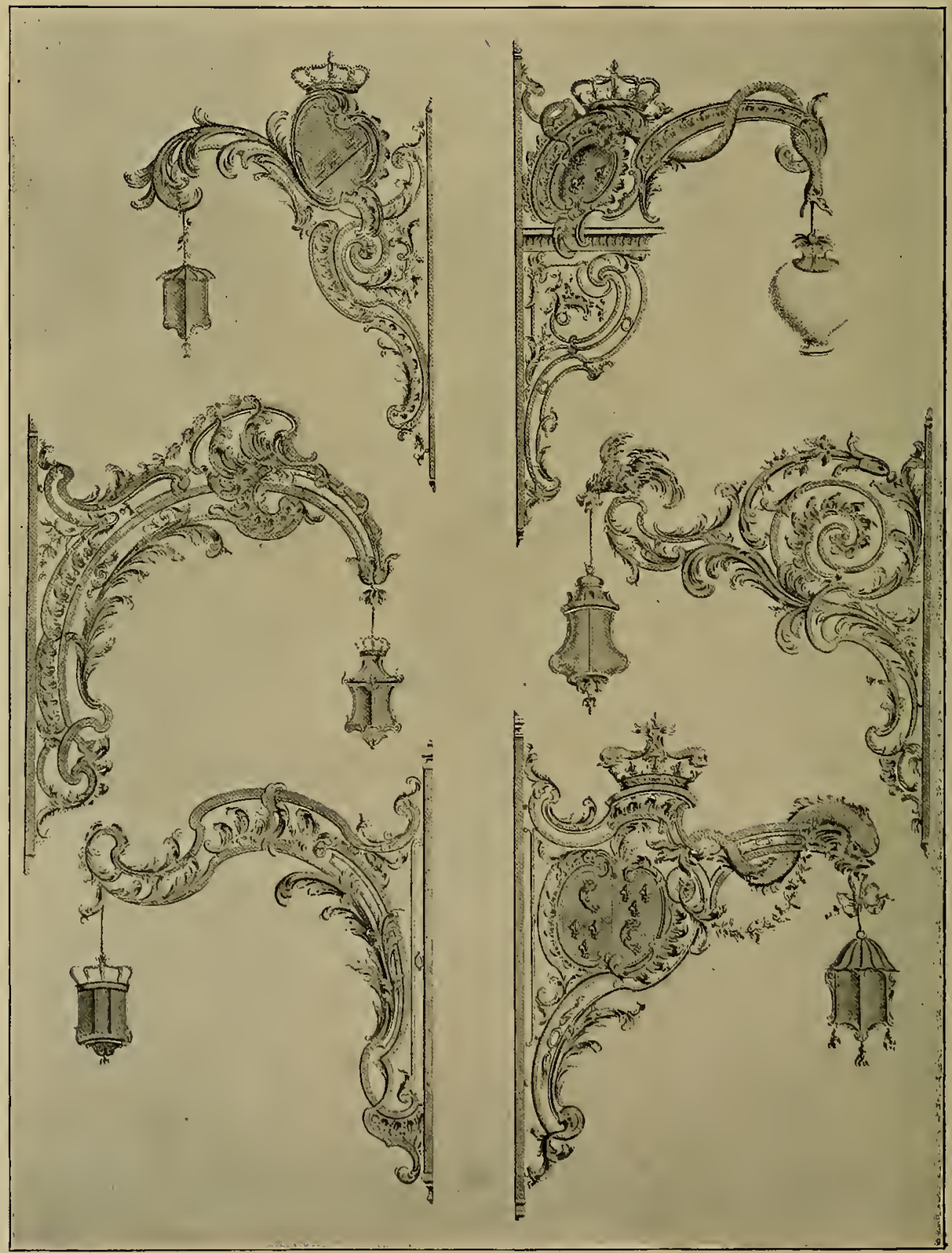

Abb. 94. Laternen (Lamour, Recueil). 
wurf doppelte Pilaster zu Seiten der mittleren Oeffnung, während das ausgeführte Werk nur einfache Pilaster besitzt. Es ist leicht ersichtlich, worauf diese Veränderungen, die das fertige Werk gegenüber diesem ersten Entwurfe aufweist, hinzielen; sie sollen dem Triumphbogen eine grössere Höhenausdehnung geben gegenüber dem erwähnten Entwurfe, der etwas gedrückt und in die Breite gezogen erscheint. Vielleicht hat der König selbst den Anstoss zu dieser Umgestaltung gegeben. Lamour berichtet uns wenigstens in der Einleitung seines Werkes, dass Stanislaus seine Werkstatt besucht und seine Zeichnungen korrigiert habe. Die angeführte Unterschrift des Stiches kann demnach

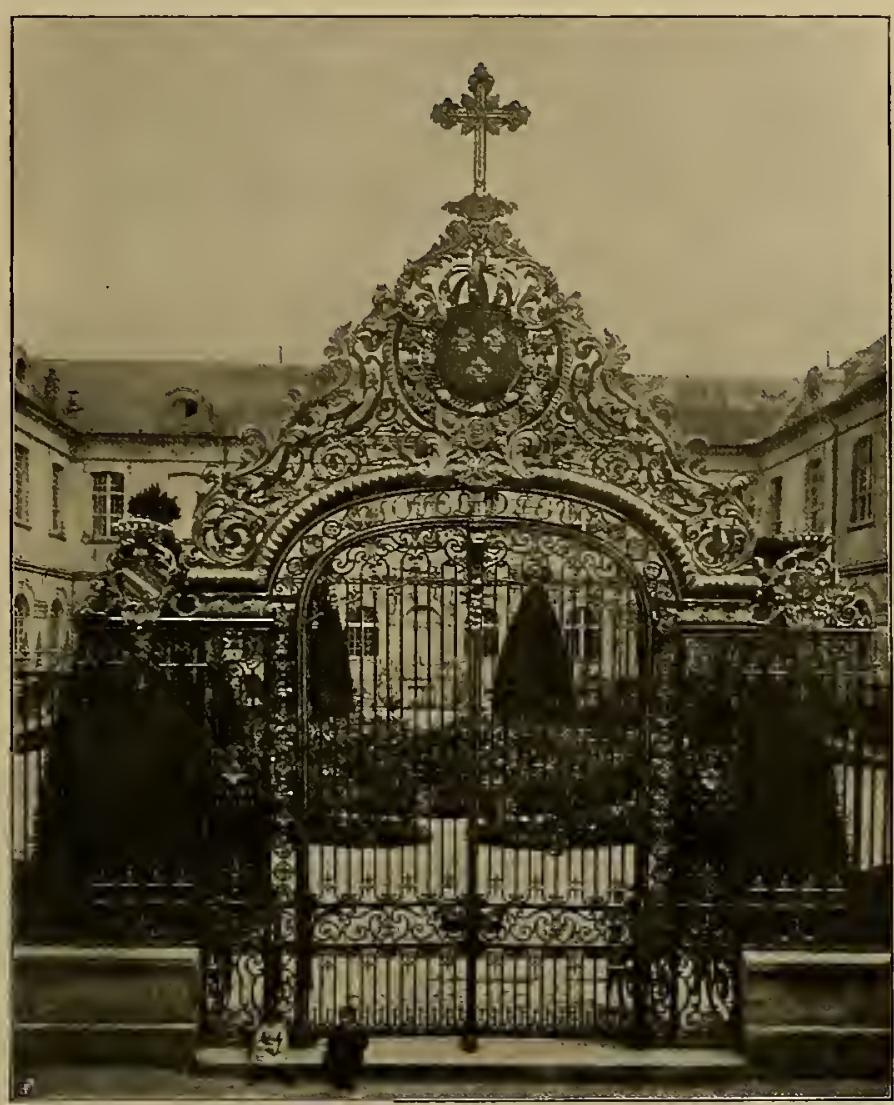

Abb. 95. Portal vor dem Hôtel Dieu zu Troyes. nur auf die geistige Ur-

heberschaft Lamours sich beziehen.

Die beiden Abschlussgitter, bei denen die Kunst Lamours sich am höchsten erhebt, dienen als Umrahmungen zweier Fontänen, von denen die eine mit der Figur des Poseidon, die andere mit der der Amphitrite, beide umgeben von Meergottheiten und Amoretten, geschmückt ist. In den seitlichen Portalen des einen Aufbaues sind.kleine Gruppen mit Amoretten und Delphinen eingestellt, die des Gegenstückes dienen als Durchgänge. Die in Blei gegossenen Gruppen sind ein Werk des Bildhauers Barthélemy Guibal, von dessen Hand auch die früher in der Mitte des Platzes stehende Statue Ludwigs XV. herrührte. Reicher Baumschlag dient den beiden Aufbauten als wirksamer Hintergrund. Die Gitterwerke selbst sind mit Ausnahme des kleinen Steinsockels mit vieler Kunst aus Eisen gebildet. Sie haben eine Breite von $23,45 \mathrm{~m}$, eine Höhe von $10,60 \mathrm{~m}$. Besonders prächtigen Schmuck trägt das Mittelportal. Die Kapitelle der Pilaster tragen als Zierat einen Hahn und eine Sonnenmaske, die Zwickel zwischen Architrav und Rundbogen sind mit Waffentrophäen ausgefüllt. Die hochaufragende Bekrönung zeigte ursprünglich in ihrer Mitte das Wappen der französischen Könige. Zur Zeit der Revolution wurde dasselbe indessen, ebenso wie die Namenszüge des Königs Stanislaus in den Aufsätzen der seitlichen Portale, ausgebrochen. Bei einer Wiederherstellung des Gitters im Jahre 1864 ersetzte man die drei Lilien des bourbonischen Wappens durch die Distel der Stadt Nancy. Auch die beiden pyramidenförmigen Aufsätze oberhalb der Pilaster, welche die Medaillons des Mars, der 


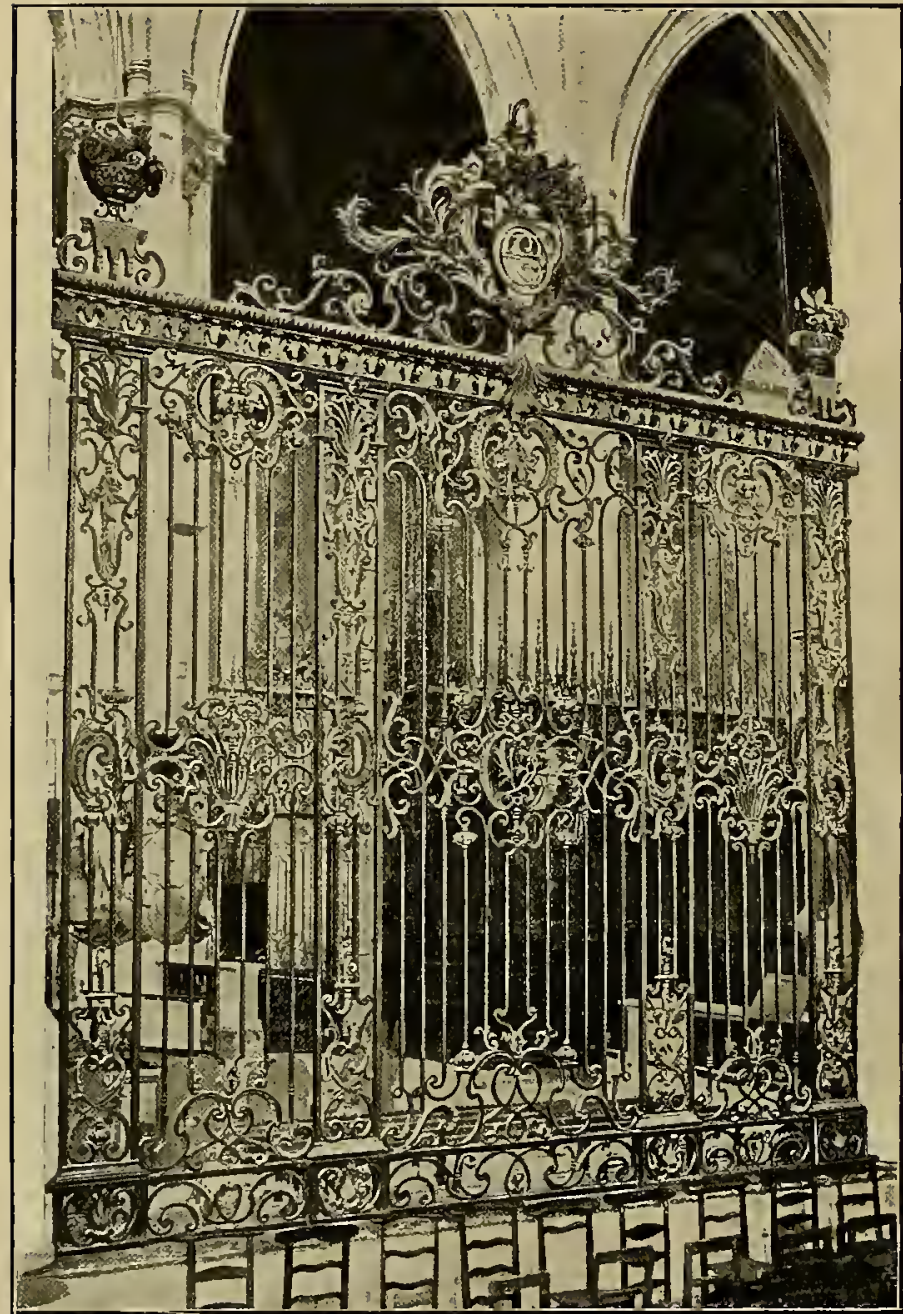

Abb. 96. Gitter in der Kathedrale zu Amiens.

Es ist ein reifes, abgeklärtes Rokoko, das mit mannigfaltiger Ausbildung des Ornaments im einzelnen klare Linienführung im ganzen und ein weises Masshalten in der Anwendung der Ziermotive verrät. Neben jener palmenschossartigen Bildung, die sich als Ausläufer des Laubwerks aus der Zeit Ludwigs XIV. ergab, erscheint das Muschelwerk in voller Ausgestaltung. Während dieses Muschelwerk als unpersönliches Ornament die Schwingungen des Stabwerkes begleitet, findet daneben auch das naturalistische Pflanzenornament, den Gesetzen seines natürlichen Wuchses folgend, eine bescheidene Anwendung, weniger bei den Triumphbogen, als bei den übrigen vier die Zugänge des Platzes einfassenden Portalanlagen, bei denen es in den Gesimsbekrönungen, den Laternenarmen und Vasen auftritt. Diese Portale schie.

Minerva, des Apollo und der Ceres, umgeben von Fahnen und kriegerischen Emblemen, zeigen, waren 1831 wegen ihres schlechten Erhaltungszustandes entfernt worden. Erst als man 1879 in der Rumpelkammer eines Schlossers einen dieser Aufsätze wiederfand, entschloss man sich, sie zu erneuern. Der Schlosser Lipmann in Strassburg stellte die vier Aufsätze für 11000 Frcs. wieder her. (Abbild. 87-89).

Nicht nur als gewaltige technische Leistungen, sondern auch als vollendete Kunstwerke zwingen uns diese beiden Schmiedewerke hohe Bewunderung $a b$. ben sich von den die Strassenmündungen einrahmenden Häusern auf den hier erweiterten Trottoirs in die Strassen hinein; nach dem Fahrdamm zu schliessen sie mit einem sehr schön gezeichneten Pfeiler $\mathrm{ab}$, der eine Blumenvase trägt. An diesen Pfeilern sind Laternenträger angebracht, deren Endigungen als Hähne u. dgl. gestaltet sind, die in ihren Schnäbeln Laternen von gefälligen Formen tragen. Zwischen den Pfeilern ist ein offener Raum gelassen, hinlänglich breit, um zwei Wagen den Durchgang zu gestatten. Es ist möglich, dass man lediglich aus Verkehrsrücksichten von den ursprünglich auch hier geplanten 
Triumphbogen abgegangen ist. Die Zeichnung der Füllungen dieser Portale entspricht den betreffenden Gegenstücken an den Triumphbogen fast genau (Abbild. 90).

Von den den Platz umgebenden Balkonen ist der mittlere der ersten Etage des Hôtel de ville besonders prunkvoll ausgestattet (Abbild. 93). Die Mitte nimmt das Wappen des Königs ein mit den Ordensketten des h. Geistes und des h. Michael. Zwei grosse Adler halten das Wappenschild, sie heben sich von einem Gittermuster $a b$, bei welchem die rautenförmigen Oeffnungen mit einem Vierblattornament gefüllt sind. Wir erfahren von Lamour, dass er bei diesem Stück die Wirkung der ciselierten Bronze habe erreichen wollen. Auch das Innere des Hôtel de ville birgt eine bedeutende Leistung Lamours, das Treppengeländer, das mit einer überströmenden Fülle von Muschelwerk ausgestattet ist. Die stark bewegten Linien des Stabwerks scheinen in ihrem vorwärts drängenden Streben den, der die Treppe hinaufsteigt, mit sich fortzuziehen (Abbild. 91). Mit besonderem Stolz hebt Lamour hervor, dass die $25 \mathrm{~m}$ lange Handleiste des Geländers so geschickt zusammengefügt sei, dass sie aus einem Stück zu bestehen scheine. Lamour erhielt für die zum Schmuck des Hôtel de ville ausgeführ. ten Arbeiten 60411 Livres, für die Gitterwerke der Place Royale 149324 Livres. Für die Ver. goldung der Gitter und Balkone bekam dieWitwe des Philipp Niclos 1372, Nicolas Gastaldy 17328
Livres, für den Anstrich wurde dem Maler Charles Devarennes 776 Livres ausgezahlt. ${ }^{1}$ ) Nach vierjähriger Arbeit waren die Gitter samt dem übrigen Schmuck des Platzes vollendet. Den festlichen Abschluss bildete die Enthüllung des Denkmals Ludwigs XV., welche am 26 . November 1755 unter grossen Feierlichkeiten begangen wurde. Die Fontänen speiten an diesem Tage Wein aus, und vier Stadträte warfen von den Balkonen des Platzes Geld unter das Volk.

Auch die benachbarte Place de la Carrière ist mit Gitterwerken von Lamour

1) Vgl. Compte général de la dépense des édifices et batimens que le roi de Pologne a fait construire pour l'embellissement de Nancy. Lunéville 1761.

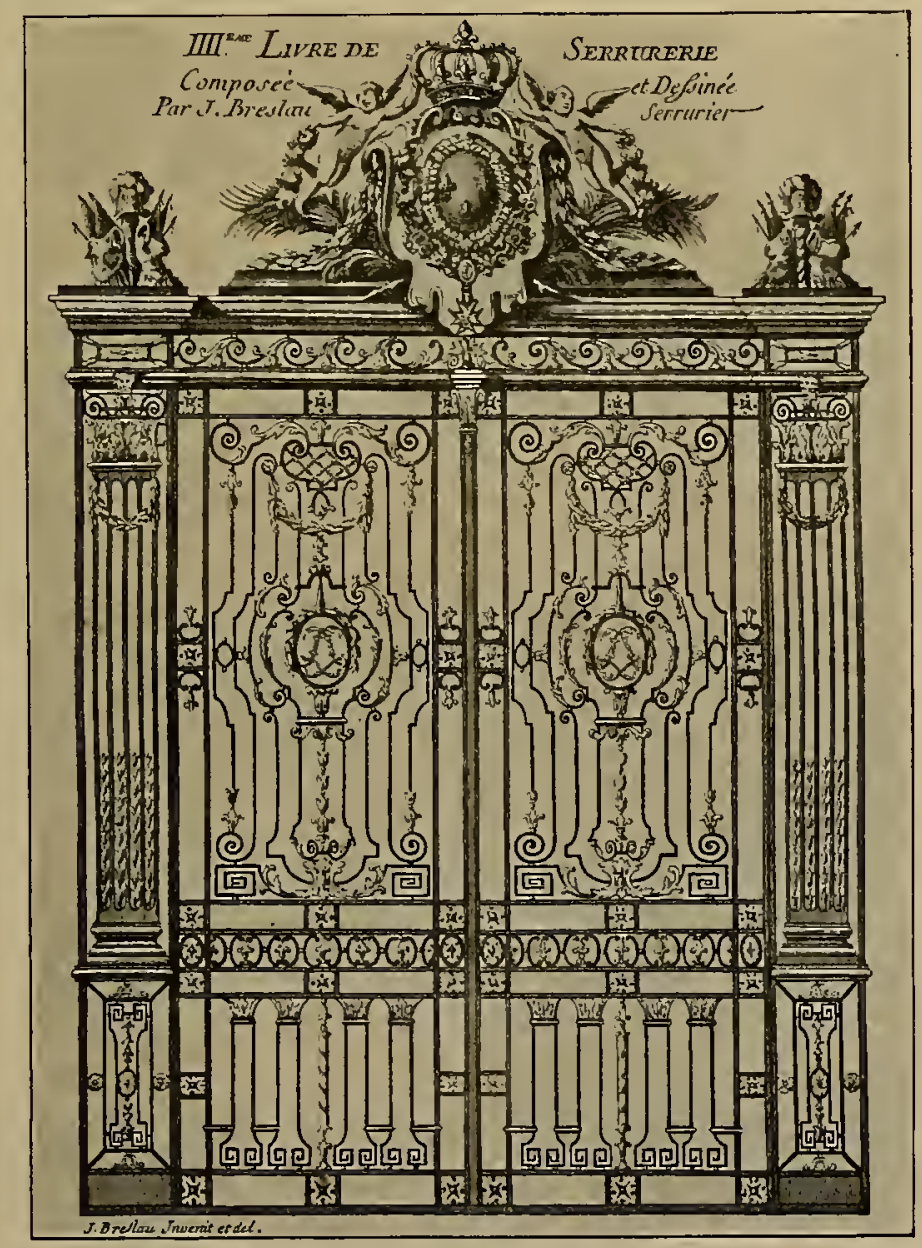

Abb. 97. Portal nach einem Stiche von J. Breslau. 


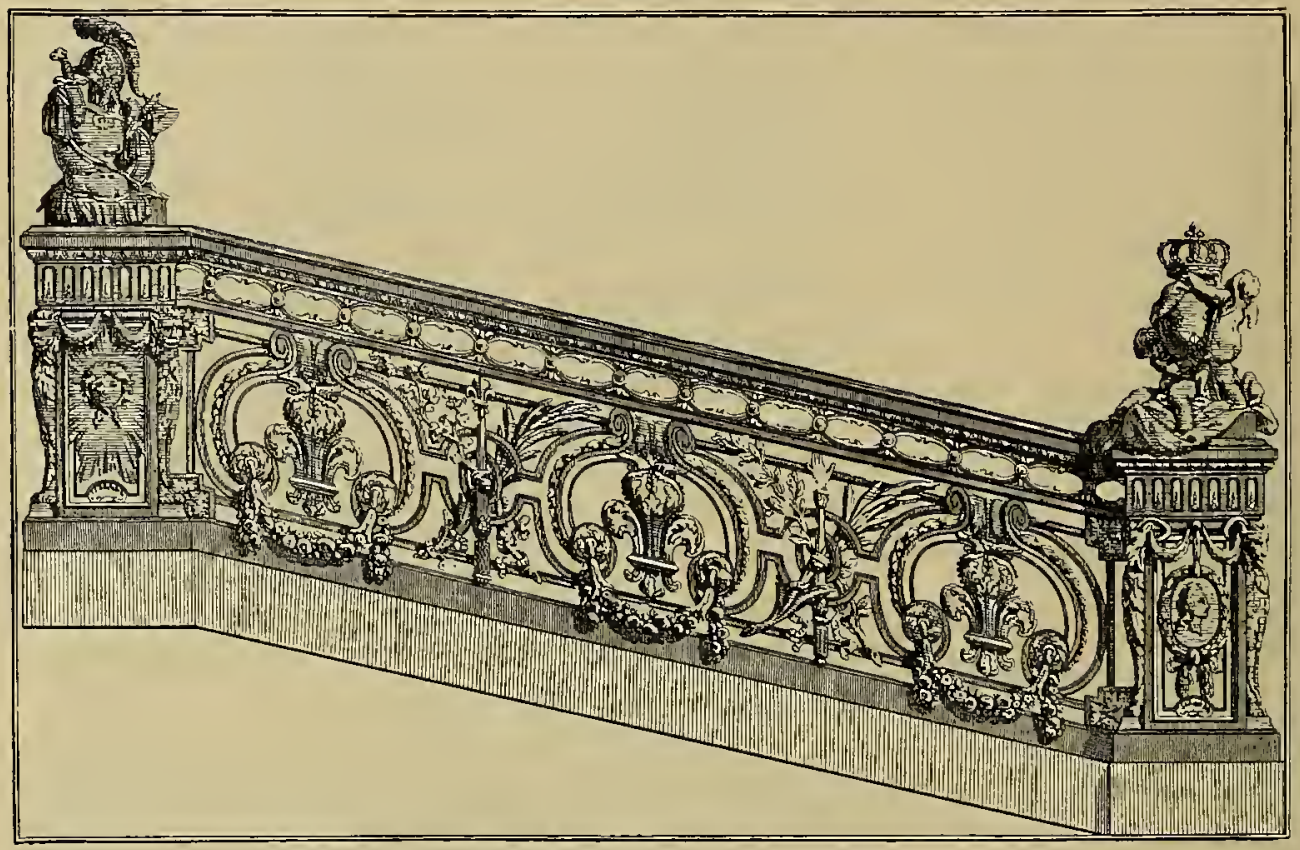

Abb. 98. Treppengeländer nach einem Stiche von J.-F. Forty.

ausgestattet, die in ihrer Bildung an die Portale der Place Royale erinnern. Zwei prächtige Gitter von seiner Hand besitzt auch die Kathedrale; das eine schliesst die Grabkapelle des Kardinals Karl von Lothringen $a b$, das andere die des Prälaten du Bouzey. Die vier anderen Kapellengitter stammen von anderer Hand, sie sind bezeichnet: Jean Maire 1759. Von den übrigen noch in grosser Zahl in Nancy erhaltenen Arbeiten Lamours verdienen die Balkone der ersten Etage seines Hauses, rue Notre Dame Nr. 32, wegen der hohen Vollendung der Arbeit besondere $\mathrm{Er}$ wähnung.

Lamour hat selbst dafür gesorgt, dass sein Name der Nachwelt erhalten blieb, indem er 1767 seine besten Arbeiten in einem aufs prächtigste ausgestatteten Kupferstichwerk in Grossfolio unter dem Titel: „Recueil des ouvrages en serrurerie, que Stanislas le Bienfaisant, Roy de Pologne, Duc de Lorraine et de Bar, a fait poser sur la place Royale de Nancy, à la gloire de Louis le Bien-Aimé; composé et exécuté par Jean Lamour son serrurier ordinaire avec un discours sur l'art de Serrurerie et plusieurs autres desseins de son invention Dédié au Roy" veröffentlichte und dem König widmete. $\left.{ }^{1}\right)$ Die Widmung an den König ist auf dem ersten Blatt innerhalb einer schönen Rokokoumrahmung angebracht, welche im Stile seiner Schmiedearbeiten gehalten ist. Auf der unteren Leiste des Rahmens sind in einer kleinen Vignette schmiedende Amoretten in einer Grotte dargestellt. Der obere Teil des Rahmens umschliesst ein grösseres, von Collin gestochenes Bild, welches den Besuch des Königs in der Schmiede Lamours nach einem jetzt in Lunéville befindlichen Gemälde Bénards vorführt (Abbild. 92). Man ist gerade mit der Herstellung eines der beiden Triumphbogen der Place Royale beschäftigt. In der Mitte der Schmiedewerkstatt steht der König, ein wohlbeleibter Herr und mustert, mit einem Augenglas bewaffnet, einen der Pfeiler,

1) Neudruck: Jean Lamour, Recueil des ouvrages en serrurerie. A. Levy. Paris. 
auf den Lamour mit der rechten Hand hinweist, während er in der Linken den Plan des Ganzen hält. Im Hintergrunde sind mehrere Arbeiter mit der Montierung des Triumphbogens beschäftigt, im Aufsatz des mittleren Portals sind deutlich die drei Lilien der Bourbonen zu erkennen. Rechts davon arbeitet ein Mann mit einer grossen Feile an einem Schraubstock, links im Vordergrunde vergleichen mehrere Leute, über einen Tisch gebeugt, die geschmiedeten Eisenteile mit der Werkzeichnung. Die Kamine der beiden Schmiedeessen führen direkt $\mathrm{zu}$ den Fenstern hinaus. Es war eine alte, nicht mehr im Gebrauch befindliche Kirche, in der Lamour seine Werkstatt eingerichtet hatte.

In grossen Stichen führt uns dann Lamour seine wichtigsten Werke vor. Besonders wertvoll sind die Abbildungen solcher Schmiedearbeiten, die nicht mehr vorhanden sind, wie die von Commercy und Chanteheux. Andere Entwürfe scheinen überhaupt nicht zur Ausführung gelangt, sondern als Vorlagen gezeichnet zu sein. Dazu gehören eine grössere
Anzahl von Wandarmen für Laternen und Aushängeschilder mit den Wappen des Königs, des Dauphins u. s. w. (Abb. 94), ferner Bekrönungen aller Art, zum Teil mit kirchlichen Emblemen und Kerzenhaltern versehen. Einer dieser Aufsätze enthält das Wappen, das den französischen Schlossern verliehen wurde; an den beiden Pyramiden rechts und links sind Schlosserwerkzeuge $u$. dgl. angebracht (Abbild. 81). Des gotischen Schlosses, das Lamour abbildet, ist schon Erwähnung gethan (S.18). Die letzte Tafel bietet Ornamente in natür. licher Grösse.

Stanislaus wusste in wahrhaft könig. licher Art seinen Hofschlosser zu ehren. Er liess sein eigenes Porträt und das Lamours als Gegenstücke in gleicher Grösse in Pastell malen und schenkte beide dem Künstler. Die Bilder befinden sich jetzt im lothringischen Museum zu Nancy. Lamour trägt auf dem Porträt die Tracht des Hofmannes, Rock und Weste von blauem Sammet mit goldenen Borten. Im Hintergrunde wird ein Stück eines der Triumphbogen der Place Royale sichtbar.

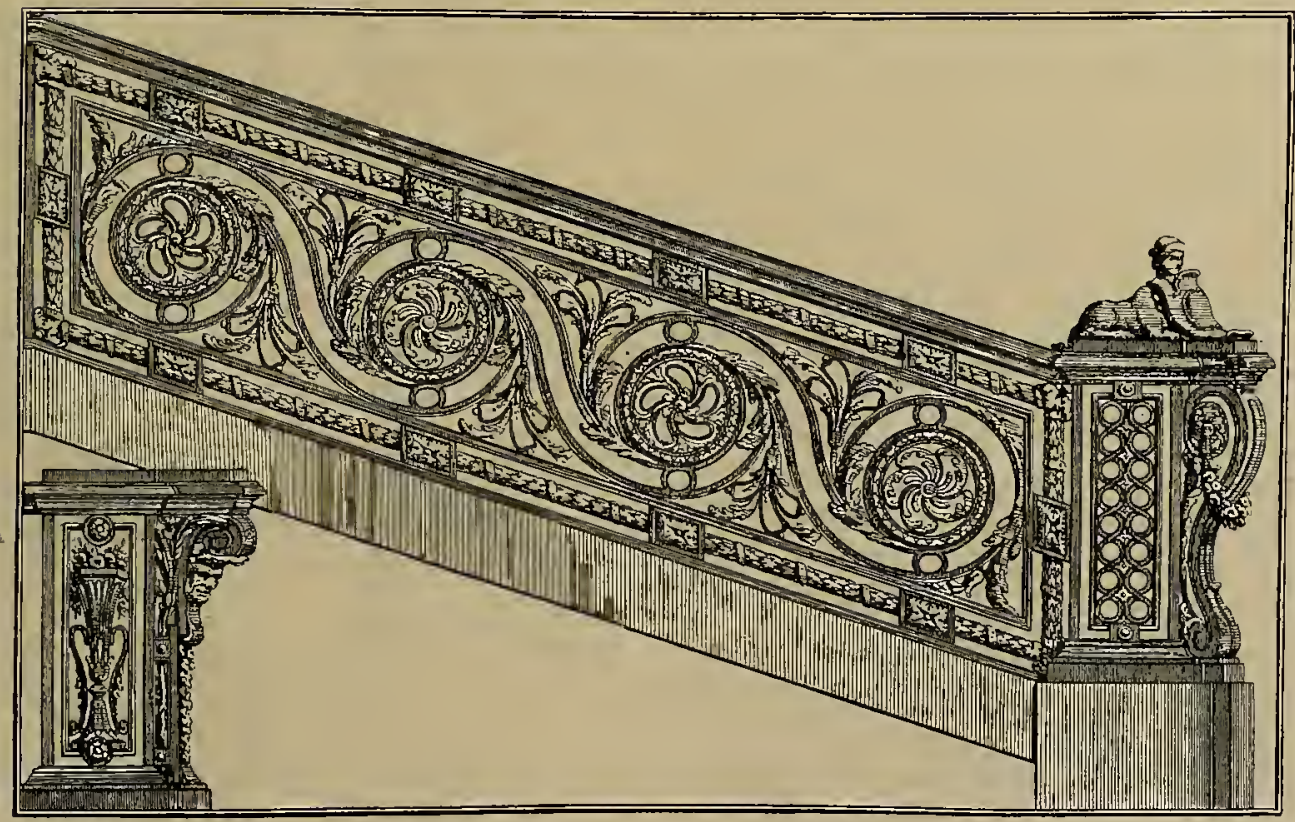

Abb. 99. Treppengeländer nach einem Stiche von J.-F. Forty. 


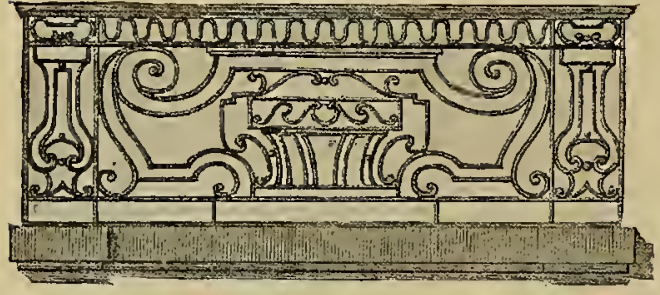

Abb. 100. Fenstergitter nach einem Stiche von J.-F. Forty.

Mit dem Tode des Königs im Jahre 1766 scheint auch Lamours Thätigkeit im wesentlichen ihren Abschluss erreicht zu haben. Die reichen Aufträge, die während der Regierung Stanislaus' ihm zugeflossen waren, hatten ihm nicht nur einen ehrenvollen Namen, sondern auch einen nicht unbedeutenden Reichtum verschafft. So war er in der Lage, eine Sammlung von Gemälden und anderen Kunstsachen allmählich zu erwerben, welche er Freunden der Kunst gern zu zeigen pflegte. Unter seinen Mitbürgern genoss er hohes Ansehen. Die Advokaten Nancys erwiesen ihm die Ehre der Aufnahme in ihre religiöse Brüderschaft $\mathrm{Er}$ starb $177 \uparrow$.

Gegenüber dem Reichtum an Schmiedewerken, welche die Stadt Nancy der Thätigkeit Lamours verdankt, ist das, was in anderen Städten Frankreichs von Eisenarbeiten in Rokokoformen sich erhalten hat, verschwindend gering. $\mathrm{Zu}$ nennen ist noch das prachtvolle Portal, welches den Vorhof des Hôtel Dieu in Troyes abschliesst, eine Arbeit des Pariser Schlossers Pierre Delphin. Es dürfte etwa der Zeit von 1730-1740 angehören und soll ursprünglich für die Abtei Clairveaux angefertigt worden sein (Abbild. 95). Besonders schön baut sich die Bekrönung auf. An den aufsteigenden Seiten ranken sich üppige, palmenschossartige Blattbüschel empor. Rechts und links vom Portal sind die Wappen der Champagne und von Navarra angebracht, während die Thorbekrönung das Königswappen trägt. Die Gestaltung der Thorflügel mit den parallel laufenden Stäben, von denen jedesmal der zweite und dritte durch einen breiten Bund zusammengefasst sind, weist auf ähnliche Bildungen aus der Zeit Ludwigs XIV. zurück. Unter den stattlichen und umfangreichen Gitterwerken, von denen sich in den Kirchen noch mehrere an Ort und Stelle befinden, verdienen eine besondere Hervorhebung die den Chor und die Kapellen abschliessenden Gitter in der gotischen Kathedrale zu Amiens (Abbild. 96). Der vornehmste Schmuck der Gitterfüllung sind palmetten-und kartuschenartige Ornamente aus zackigem Muschelwerk. In den Aufsätzen ist reiche Verwendung von natürlichen Blumen gemacht. Der Schlosser Veyrens zu Corbie führte das Gitter nach Entwürfen von René Michel Slodtz aus.

Veyrens verfertigte auch einen Baldachin in Gestalt einer Palme für den Hauptaltar der Abteikirche zu Valvire,

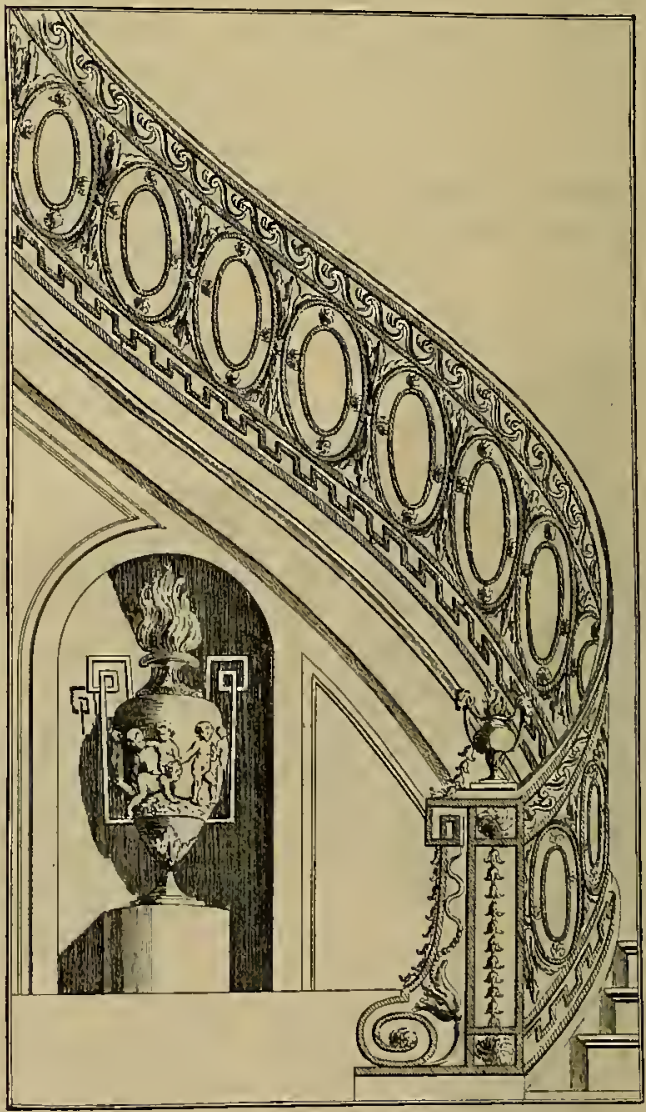

Abb. 101. Geländer nach einem Stiche von Desboeufs du Saint-Laurent. 
der vor der Abliefe. rung in Amiens ausgestelit wurde. Auch sonst pflegten die Schlosser besonders kunstvolle Arbeiten nach ihrer Herstellung dem Publikum zu zeigen. So konnte der berühmte, aus vier Palmen mit dem Osterlamm und anbetenden Engeln bestehende Baldachin, den der Schlosser Gérard 1769 für die Kirche St.Genevièvein $\mathrm{Pa}$ ris herstellte, drei Tage lang gegen Eintrittsgeld besichtigt werden. ${ }^{1}$ )

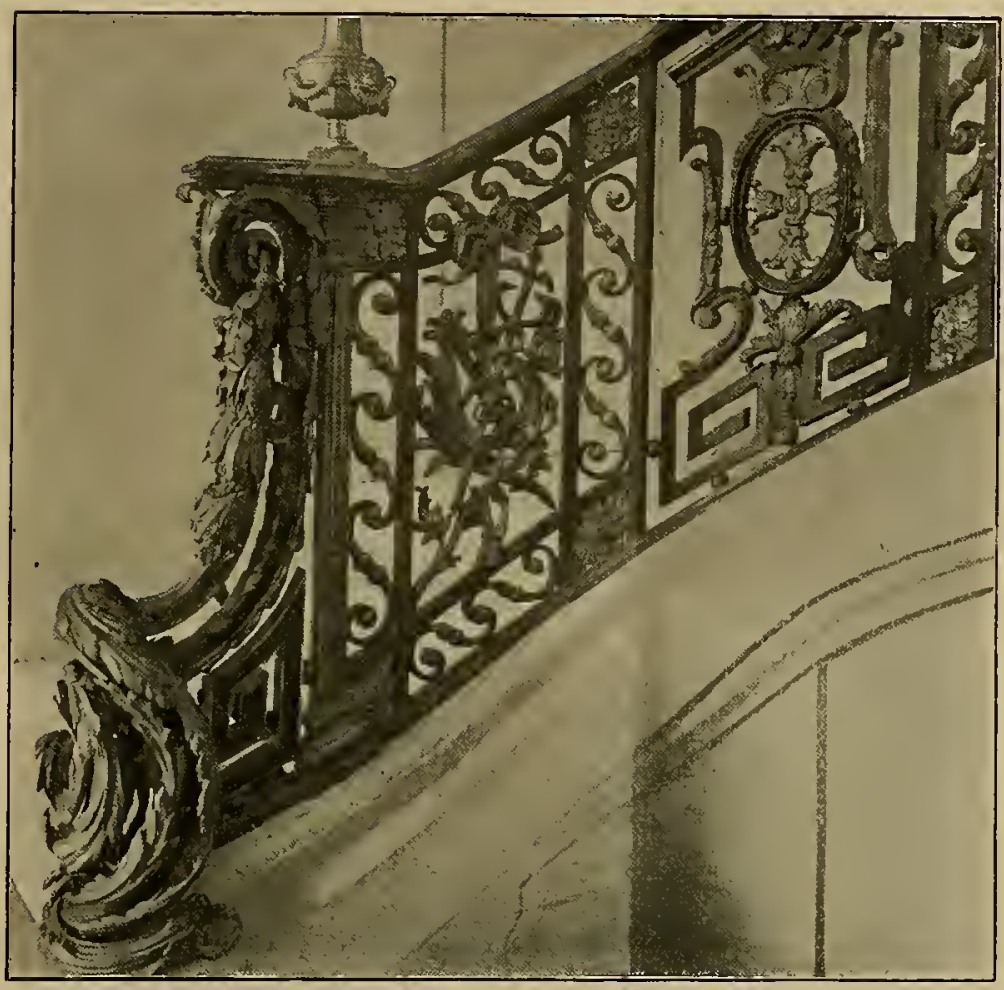

Entsprechend Abb. 102. Treppengeländer im Schlosse Petit-Trianon. ihrerkonservativen

Tendenz, längere Zeit als die übrigen Kunstübungen sich Neuerungen gegenüber zu verschliessen, gewährt die Schmiedekunst auch dem Stil, den man mit dem Namen Ludwigs XVI. zu bezeichnen pflegt, erst verhältnismässig spät Aufnahme. Während auf anderen Gebieten schon um die Mitte des 18. Jahrhunderts klassizistische Neigungen sich geltend machen, treten dieselben in Eisenarbeiten im grossen und ganzen erst in den siebziger Jahren auf. So kommt es, dass wenigstens in der Schmiedekunst so ziemlich der Stil Ludwigs XVI. sich mit der Regierungszeit dieses unglücklichen Monarchen deckt.

Ludwig XVI. übte, ebenso wie Ludwig XIII., selbst das Schlosserhandwerk aus. Noch jetzt existiert seine Schmiedewerkstatt. Sie befindet sich im Dachstockwerk der Hauptfaçade der Cour

1) Vgl. Havard, H., Dictionnaire de l'ameublement unter dem Worte Serrurerie. de Marbre in Versailles rechts von der Uhr. Hier verfertigte Ludwig XVI. mit Unterstützung des Schlossers Gamain, der während der Revolution in schändlichster Weise den König verraten sollte, und eines Gehilfen, namens Durey, Schlösser, Schlüssel, Riegel, Hämmer u. a. Der robusten Natur des Königs sagten diese alle Körperkräfte anspannenden Arbeiten besonders zu. Seine delikate Gemahlin nahm freilich öfter Anstoss, wenn er mit Händen, die die Arbeit geschwärzt hatte, erschien. Sie nannte ihn wohl im Scherze ihren Vulkan. Es wird erzählt, dass der König, als einst Feuer in einem benachbarten Gemach ausgebrochen war und man die Pforten desselben nicht öffnen konnte, selbst mit seinen Werkzeugen herbeigeeilt und die Thür aufgebrochen habe, so dass man des Feuers Herr werden konnte. ${ }^{2}$ ) Im Conservatoire des arts et métiers zu

9) Siehe: d'Hézecques a. a. O. S. 159. 


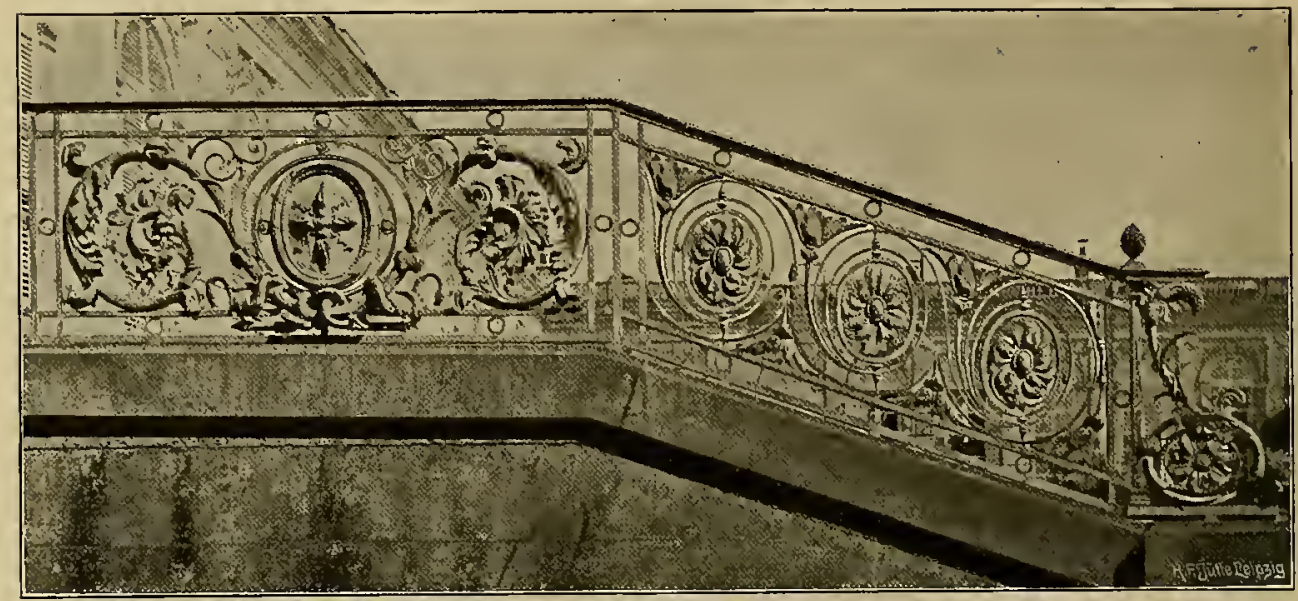

Abb. 103. Geländer am Schlosse Grand-Trianon.

Paris werden noch die Werkzeuge, deren der König sich bediente, aufbewahrt.

Auch für den Stil Ludwigs XVI. sind wir in der Schmiedekunst vor allem auf die Ornamentstiche angewiesen. Sie zeigen uns im allgemeinen ein starkes Sinken der künstlerischen Erfindung, es sind meistens trockene öde Kompositionen, die mit der sonstigen zierlichen Eleganz und Grazie dieses Stiles wenig gemein haben. $\mathrm{Zu}$ den frühesten Stichen von Schmiedewerken dieser Art gehören die im 5. Bande der Recueil élémentaire d'Architecture des Architekten Neufforge erschienenen Tafeln mit Eisenarbeiten. Es sind ziemlich langweilige und geschmacklose Entwürfe von schlichter, meist gradliniger Bildung; wo gebogene Linien vorkommen, bewegen sie sich meistens in der Kreisform. Auch die in dem etwa 10 Jahre später veröffentlichten Supplementbande abgebildeten zahlreichen Schmiedearbeiten weisen keinen nennenswerten Fortschritt auf.

Neben solchen radikalen Unternehmungen, an die Stelle der keck geschwungenen Linienzüge des Rokoko streng symmetrische Linienkompositionen zu setzen, stehen dann Arbeiten, die noch dasgeschweifteStabwerk beibehalten haben, wie zum Beispiel das Vorlagewerk des Schlossermeisters Gabriel Bonthomme von 1775 , in dem nur die mäanderförmigen
Endigungen der Stäbe eine ernstere Note in die im übrigen lebendige Bewegung des Stabwerkes bringen. Die ungefähr in dieselbe Zeit fallenden Veröffentlichungen des Schlossermeisters J. Breslau bieten Vorlagen für Gitter, welche in ihrer Komposition lebhaft an Arbeiten aus der Zeit Ludwigs XIV. anklingen; sie sind nur insofern abgewandelt, als die Linienführung durch eine ausgedehnte Verwendung gerader Linien statt der gebogenen lebloser und kälter geworden ist (Abbild. 97). Die grossen, reich ausgestatteten Portale sind mit Bekrönungen versehen, welche mit Trophäen, Wappen, Figuren u. dgl.

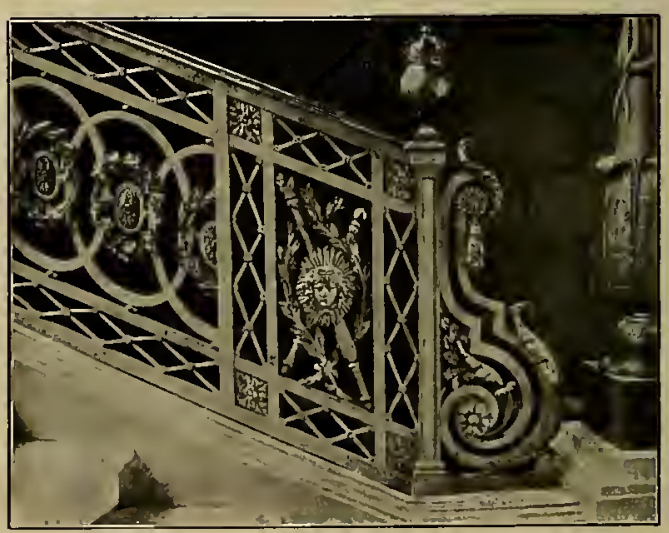

Abb. 104. Treppengeländer im Schlosse zu Compiègne. 
geschmückt sind. Einen Anhalt zur Bestimmung der Zeit, in welcher die Stiche Breslaus entstan. den sind, geben mehrere Folgen von Entwürfen mit der Bezeichnung: Inventé et dessiné par B ... en 1775, welche zum grossen Teil Gegenstiche nach Breslau enthalten.

Der führende Meister unter den Ornamentstechern für Schmiedeeisen aus jener Zeit ist lean-François Forty, der sich selbst als Des. sinateur bezeichnet. $\mathrm{Er}$ bietet in drei Folgen zu je sechs Blatt Fensterbrüstungen, Balkone und Treppengeländer. Unter Fensterbrüstungen (appuis des fenêtres) sind in den Fensterrahmen ein. gespannte niedrige Gitter im Gegensatz zu den aus der Fläche der Mauer hervortretenden Balkonen zu verstehen. Alle

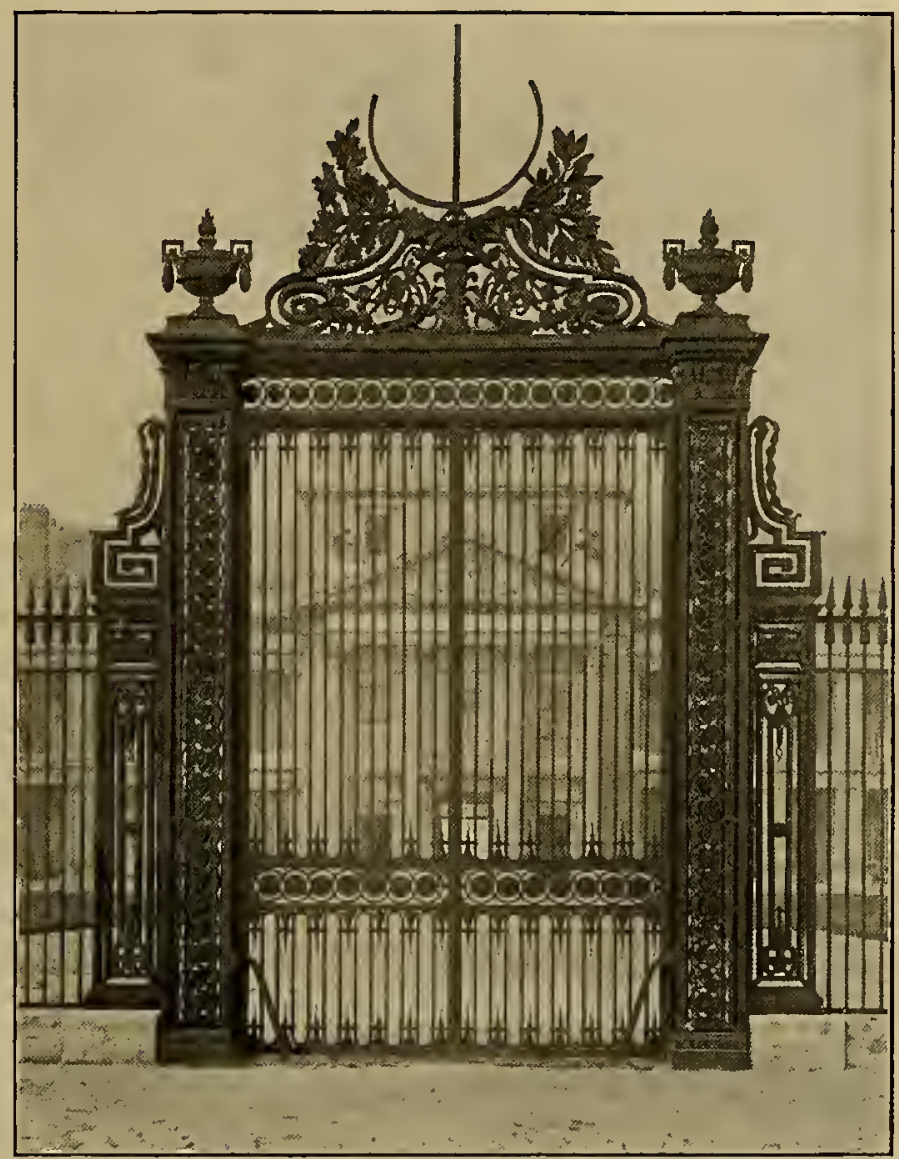

Abb. 105. Portal der Ecole militaire zu Paris. seine Entwürfe erfreuen durch flotte, sichere Linienführung und Grosszügigkeit der Motive, die von eigenartiger, selbstständiger Erfindung sind. Die Füllungen seiner Fensterbrüstungen und Balkone enthalten gewöhnlich ein einheitliches, grosses Ornamentmotiv von schöner und mannigfaltiger Zeichnung (Abbild. 100 u. 109). Bei manchen herrscht das Stabwerk fast allein vor, bei den meisten wird ein grösserer oder geringerer Gebrauch von Akanthusblättern, -rosetten und -kelchen gemacht. Bei reicheren Arbeiten kommen dicke Blattguirlanden, Vasen und Embleme allerlei Art hinzu. Besonders stattlich und prunkvoll sind seine Treppengeländer. Neben der aus einer Folge von Balüstern bestehenden älteren Form des Treppengeländers bringt er mehrere in dieser Zeit beliebte Bil- dungen, bei der die ganze Füllung des Geländers sich aus einem einzigen Motiv zusammensetzt, dem sogen. "laufenden Hunde", welches aus einer Aneinanderreihung von schräggestellten Sförmigen Stäben oder Bändern besteht. Diese S-Schnörkel stossen entweder mit ihren Spitzen zusammen, oder sie sind so aneinander gefügt, dass die übereinanderliegenden Teile zweier sich begegnenden S-Stäbe kleinere oder grössere Kreise oder Ovale mit eingeschriebenen Akanthusrosetten bilden, wie bei dem Treppengeländer der Ecole militaire (Abbild. 106) oder dem Geländer am Schloss Grand Trianon (Abbild. 103). Die aufsteigende Bewegung dieses Ornaments eignet sich vortrefflich für den Zweck des Treppengeländers und bietet eine der besten 
Lösungen dieser schwierigen Aufgabe, die stets dem Schlosser viel Kopfzerbrechen gemacht hat. Ein besonders prächtiger Entwurf stellt in der Füllung sich wiederholende heraldische Lilien in einer nierenförmigen Umrahmung als Hauptmotiv dar, dazwischen sind jedesmal Scepter auf gekreuzten Palmen- und Lorbeer- bezw. Epheuzweigen angebracht. Die mit der Sonnenmaske und einem Medaillon geschmückten Pfeiler tragen eine Kriegstrophäe und zwei Putten mit dem königlichen Wappen. Wie aus den erhaltenen Originalen jener Zeit ersichtlich ist, waren die Ornamente wohl zur Ausführung in Bronze bestimmt, nur das Stabgerüst wurde aus Eisen gebildet (Abbild. 98 u. 99).

Verwandt mit Fortys Arbeiten, aber etwas nüchterner und trockener sind die Entwürfe des Architekten Desboeufs du Saint-Laurent, welche, von Pelletier graviert, in drei Heften zu sechs Tafeln (Balkone, Treppengeländer und Portalbekrönungen) erschienen. Das erste Heft trägt das Datum 1775. Bei seinen Treppen- geländern benutzt Desboeufs neben dem laufenden Hunde eine Reihe von zwei konzentrischen Kreisen, die entweder sich mit ihren Peripherien berühren (Abbild. 101) oder sich überschneiden, wie bei der Treppe im Schloss zu Compiègne (Abbild. 104). Weniger glücklich sind die Entwürfe für Balkone, bei denen er Muster benutzt, die nicht nur in der horizontalen, sondern auch in der vertikalen Richtung, also nach allen vier Seiten hin rapportieren, d. h. nicht abschliessen, sondern beliebig weiter fortgesetzt werden können.

Die übrigen Zeichner für Schmiedearbeiten im Stil Ludwigs XVI., Boucher fils, Caillouet, Fay, Aubert Parent verdienen kaum Berücksichtigung. Ihre Arbeiten sind dürftig, phantasielos und ohne jeden Reiz. Auch Lalonde, sonst ein fruchtbarer Geist, kommt in seinen Entwürfen für Gitter selten über steife langweilige Stabgerüste hinaus. Seine Schlösser, Schlüssel, Riegel und Klopfer sind zur Ausführung in Bronze bestimmt. Man beschränkte sich für das Schmiede-

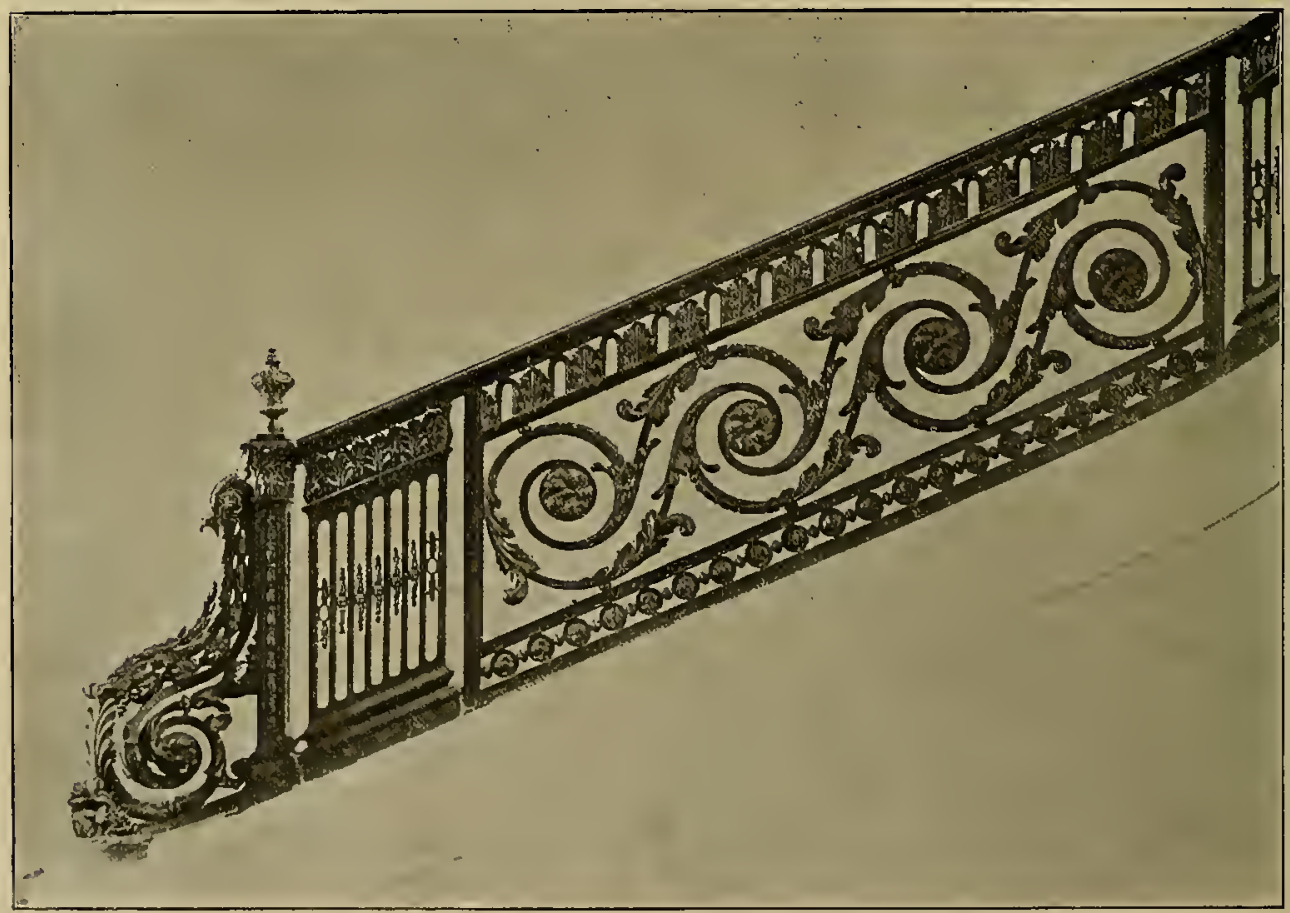

Abb. 106. Treppengeländer in der Ecole militaire zu Paris. 
eisen jetzt fast ausschliesslich auf das Gitterwerk, und auch hier verwandte man für die Ornamente nunmehr vorzugsweise Bronze, das mit den zumeist blank gefeilten Eisenstäben durch Niete verbunden wurde.

Eines der schönsten noch vorhandenen Beispiele dieser Verbindung von Schmiedeeisen mit Bronzeornamenten ist das Geländer der Haupttreppe in Petit Trianon (Abbild. 102). Hier sind die Eisenstäbe mit einem grünen Anstriche versehen, der vortrefflich $\mathrm{zu}$ den vergoldeten Bronzeornamenten steht. Besonders prächtig ist der wie ein Schlangenleib sich aufbäumende Anlauf gestaltet. Der Knauf hat die Form einer Vase. Die erste Füllung hinter dem Anlauf ist mit reichem Schmuck versehen, eine an einem Bande aufgehängte Lyra und ein Merkurstab zwischen einem Palmen- und Lorbeerzweige; das mittlere Feld des ganzen Geländers trägt die Initialen der Königin Marie Antoinette, die indessen erst später hinzugefügt sind, da das Geländer wahrscheinlich zwischen 1765 und 1768 geschaffen ist und zwar von Gamain, dem Vater des erwähnten Gehilfen Ludwigs XVI. Gamain verfertigte auch in Gemeinschaft mit dem Mechaniker Richer die Maschinerie jenes „Tischlein deck' dich", das sich Ludwig XV. in Petit Trianon hatte einrichten lassen. Dasselbe verschwand auf den Druck einer Feder hin im Fussboden, um voll besetzt wieder empor zu tauchen. Nach einem Rechnungsbericht von 1791 hatte Gamain eine Rechnung von 13264 Frcs. für seine in Petit Trianon geleisteten Schlosserarbeiten aufgestellt; 7700 Frcs. hatte er schon erhalten, den Rest schuldete man ihm noch. Auch das einfache, fast schmucklose Gitter der Cours d'honneur stammt wohl von ihm; hier sind die Ornamente ebenfalls Bronze. Es ist wahrscheinlich, dass die Erfindung des schönen Treppengitters auf den Erbauer des Schlosses, den jüngeren Gabriel, zurückgeht. ${ }^{1}$ )

1) Desjardins, G., Le Petit-Trianon. Versailles 1885. S. 33 und 406 .

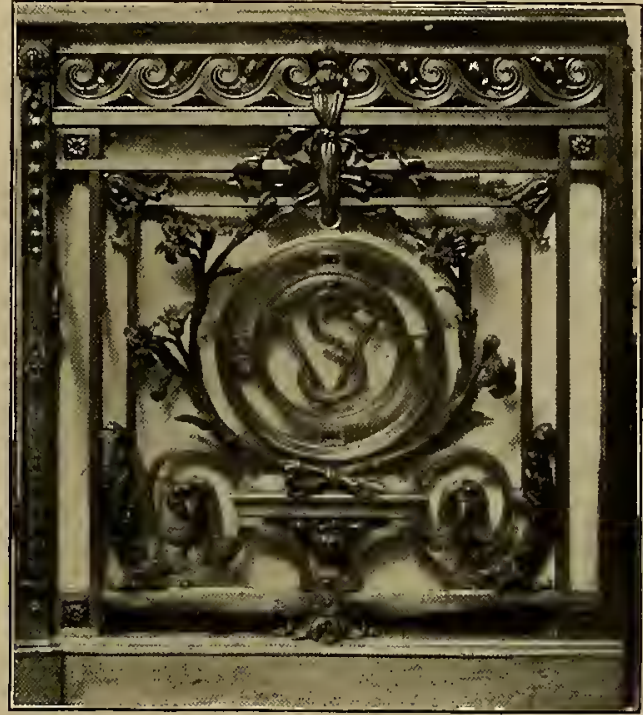

Abb. 107. Gitter in St. Germain-l'Auxerrois zu Paris.

Ganz aus Eisen gebildet ist dagegen die stattliche Balustrade, die sich an der Nordwestecke des Schlosses Grand Trian on befindet. Der ansteigende Gitterteil ist mit einem sich tot "laufenden Hunde", gefüllt, der hier drei grosse Ovale mit Akanthusrosetten einschliesst, während. in die Zwickel breite Akanthuskelche gesetzt sind. Der dann folgende, horizontal liegende Abschnitt des Gitters ist mit zwei symmetrischen, starken Akanthusspiralen gefüllt, das ovale Medaillon in der Mitte, unterhalb dessen zwei Schlangen ihre Leiber zusammentingeln, ist mit einem Blitz geschmückt (Abbild. 103).

Auch sonst sind die Bauten Jean. Jacques Gabriels mit prächtigen Gitter. werken versehen. Im Schlosse zu Com. piègne, das er umbaute, legte er eine grosse Festtreppe an mit einem prachtvollen Geländer, das ähnlich wie bei der Treppe von Petit Trianon hinter dem als grosse Volute gestalteten Anlauf zunächst ein besonders reich ausgestattetes Feld zeigt. Auch hier sind die vier Ecken dieses Feldes durch rautenförmige Rosetten markiert. Den Hauptschmuck bildet eine Sonnenmaske auf gekreuzten Sceptern zwischen Lorbeerzweigen. Dann folgt 


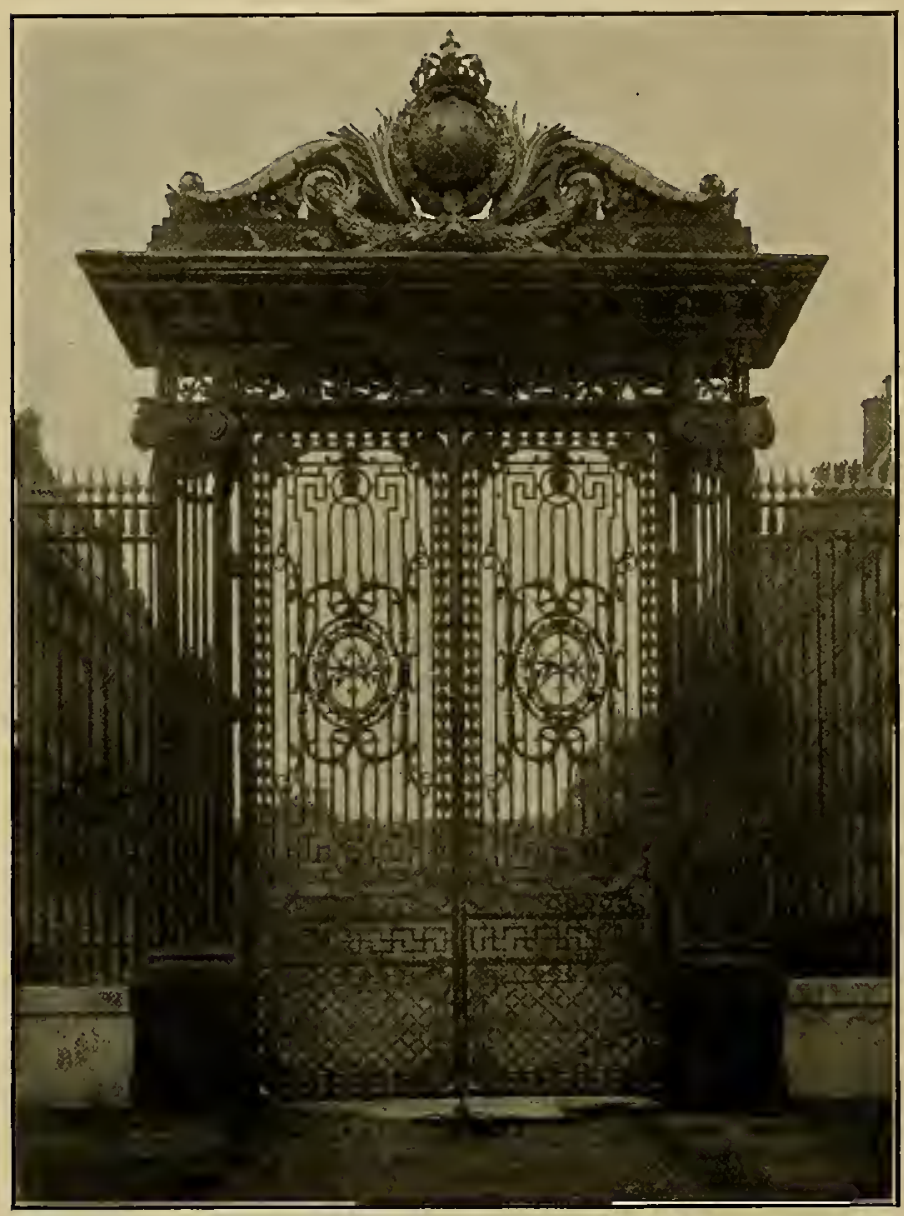

Abb. 108. Portal des Justizpalastes zu Paris.

volles Motiv bringt Leben in die sonst starre Regelmässigkeit der parallelen Linien hinein: das sind die kleinen gewellten Stacheln, die von dem die Enden der Stäbe vereinigenden Bunde ausgehen. Sowohl die jede Füllung in zwei ungleiche Hälften teilende Querleiste, wie die Flächen der einrahmenden Pilaster und des Architravs sind mit dem am Treppengeländer von Compiègne im grossen angewandten Ornament der sich überschneidenden Kreise mit einbeschriebenen Rosetten gefüllt. Die unterhalb der Kapitäle seitlich neben den Pfeilern ausladenden, auf kurzen kräftigen Eisenpfeilern ruhenden Voluten erinnern lebhaft an das gleiche Motiv am Portal des Gitters der Cour Royale zu Versailles. Auch die Gitterstäbe in Form von Lanzen mit eine fortlaufende Reihe sich überschneidender Kreise, durch Rosetten verbunden, welche einen konzentrisch einbeschriebenen Lorbeer - oder Epheuzweig um. schliessen (Abbild. 104).

In Paris besitzt die Ecole Militaire auf dem Marsfelde, die Gabriel in den Jahren 1752-1773 erbaute, in dem Portale des Vorhofes und dem Treppengeländer vortreffliche Schmiedearbeiten. Die Wirkung des Portals ist leider durch das Fehlen des Oberteils der Bekrönung stark geschädigt (Abbild. 105). Sehr einfach, aber dabei doch von gutem harmonischen Zusammenklang sind die übrigen Teile des Portals. Die Thürflügel sind aus glatten, paarweis zusammengefassten Stäben gebildet. Nur ein unscheinbares, aber höchst wirkungs-

Fransenbehang stammen ebendatier. Sie sind überhaupt in dieser Zeit wieder sehr beliebt. Das herrliche Treppengeländer der Ecole militaire mit schwungvoll gezeichnetem Anlauf und einer zierlichen Vase als Knauf setzt sich aus langgestreckten Feldern zwischen gedrungenen, breiten kannelierten Pilastern zusammen. Die grossen Felder füllt ein viergliedriger, in sich geschlossener "laufender Hund" mit Akanthusblättern aus, die die Stabspiralen fast in ihrer ganzen Länge begleiten $(\mathrm{Ab}$ bild. 106). Das von Gabriel erbaute Ministerium der Marine besitzt ebenfalls noch ein gutes Treppengeländer.

Ein sehr stattliches Geländer befindet sich auch in dem 1763 von Constant d'Jvry errichteten Treppenhause des Palais 
Royal. Es ist aus blank gefeiltem Eisen mit vergoldeten Bronzeornamenten gebildet. Seine Füllung setzt sich aus Kreisen mit einbeschriebenen Rosetten, welche mit ihren Peripherien aneinanderstossen, zusammen, die Zwickel sind mit Akanthuskelchen besetzt. Das Gitter soll vom Schlosser Corbin nach Modellen des Jacques Caffieri angefertigt sein. ${ }^{1}$ ) Das Treppengeländer des früheren Hôtel des Postes (Hôtel d'Armenonville), das mit einem "laufenden Hunde" geschmückt ist, wird jetzt in den Sammlungen des Musée des arts décoratifs zu Paris aufbewahrt.

Von sonstigen noch vorhandenen Treppenbrüstungen ist noch das der Kanzel in St. Roch zu erwähnen, das ebenfalls aus blank gefeiltem Eisen mit Bronzezieraten besteht und wahrscheinlich von Garnier verfertigt ist. ${ }^{2}$ ) Von gleicher Arbeit ist auch das schöne Kommuniongitter in St. Germain l'Auxerrois, der kleinen gotischen Kirche gegenüber dem Louvre (Abbild. 107). Es besteht aus mehreren Füllungen, von denen die dargestellte das Monogramm SV (Sainte Vierge?) in einem doppelkreisförmigen Medaillon, umrahmt von Lilienzweigen, enthält. Das Medaillon hängt an einer Bandschleife, bekanntlich ein für den Stil Ludwigs XV1. charakteristisches Motiv.

Wohl die späteste erhaltene Schmiedearbeit mit Bronzebeschlägen ist das Portal und Gitter des Justizpalastes in

1) Champeaux, A. de, L'art décoratif dans le vieux Paris. Paris 1898. S. 264.

2) Abbildung bei Starkie Gardner, Ironwork 11, Fig. 123.
Paris (Abbild. 108). Die Thorbekrönung mit dem königlichen Wappen ist erst im 19. Jahrhundert wieder hinzugefügt worden. Es hat sich noch ein Stich erhalten, der bis auf geringe Abweichungen genau die Form dieses Portals zeigt. Er ist das erste Blatt von einer Stichfolge und trägt die Ueberschrift: „Différentes Grilles pour les Chateaux, les Choeurs et les Chapelles de Communion. Composé et Dessiné par la Londe en 1789 " und die Unterschrift: „La Grille du Palais Marchand Terminé d'après le desin de Mr. Antoinne Archittec du Roy". Der damalige Name Palais Marchand für das jetzige Palais de Justice hat sich noch in der im Palais befindlichen Galerie Marchande erhalten. Der künstlerische Anteil an der Herstellung des Gitters verteilt sich vielleicht in der Weise, dass Lalonde, dessen Stil das Gitterthor durchaus entspricht, den mehr skizzenmässigen Entwurf, dem Architekten Antoine die ausführliche Zeichnung des einzelnen anheimfiel. Der Schlosser Bigonnet unternahm die Herstellung des Portals, das 200000 Livres kostete.

Die politischen Ereignisse des ausgehenden Jahrhunderts sowohl, wie auch die neue Geschmacksrichtung, die die Kunst des alten Hellas und Rom, wo eine eigentliche Schmiedekunst unbekannt war, zum Vorbilde nahm, waren der weiteren Entwickelung der Schmiedekunst nicht förderlich. In der sog. Empirezeit kommen geschmiedete Arbeiten von künstlerischer Form fast gar nicht mehr vor, an die Stelle der Schmiedearbeit trat nun der Eisenguss, der für eine längere Zeit das Feld behaupten sollte.

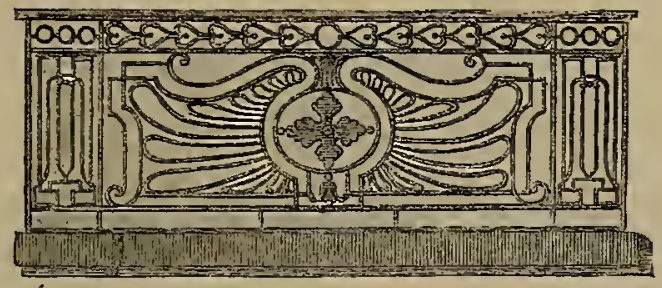

Abb. 10y. Fenstergitter nach einem Stiche von J.-F. Forty. 


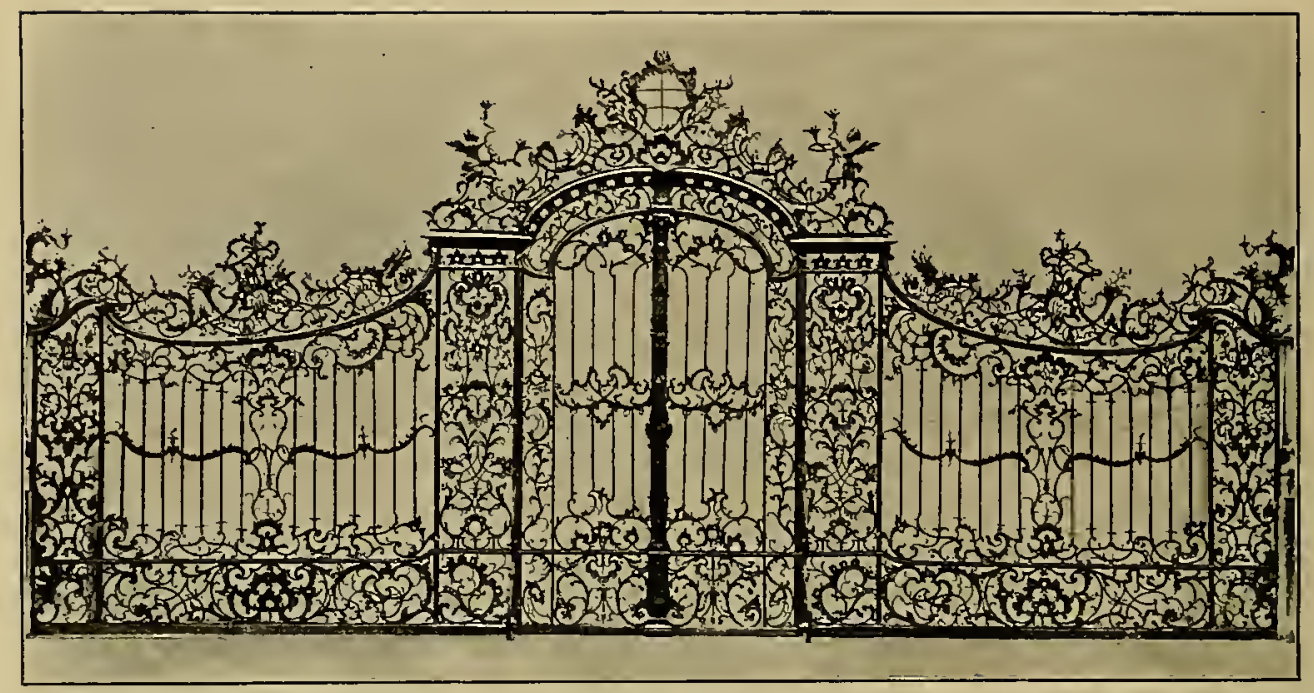

Abb. 110. Chorgitter in der Abteikirche zu Amorbach.

\section{Deutschlands Schmiedekunst zur Zeit des Rokoko und Zopfstils.}

Einer der bedeutendsten Vorkämpfer des deutschen Rokoko, der auch durch vortreffliche Entwürfe diesem Stile Eingang in die Schmiedekunst verschaffte, war Franz Cuvilliès, der Hofbaumeister der bayerischen Kurfürsten zu München. Geboren zu Soignies im Hennegau, wurde er wegen seiner mangelhaften Körperbildung noch in jungen lahren als Hofzwerg vom Kurfürsten Max Emanuel, der damals als Statthalter der Niederlande in Brüssel lebte, in dessen Haushalt aufgenommen, und, da er grosse Talente zeigte, sorgfältig erzogen. 1717 wurde er Fähnrich im Leibregiment zu Fuss; wahrscheinlich war diese Bestallung nur ein Vorwand, um ihm eine Besoldung zukommen zu lassen. $\mathrm{Zu}$ seiner weiteren Ausbildung wird er dann 1720 mit einer vom Kurfürsten ihm gewährten Unterstützung von 1100 Gulden jährlich - für die damalige Zeit eine sehr hohe Summe nach Paris gesandt und geniesst hier den Unterricht des Architekten Jacques François Blondel. Fünf lahre später er- hielt er seine Anstellung als Hofarchitekt des bayrischen Kurfürsten. Seine im reifsten Rokoko ausgeführten Hauptwerke, die reichen Zimmer in der Residenz zu München und die Amalienburg im Nymphenburger Park, fallen noch in die dreissiger Jahre.

Uns interessieren hier zunächst seine Entwürfe für Schmiedearbeiten, von denen er zwei Büchlein zu je sechs Tafeln herausgegeben hat. ${ }^{1}$ ) Aus dem Titel der Bücher, welche die Bezeichnung tragen: "Nouvellement Inventé par François de Cuvilliès, Conseiller et Architecte de Sa Majesté Imperialle", folgt, dass sie zwischen dem 12. Februar 1742 und dem 20. Januar 1745, als Karl Albert unter

1) Neudruck: Kunstschmiedearbeiten im Stil des Rokoko von François du Cuvilliès. Berlin, Ch. Claesen \& Co. - Ueber das Leben Cuvilliès vgl. Trautmann, F., Der kurfürstliche Hofbaumeister Franz Cuvilliès und sein Schaffen in Altbayern, in der Monatsschrift des historischen Vereins von Oberbayern. 4 lahrg. 1895, S. $68 \mathrm{ff}$. 


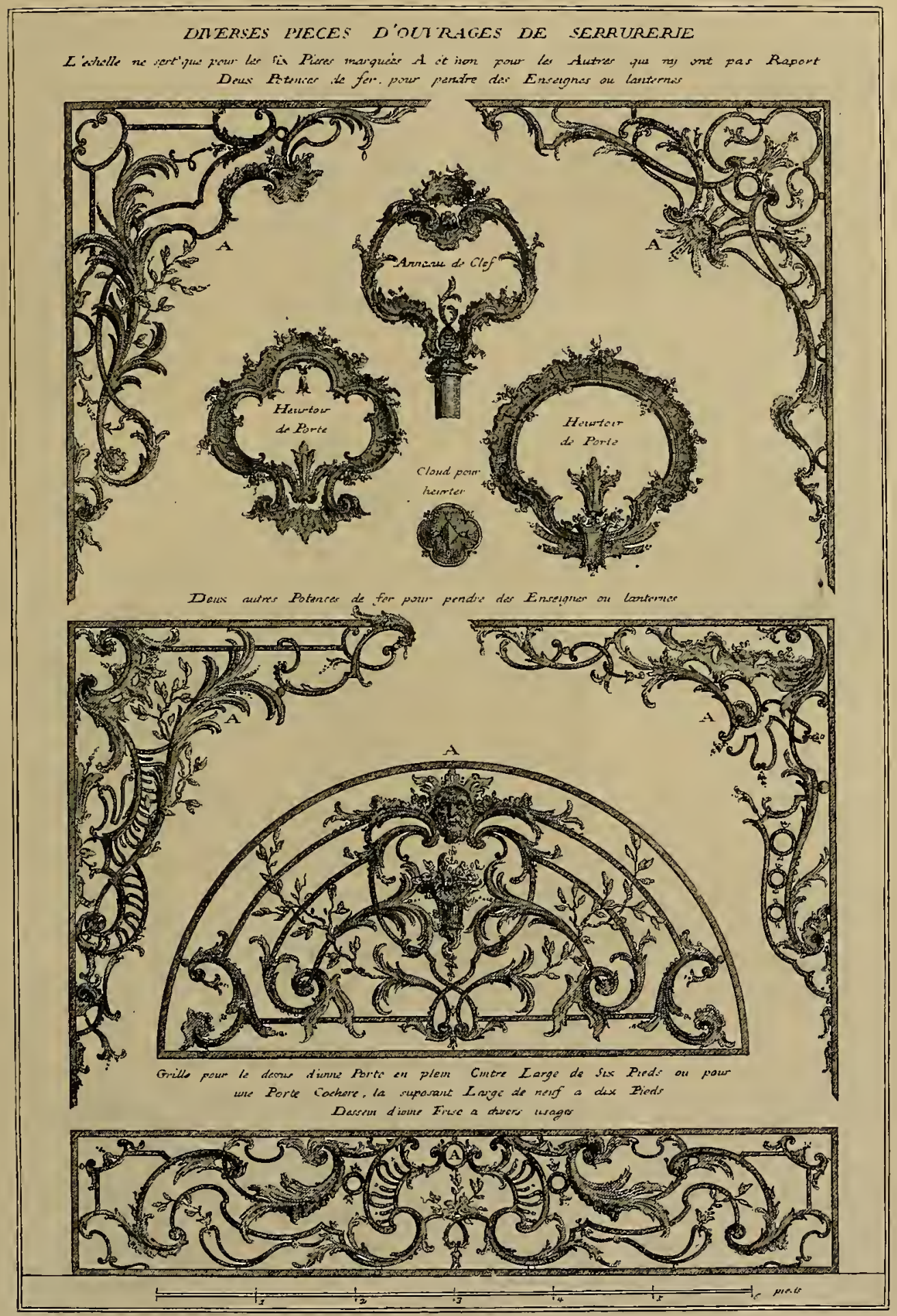

Abb. 111. Entwürfe für Schmiedearbeiten von F. Cuvilliès. 


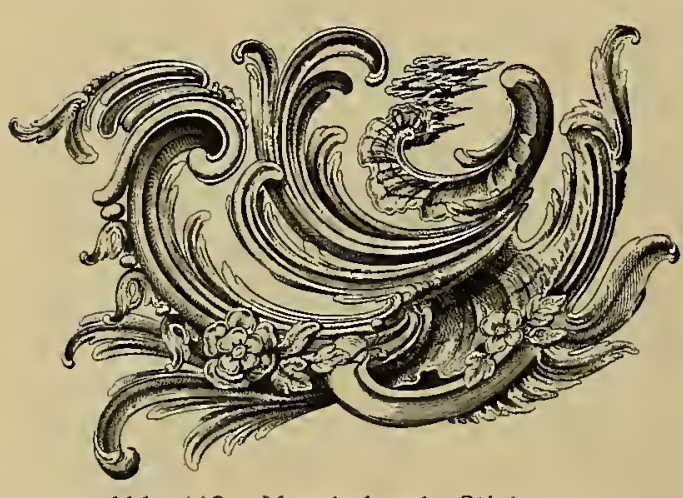

Abb. 112. Muschelwerk, Stich von J. L. Birckenfeld.

liche Anklänge an die in der Distribution des maisons de plaisance von Blondel 1738 abgebildeten Schmiedearbeiten (vgl. Abbild. 82, sowie Cuvilliès 7 livre pl. 1 mit Blondel pl. 57, Cuvilliès 7 livre pl. 2 mit Blondel pl. 52 , Cuvilliès 8 livres pl. 2 und 3 mit Blondel pl. 53, Cuvilliès 8 livre pl. 5 mit Blondel pl. 55).

Das, was die Ornamentstiche des Cuvilliès vermissen lassen, eine klare, zur Ausführung in Schmiedeeisen brauchbare Zeichnung des für die deutschen Schlosser neuen Ornamentes, des Muschelwerks, bieten die Tafeln eines sehr fleissi-

dem Namen Karl XII. deutscher Kaiser war, entstanden sein müssen. Sie sind von Charles Albert de Lespilliez gestochen und enthalten Portale, Balkongitter, Treppengeländer, Oberlichte, Wandarme, Klopfer, Schlüsselschilder, Schlüsselgriffe, Riegel u. s.w. Ein Blatt giebt Riegel und Schlossteile zur Ausführung in Bronze. Es sind zum Teil gefällige Kompositionen mit Hervorhebung des Stabwer. kes, das sich in lebendig bewegten Linien ergeht. Das Muschelwerk, das ein rindenartiges Aussehen hat, ist meistens nur skizzenhaft angedeutet. Dazu kommen als weiterer Zierat Palmenzweige, natürliche Pflanzen und Blumen aller Art, auch hier und da Masken und Blumenvasen (Abbild. 111). Das nahe Verhältnis Cuvilliès zu Blondel, dessen Unterricht er ja genossen, kommt auch in diesen Stichen zum Ausdruck. Sie zeigen zum Teil deut-

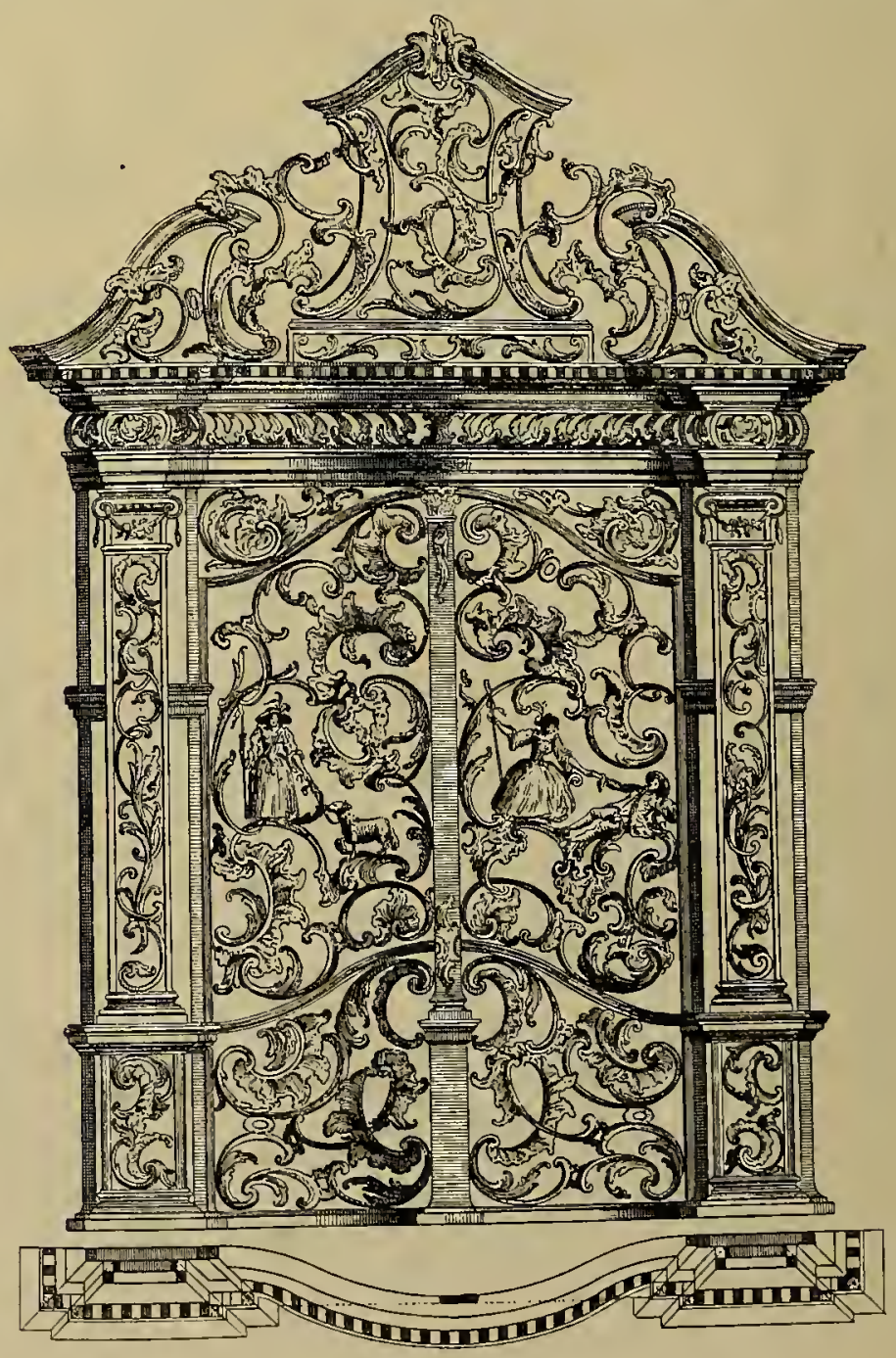

Abb. 113. Portal (Ordo Jonica), Stich von J. L. Birckenfeld. 
gen Stechers, des Augsburger Schlossermeisters Johann Samuel Bir. ckenfeld, die derselbe im Verlage des Martin Engelbrecht und des Johann Georg Hertel her. ausgab. Ein Teil seiner Stichfolgen geben flott gezeichnetes Muschelwerk in natürlicher Grösse. Die erste Folge betitelt er: "Neu inventiert Lauberbuch bestehend in 6 Theil, denen Anfängern der Zeichnung zum Nuzen oder vielmehr den jenigen welche keine gelegenheit haben, sich informieren $\mathrm{zu}$ lassen. durch Joh. Samuel Birckenfeld, Schlossermeister gezeichnet". Sie sind jedenfalls sehr brauchbar und geben gute Vorlagen für das neue Ornament

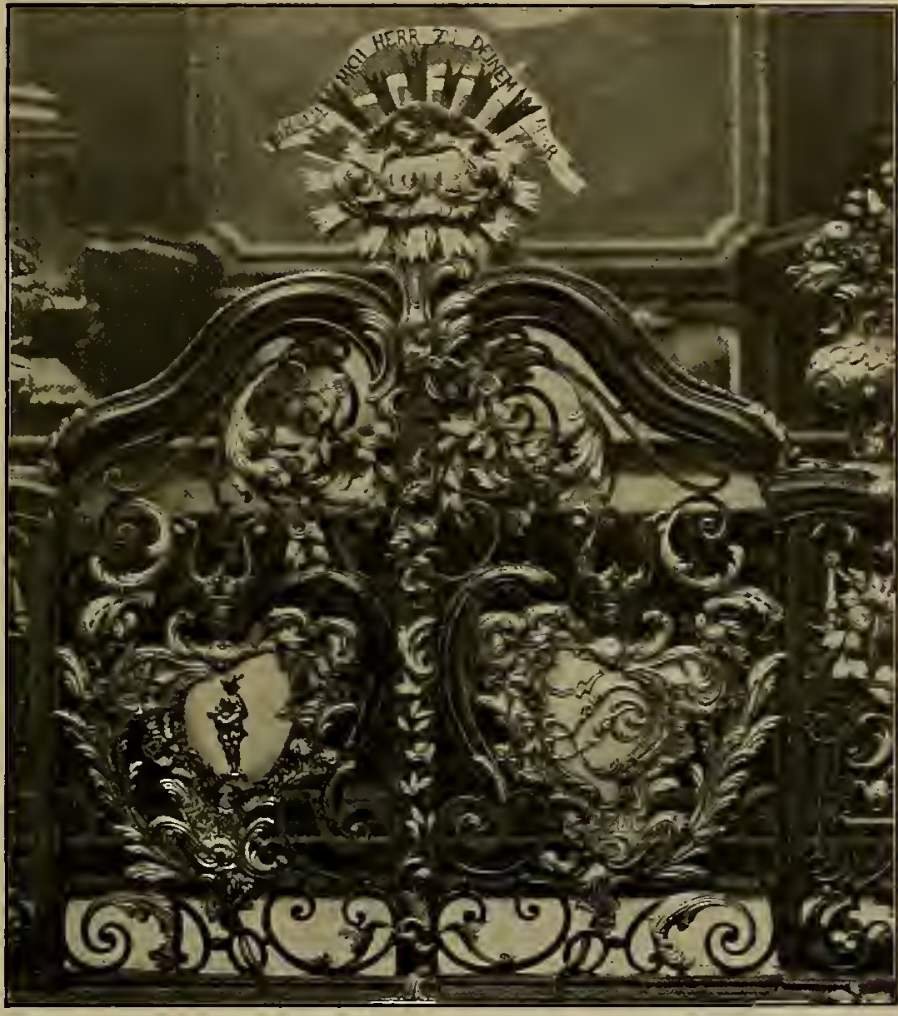

Abb. 114. Gitter in der Barfüsserkirche zu Augsburg.
(Abbild. 112). Ausserdem veranstaltete er auch eine Veröffentlichung von ähnlichem Muschelornament mit beigefügtem Stab. ansatz in kleinerem Massstabe. $\mathrm{Er}$ begründet auf dem Titelblatt der neuen Folge dieselbe mit den Worten: „Weilen aus vielfältiger erfahrung, dass es denen jenigen welche nach lernung Grosser Lauber-Gitterwerck zu Zeichnen anfangen, sehr Schwer Kleinere reinlich nachzumachen ankömt. So hat es mir in diesem Vorbericht anlass gegeben (um es denen jenigen desto leichter zu machen) von zerschiedenen Sorten kleiner in Spreng. werck (d. i. Gitterwerk) tauglicher Lauber mitzutheilen, um sich zuvor auf solche Art Exercieren zu können." In einem längeren Gedichte, das auf dem zweiten Blatte folgt, wendet er sich gegen solche, welche behaupten, man könne seine Zeichnungen nicht schmieden.

"Wer einen Zweifel hat der kō̄e nur zu mir ich stelle ihm davon die möglichkeit selbst für

Ich wollte noch vielmehr von eisen machen können

Wan man zusamt dem Ruhm den Lohn auch wollte gönnen."

Ausserdem hat Birckenfeld noch eine Anzahl von Folgen mit Vorlagen für Gitter, Wandarme, Untersätze, Kaminböcke, Leuchter, Traufstützen, Schlossteile u. s. w. herausgegeben. Seine Gitter sind zum grossen Teil wenig bedeutend in der Komposition, oft wird die Klarheit der Zeichnung durch übergrosse Verwendung von Muschelwerk gestört. Am besten ist noch eine bei Hertel erschienene Folge von sechs Blatt mit Portalen, von welcher fünf die Bezeichnung führen: Ordo Toscana, Dorica, Jonica (Abbild. 113), Corinthia und Composita. Die Kapitäle der Pfeiler sind jedesmal in der Art der genannten Säulenordnungen gebildet, während die Flächen des Schafts mit Rokokoschnörkeln gefüllt sind. Einige sind recht 


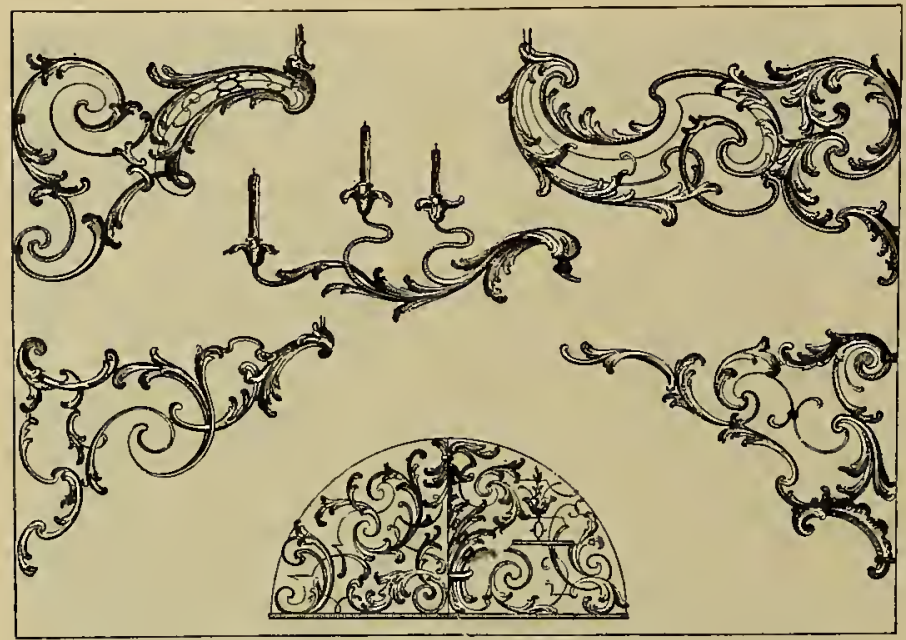

Abb. 115. Vorlagen für Schmiedearbeiten von E. Eichel.

Augsburg, das sich noch jetzt dort befindet und das Datum 1760 trägt. Die Abbildung 114 stellt die Eingangsthür des Gitters dar, dessen oberer Rand stark geschweift ist. Die Thorflügel tragen zwei Kartuschen mit dem Wappen und dem Monogramm Peter Laires, zu beiden Seiten desselben sind grosse Palmzweige durch das Gitter gesteckt. Neben dem Muschelwerk, das hier in einer eigentümlichen Form mit regelmässigen Riefeln

gut im Aufbau und Umriss, wenn auch überreich mit Muschelwerk ausgestattet, zwischen welches auf den Thürflügeln kleine Figuren, Schäfer und Schäferinnen, Jäger und Tiere, zum Teil recht glücklich, hineinkomponiert sind. Die Entwürfe für Drücker, Schlossbleche, Griffe und Anschlagplatten sind zumeist in Originalgrösse dargestellt. Die als Zierat hinzugefügten Köpfe und Tiere sind nicht recht mit dem Muschelwerk organisch verbunden.

Aus der Kunst-Gewerbe- und Handund umgeschlagenen, leicht gewellten Rändern auftritt, sind auch zum Schmuck des elegant gezeichneten Stabwerkes natürliche Blumen und sehr ins Kraut geschossene Akanthusblätter verwandt worden. Die Pfeiler an den Seiten tragen Blumenvasen.

Mit ganz geringen Abweichungen sind zwei Teile des Gitters in einer Stichfolge von Emmanuel Eichel, ${ }^{1}$ ) die bei Joh. Georg

1) Nach P. v. Stetten (a. a. O. I. S. 409) wird der Kupferstecher Emmanuel Eichel 1770 Instruktor an der Zeichenschule des evangelischen Gymnasiums in Augsburg (geb. 1717). werks-Geschichte der Reichs-Stadt Augsburg von Paul von Stetten (Augsburg 1779) erfahren wir, dass der Vater des Ornamentstechers, Johann Balthasar Birckenfeld, auch ein Schlosser war, „welcher ungemein feine, zierliche und künstliche Schlösser verfertigte", und dass sein Sohn "nicht geringer in dergleichen Arbeiten " gewesen sei. Von der Hand des letzteren stamme das vom Kaufmann Peter Laire gestiftete Gitter in der Barfüsserkirche zu

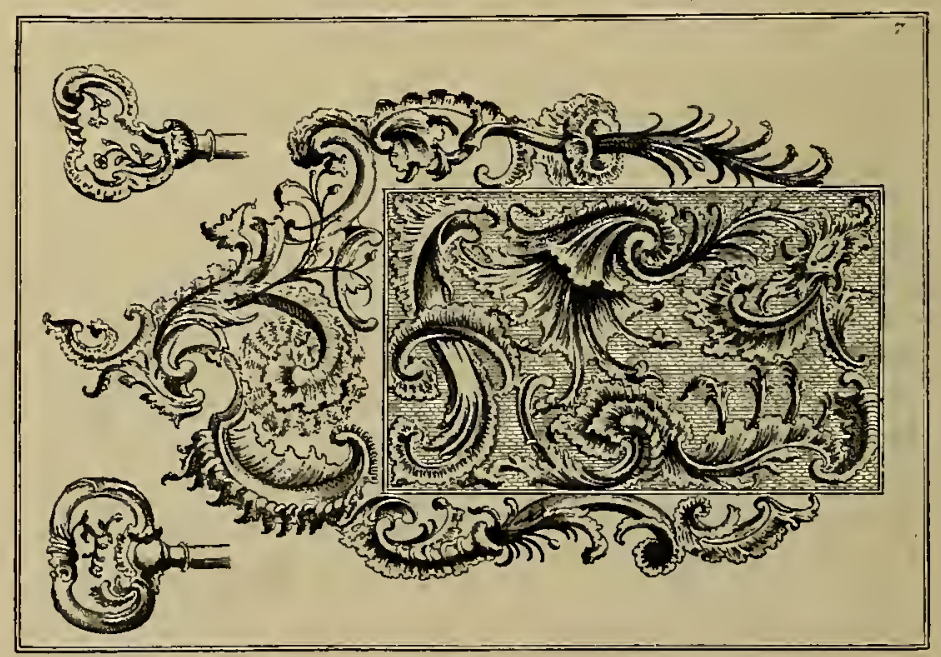

Abb. 116. Schloss und Schlüsselgriffe nach einem Stichc von J. Baumann. 
Hertel (Verl.-Nr. 134) erschien, abgebildet. Da sich Eichel in seinen sonstigen Stichen als ein selbständiger,erfindungsreicher Künstler offenbart, so bietet diese Entlehnung nur wieder einen Beweis für dieHarmlosig. keit, mit der man damals Arbeiten anderer kopierte, ohne sich über die Frage des geistigen Eigentums grosse Skrupel zu machen. Eichels übrige Entwürfe, seine Kreuze, Wandarme, Leuchter und Treppengeländer sind zum Teil von schöner, fliessender Linienführung (Abb.115). Bei manchen Arbeiten macht er nur bescheidenen Gebrauch von Muschelwerk, so dass die keck geschwungenen Züge der Stäbe klar her. vortreten, bei anderen überschwemmt das wellenartig emporschiessende Muschelwerk zu sehr die Zeichnung des Stab. gerüstes.

Yoch viel schlimmer macht sich dieses Ueberwuchern des Muschelwerkes in den bei Martin

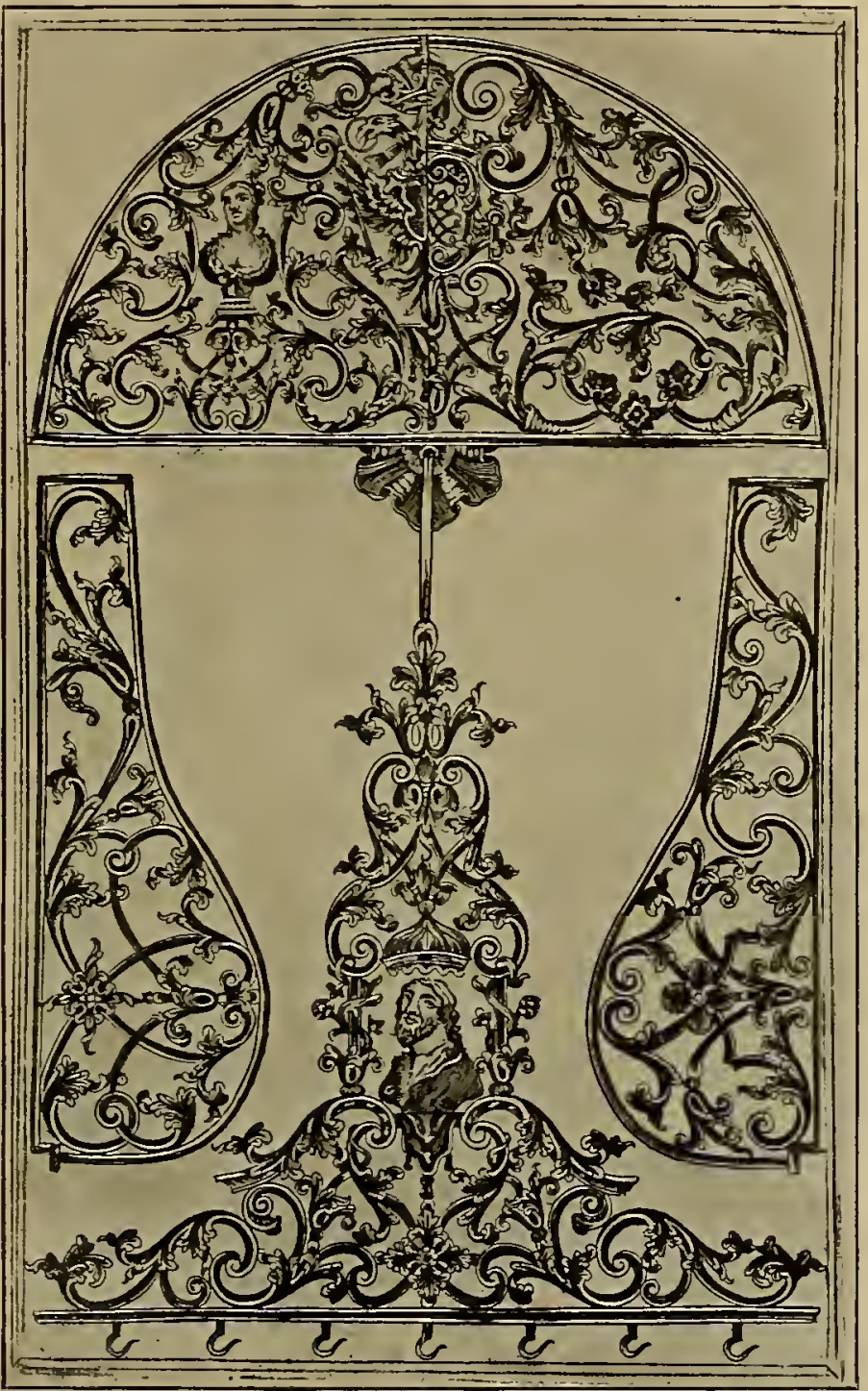

Abb. 117. Vorlagen für Schmiedearbeiten von J. A. Graffenberger.
Engelbrecht in Augsburg erschienenen Stichen des Joseph Bau. mann geltend. Die weichlichen, wolligen Schnörkel füllen mit ihren breiten lappigen Flächen fast den ganzen Grund(Abbild.116). Aehnlich ist es mit den von Philipp Jakob Kessel gezeichneten und von Mathias Losherr gestochenen Entwürfen mit fedrig zerflatterndem Muschelwerk. Die Zeichnung wirkt, da jedes klare Kompositionsschema fehlt, unruhig und zerrissen. Und doch sind auch solche mit Muschelwerk überladenen Vorlagen, wie z. B. die Oberlichtgitter des Klosters Ottobeuren beweisen, in Wirklichkeit ausgeführt worden. Die unter dem Doppeltitel ,Schlosser Riss“, „,Dessins de serrureries" durch Hertel veröffentlichten Stiche von Franz Xaver Haber. mann betonen freilich das Stabgerüst, zeigen aber sonst krause, unruhige Formen.

Oesterreichischer Herkunft scheint der Stecher JohannAndreas Graffenberger gewesen zu sein. Seine früheren Vorlagen geben Gitter, welche eine Weiterbildung der österreichischen Schmiedearbeiten in 
Laub- und Bandelwerkformen darstellen. Nur sind die gebrochenen Linien durch rundlich gebogene ersetzt. Der Akanthus ist lebendig bewegt, indem die Spitzen der Blätter umgebogen sind. In späteren Entwürfen erscheint das Muschelwerk, das

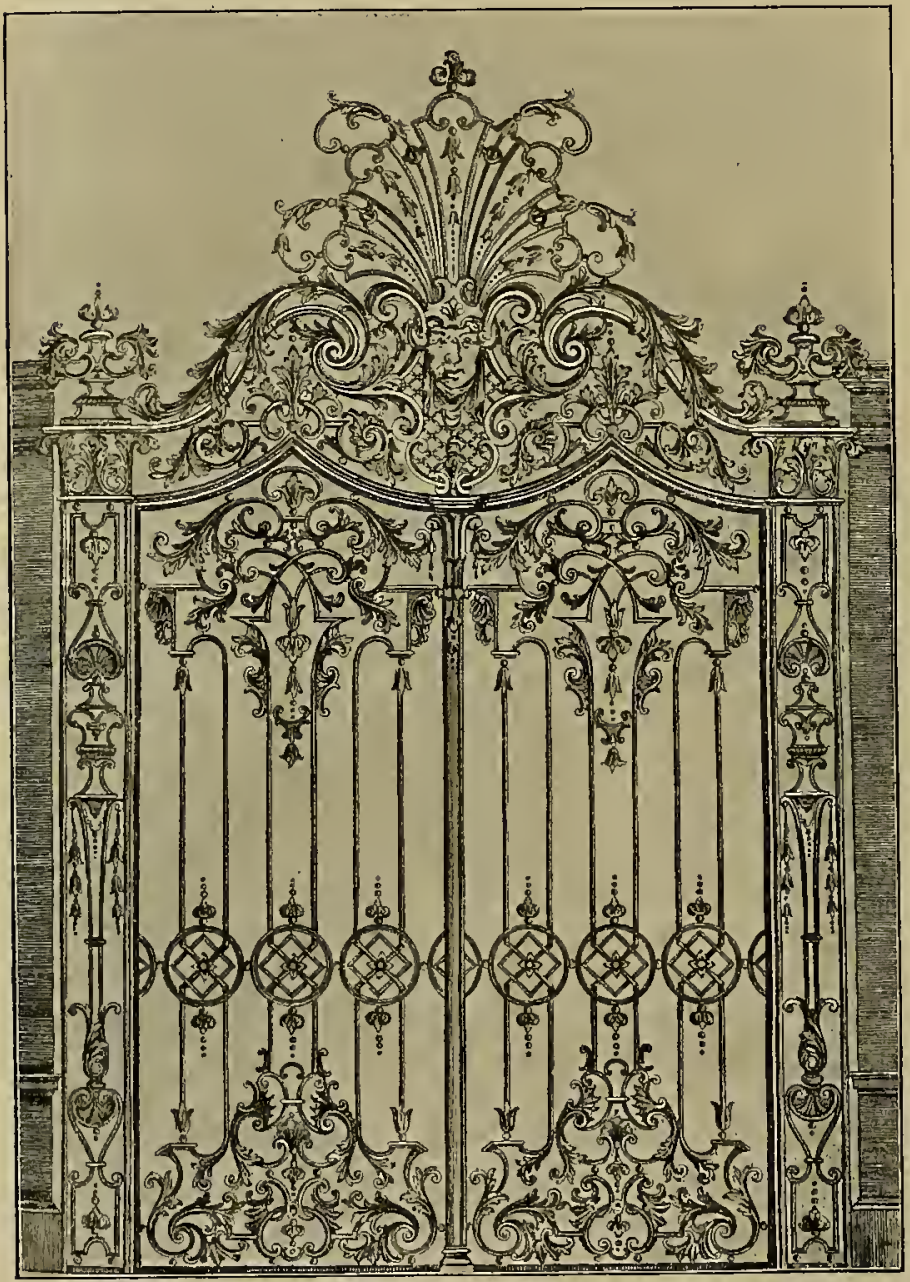

Abb. 118. Portal nach einem Stiche von H. G. Forster.

Gute, frisch empfundene Entwürfe selbständiger Erfindung bietet auch das Schlosserbüchlein des Heinrich Gottlieb Forster (Forshter schreibt er sich), Schlossermeisters und Eisenschneiders in Brünn, der 1723-25 verschiedene Gitterthore im Schlosse Nikolsburg in Mähren ausführte. ${ }^{1}$ ) Auch hier finden wir noch $\mathrm{Re}$ miniszenzen an das Laubund Bandelwerk, das ja gerade in den Ländern der österreichisch-ungarischen Monarchie eine Heimat gefunden hatte. Neben reichausgebildetem Muschelwerk, das bald an die Rippen der Muscheln, bald an Fledermausflügel anklingt, findet auch der Akanthus, sowie Masken und Tiere Verwendung (Abb. 106).

Auch Deutschland besitzt ein Nancy und einen Lamour, das ist Würzburg, wo der Schlossermeister Oegg im Verein mit dem Architekten Balthasar Neu. mann Schmiedewerke schuf, die an Schönheit der Zeichnung nur wenig hinter des Lothringers unvergleichlichen Arbeiten zurückstehen, sie aber an technischer Vollendung weit übertreffen. Leider sind die Würzburger Schmiedearbeiten nicht so vom Glück be-

mit seinen tiefausgeschnittenen Formen dem Akanthuslaub Graffenbergers sich annähert. Einer der Stiche zeigt ein Portal von gutem Aufbau. Die Füllungen sind nicht ohne Geschmack gegliedert. In der Ausführung würde das Gitterthor jedenfalls noch eine bessere Figur machen, als in der ziemlich ungeschickten Zeichnung. günstigt worden, wie die von Nancy. Ein grosser Teil derselben ist verloren gegangen, und ein so stolzes Abbildungswerk, wie Lamour es uns hinterlassen, existiert nicht, das uns für das Fehlende einen Ersatz bieten könnte.

1) Siehe: Schireck, C., Die Kunstschlosserei in Mähren. Brünn 1893. S. XVl. 


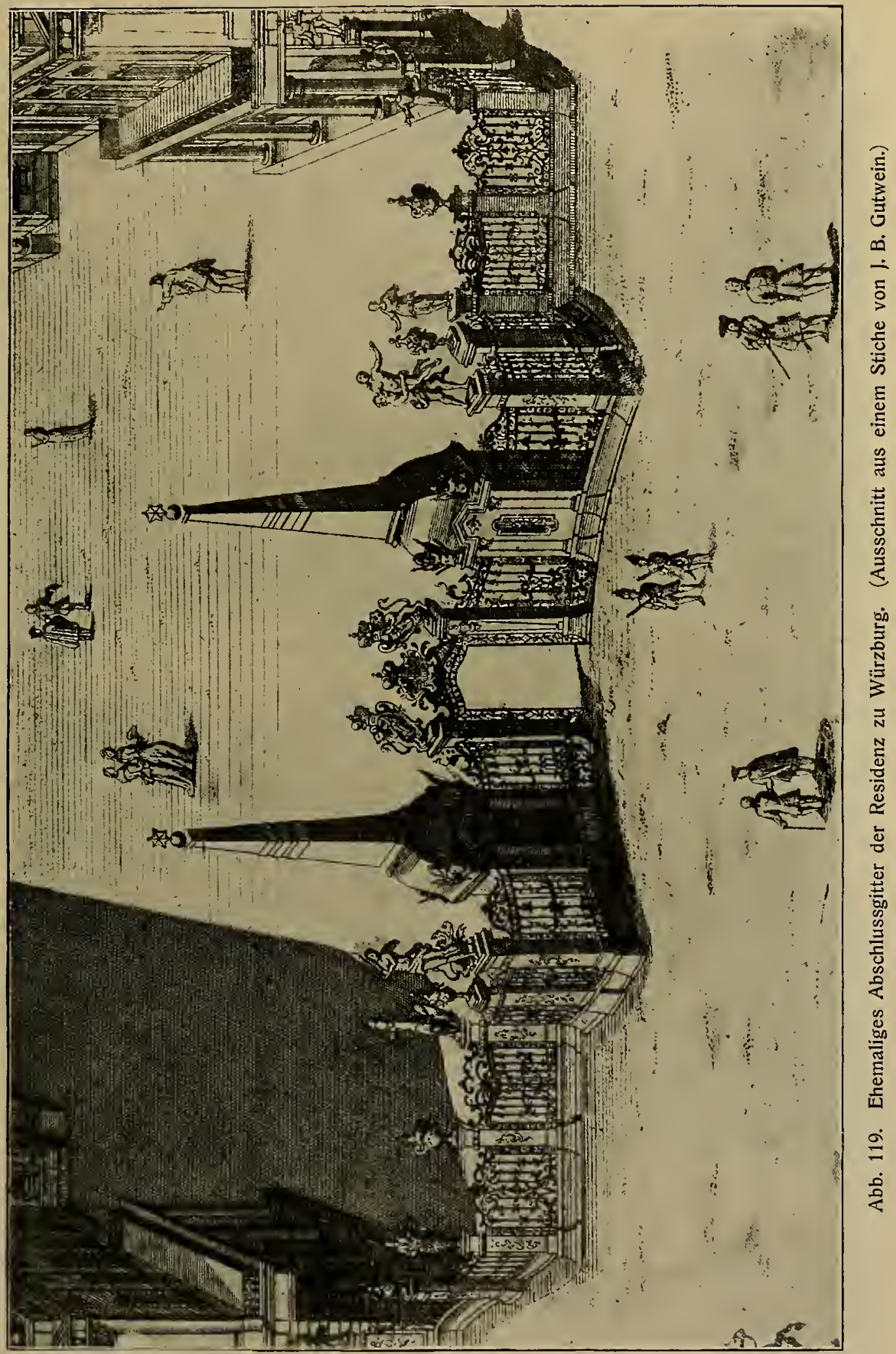




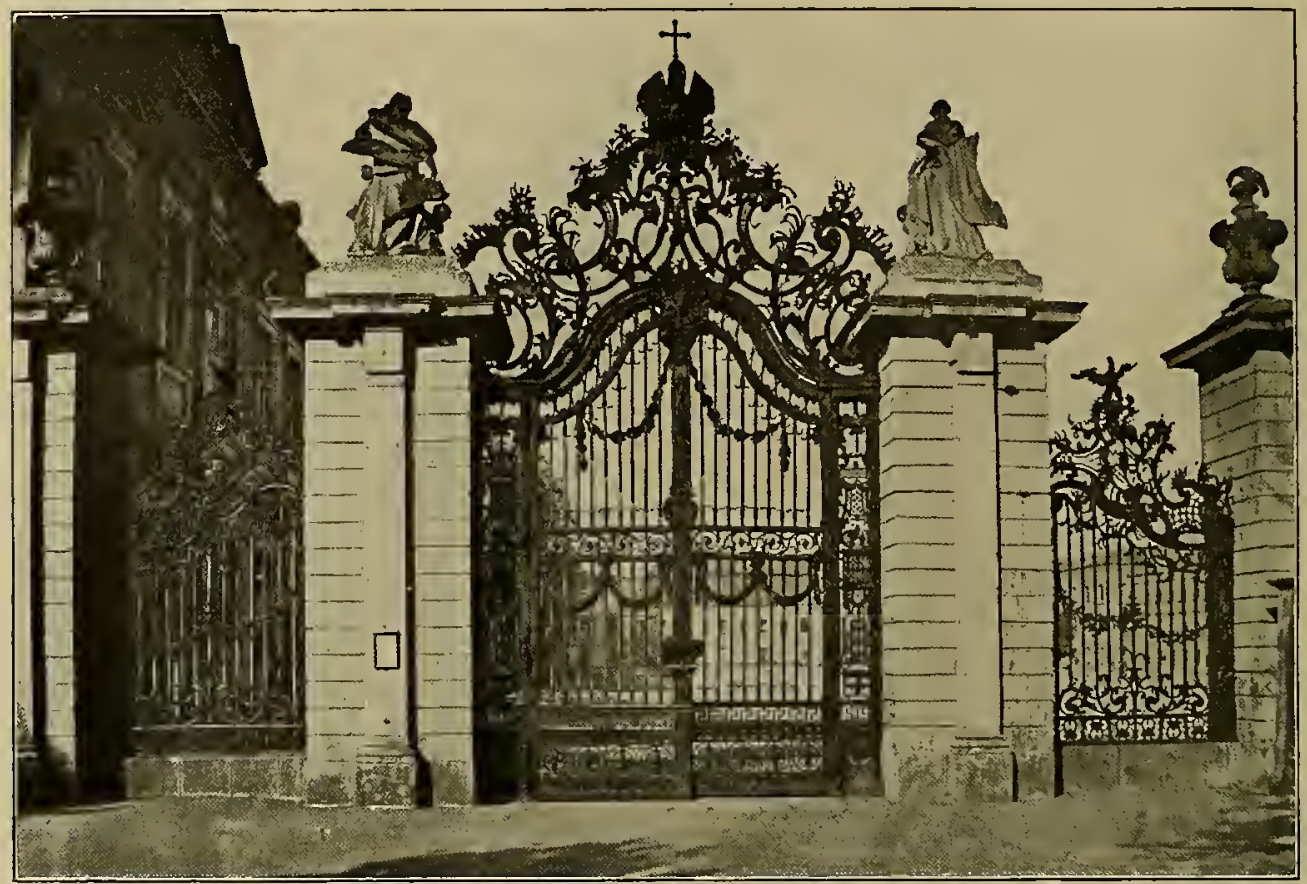

Abb. 120. Gartenthor der Residenz zu Würzburg (am Residenzplatze).

Johann Georg Oegg $(1703-80)$ stammt aus Siltz in Tirol. Nachdem er bei seinem Oheim Peter Oegg in Linz eine längere Lehrzeit durchgemacht hatte, kam er nach Wien und arbeitete dort in der Hofschlosserei. Die Erbauung des fürstbischöflichen Residenzschlosses zu'Würzburg durch Balthasar Neumann, zu deren Ausschmückung neben den übrigen Künsten und Handwerken auch die Schmiedekunst in weitgehendem Masse hinzugezogen werden sollte, war die Veranlassung zu seiner Berufung als fürstbischöflicher Hofschlosser nach Würzburg. Man nimmt an, dass Neumann in Wien gewesen sei. Eine Bestätigung dafür giebt auch seine Bekanntschaft mit Oegg, den er dort kennen gelernt haben wird.

In Würzburg errang Oegg sich bald durch seine Kunst eine angesehene Stellung, die er auch trotz der Anfeindungen der zünftigen Stadtschlosser, an deren Spitze Marcus Gattinger, der Verfertiger des grossen Chorgitters im Dom, stand, und die natürlich den Eindringling mit scheelen Augen ansahen, zu behaupten

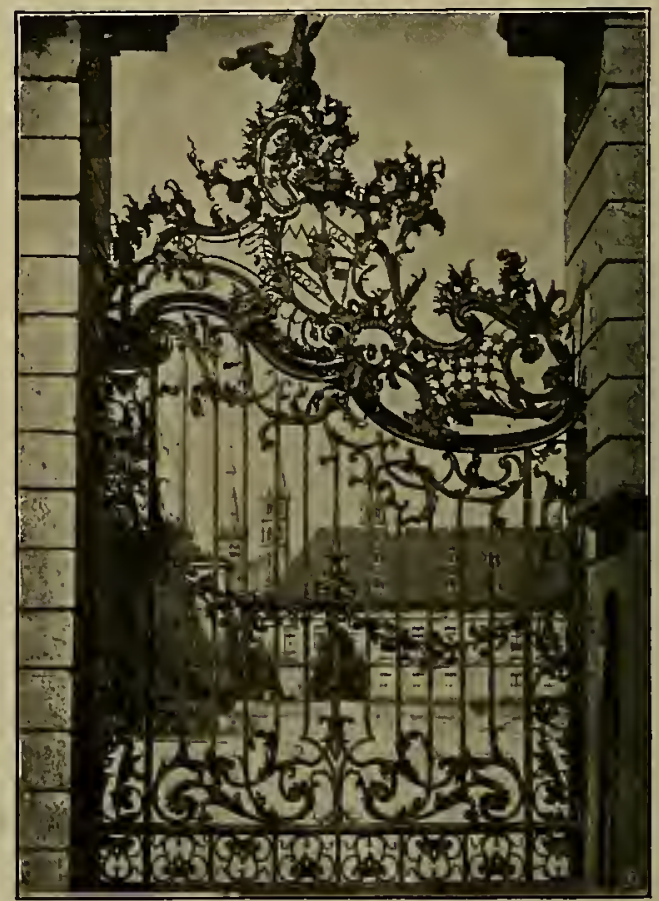

Abb. 121. Seitenteil des Portals der Abb. 120. 
wusste. Dass es dabei zuweilen auch zu handgreiflichen Reibereien kam, bei denen die Parteien vom Leder zogen, ist bei den rauhen Sitten jener Zeit nicht verwunderlich. Oegg behielt bis 1769 sein Amt als Hofschlosser, dann trat er es an seinen Sohn Anton $\mathrm{ab} .{ }^{1}$ )

Eine der ersten Arbeiten Oeggs für die $\mathrm{Re}$ sidenz dïrfte wohl das Oberlichtgitter amSeitenportal des Schlosses sein, das das Monogramm des kunstsinnigen Fürstbischofs Friedrich Karl von Schönborn (regierte 1729-1746) trägt, dem das Hauptverdienst an der Förderung des Baues gebührt. Stilistisch ist es wenigstens vor alle übrigen Schmiedewerke der Residenz zu setzen, da das Muschelwerk noch völlig fehlt. Es ist noch das alte Laub- und Bandelwerk, nur mit der Abwandelung, dass die Stäbe in rundlichen $\mathrm{Li}$ nien sich bewegen. Die Endigungen der Stäbe sind zu schneckenartigen Voluten aufgerollt. ${ }^{2}$ )

Seit 1737 arbeitete der Meister dann an einem Schmiedewerk, das leider ganz verloren gegangen ist, nämlich dem grossem Abschlussgitter, das den Ehrenhof

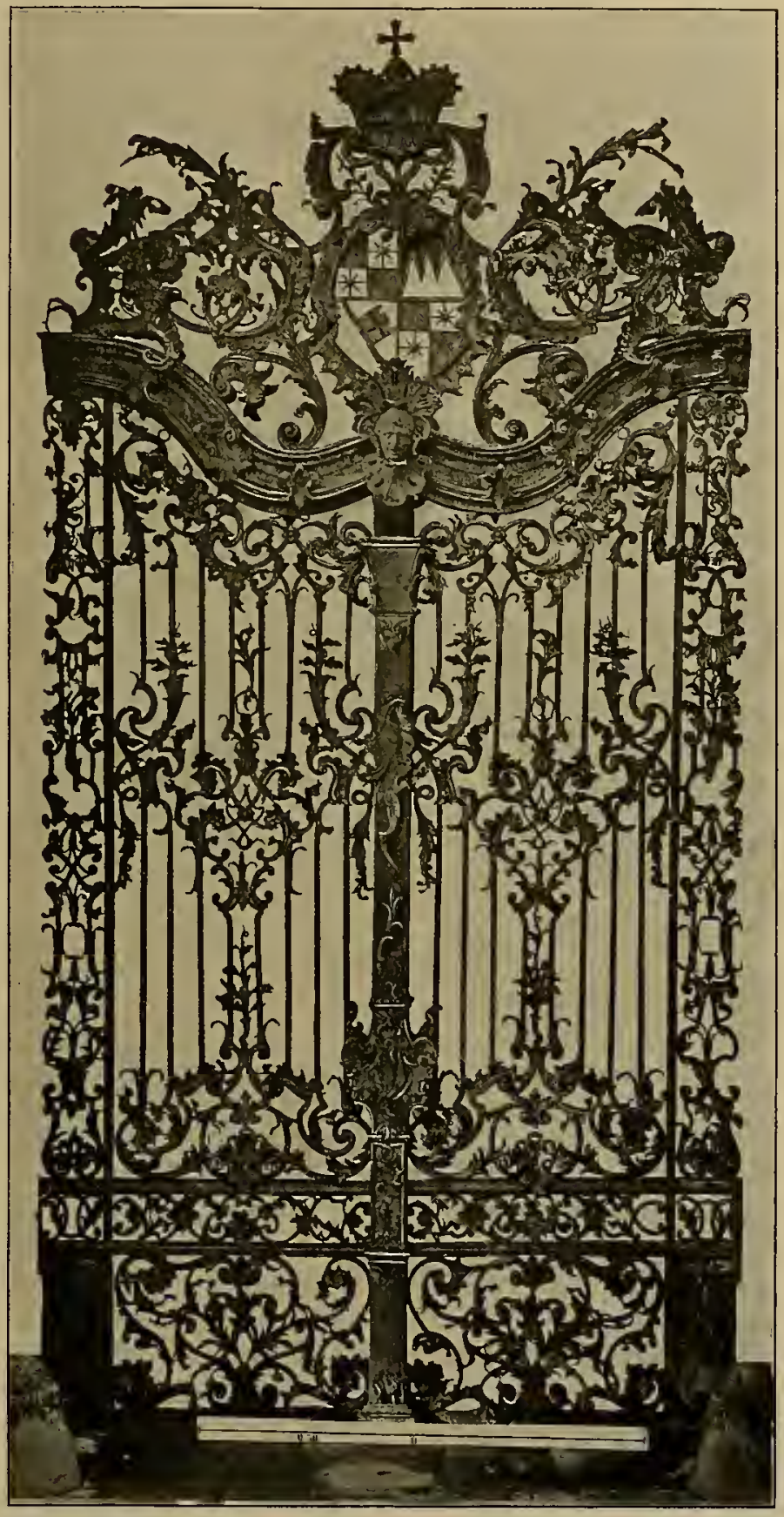

Abb. 122. Gartenthor der Residenz zu Würzburg (am Rennweg). abgrenzte, indem es die vorspringenden Flügel des Schlosses verband. In einem

1) Vgl. Stamminger, Würzburgs Kunstleben im 18. Jahrhundert, im Archiv d. hist. Vereins f. Unterfranken u. Aschaffenburg 1892.

Schreiben Neumanns vom 5. Januar 1737 wurde mit Oegg der Preis für seine Ar-

3) Abbildungen der Würzburger Gitter in Ehemann, F., Kunstschmiedearbeiten aus dem XV1.-XVIIl. Jahrhundert. Berlin 1884. 


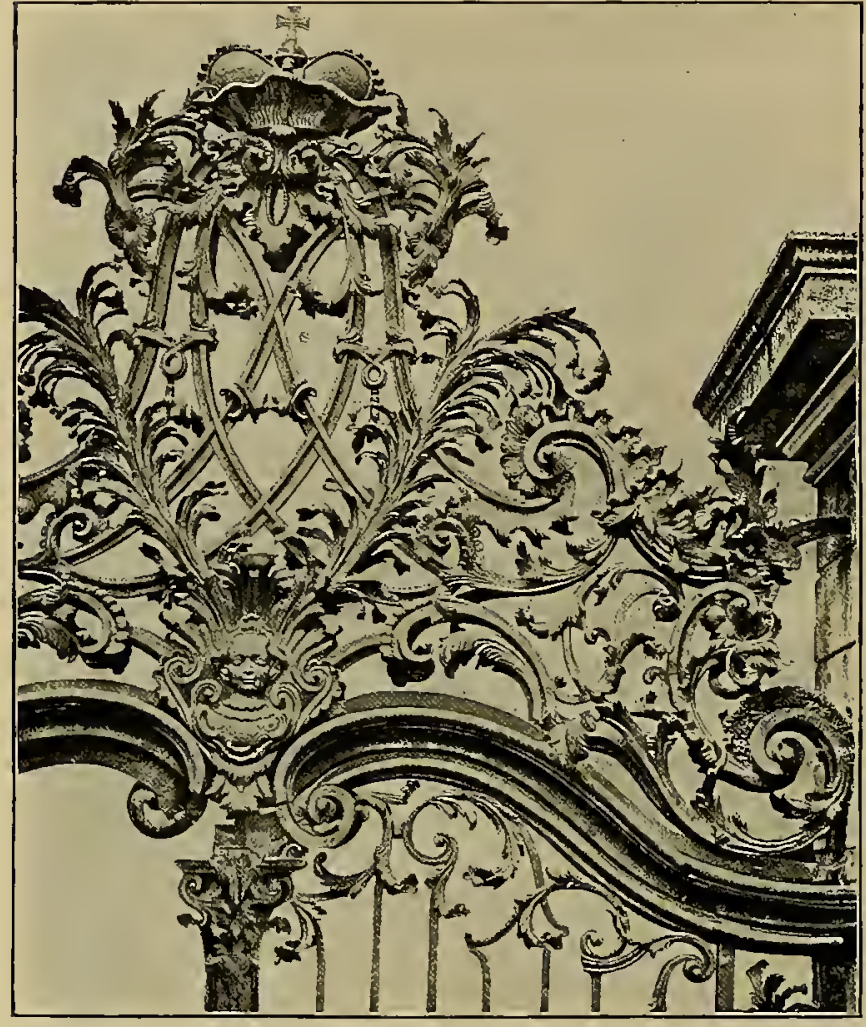

Abb. 123. Teil eines Portals der Residenz zu Würzburg (an der Hofpromenade).

und Steinarchitektur zu glücklicher Harmonie vereinigt hatte. Auch die noch zu erwähnenden Obelisken waren nach dem genannten Briefe des Fürstbischofs in dem Entwurfe Hildebrands vorgesehen. $\mathrm{Da}$ am 1. März 1741 schon die Pfeiler zum Gitter gesetzt worden waren, und in demselben Jahre ein besonders hoher Posten für Schmiedearbeiten in den Rechnungen steht, nämlich 31,933 Gulden, so ist es möglich, dass das Gitter damals schon fertig gestellt wurde. Die Bildhauerarbeiten waren freilich noch zur Zeit der Vollendung des Schlosses im Rohbau, 1744, nicht völlig ausgeführt worden. Einen Teil des plastischen Schmuckes stellte der Bildhauer J. W. von der Auvera her, der dafür 4100 Gulden erhielt; Oegg bekam für die Gitter 28,745 Gulden. Um dieselbe Zeit

beit dahin bestimmt, dass er 10 Batzen für das Pfund erhalten sollte. Der erste Entwurf zu diesem Abschlussgitter stammt, wie wir aus einem Brief Friedrich Karls vom 11. September 1744 erfahren, von Johann Lucas von Hildebrand her, dessen Rat der Fürstbischof für seinen Bau heranzog. Nach einer Mitteilung Neumanns vom 16. Februar 1739, dass er "auch den schluss des Haubthofes mit denen Statuen nach des Herrn von Hildebrands meinung zusammengesetzt " habe ${ }^{1}$ ), scheint Neumann diesen Aufriss Hildebrands selbständig verwertet $\mathrm{zu}$ haben. Jedenfalls aber ist der Hauptgedanke, die Gliederung des Eisengitters durch starke Steinpfeiler, durchaus im Sinne Hildebrands, der ja ganz ähnlich am Belvedere und am Schloss Hof an der March Schmiedewerk

1) Vgl. Keller, Ph. J., Balthasar Neumann. Würzburg 1896 . S. $67 \mathrm{ff}$. wie das Hauptgitter werden auch die Balkonbrüstungen, die aus sich wiederholenden gegossenen Eisenbahistern bestehen, für welche Oegg drei Batzen für das Pfund erhielt, angefertigt worden sein.

Leider wurde 1821 aus Unverstand, wie man damals glaubte „aus guten architektonischen Gründen", indem man sich für klüger hielt, als der Erbauer des Schlosses selbst, das Abschlussgitter entfernt und nach mündlicher Ueberlieferung alter Würzburger nach England verkauft.

Doch können wir uns aus Stichen eine annähernde Vorstellung von der Gestalt dieses Gitters verschaffen.

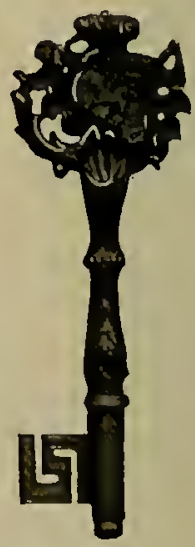

Abb. 124.

Schlüssel im Kunstgewerbemuseum zu Berlin. 


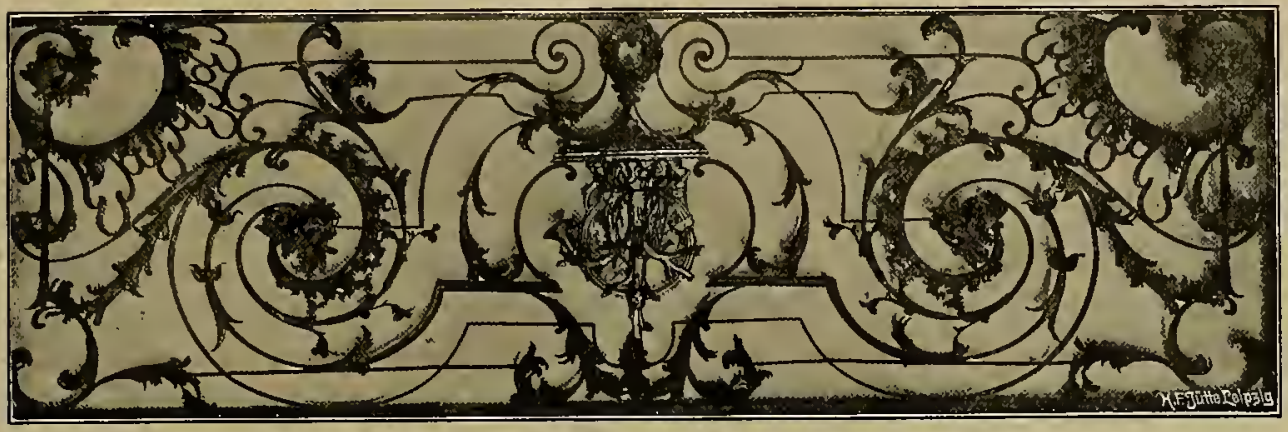

Abb. 125. Gitter im Treppenhause des Schlosses zu Brühl.

Die Sammlungen des historischen Vereins in der Residenz in Würzburg besitzen zwei sehr seltene, voneinander unabhängige Stiche, die uns eine authentische Darstellung des Hauptgitters geben. ${ }^{1}$ ) Der kleinere Stich ist bezeichnet: „J. C. Berndt Nürnberg", der grössere trägt die Unterschrift: „M. Müller Inge. et Archit. del. J. B. Gutwein Aulae et Universit: Chalcogr: fecit. Wirceb". Einen Ausschnitt aus dem letzteren giebt die Abbildung 119. Darnach trat das Gitter, das ausser dem Portal aus 16 schmiedeeisernen Gitterteilen bestand, im Zickzack vor die Fluchtlinie der Front der Seitenflügel hervor. Die das Portal flankierenden Steinpfeiler trugen Löwen mit Wappenschildern, dann folgten, ähnlich wie bei den Versailler Gittern, Wachthäuser, von hohen Obelisken bekrönt. Auf den übrigen Steinpfeilern standen abwechselnd Statuen und Blumenvasen. Die beiden Gruppen, Herkules im Kampfe mit der Hydra und mit Antäus, haben sich noch erhaiten und sind in den Glacisanlagen aufgestellt.

Wenn wir also auch den Verlust des

1) Der Stich des A. Corvinus in dem 1740 von Salomon Kleiner herausgegebenen Werke über "Dic Residenz-Stadt Würzburg" zeigt ein abweichendes Gitter. Dasselbe beruht aber auf freier Erfindung, da damals ja das Gitter überhaupt noch nicht fertig gestellt war. - Den Hinweis auf die Stiche von Berndt und Gutwein verdanke ich dem Sekretär des historischen Vereins von Unterfranken lund Aschaffenburg Herrn Dr. A. Gottfried_Ziegler.
Hauptgitters vor dem Ehrenhof zu beklagen haben, so ist doch noch immer reichlich übrig geblieben, den Ruhm Neumanns und des kunstreichen Meisters Oegg zu verkünden. Erhalten haben sich noch, abgesehen von dem erwähnten Oberlichtgitter, die drei aus einem grossen Portal und zwei Seitengittern bestehenden Garteneingänge am Residenzplatz, an der Hofpromenade und am Rennweg, die Portalbekrönungen am Rennweg in der Fluchtverlängerung der Vorderfront, mehrere Sperrböcke auf dem breiten Gesims zwischen den beiden Stockwerken, die Gitter der Arkaden, sowie eine eiserne Thür, ein Paar bemalte Wandleuchter und ein zierlicher Schlossbeschlag im Innern des Schlosses. Nicht mehr an Ort und Stelle befinden sich zwei Gitter, welche früher am Rennweg, dort, wo nur noch die Bekrönungen vorhanden sind, aufgestellt waren; sie sind jetzt im Besitz des Bayrischen Nationalmuseums in München.

Alle diese Gitter sind erst nach der Errichtung des Ehrenhofgitters in einem Zeitraum von ungefähr 25 Jahren entstanden. Die Zeit ihrer Herstellung lässt sich im einzelnen an den beigefügten Wappen und Monogrammen annähernd feststellen. Unter der Regierung des Nachfolgers Friedrichs Karl von Schönborn, des Fürstbischofs Anselm Franz von Ingelheim, der von 1746 bis 1749 regierte, sind das Portal an der Hofpromenade und die Seitenteile des Garteneingangs am Rennwege, unter Philipp von Greifenklau (1749 
bis 1754) sind das Gartenthor am Rennweg und die Seitengitter am Rennweg in der Fluchtverlängerung der Vorderfront angefertigt worden. Oegg erhielt in den Jahren 1752-54 ein Honorar von 33,784 Gulden. Das Mittelportal des Garteneingangs am Residenzplatze selbst, sowie der Thorbogen am Rennweg in der Fluchtverlängerung der Vorderfront, welcher ungefähr eine genaue Wiederholung der Portalbekrönung des Garteneingangs am Residenzplatze ist, tragen das Monogramm des Adam Friedrich von Seinsheim (1755 bis 1779). Die Gitter in den vom Hofbaumeister 1. P. Geigel errichteten Ar-

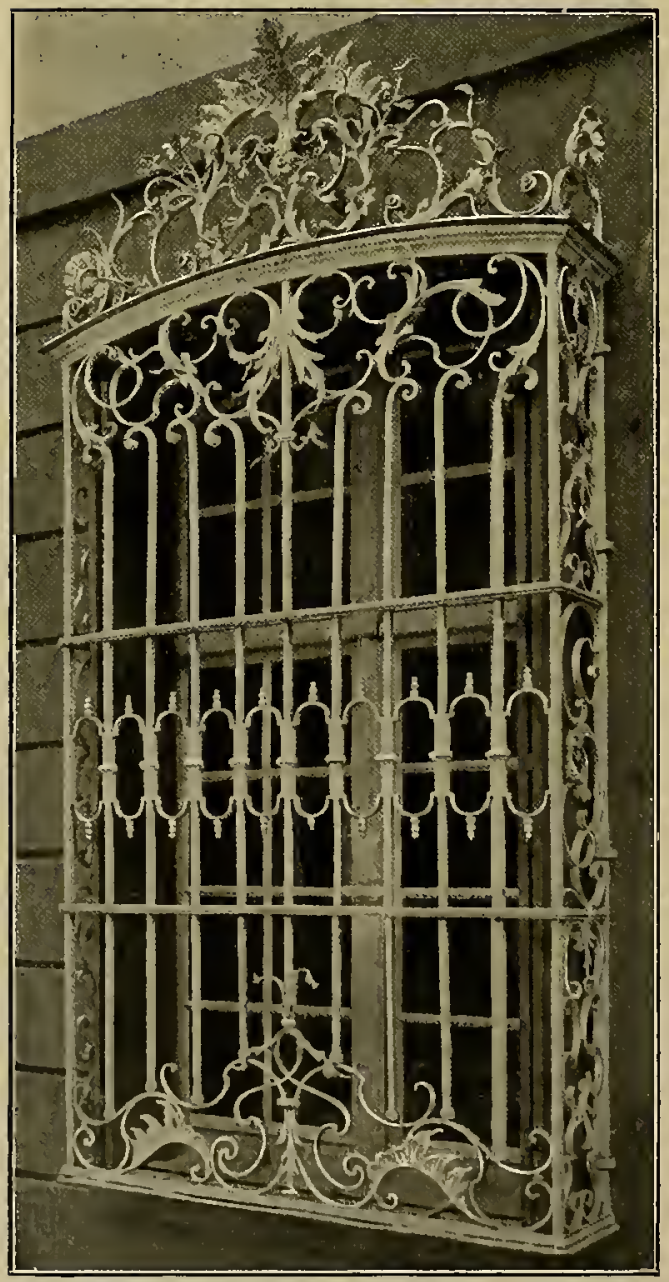

Abb. 126. Fensterkorb am Hause Rittergasse 21 zu Basel. kaden können nicht vor 1770 , dem Jahr der Erbauung dieser Anlagen, entstanden sein. (Vgl. Abbild. 120-123.)

Was nun zunächst die Erfindung dieser prachtvollen Gitter angeht, so rührt zweifellos der Entwurf zu den bis 1753, dem Todesjahre Neumanns, angefertigten Gitter von diesem genialen Architekten selbst her, der nicht nur die äussere Architektur der Residenz geschaffen, sondern auch ihre gesamte innere Einrichtung und sonstige Ausstattung bis zum Schlüssel herab selbst entworfen hat. Das sog. Skizzenbuch Neumanns in der Kgl. Universitätsbibliothek zu Würzburg enthält auf Blatt 143 eine Zeichnung des Gitterthores am Residenzplatze, dessen Seitenteile fast genau mit den ausgeführten Gittern übereinstimmen. Das Portal in der Mitte weist dagegen eine den Seitengittern entsprechende Bildung auf, während ja das jetzige Portal klassicistische Formen zeigt. Das Blatt trägt das Datum: 28. Sept. 1748. Blatt 22 stellt zwei Eingänge mit Eisengittern des Lustgartens des Schlosses Schönborn in Niederösterreich dar, die sich mit dem betreffenden Stiche von Gutwein genau decken, Blatt 42 zwei Schlüssel mit hübschen Griffen und dem Monogramm und Namenszug Karl Friedrichs, Blatt 142 die einfachen, nur mit Monogramm und Löwen geschmückten Fenstergitter der Schönbornschen Kapelle am Dom zu Würzburg, Blatt 144 ein dreifaches, den Wiener Arbeiten verwandtes Portal mit dem Wappen der Schönborn; Blatt 145 enthält die Zeichnungen verschiedener Gitter von Schlosshof.

Ueberhaupt trägt die Ornamentik der Gitter bis in die kleinsten Details durchaus den Charakter der sonstigen Arbeiten Neumanns. Die bezeichnenden Merkmale seines Rokoko, das wild bewegte, zerrissene Muschelwerk, welches in seiner zerflatternden Bildung an die vom Winde gepeitschten, zersprühenden Wellen erinnert, die dazwischen geschobenen Palmzweige u. a. sind Eigentümlichkeiten, die sich auch in den Innen- 
dekorationen Neumanns vorfinden. Den unter Neumanns Leitung angefertigten Gittern gemeinsam ist die Unterbrechung der vertikal laufenden parallelen Stäbe durch zwei sich kreuzende Palnzweige, Blumengehänge oder S-förmige, mit reichem Blattwerk geschmückte Stäbe. Nur das Thor des Garteneingangs am Rennweg zeigt eine abweichende Bildung, indem an die Stelle der glatt durchlaufenden Stäbe eine vielgliedrige Komposition gesetzt ist.

Eine ganz besondere Gestaltung unterscheidet das Portal am Residenzplatze von den übrigen Eingängen. Während

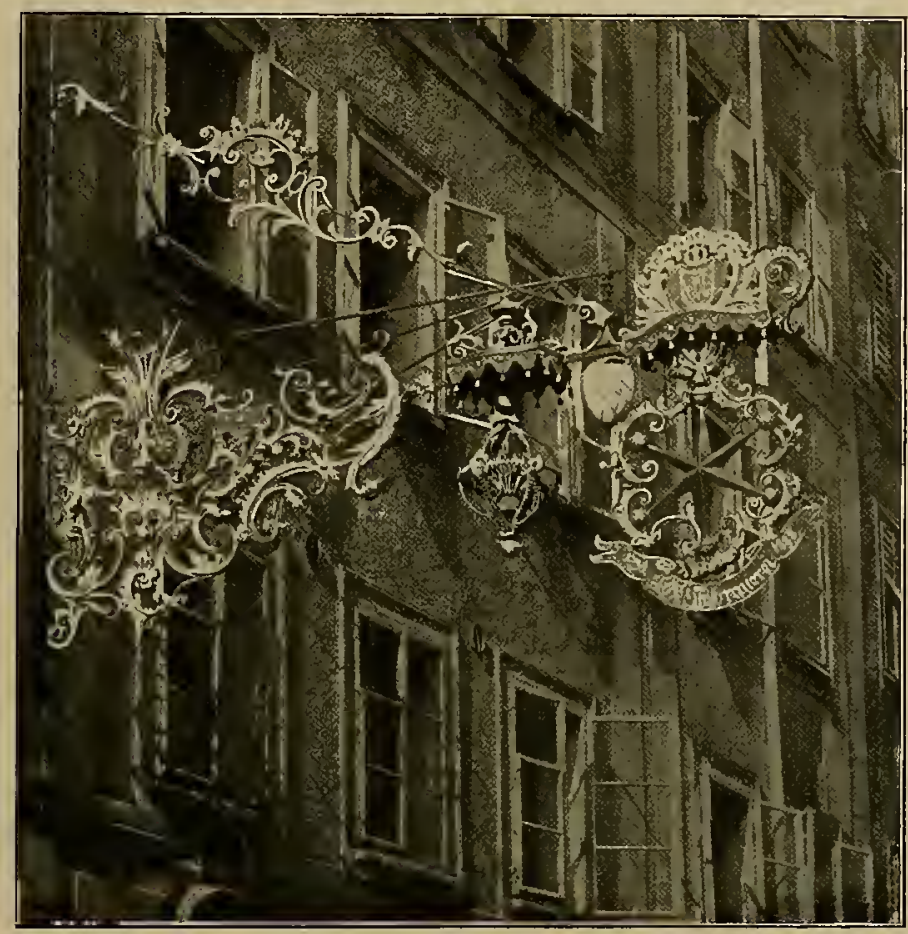

Abb. 127. Aushängeschild der Sternbrauerei in Salzburg. in der Bekrönung noch das bewegte Linienspiel des Rokoko fortlebt, herrscht dagegen in der Dekoration der Thürflügel und Seitenpilaster die kalte Ruhe des Klassicismus, die sich sowohl in der von regelmässigen Linien umschriebenen Komposition des Ganzen, wie im einzelnen Ornament ausspricht. Doch fehlt auch hier neben den eigentlichen Ornamenten des Zopfstils, den Mäandern, den Laubguirlanden, dem "laufenden Hund“, den aus Kreisen und Rosetten gebildeten Friesen u. s. w. das Muschelwerk nicht ganz. Eine ähnliche Mischung neuer und alter Formen zeigen auch die im übrigen bedeutend schwächeren Gitter der Arkaden.

Die technische Ausführung dieser Gitterwerke ist, wie schon hervorgehoben wurde, vollendet. Die Stäbe sind durchschnittlich $3-4 \mathrm{~cm}$ stark, das Muschelwerk und die Palmwedel sind aus mehrere Centimeter dicken Band- bezw. Stabeisen herausgeschmiedet. Die plastische Bildungsfähigkeit des Eisens ist aufs höchste entwickelt. Das spröde Ma- terial ist in zierliche Formen aufgelöst, ja selbst in zarte Blütenblätter verwandelt, der tote Stoff ist durch die kunstreichen Hände des Meisters zu reichem Leben auferweckt. Die glatten ruhigen Massen der Steinpfeiler, zwischen welche die Gitter eingespannt sind, steigern noch in wirkungsvollem Kontrast den Eindruck entzügelter Leidenschaft, der aus dem lebendig gewordenen Eisen spricht, sie wirken wie gewaltige Felsen, an denen die tobende Brandung ohnmächtig anprallt, um dann wieder in sich selbst zurückzukehren.

Auch die köstlichen Gitterwerke an der 1736 geweihten Schönbornschen Kapelle am Dom zeugen von der Meisterschaft Oeggs, dem zweifellos diese Arbeiten zuzuschreiben sind. Das Chorgitter im Dome selbst vollendete Marcus Gattinger 1749. Es ist dem von demselben Schlosser stammenden Chorgitter der Abteikirche zu Amorbach (Abb. 110) sehr verwandt.

Ein bezeichnetes Werk Oeggs ist ein 


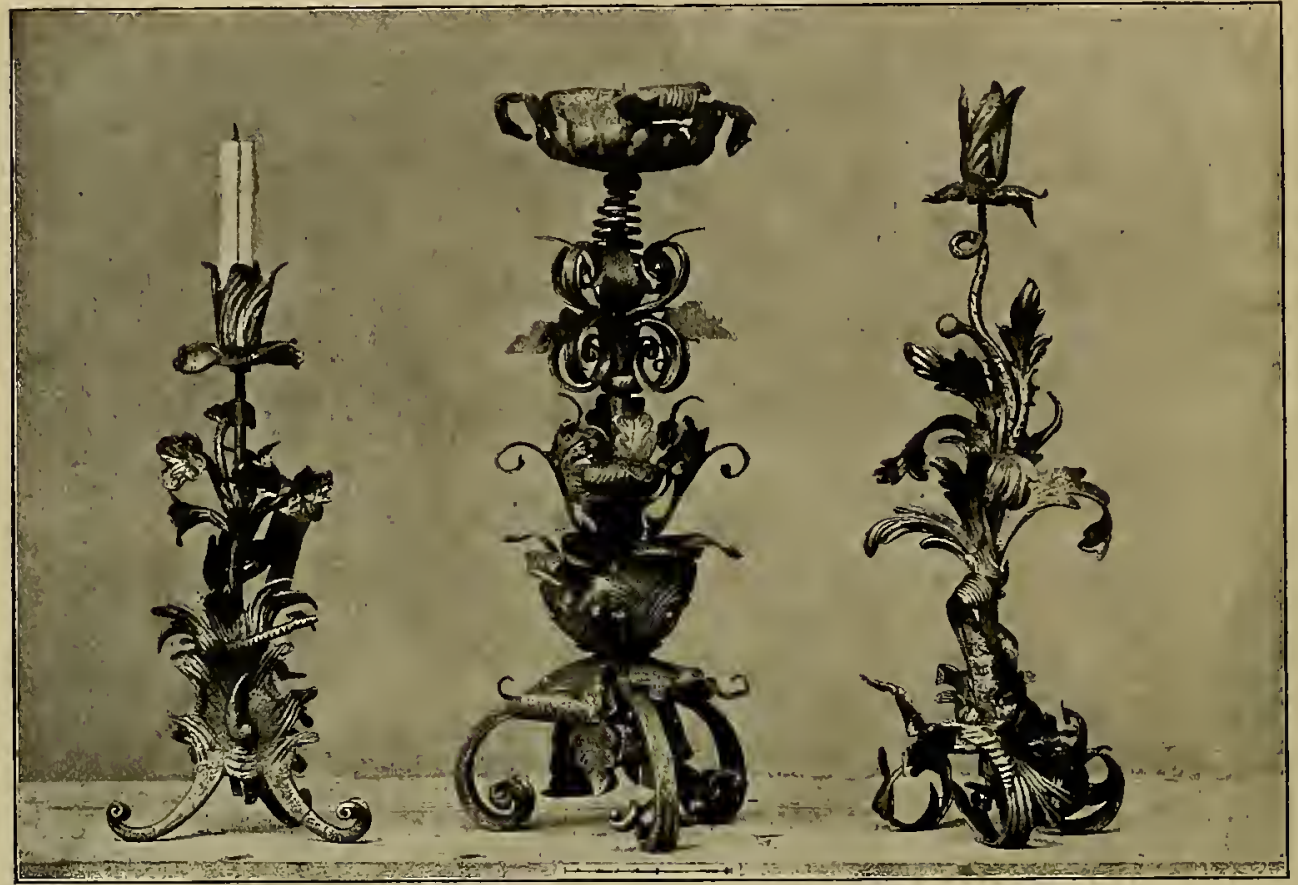

Abb. 128. Leuchter im Bayrischen Nationalmuseum zu München.

als Trinkgefäss dienender grosser Zunftschlüssel in der Sammlung des historischen Vereins in der Residenz mit Ornamenten in Kupfer und Messing, der das Datum 1740 trägt. Zwischen Rohr und Bart sind in durchbrochenem Kupfer die Buchstaben J. G. O. angebracht. Ausserdem ist der Schlüssel mit hübschen Inschriften versehen:

Die hoch Furstlich Schlosserey

Dies Zeichn Fur sich gemacht in dem Jahr wies hier Dabey Doch niemand sonst veracht

Von gott ist alle Kunst viel lob ist eidel Dunst

Von sonstigen Arbeiten, die man auf Oegg zurückführen möchte, ist das Gestell auf dem Recepturtische der Apotheke des Juliushospitals in Würzburg zu nennen, das die Jahreszahl 1762 trägt und noch in die Formen des Rokoko gekleidet ist ${ }^{\mathfrak{1}}$ ), sowie ein grosser Wandarm, der ein Aushängeschild mit einem Kreuz trägt. $\mathrm{Er}$

1) Abbildung bei Hefner-Alteneck, a. a. O. ll, Tafel 82 . ist vom Berliner Kunstgewerbemuseum aus der Sammlung Ettlinger in Würzburg erworben worden und schliesst sich ebenso wie das Wagegestell in seiner Ornamentik direkt an die Gitter des Residenzschlosses an. Dasselbe Museum besitzt auch einen aus Eisen geschnittenen kleinen Schlüssel mit Ziervergoldung, dessen Griff als unregelmässig geschweifte Kartusche gestaltet ist, durch welche über Kreuz ein Schwert und ein Bischofstab gesteckt ist. Unter einem Fürstenhut ist auf der einen Seite das Monogramm von Friedrich Karl von Schönborn, auf der anderen der gekrönte schreitende Löwe aus dem Wappen der Schönborn, beides auf vergoldetem Grunde dargestellt. Das Rohr ist in seinem oberen Teil wie der geschuppte Leib eines Fisches gebildet, den unteren Teil umhüllen zierlich geschnittne Akanthusblätter auf goldenem Grunde (Abbild. 124). Auf der Ausstellung des Burlington Fine Arts Club in London von 1900 war aus dem Besitze der M. Whitcombe Green ein Schlüssel ausgestellt, der auf der 
einen Seite des Griffes den Kopf des genannten Fürstbischofs, auf der anderen den schreitenden Löwen zeigt und mit Goldtausia geschmückt ist. $\left.{ }^{1}\right)$ Also auch diese Kunst war Oegg nicht fremd, denn auf ihn dürfen wir wohl auch dieses Stück zurückführen.

Auch die Bauten des schon unter den Ornamentstechern des Rokoko vorgeführten Franz Cuvilliès sind reich an Eisenarbeiten, wenn er auch keinen Oegg zu ihrer Ausführung gefunden hat. In dem von ihm geschaffenen "Reichen Zimmern"der Residenz zu München (1730-37) hat die Schmiedekunst in den vortrefflichen Kaminvorsätzen, die einen grossen Teil der Räume schmücken, Bethätigung gefunden. Sie sind wahrscheinlich Arbeiten des Schlossers Yikolaus Berneckher, der auch das herrliche Geländer der leider schon 1764 wieder zerstörten Prachttreppe geschmiedet hat. Von demselben rühren auch die Eisenarbeiten am ehemaligen Palais Preysing (jetzt Bayer. Hypotheken- und Wechselbank) her. Berneckher hatte seine Kunst in der französischen Schlosserei erlernt, welche der Kurfürst Max Emanuel im Zeughause eingerichtet und der Leitung des Schlossers Antoine Motté und des Kunst - und Eisendrechslers François Houard unterstellt hatte. $\left.{ }^{2}\right)$ Die ebenfalls von Cuvilliès in den Jahren $1734-40$ erbaute Amalienburg im Nymphenburger Schlossgarten besitzt einen zierlich gearbeiteten Rundbalkon an dem Aussichts. plateau, welches sich auf dem Dache des Schlösschens befindet. Die Herstellung desselben geschah durch den Nymphenburger "Bestandtschlosser" Andreas Aignman. $\left.{ }^{3}\right)$ Die Komposition des Balkons beschränkt sich im wesentlichen auf das

1) Abgeb. in: Burlington Fine Arts Club. Exhibition of chased and embossed steel and ironwork of European origin. London 1900. pl. 19, Fig. 3, Nr. 76.

2) Vgl. Aufleger und Trautmann, Die reichen Zimmer der Königl. Residenz in München. München 1893. S. 3 u. ff.

3) Aufleger und Trautmann, Die Amalienburg im Königl. Schlossgarten zu Nymphenburg. München 1894 S. 7. gefällige Linienspiel der Stäbe, ohne dass von Ornamenten ausgedehnte Verwendung gemacht ist.

In reichem Umfange kommt auch die Schlosserkunst in dem Schlosse des Kurfürsten von Köln Clemens August zu Brühl zur Geltung, an dessen Ausschmückung ebenfalls Cuvilliès weitgehenden Anteil hatte; speciell die Schmiedearbeiten scheinen zum grössten Teil auf ihn zurückzugehen. Auf den Aussenseiten schmückt das Schloss eine fortlaufende Reihe von Balkonen, das grosse Treppenhaus ist mit schönen Balustraden und einer grossen Laterne in Schmiedeeisen versehen, und im Konzertsaal, der durch zwei Stockwerke hindurch geht, läuft in der Höhe des zweiten Stockes eine mit einem schmiedeeisernen Geländer ausgestattete Galerie herum. Die Schmiedearbeiten im Treppenhause wurden von den Schlossern

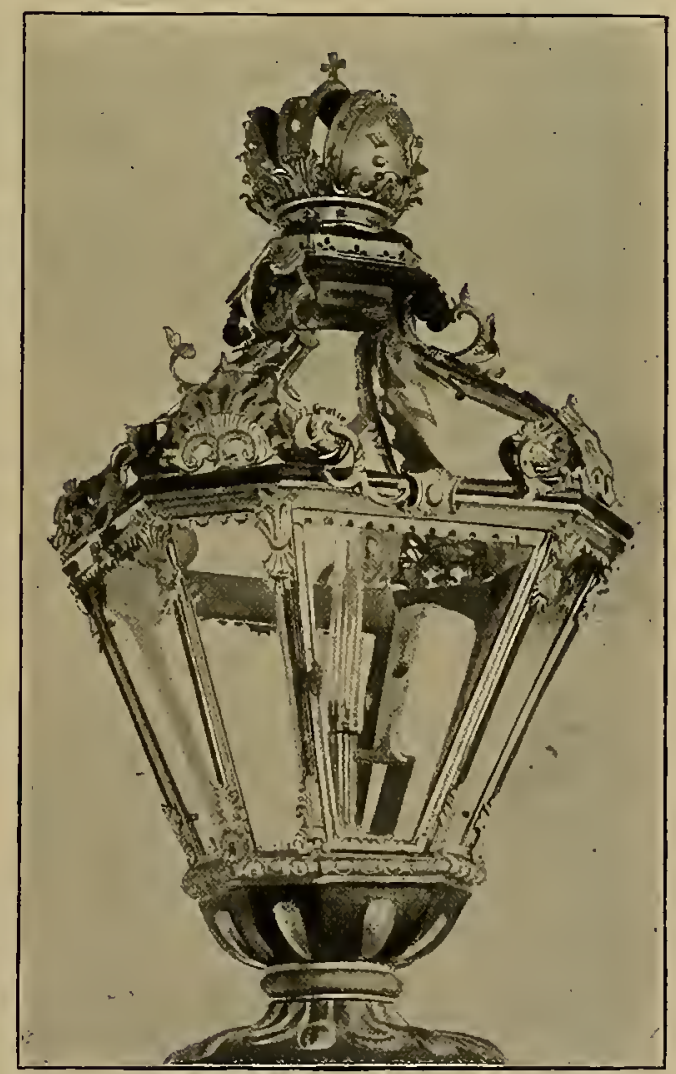

Abb. 129. Laterne im Schlosse Hetzendorf. 


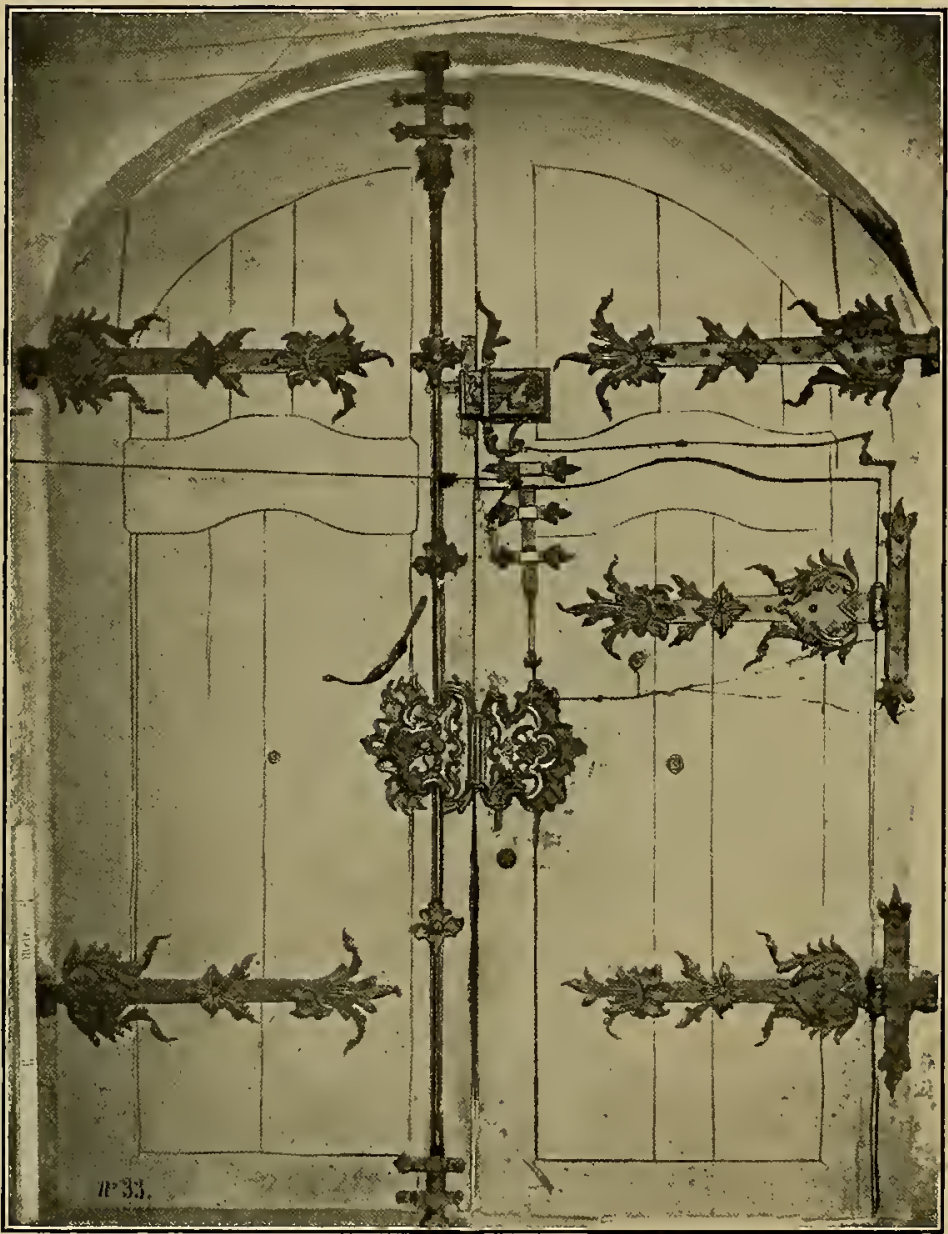

Abb. 130. Thür am Zeughause zu Augsburg.
Fast in jedem Schloss der damaligen Zeit fand in ähnlicher Weise das Schmiedeeisen in mehr oder minder ausgedehntem Um. fange Verwendung. Es würde zu weit führen, wollte man alle Beispiele namentlich aufführen. Erwähnt seien nur noch die Eisenarbeiten des entzückenden Schlöss. chensWilhelmsthal bei Kassel, welches 1767 vom Architekten Simon Louis Du Ry vollendet wurde. Wäh. rend die Altane nach dem Park hin, ähnlich wie beim Würzburger Schloss, von Geländern aus ge. gossenen Eisenbalüstern eingefasst sind, ist die Vorderseite mit zierlichen schmiede. eisernen Balustraden ausgestattet. Im Innern führt ein elegant gezeichnetes Treppen-

Köbst und Müller ausgeführt und 1743 vollendet. ${ }^{1}$ ) Einzelne Füllungen des Geländers sind in der Mitte mit Emblemen der Jagd und ähnlichem geziert, die, soviel wenigstens aus den Photographien zu ersehen ist, in Gussmetall angefertigt sind. Die Zeichnung des Muschelwerks, die Verwendung palmenartiger Schosse, sowie die hin und wieder im Stabwerk auftretenden gebrochenen Linien entsprechen den Gepflogenheiten Cuvilliès, wie wir sie aus seinen übrigen Dekorationen kennen (Abbild. 125).

j) Vgl. Renard, E., Die Bauten der Kurfürsten Joseph Clemens und Clemens August von Köln, in den Jahrbüchern des Vereins von Altertumsfreunden im Rheinlande, Heft C. S.29.

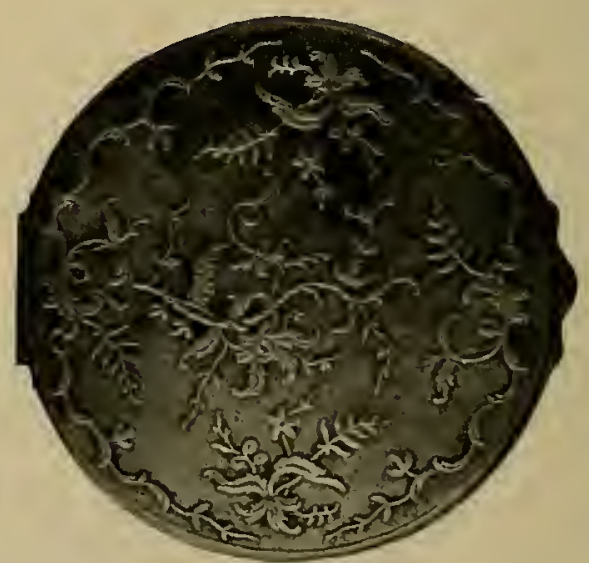

Abb. 131. Tauschierte Dose im Kunstgewerbemuseum zu Berlin. 
geländer in dunkelblauer Farbe mit Gold zum oberen Stockwerke.

Auch das Bürgerhaus machte von schmiedeeisernen Arbeiten je nach dem Massstabe der Verhältnisse seines Besitzers Gebrauch. Eines der schönsten, noch bis vor kurzer Zeit fast völlig mit seiner inneren Einrichtung erhaltenen Privatgebäude des18. Jahrhunderts war das Haus des ehemaligen Kaufmanns und Bürgermeisters Johann von Wespien in Aachen, welches um 1740 von Johann Joseph Couven erbaut wurde. Es enthielt an Schmiedearbeiten einen Balkon, ein interessantes Treppengeländer und prächtige Kaminvorsätze.

Ein bei Stadthäusern sehr beliebter Schmuck jener Zeit, der freilich zunächst einem praktischen Bedürfnisse, nämlich der Sicherung der Häuser "diente, ist das Fenstergitter. Es tritt in dreifacher Form auf. Entweder bleibt es in der Fläche des Fensterrahmens, oder es schliesst als flacher rechteckiger Kasten das Fenster $a b$, wie der in der $A b$ bildung 126 dargestellte Fensterkorb des Hauses Ritterstrasse 21 zu Basel, oder es hat eine geschweifte Form, indem der untere Teil weit aus-

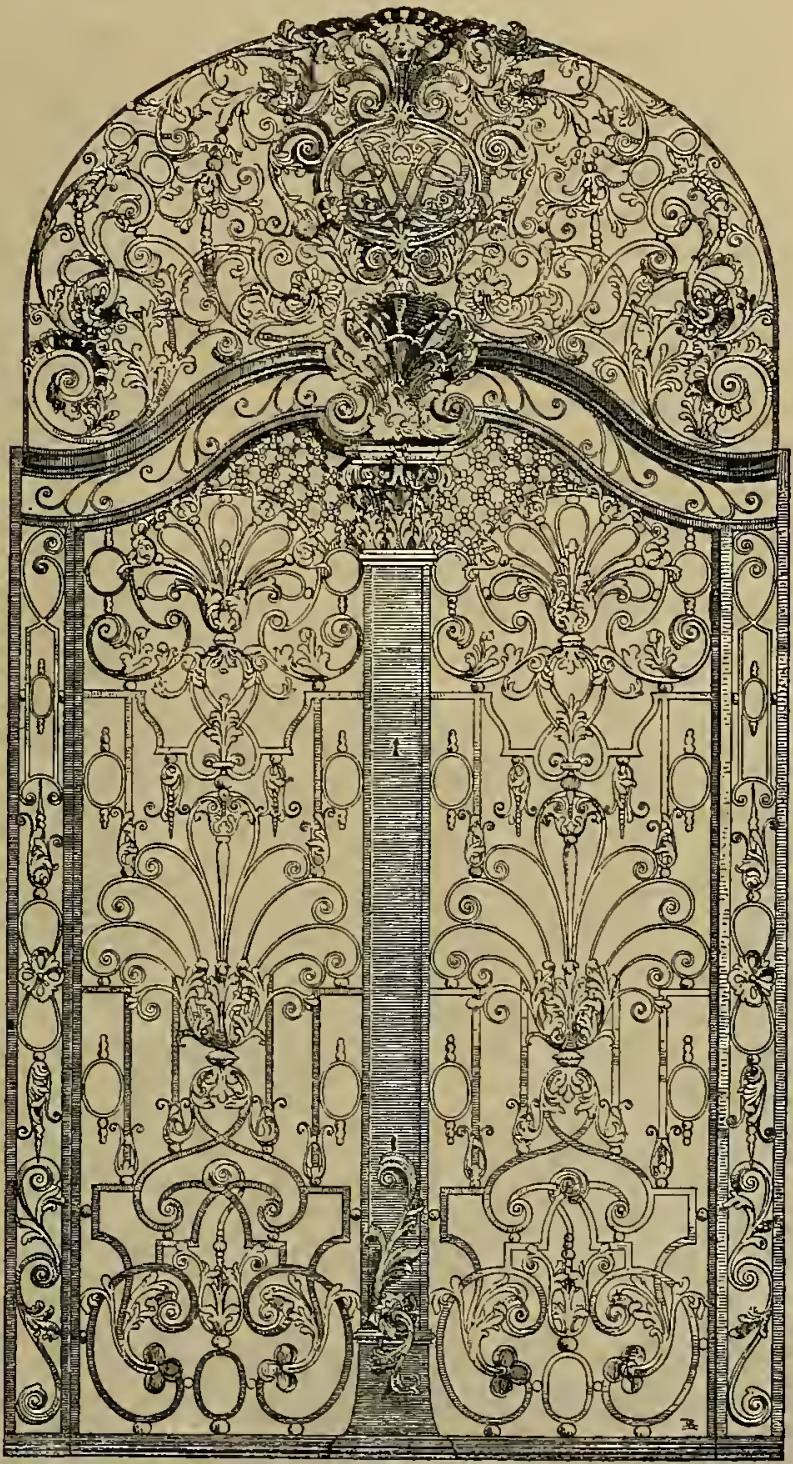

Abb. 132. Portal im Kunstgewerbemuseum zu Leipzig. gebaucht ist, so dass ein Herauslehnen aus dem Fenster zur bequemen Aussicht nach den Seiten hin ermöglicht wird. Diese dritte Gattung nannte man damals Bauchgitter, in Frankreich hiessen diese Gitter grilles à la tombeau.

In verhältnismässig grosser Anzahl haben sich auch noch schmiedeeiserne Wandarme mit Aushängeschildern von Gewerkschaften und Wirtshäusern erhalten, sowohl in den öfentlichen Sammlungen, wie auch an ihrem ursprünglichen Ort.

Eines der besten Beispiele dieser Art befindet sich noch jetzt an der Sternbrauerei in Salzburg (Abbild. 127). Nicht nur der Wandarm und das Aushängeschild, sondern auch die als Stützen des Armes dienenden Windeisen sind mit reichem Schmuck bedacht worden. Für Geräte verwendet auch das Bürgerhaus jetzt nur selten noch das Eisen. Schmiedeeiserne Leuchter, wie die in der Abbildung 128 dargestellten im Bayrischen Nationalmuseum in München, kommen nicht häufig vor. Auch 
schmiedeeiserne Thürbeschläge, wie die der Thür im Zeughause zu Augsburg (Abbild. 130) sowie Schlösser, wie das von David Nordmann in Regensburg, das sich im Münchener Nationalmuseum befindet, gehören zu den Seltenheiten (Abbild. 133). Zum Schmucke des Schlosses wird jetzt das Messing bevorzugt. Die Deckplatte wird mit Vorliebe mit einer durchbrochenen, mit Reliefdarstellungen oder gravierten Ornamenten versehenen Messingplatte verziert, welche den blanken Grund des Eisens durchsehen lässt.

Dagegen wurde das Eisen in veredelter Form, nämlich mit tauschiertem Zierate, gern zur Herstellung aller möglichen Kleingeräte u. dgl., von Dosen, Essbestecken, Fächern. Stockgriffen, Schnallen, auch Leuchtern und Lichtputzscherenu.s.w. benutzt (Abbild. 131). Die Ornamente wurden in Gold, Silber, Kupfer, Messing und sonstigen Legierungen von verschiedenen Farbtönen eingelassen und zwar entweder als flache Blechstückchen, die dann mit gravierter Innenzeichnung versehen wurden, oder plastisch modelliert und ciseliert. Das Eisen wird entweder blank gefeilt oder blau angelassen. Bei einer grossen Gürtelschnalle im Berliner Kunstgewerbemuseum sind die Ornamente in flachem Relief geschnitten, der aufge-

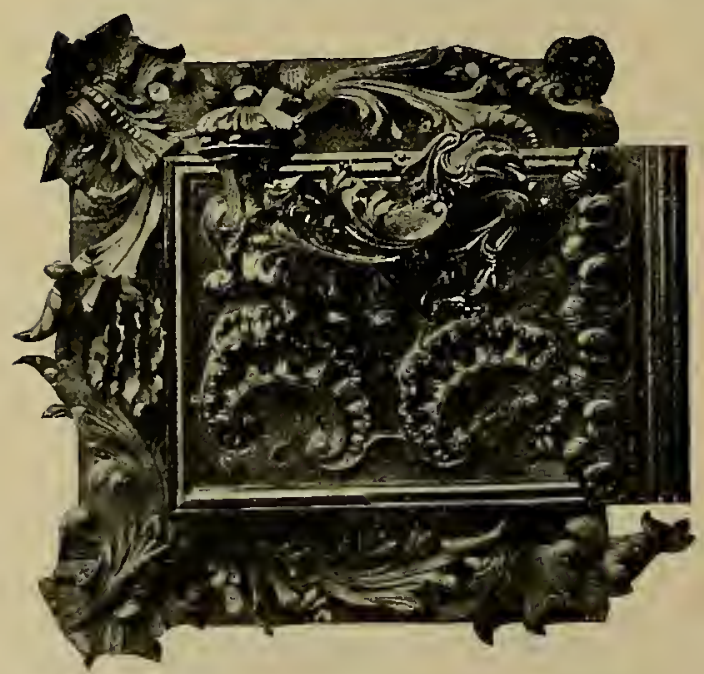

Abb. 133. Schloss im Bayerischen Nationalmuseum in München.

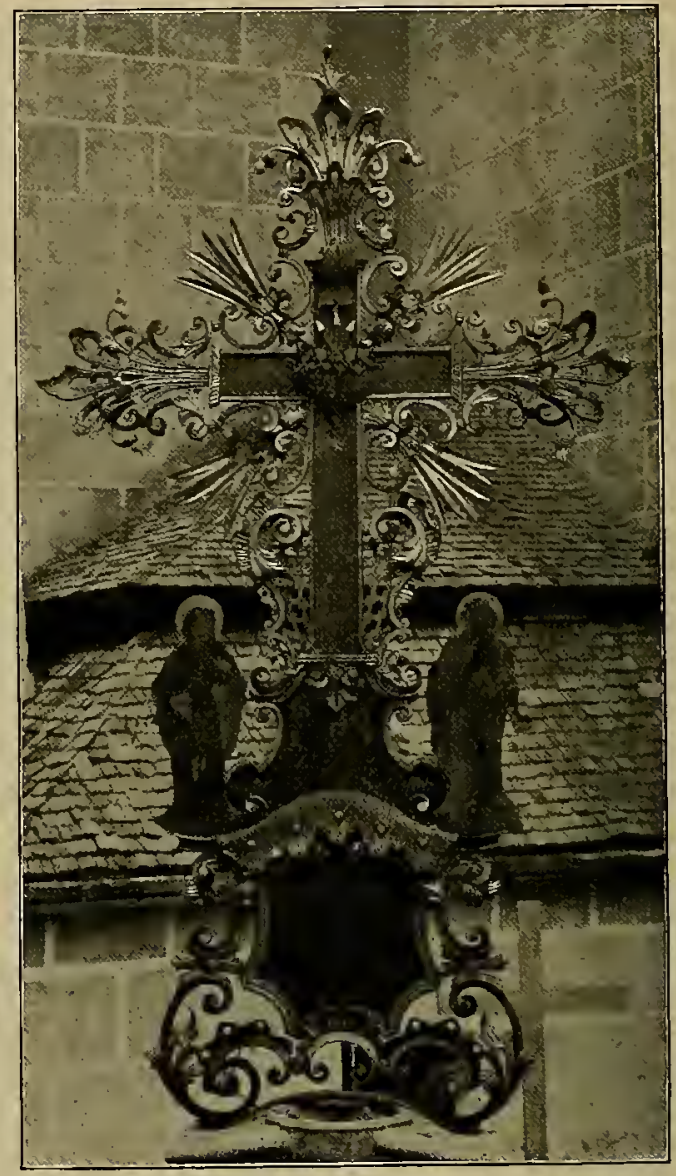

Abb. 134. Grabkreuz auf dem St. Peterskirchhofe in 'Salzburg.

rauhte Grund ist mit Goldblättchen bedeckt.

Vielfache Anwendung fand das Gitterwerk besonders auf den Friedhöfen zum Abschluss der Grüfte. Besondere stattliche Schmiedearbeiten dieser Art befinden sich noch auf dem Johanniskirchhof in Leipzig. Das schönste derselben, ein Portal mit der Jahreszahl 1751, wird im dortigen Kunstgewerbemuseum aufbewahrt (Abbild. 132). Auch die Sitte der Friedhofkreuze wird beibehalten (Abbild. 134).

In ausgedehntem Masse findet auch jetzt noch in den Kirchen die Schmiedekunst ein reiches Feld zur Bethätigung ihrer Leistungsfähigkeit, sowohl im Innern der Kirchen, wie im Aeussern. So schliessen z. B. den Eingang der Jesuitenkirche zu 
Mannheim, welche $1733-56$ von dem Architekten des pfälzischen Hofes Alessandro Galli Bibiena erbaut wurde, prachtvolle Gitterthore mit einer übersprudelnden Fülle von Schmuckwerk ab, welche an Vortrefflichkeit der Arbeit nicht viel hinter den Würzburger Gittern zurückbleiben. Der Name des Schlossermeisters Peter Schoch wird mit ihnen in Verbindung gebracht $^{1}$ ) (Abbild. 135).

In zahlreichen, besonders süddeutschen Kirchen führte die schon erwähnte Sitte, durch die ganze Kirche der Quere nach ein Abschlussgitter zu setzen oder den Chor und die Kapellen durch Gitter abzugrenzen, zur Herstellung umfangreicher Schmiedewerke. So zieht sich in der Abteikirche des früheren Benedik. tinerklosters Amorbach im bayrischen Odenwald ein gewaltiges Gitter quer durch das Langhaus, in seiner bewegten Ornamentik einem grünenden Spalier in lebendigem Wachstum vergleichbar (Abbild. 110). Die fortlaufende Bekrönung des Gitters ist mit Leuchtern besetzt, von denen die über den Thorpilastern befindlichen von Engeln getragen werden. Es ist ein Werk des Rivalen Oeggs, des Schlossermeisters Marcus Gattinger in Würzburg, von dem auch das Chorgitter im Dom zu Würzburg selbst stammt. Am 17. April 1748 wurde mit ihm ein Accord abgeschlossen, wonach er das Gitter in Amorbach gegen eine Summe von $4650 \mathrm{fl}$.

1) Hefner-Alteneck. a. a. O. II. S. 15. nebst 6 Dukaten Aufgeld innerhalb zweier Jahre herstellen sollte. Er erhielt sogleich 300 Gulden Anzahlung, die übrige Summe in Raten innerhalb der beiden folgenden Jahre. 1749 lieferte er die beiden kleinen Gitter für die Seitenschiffe $a b$. Das grosse Gitter wurde nach erfolgter Restzahlung von Würzburg nach Amorbach geschafft und 1750 aufgestellt. ${ }^{2}$ )

Ein stattliches Chorgitter besitzt auch die Klosterkirche von St. Gallen, welches von Anton Dirr entworfen und von dem

9) Sponsel, J. L., die Abteikirche zu Amorbach. Dresden 1896. S. 47 u. ff.

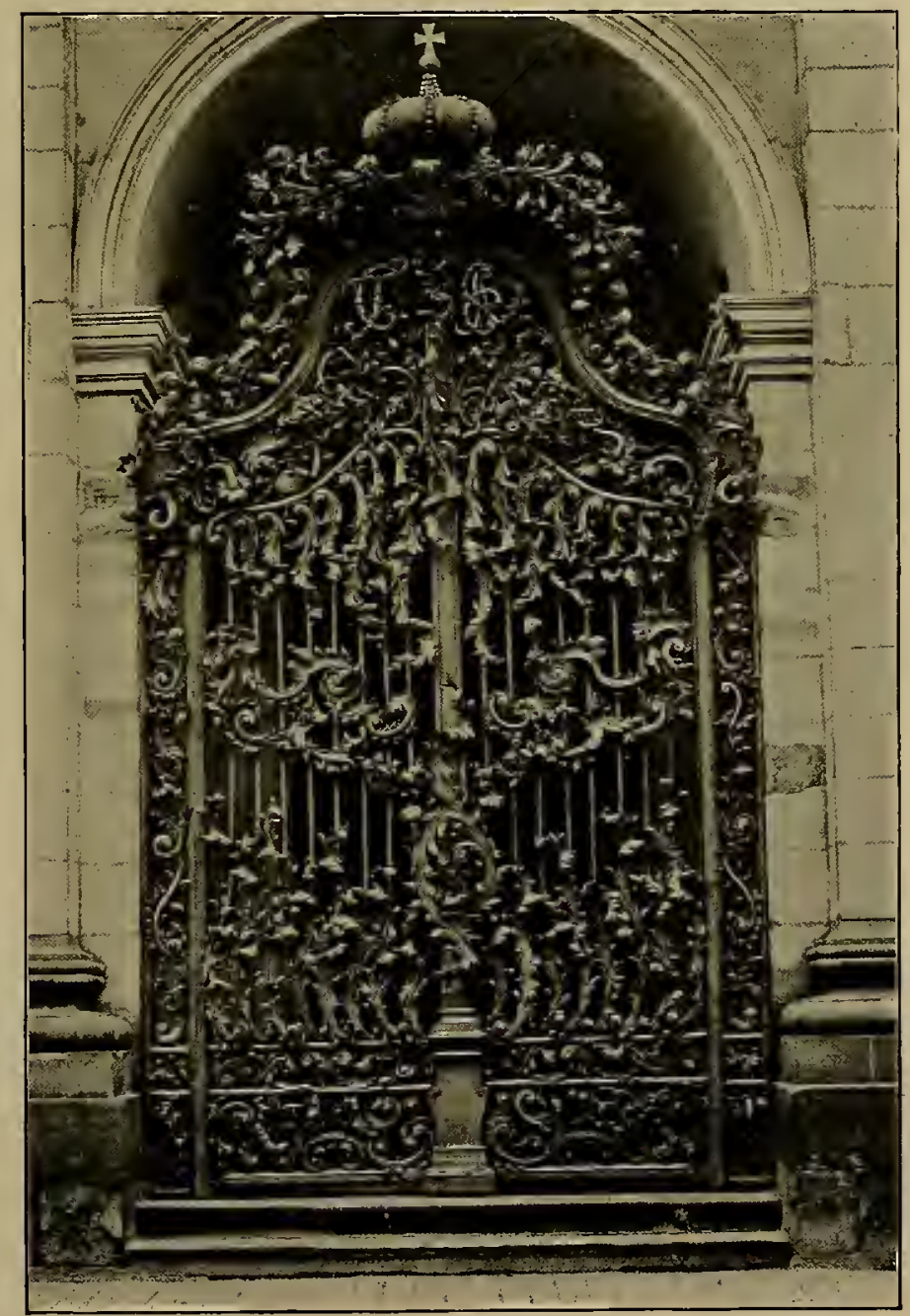

Abb. 135. Gitterthor an der Jesuitenkirche in Mannheim. 
St. Gallenschen Hofschlosser Joseph Mayer von Rütschwil 1769-71 ausgeführt worden ist. $\left.{ }^{1}\right)$ Schöne Abschlussgitter des Langhauses befinden sich in der Hofkirche zu der Kirche der ehemaligen Benediktinerabtei Weingarten in Württemberg (Abbild. 136). Das Gitter erhebt sich direkt hinter dem sog. Kreuzaltar, d. h. dem

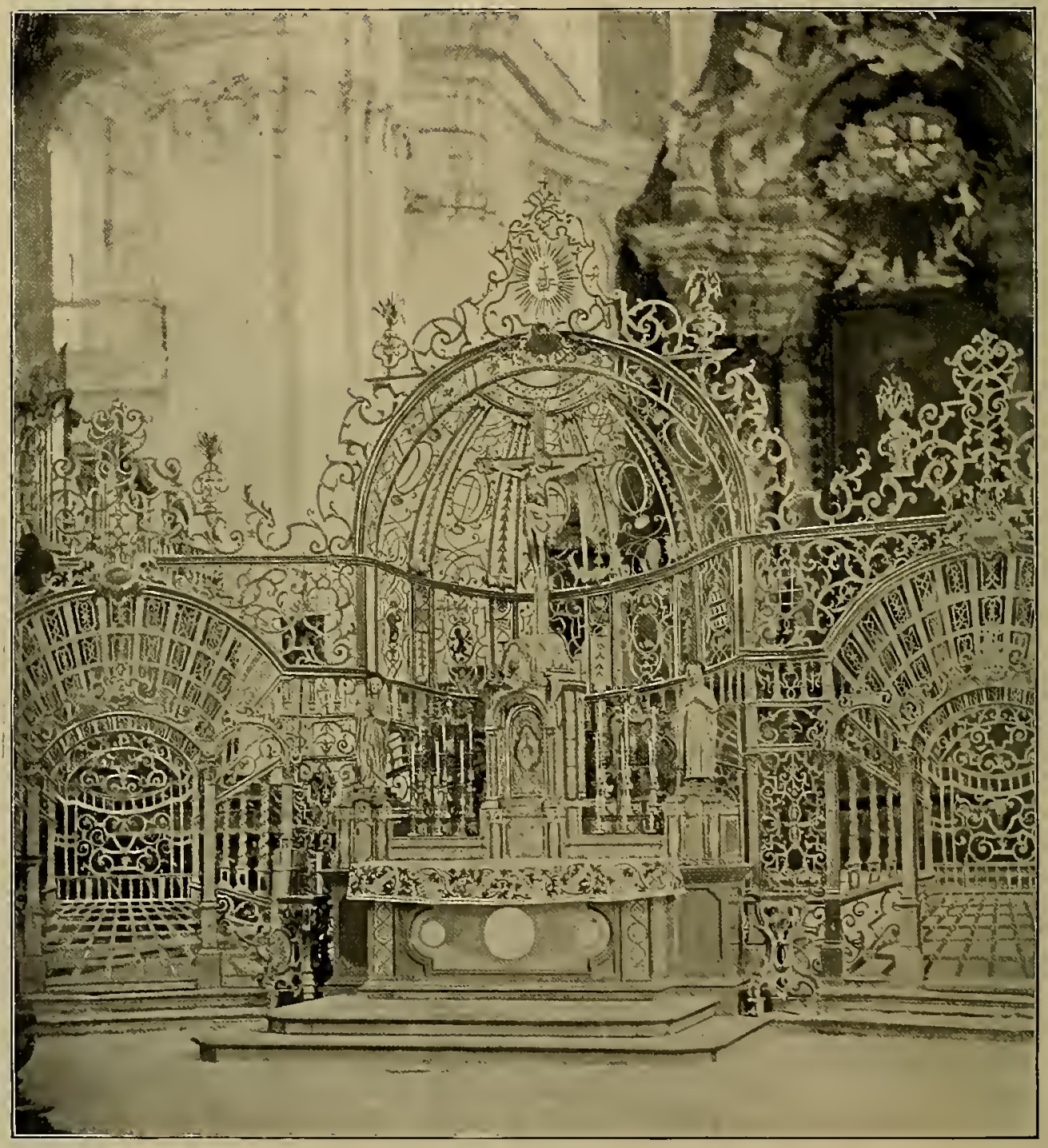

Abb. 136. Chorgitter der Kirche zu Weingarten.

Fürstenfeld und der Klosterkirche zu Diessen in Bayern.

Vielfach haben diese Chorgitter auch jetzt noch perspektivische Bildung, wie z. B. das Abschlussgitter des Chores in

1) Kick, W. a. a. O. S. 12. freistehenden Altar an der Grenze zwischen Chor und Vierung. Infolgedessen wirkt der Mittelteil des Gitters wie eine gewaltige Nische, in der der Altar zu stehen scheint. Die Vorstellung einer wirklichen Apsis wird noch verstärkt durch die runden Scheinfenster, die in der Wölbung 


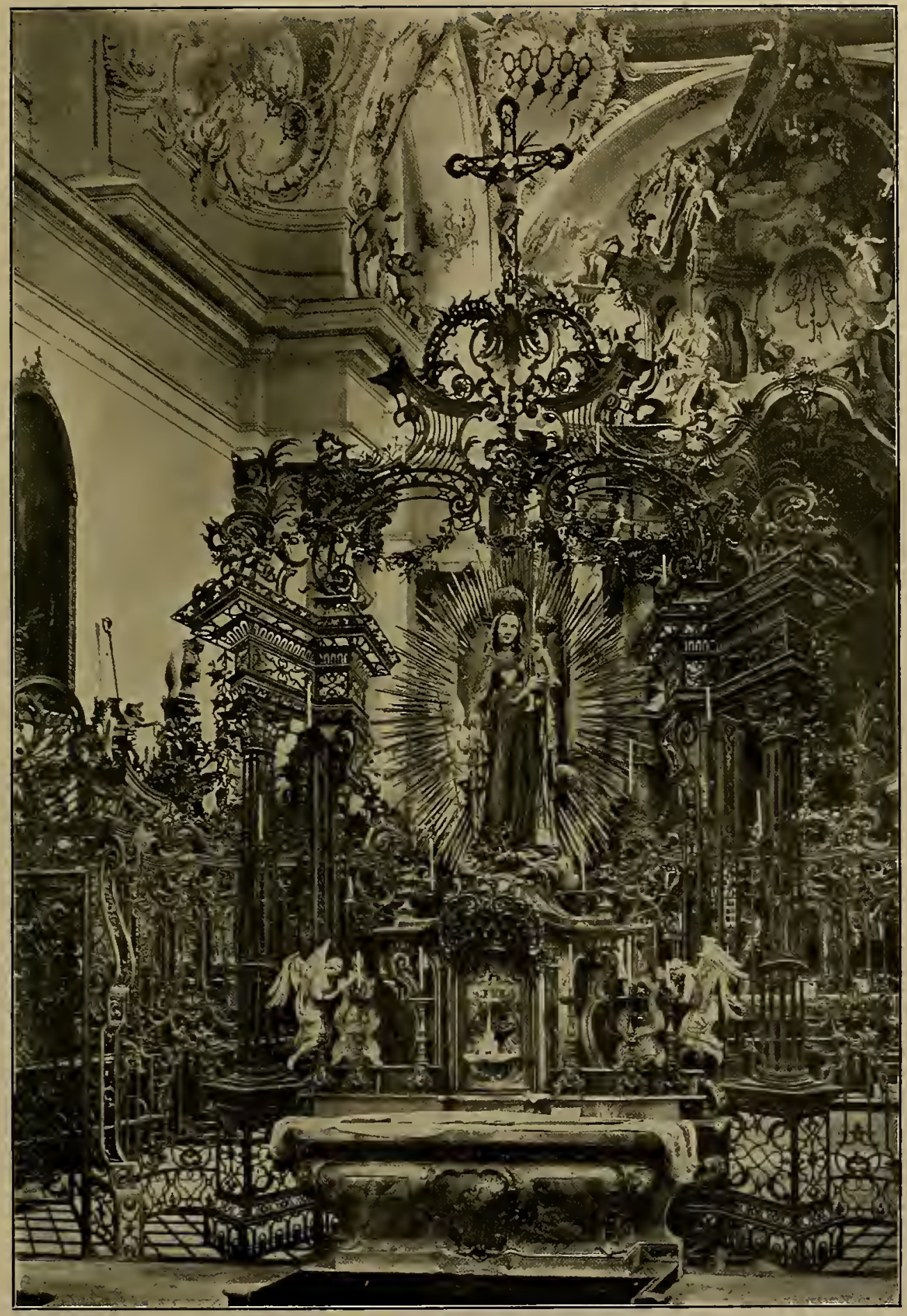

Abb. 137. Mittelteil des Chorgitters in der Kirche zu Zwiefalten. 
angebracht sind. Auf dem Abschnitt des Gitters unterhalb der Wölbung sind in ovale Felder Wappenzeichen eingelassen. Die Thüren, welche zu beiden Seiten des Altars auf den Chor führen, sind, wie auch bei früheren Beispielen dieser Art, als lange Galerien, die von Tonnengewölben gedeckt sind, gestaltet. Die Seiten dieser Scheingalerien sind mit Korkziehersäulen, die natürlich auch nur Coulissen sind, ge-

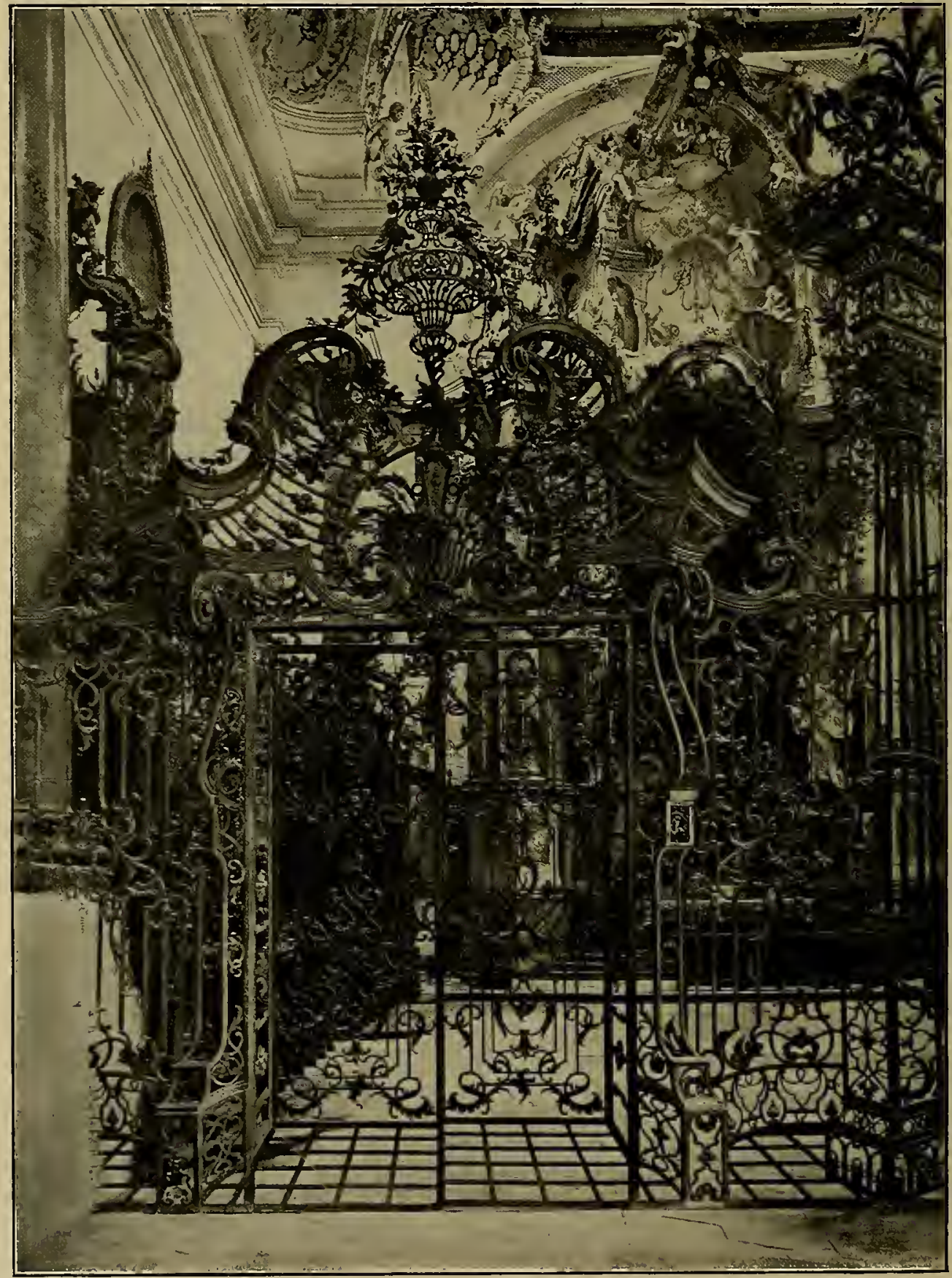

Abb. 138. Seitenteil des Chorgitters in der Kirche zu Zwiefalten. 


\section{Fig. A.}
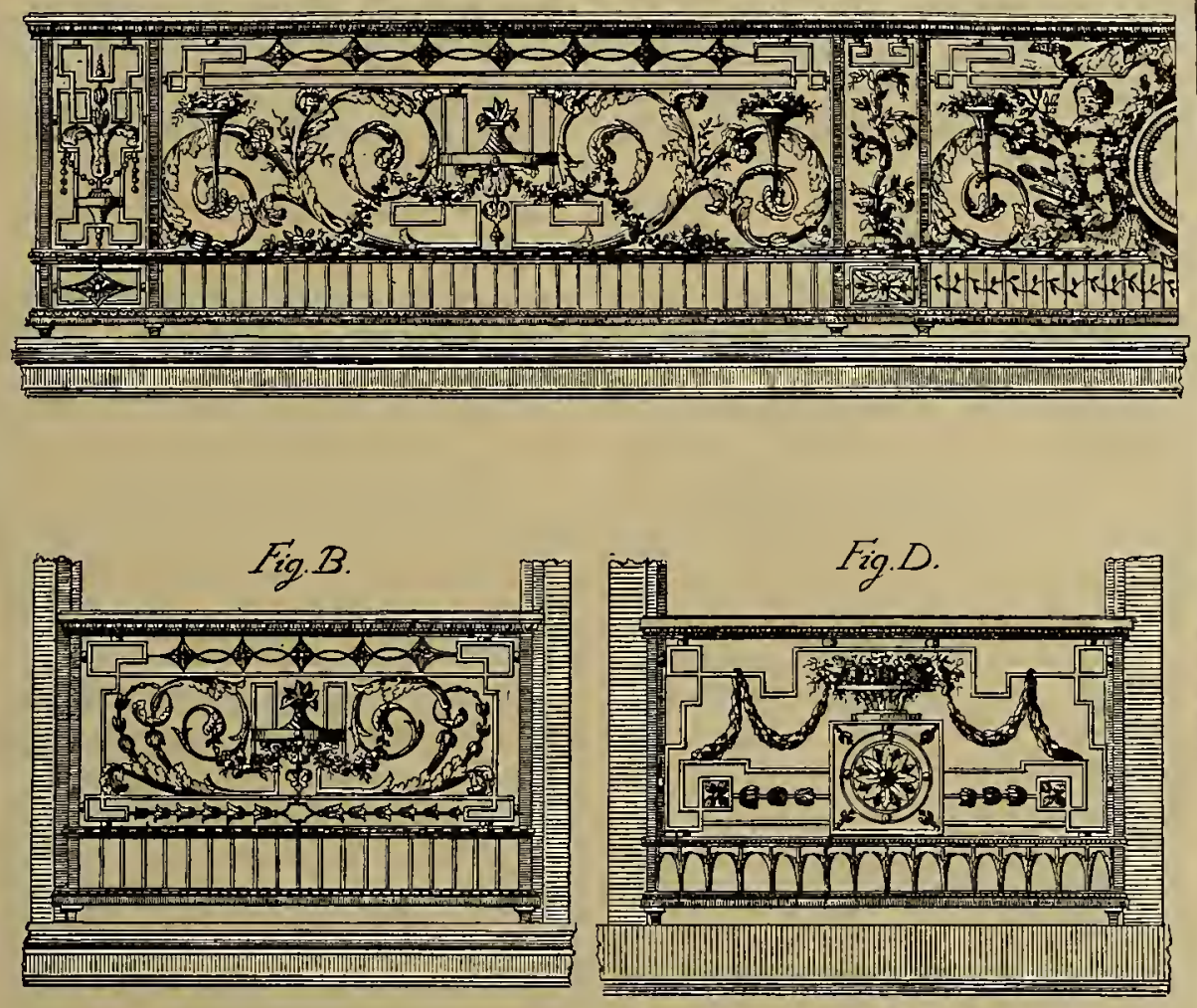

$$
\text { Fig.C. }
$$

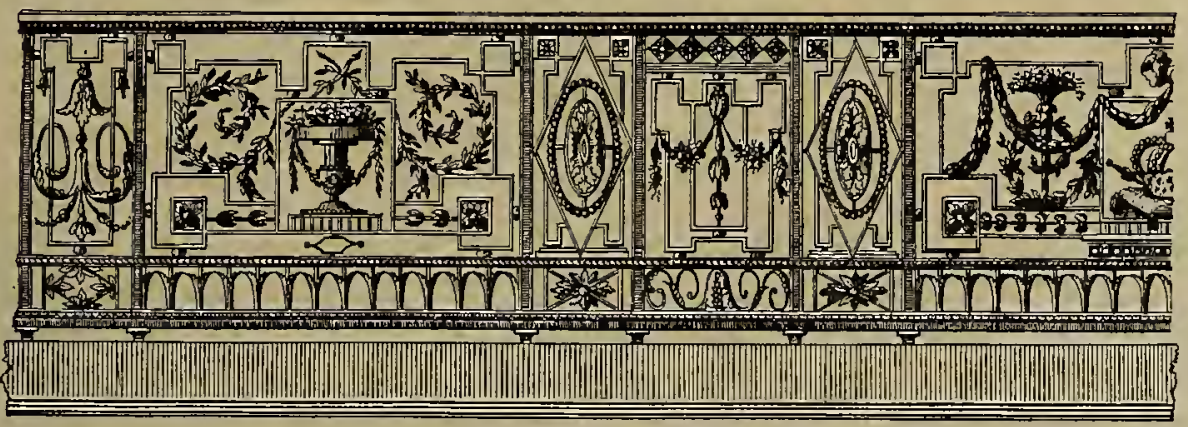

E

Abb. 139. Vorlagen für Balkongitter von J. Zipper.

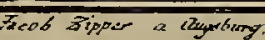


ziert. Die Linienführung des Stabgerüstes erinnert in seinen gebrochenen Formen an das Laub- und Bandelwerk, indessen geht die Ornamentik im einzelnen schon in das Rokoko über.

Noch prächtiger ist das Chorgitter der ehemaligen Abteikirche zu Zwiefalten, ebenfalls in Württemberg (Abbild.137 u.138).

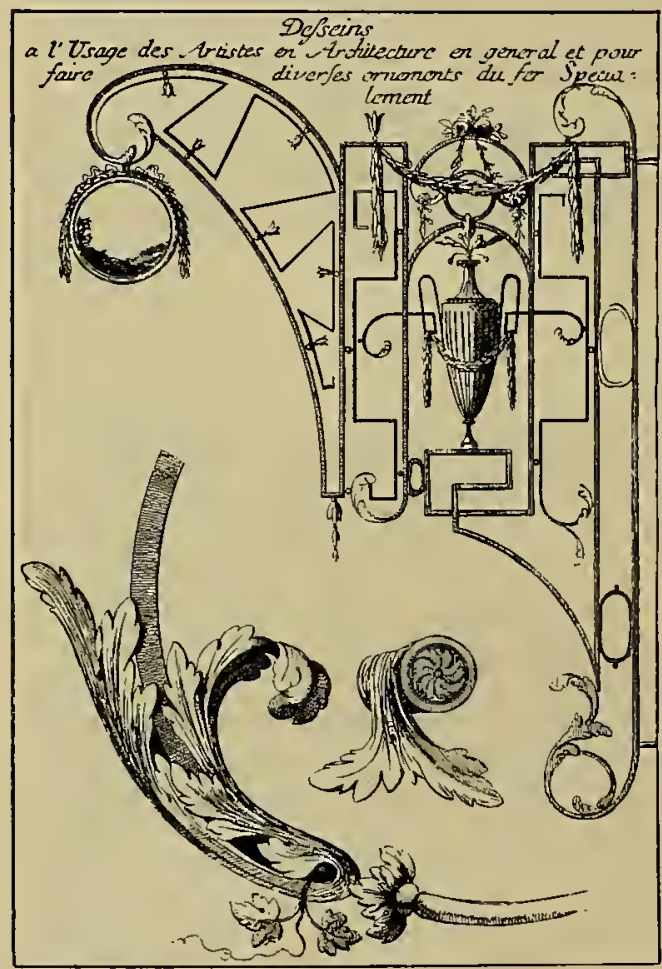

Abb. 140. Entwürfe für Schmiedearbeiten von J. Hauer.

Hier ist die Mitte wie einer jener grossen Rokokoaltäre mit vorgesetzten Säulen, verkröpftem Gebälk und gebrochenem Giebel gestaltet. Sie wirkt wie ein Rahmen für das aus Holz geschnitzte Marienbild auf dem vor dem Gitter stehenden Altare. Die perspektivische Wirkung ist so gelungen, dass man thatächlich von den Abbildungen getäuscht werden kann. Und doch liegt alles Eisen nur in einer Fläche. Sehr schön sind auch die Seitenportale mit ihren grossen Voluten, Palmetten und Blumenkörben. Es ist eine der vollendetsten Eisenarbeiten, die je ge- schaffen worden sind. Das Gitter wurde 1756 aufgestellt. 1751 wird berichtet, dass „absonderlich wegen dem grossen Gätter vor dem Chor die Hammerschmiede aufgerichtet worden" sei. Also hat die Arbeit 5 Jahre gedauert. Der Verfertiger des Gitters war ein Schlossergeselle Namens Joseph Büssel aus Rankweil bei Feldkirch. ${ }^{1}$ )

Das Rokoko hielt sich in Deutschland in einzelnen Bezirken noch bis in die achtziger Jahre hinein. So besitzt $z$. B. die Altrossgärtner Kirche im Reg.-Bez. Königsberg ein Oberlichtgitter in Rokokoformen, welches die Jahreszahl 1784 trägt.

Der klassizistische Stil hat in Deutschland auf dem Gebiete der Schmiedekunst nur wenig Spuren hinterlassen. Er tritt auch in Deutschland bedeutend später auf als in Frankreich, zu einer Zeit, als die Schmiedekunst schon stark im Niedergange war.

Auch die deutschen Ornamentstecher in jener Zeit bieten wenig Erfreuliches. Einen Forty suchen wir vergebens unter ihnen. Fast ausschliesslich erscheinen die Stiche für Schmiedeeisen jetzt in Augsburg. Wohl der bedeutendste Stecher jener. Zeit für Schmiedeeisen ist Johann Hauer aus Augsburg, der eine längere Zeit in Paris gelebt haben muss (1748 bis 1820). Mehrere seiner Hefte sind unterzeichnet: Inventes desines et graves par J. Hauer a Paris, Rue St. Ursule; andere erschienen bei den Augsburger Verlegern Joh. Gradmann, Joh. Georg Hertel u. C. A. Grossmann. Hauers Entwürfe stellen Gitter, Wandarme, Wandleuchter, Grabkreuze u. dergl. dar, zum Teil sind die Ornamente in grösserem Massstabe beigezeichnet. Seine Linienführung ist infolge der starken Verwendung der Formen des Rechtecks und des Kreises, sowie regelmässiger Ovale etwas trocken und langweilig. Vielfach wirken seine Gitter dünn, da die klare Zeichnung des Stabwerks nur wenig durch Ornamente belebt ist. Seine Ornamentik ist die für jene Zeit charakteristische: Mäander,

1) Kick, W. a. a. O. S. 8. 


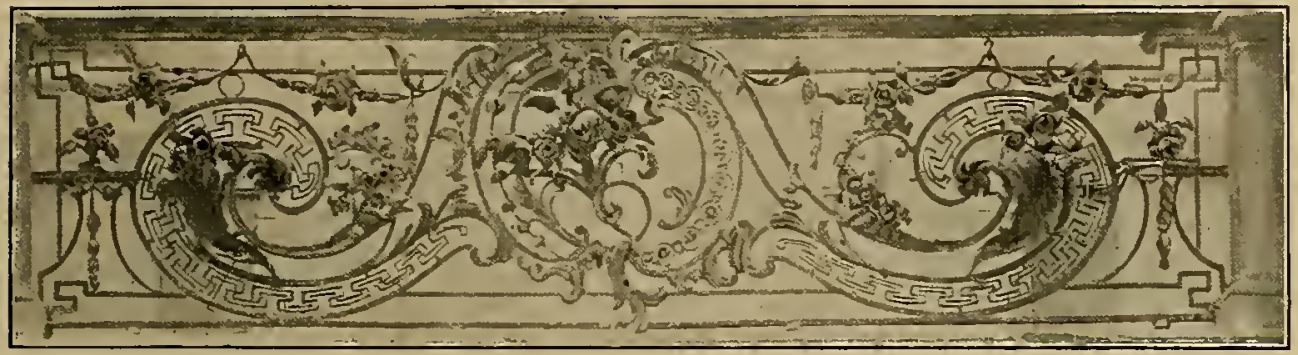

Abb. 141. Balkongitter am Ungarischen Ministerium in Wien.

Wellenbänder, „laufender Hund", Lorbeerfestons, ovale und runde Akanthusrosetten, Bandschleifen und natürliche Blumen. $\mathrm{Er}$ scheint viel Anklang gefunden zu haben, denn von den erhaltenen Arbeiten erinnern manche an seine Entwürfe. Besonders die eigenartige Form seiner Wandarme kehrt häufig wieder (Abbild. 140 u. 146).

Auch der schon genannte Verleger und Kupferstecher Karl August Grossmann gab ein Buch "Neueste Schlosserarbeit" heraus, das jedoch, ebenso wie die von
Fietta u. Comp. zu Kriegshaber bei Augsburg veröffentlichten Stiche, unbedeutend und dürftig ist. Vielleicht schon dem Anfange des 19. Jahrhunderts angehörig sind 6 Hefte mit Schmiedearbeiten von Jakob Zipper in Augsburg, die deshalb für uns besonders interessant sind, weil sie ausser Entwürfen jedesmal Tafeln nebst Erläuterungen in der Art der Abbildungen des Schlosserbuches von : Duhamel du Monceau bringen, in denen die Herstellung der vorgeführten Schmiede-

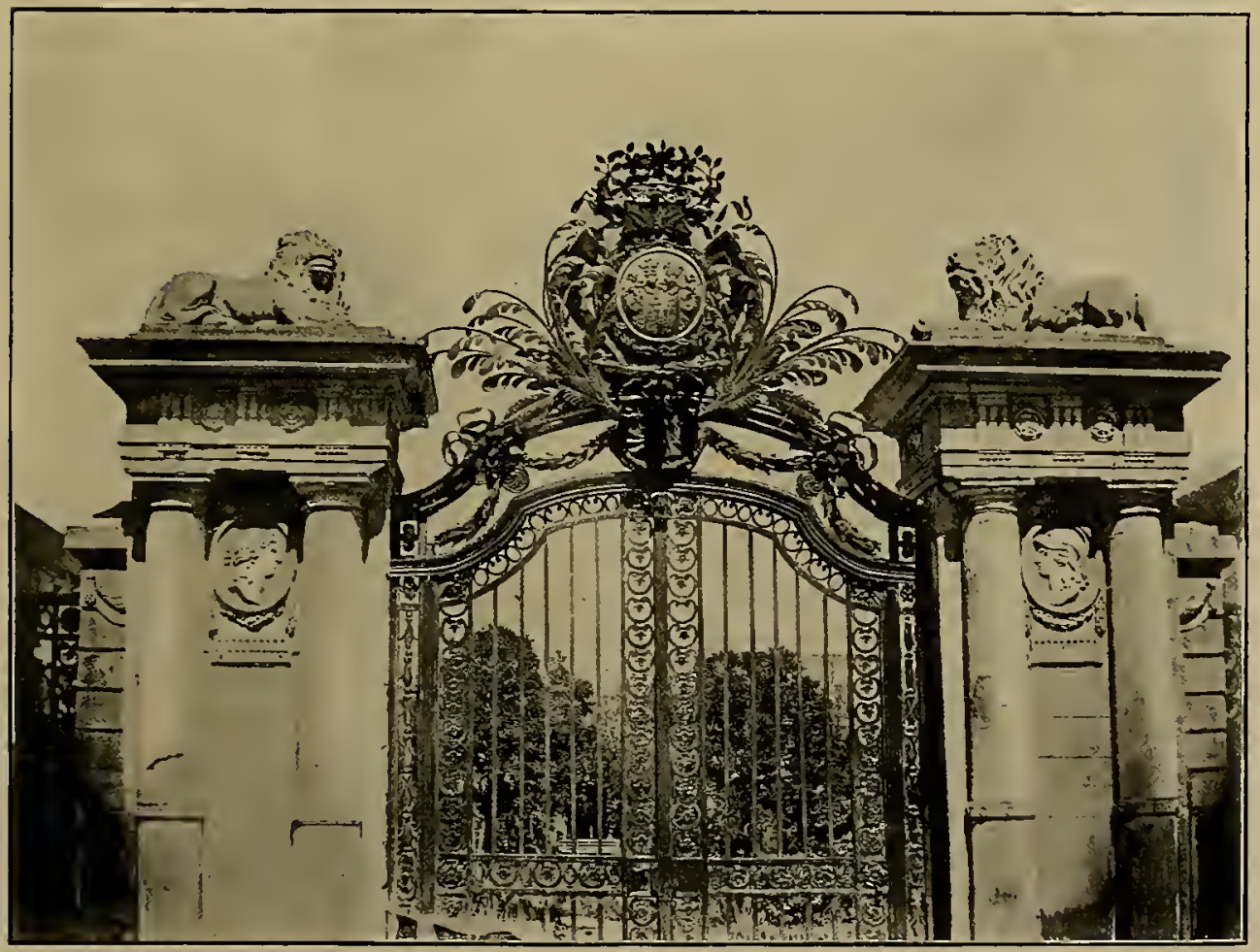

Abb. 142. Thor der ehemaligen Schüleschen Kattunfabrik zu Augsburg. 
arbeiten genau erklärt wird. Wir ersehen daraus, dass zur Herstellung der Ornamente fast ausschliesslich Gesenke benutzt wurden. Zipper bemerkt, dass diese Gesenke von Messing nach einer vom Bildhauer geschnittenen Form gegossen werden könnten, falls man sie nicht von Stahl machen wolle. Die Biegungen der Stäbe wurden an starken eisernen Lehren, die auf Klötzen befestigt waren,

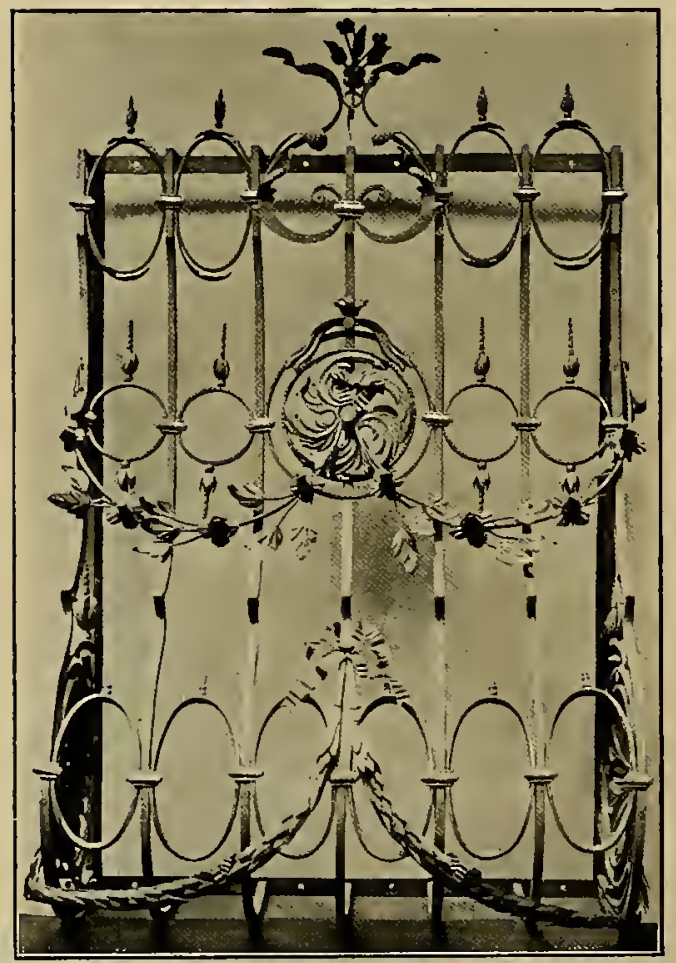

Abb. 143. Fensterkorb im Bayerischen Gewerbemuseum zu Nürnberg.

ausgeführt, ganz ähnlich wie das auch in dem Werke von Duhamel du Monceau beschrieben wird. Die Entwürfe Zippers, die für die damalige Zeit ganz ansehnliche Leistungen darstellen, zeigen einen reichen Gebrauch von Akanthusranken, die in jenen für das Ende des 18. Jahrhunderts eigentümlichen mageren, metallischen Formen auftreten (Abbild. 139). Merkwürdig ist auch das Auftauchen pseudogotischer Ornamente, die ja bekanntlich in England schon in der Mitte des 18. Jahrhunderts in die Erscheinung traten.

Wie schon bemerkt, ist die Zahl der noch vorhandenen, also wohl auch der überhaupt geschaffenen Schmiedearbeiten in antikisierenden Formen sehr klein. Der Gitterwerke dieser Art in Würzburg wurde schon bei Besprechung der Arbeiten Oeggs gedacht. Ebenso wie dort ältere und neuereFormen sich in eigenartiger Mischung zusammenfanden, so ist bei dem Balkon des Ungarischen Ministeriums in Wien ebenfalls noch Ornamentik und Linienführung des Rokoko mit späteren Formen verbunden (Abbild. 141). Auch die schon den siebziger Jahren angehörende stattliche Portalbekrönung, welche sich im Besitz des Hamburgischen Museums für Kunst und Gewerbe befindet, zeigt noch Anklänge an ältere Stilelemente. Sie schmückte bis vor nicht allzulanger Zeit noch das Eingangsthor der ehemaligen Kattunfabrik von J. H. Schüle vor dem roten Thor in Augsburg und soll von J. M. Endres hergestellt sein. In einer von Palmzweigen umgebenen Kartusche ist das aus vergoldetem Kupfer getriebene Schülesche Wappen angebracht (Abbild. 142).

Das Fenstergitter mit ausgebauchtem Unterteil, das im Bayerischen Gewerbemuseum zu Nürnberg aufbewahrt wird (Abbild. 143), ist dagegen schon völlig in antikisierende Formen gekleidet. Es gehört dem Formenkreise an, der in den Stichen Hauers uns entgegentritt. Vielfach wird jetzt, wie in Frankreich die Goldbronze, so in Deutschland das Messing zum Schmuck des Eisenkörpers verwandt. Ein kleiner Wandarm im Museum für Kunst und Gewerbe in Hamburg ist mit Messingrosetten geschmückt, und bei einer sehr gut aufgebauten Laterne im Berliner Kunstgewerbemuseum sind die Zierteile sämtlich aus dünnem Messingblech gebildet. Ebenda befindet sich auch ein sehr reich ausgestattetes Grabkreuz, ganz aus Schmiedeeisen gefertigt. Wohl das in Form und Ausführung edelste Werk der Schmiedekunst jener Zeit ist die aus Eisen 


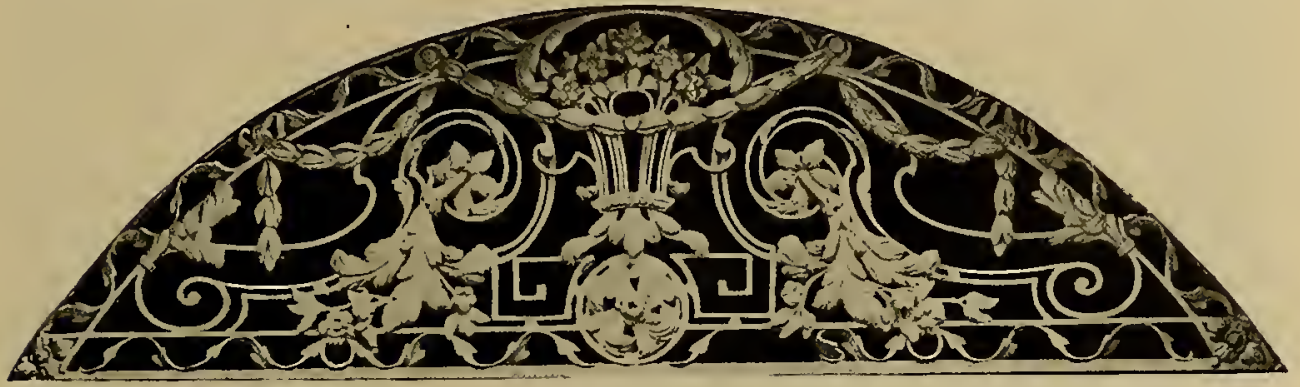

Abb. 144. Oberlichtgitter am Hause Adlerstrasse 27 in Nürnberg.

getriebene Thür an der Reichen Kapelle in der Residenz zu München (Abb. 145). Die oberen Füllungen sind mit je einem Löwenkopf geschmückt, aus dessen Maule die Embleme der weltlichen und geistlichen
Gewalt herunterhängen. Auf den Feldern in der Mitte und unten sind Rosetten mit korrekt gezeichnetem Akanthus angebracht. Eine besondere Erwähnung gebührt auch noch wegen der Seltenheit derartiger Ge-

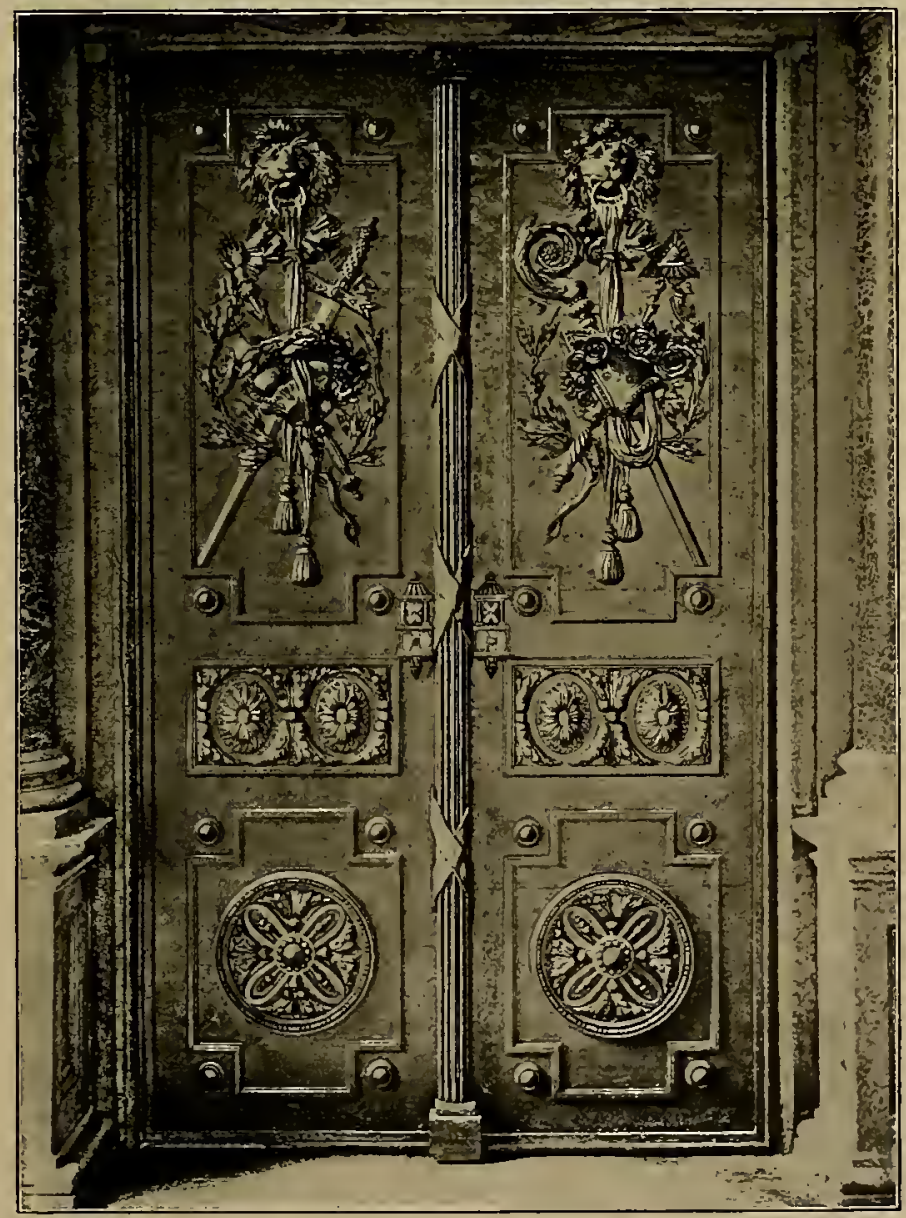

Abb. 145. Thür an der Reichen Kapelle in München. 
räte überhaupt ein schmiedeeiserner Taufständer in der Stadtkirche zu Ludwigslust in Mecklenburg mit dem Namen des Schlossers A. Niens und der Jahreszahl 1804. ${ }^{1}$ ) Bei der geringen Zahl der noch erhaltenen

1) Abbildung bei Schlie, F., Die Kunst-
Schmiedewerke der klassizistischen Stilrichtung verdient jedes einzelne $\mathrm{Be}$ achtung.

und Geschichtsdenkmäler des Grossherzogtums Schwerin, Bd. 11I. Schwerin 1899. S. 246.

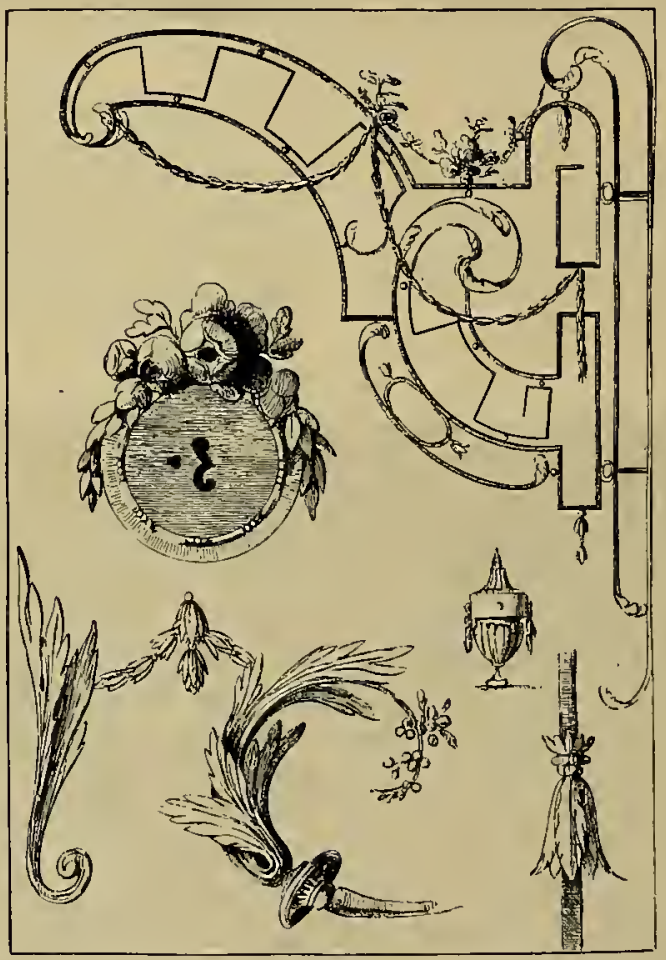

Abb. 146. Entwürfe für Schmiedearbeiten von J. Hauer. 


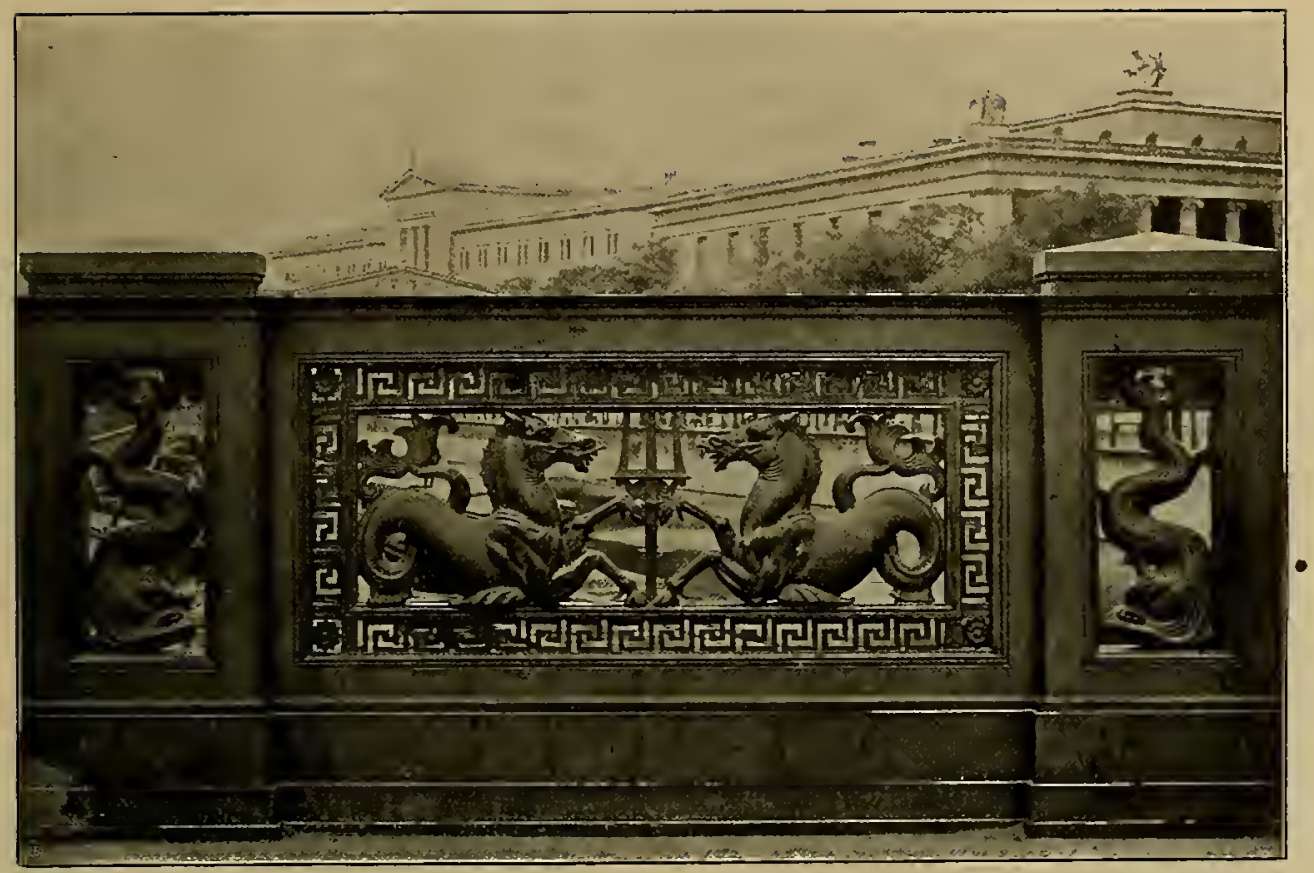

Abb. 147. Gusseisernes Geländer an der Schlossbrücke in Berlin.

\section{Die Schmiedekunst im 19. Jahrhundert.}

Mit der Wende des 18. Jahrhunderts beginnt eine höchst trostlose Periode in der Geschichte der Schmiedekunst, welche ungefähr die erste Hälfte des 19. Jahrhunderts umfasst. Es ist dieselbe Zeit, in der auch auf allen anderen Gebieten der künstlerischen Thätigkeit ein trauriger Niedergang erfolgte. Die Gründe dieser allgemeinen Stagnation waren wirtschaftlicher Natur. Die vollständige Erschöpfung des Nationalwohlstandes, welche nach den Befreiungskriegen in Deutschland herrschte, entzog der Kunst die nötige Nahrung. Allmählich ging bei dem gänzlichen Mangel jeder Uebung die alte gute handwerkliche Fertigkeit völlig verloren, nicht nur in Deutschland, sondern auch in Frankreich. Es kam soweit, dass um 1840 der französische Architekt Viollet-le-duc in ganz Paris keinen Schlosser finden konnte, der im stande gewesen wäre, auch nur das einfachste Gitter zu schmieden. Wie tief schliesslich das künstlerische Vermögen gesunken war, zeigen am besten die Sammlungen von schmiedeeisernen Geländern von Fr. Vogt. Sie enthalten Gitter von solch dürftiger und öder Erfindung, wie sie geistloser und armseliger nicht gedacht werden können.

Man half sich jetzt meistens mit dem Eisenguss, in welchem man ein bequemes Mittel gefunden zu haben glaubte, die mühsame Schmiedearbeit zu ersetzen, da ja durch den Guss jeder Gegenstand leicht zu Dutzenden hergestellt werden kann. Dabei verzichtete man freilich auf die lebendige Wirkung der Handarbeit, die jedem geschmiedeten Stück etwas Persönliches, Individuelles giebt, zugleich auch auf die weit grössere Festigkeit und Haltbarkeit des geschmiedeten Gegenstandes gegenüber dem gegossenen. Welchen Umfang schon gleich in den ersten Jahrzehnten des neuen Jahrhunderts der Eisenguss angenommen hatte, zeigt das Musterbuch eines Pariser Eisen- 
giessers André, in dem alle möglichen Gegenstände vom kleinsten Gitterteil bis zur Statue abgebildet sind. Sogar zierliche Schmucksachen und Neujahrskarten mit Ansichten wurden von der $\mathrm{Kgl}$. Eisengiesserei in Berlin, die wegen ihres besonders feinen Gusses berühmt war, ausgeführt. Eines der besten Werke aus Eisenguss jener Zeit ist das Geländer der von Schinkel 1822-1824 erbauten Schlossbrücke in Berlin (Abbild. 147).

Während also in künstlerischer Hinsicht die erste Hälfte des 19. Jahrhunderts einen gewaltigen Tiefstand in der Geschichte des Eisens bedeutet, machte dagegen die technische Bearbeitung des Eisens Riesen. fortschritte. In diese Zeit fällt nämlich die Vervollkommnung der Walzwerke. Die Einführung der Eisenbahnen um 1830 und der dadurch herbeigeführte gewaltige Verbrauch von Eisenschienen gab die Veranlassung dazu. Auch die Erfindung der Dampfhammer geschah in dieser Zeit. Beide ermöglichten eine Verarbeitung des Eisens in einem Massstabe, wie er bis dahin unbekannt gewesen, und führten eine völlige Umwälzung in der Architektur herbei, indem es jetzt möglich war, gewaltige Räume mit einem Eisengerüst zu überspannen.

Der riesige, aus Glas und Eisen erbaute Kristallpalast auf der Weltausstellung in London im Jahre 1851 war eine der ersten Schöpfungen dieser neuen Eisenkunst. Aber diese neue gewaltige Errungenschaft war nicht das einzige, was jene erste Weltausstellung brachte. Ebenso bedeutungsvoll und wichtig war die durch die Nebeneinanderstellung der Erzeugnisse jener Zeit mit den besten Kunstwerken der Vergangenheit hervorgerufene Erkenntnis, wie stark das Kunstvermögen gesunken sei, und dass man alles daran setzen müsse, um das Kunstgewerbe wieder zu seiner früheren Höhe emporzuheben.

Besondere Verdienste um die Wiederbelebung der alten Schmiedekunst erwarb sich der schon erwähnte Viollet-le-duc. Unter seiner Leitung entstanden in der
Mitte der fünziger lahre die Beschläge der Mittelthür von Notre-Dame in Paris, welche von dem Schlosser Boulanger nach dem Vorbilde der alten Beschläge ausgeführt wurden. $\mathrm{Zu}$ Anfang der sechziger lahre regt es sich auch in Deutschland. Man beginnt jetzt die noch vorhandenen alten Schmiedearbeiten $\mathrm{zu}$ veröffentlichen und nach ihnen zu arbeiten. Und so hat sich denn allmählich die Schmiedekunst an den alten Vorbildern wieder zu der Leistungsfähigkeit der früheren Jahrhunderte emporgearbeitet und zahlreiche vortreffliche Schmiedewerke in Anlehnung an die Werke der Vergangenheit geschaffen.

Die Bemühungen der letzen Jahre, eine neue Kunstsprache zu schaffen, in der sich der Charakter unserer Zeit in seiner Eigenart aussprechen könne, sind in der Schmiedekunst noch wenig zur Geltung gekommen. Auch die letzte Pariser Weltausstellung bot nach dieser Richtung hin keine Ueberraschungen. Die meisten Schmiedearbeiten schlossen sich, wie z. B. die österreichischen und italienischen, an ältere Vorbilder an. Die französischen Schmiedewerke zeigten zum grossen Teil einen wild ins Kraut geschossenen Naturalismus. Den überzierlichen Formen fehlte jene kernhafte Kraft, die man doch bej Eisenarbeiten zu sehen wünscht. Auch die Werke des Hauptmeisters unter den französischen Schlossern, des Emile Robert, litten zumeist an demselben Fehler. Seine beste Leistung war noch ein Kronleuchter für elektrisches Licht, der vom Hamburger Museum für Kunst und Gewerbe erworben wurde. Hier sind ja jene zierlich leichten Formen ganz am Platze. Auch sonst fehite es nicht an vortrefflichen Arbeiten, wie das durch elegante Bewegungen der Hauptlinien sich auszeichnende Portal des Petit Palais, welches nach einem Entwurfe des Architekten Girault von L. Bardin ausgeführt worden ist (Abbild. 148).

Weitaus die besten Leistungen, besonders in technischer Hinsicht, stellten die deutschen Schmiedearbeiten dar. Ein Bravourstück ersten Ranges war die bekannte Gruppe des Adlers, der einen 


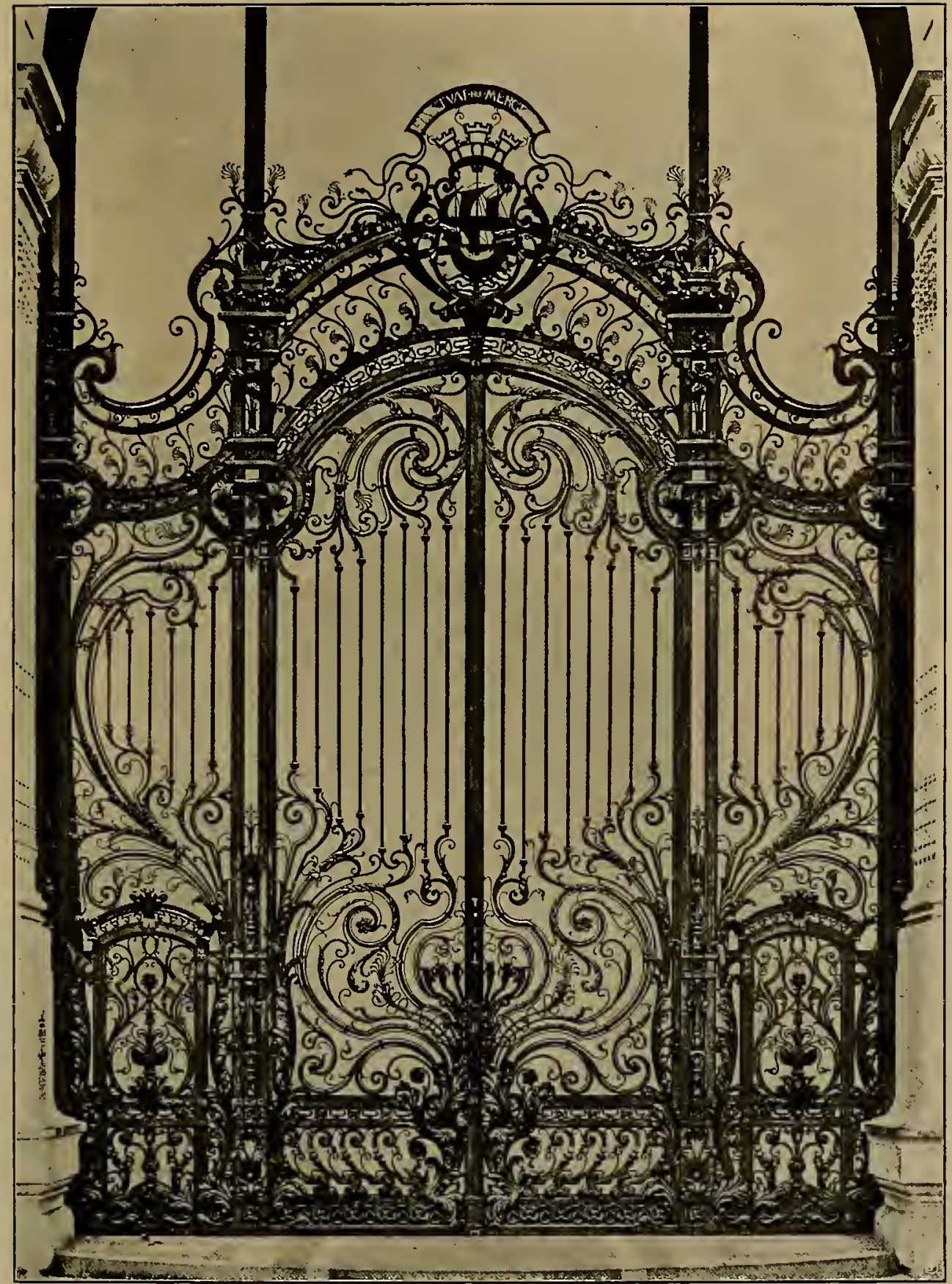

Abb. 148. Portal des Petit Palais (Weltausstellung zu Paris 1900). 
Drachen bezwingt, in der Mitte des Lichthofes der deutschen Abteilung, ein Werk der Firma Gebr. Armbrüster in Frankfurt a. M., nach einem Modell von Professor Fritz Hausmann ausgeführt (Abbild. 150). Hervorragende Leistungen waren auch zwei grosse Gitterwerke, die als Umrahmung zweier Ausstellungsgruppen dienten. Die eine, nach Angabe des Architekten J. Radke von Schulz und Holdefleiss in
Berlin gezeichnet und geschmiedet, fasste die Textilausstellung ein (Abbild. 149), die andere, welche von Paul Krüger in Berlin ausgeführt wurde, bildete die Abgrenzung der Metallabteilung. Zahlreiche ausgestellte Schmiedearbeiten waren in einem Material hergestellt, das seit einigen Jahren in der Schmiedekunst vielfach Anwendung gefunden hat, nämlich in der schmiedbaren Aluminiumbronze, einer

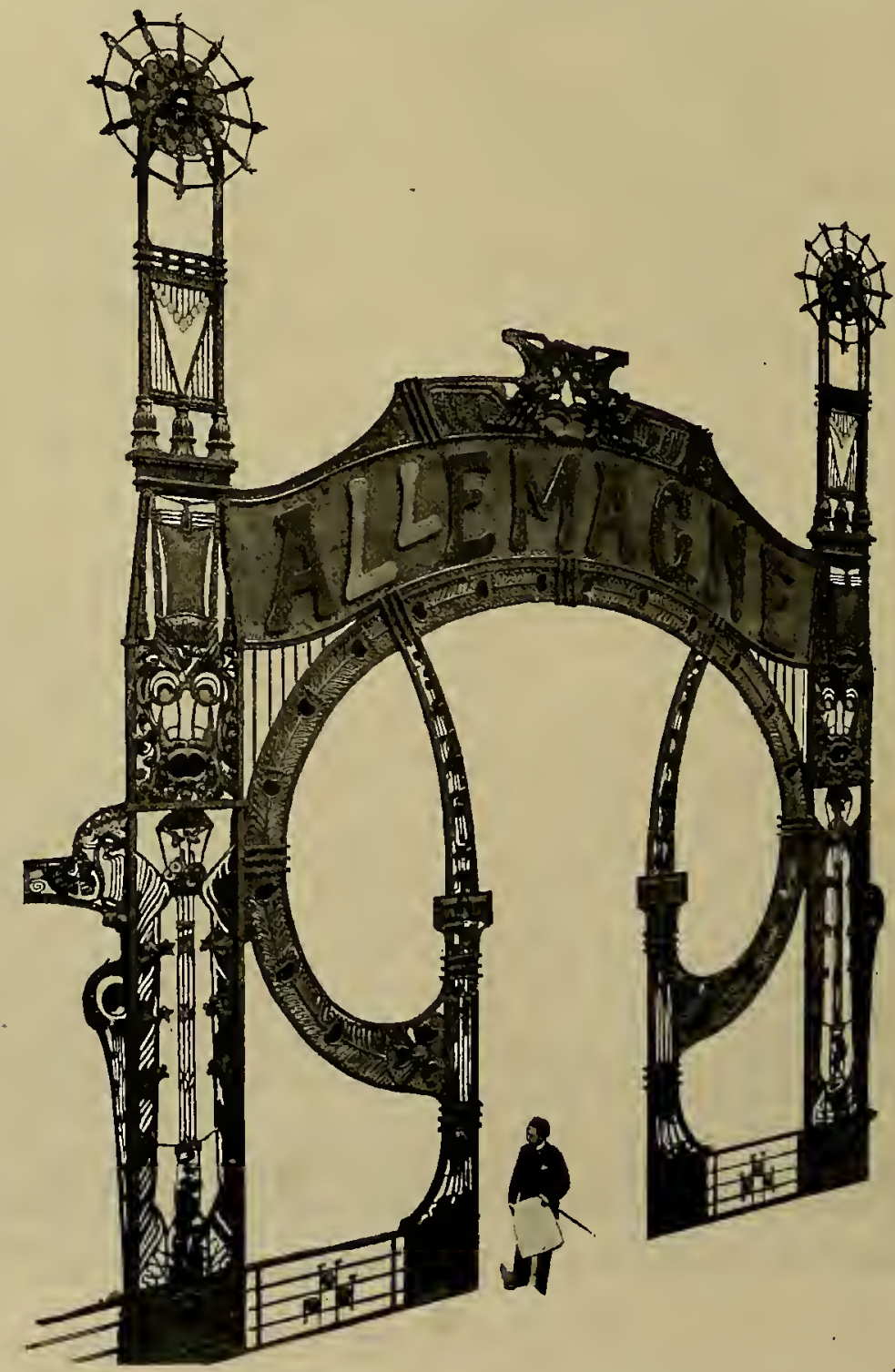

Abb. 149. Eingang zur Textilabteilung (Weltausstellung zu Paris 1900) von Schulz u. Holdefleiss, Berlin. (Aus der ${ }_{n}$ Berliner Architekturwelt“.) 


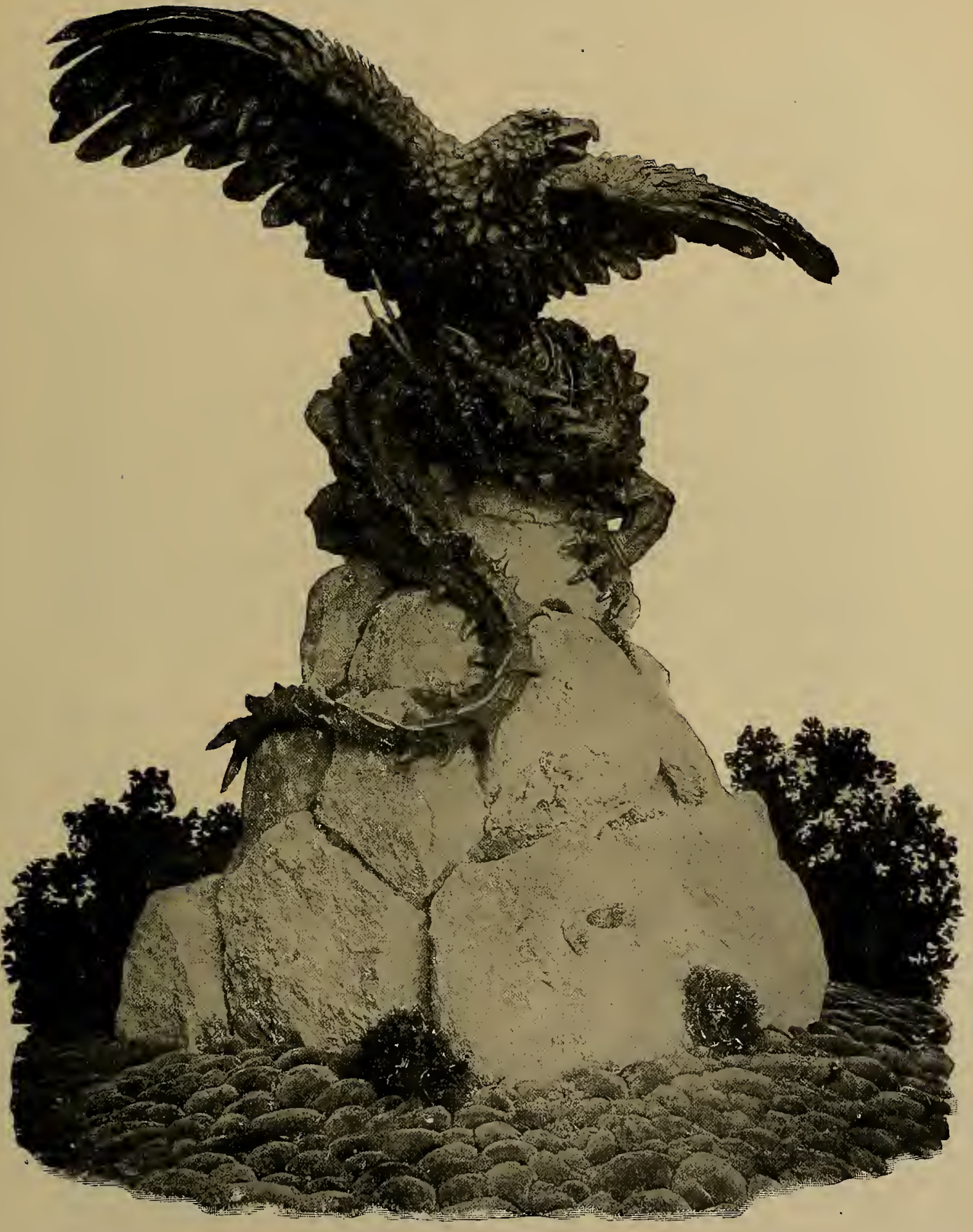

Abb. 150. Schmiedeeiserne Gruppe von Gebr. Armbrüster in Frankfurt a. M.

(Weltausstellung zu Paris 1900). 
Legierung von 90-95 Prozent Kupfer und 10-5 Prozent Aluminium. Ihre goldglänzende Farbe und ihre grössere Widerstandsfähigkeit gegen Oxydation geben ihr manche Vorzüge vor dem Eisen. Dem steht aber wieder ihre grosse Kostbarkeit sowie der Umstand gegenüber, dass sie nicht schweissbar ist; darum wird ihr Gebrauch immer nur ein beschränkter bleiben.

Nachdem das 19. Jahrhundert zugleich mit einer hohen Vervollkommnung der technischen Hilfsmittel auch die verloren gegangene Kunstübung wiedergebracht hat, steht die Schmiedekunst für die neuen Aufgaben, die das 20. Jahrhundert ihr bringen wird, gerüstet da. Diese bestehen zunächst in einer Umbildung vieler bis dahin gebräuchlichen Formen, wie z. B. auf dem Gebiete des Beleuchtungswesens, wo die totale Umwälzung, die sich in den letzten hundert lahren vollzogen hat, gebieterisch nach neuen Lösungen in der Bildung der Beleuchtungskörper verlangt. Noch grössere Aufgaben aber scheint die $\mathrm{Zu}$ - kunft der Schmiedekunst bei den neuen gewaltigen Eisenbauten, den Bahnhofshallen, Ausstellungsgebäuden, Brücken u. s. w. vorbehalten zu haben. Hier gilt es, nicht nur den dekorativen Beigaben, sondern auch den konstruktiven Teilen eine grössere künstlerische Ausbildung angedeihen $\mathrm{zu}$ lassen, als bisher geschehen. Interessante Versuche nach dieser Richtung hin sind z. B. schon bei der Bonner Rheinbrücke und der neuen Berliner Hochbahn durch Bruno Möhring, Alfred Grenander u. a. gemacht worden. Eine besondere Pflege bedarf endlich auch die Herstellung von Ziereisen auf den Walzwerken. Wenn auch die eigentliche Schmiedekunst von denselben nur mässigen Gebrauch machen wird, so sind dieselben doch bei Dekorationen grossen Massstabes nicht zu entbehren. Aber auch zur Herstellung guter und billiger Massenware sind sie sehr geeignet. Diese Maschinenarbeit in künstlerische Bahnen zu lenken, ist bisher noch kaum versucht worden. 


\section{Register.}

A.

Aachen, Wespiensches Haus 127.

Aignman, Andreas 125.

d'Allembert 5 .

Altdorf 60.

Altrossgarten 134.

Aluminiumbronze 142 .

Amalienburg 125.

Amiens, Kathedrale 102.

Amorbach 129.

André 140.

Antoine 109.

Armbrüster; Gebr. 142.

Aetzen 3. 14.

Augsburg, Barfüsserkirche 114.

- heil. Kreuzkirche 76.

- St. Ulrichskirche 58. 65.

B.

Babel 89. 90.

Babin 85.

Bardin, L., 140.

Barras de 1a Penne 42.

Basel 127.

Baumann, Joseph 115.

Beauvais 50 .

Bemalung 3. 16.

Bérain, Jean 22. 42.50 .73$.

Berlin, Hohenzollernmuseum 71.

- Kunstgewerbemuseum 55. 63. 71. 82. 124. 136.

- Neues Museum 70. 71.

- Nikolaikirche 84.

Berneckher, Nikolaus 125.

Bigonnet 109.

Birckenfeld, Joh. Balthasar 114.

- Joh. Samuel 113.

Blaumalerei 3. 16.

Le Blond 38.

Blondel, Jacques François 33. 47. 85. 110. 112.

Bonnard, Nicolas 40. 47.

Bonthomme, Gabriel 104.

Breslau, J. 104.

Breton, Mathurin le 21. 27. 33.

Bridou 18.

Briseux, C. E. 89. 90.

Brisville, Hugues 22. 42.53.

Brühl 125.

Büssel, Joseph 134.
C.

Caffin, François 48.

Cambridge, Trinity College 54.

Chanteheux 92. 101.

Chatsworth 54.

Chopitel 7.

Commercy 92. 101.

Compiègre, Schloss 106. 107.

Corbin 109.

Cotte, Robert de 47. 48. 50. 85.

Cuvilliès, Franz 110. 125. 126.

\section{D.}

Daviler 42. 50. 71. 74 .

Decker, Paul 73.

Delobel 33. 38.

Delphin, Pierre 102.

Demouchy, Jean 34.

Desboeufs du Saint - Laurent 106.

Diderot 5.

Diessen 130.

Dijon, Kathedrale 40.

- Ecole Saint-François de Sales 49.

Dresden, Grünes Gewölbe 68.

Dufour 28.

Duhamel du Monceau 7. 8. 10. 12. 18. 20. 136.

Durey 103.

\section{E.}

Eichel, Emmanuel 114.

Eisenschnitt 3. 14.

Eisenspalterei 4. 6 .

Eisgrub 82.

Endres, J. M. 136.

Félibien 20.

\section{F.}

Fietta u. Comp. 135.

Fischer von Erlach, Joh. Bernh. 78. 81.

Fontaine, J. V. 88.89.

Fordrin, Alexis 50.

- (Foudrain), Louis 38. 48. 50. 53. 85 .

Forster, Heinrich Gottlieb 116.

Förster, Heinrich Gottfried 73.

Forty, Jean François 105. 134.

Frankfurt a. M. S4.

Fürstenfeld 130.
G.

Gabriel, Jean Jacques 107.

Gallen, St. 129.

Gamain 103.

Gattinger, Marcus 118.123.129.

Gautier, Jean 40.

- Pierre 40.

Gérard 103.

Gesenke 10. 12.

Girault 140 .

Goy 27.

Graffenberger, Joh. Andreas 115.

Gran, Daniel 81.

Gravieren 3. 14.

Graz, Landesmuseum 82.

Grenander, Alfred 144.

Grossmann, Karl August 135.

Grosso, Niccolò, gen. Caparra 2.

Guérard, Nicolas 40. 47.

Guggenberger, Wolf 58 .

Guibal, Barthélemy 97.

\section{H.}

Habermann, Franz Xaver 115.

Hamburg, Museum f. Kunst u. Gewerbe 62. 136. 140.

Hammerwerke 3. 4.

Hampton Court 52. 54.

Hapacher, Wolf 58.

Hartmann, Gottfried 76.

Hasté, Michel 34. 36. 40.

Hauer, Johann 134. 136.

Hausmann, Fritz 142.

Helleweg, Wilhelm 61.

Héré, Emmanuel 92. 93.

Hesse, Eoban 4.

Heyden, Christian von der 72 .

Hildebrand, Joh. Lukas von 78. 79.120.

Hoch, Joh. Michel 76.

Hoppert, Bartholomäus 67.72.

Holdefleiss (Schulz u. Holdefleiss) 142 .

Houard, François 125.

Huquier, Gabriel 86. 88.

\section{I.}

Innsbruck, Hofkirche 58.

Jousse, Mathurin 20. 22.

Justi, Joh. Heinr.Gottlob von 8. 
K.

Kessel, Philipp Jakob 115.

Köbst 126.

Königsberg 60 .

Kopenhagen, Schloss Rosenborg 68 .

Krüger, Paul 142.

\section{L.}

La Flèche 20.

Lalonde 106. 109.

Lambach $5 \%$.

Lamour, Jean 18. 20. 90.

Langley, Battey 56.

Lauingen 59.

Leipzig, Kunstgewerbemuseum 128 .

Lemercier 25.

Leonardo da Vinci 4.

Lepautre, Jean 25. 27. 34. 36. 38. 42. 43. 44. 45.

De Lespine 36.

Leszczynski, Stanislaus 91. 97. 101.

Leygebe, Gottfried 67.

Lipmann 98.

London, Kristallpalast 140.

- St. Paulskirche 52. 55.

- South Kensington Museum 21. 54. 59. 64.

- Westminsterabtei 55.

Löten 3. 14.

Ludwigslust 138.

Luzern 64.

M.

Maire, Jean 100.

Maison-sur-Seine 22. 25. 42.53 .

Mannheim, Jesuitenkirche 129.

Mannstädt, L. u. Co. 7.

Mansart, Jules Hardouin 27.33. 47.

Maria-Einsiedeln 64. 66.

Marly 34. 37. 50.

Marot, Daniel 43. 45. 49. 73. 78 .

Marot, Jean 24. 42. 44. 46.

Marseille 40.

Mathérion, Sébastien 34.

Maugin, Christoph 27.

Mayer, Joseph 130.

Meissonnier 86.

Michel, C. 89.

Möhring, Bruno 144.

Moreau 90.

Motté, Antoine 125.

Müller 126.

- Joh. Friedrich 4.

München, bayr. Nationalmuseum 59. 61. 121. 127. 128.

- Palais Preysing 125.

- Residenz 125. 137.

N.

Nancy, Hôtel de ville 93. 99. - Notre Dame 92.
Nancy, Place de la Carrière 99.

- Place Stanislas (Royal) 93. 99.

- Tue Notre Dame 100.

Neisse 60.

Neufforge 104.

Neumann, Balthasar 116. 121.

Niens, A. 138.

Nieten 3. 14.

Nikolsburg, Schloss 116.

Nordmann, David 128.

Nürnberg, Germanisches Museum 73 .

- bayr. Gewerbemuseum 136.

Nussbaumer, Vincenz 65.

o.

Obermarchthal 61.72 .

Oegg, Joh. Georg 118. 136.

Oelker, Heinrich 64. 72.

Oppenord 88.

Ottobeuren, Kloster 115.

Oxford, All Souls 55.

$$
\text { P. }
$$

Parent, Nicolas 48.

Paris, Apollogalerie 22. 24.

- St. Denis 20.

- Ecole militaire 105. 108.

- St. Eustache 36. 37. 40.

- St.Germain l'Auxerrois 109.

- Louvre 22.

- Musée de Cluny 50.

- Notre Dame 47. 48. 140.

- Palais de Justice 109.

- Palais Royal 109.

- St. Roch 109.

- St. Sulpice 40.

- Val de Grâce 34. 35. 37. 39. 40.42 .

Patridge 54.

Payne, John 7.

Petit, Jacques 48.

Pierretz le jeune, A. 24. 34. 35. 36. 38. 42.

Polhem, Christoph 7.

Prag, Georgskirche 60.

- Nikolaikirche 82.

- Thomaskirche 82 .

$$
\text { R. }
$$

Radke, J. 142.

Réaumur 8. 18. 19.

Regensburg, alte Kapelle 60.

- St. Emmerankirche 84.

Reifell, Johann 64.

Rembeur, Jean de 21.

Richard 48.

Rieger, Hans 72.

Riga, Dom 84.

Robert, Emile 140.

Rostock, Nikolaikirche 84 .

Rouen, St. Ouen 50.

Rudolph, Christian Friedrich 74.

Rummel, Johann Georg 76.
S.

Salzburg, Florianbrunnen 58.

- Sternbrauerei 127.

Schlosshof 79. 120. 122.

Schmieden 3. 9.

Schmittner, Frantz Leopold 76.

Schoch, Peter 129.

Schreber, Daniel Gottfried 8.

Schübler, Joh. Jakob 74 .

Schulz (Sch. u. Hold efleiss) 142.

Schweissen 3. 14.

Seigneurie, Nicolas 21.

Sens 50.

Shaw, Huntington 54.

Silvestre, 1srael 25.

Stauchen 10.

Strecken 9.

T.

Tauschieren 3. 14.

Tijou, Jean 49. 52. 85 .

Treiben 3. 12.

Troyes, Hôtel Dieu 102.

\section{V.}

Vallée, S. 47. 50.

Varin 22.

Vergolden 3. 16.

Versailles, Schloss 25. 26. 28. 30. 32. 33. 34. 37. 38. 39. 42 . 53. 62. 103. 108.

- Grand Trianon 49. 105. 107.

- Petit Trianon 107.

Veyrens 102.

Verzinnen 3. 16

Viollet-le-duc 139. 140.

\section{W.}

Walzwerke 3. 4. 7. 140.

Wechter, Georg 45.

Weigel, Christoph 4.

- Christoph, jun. 73.

- Joh. Christoph 64. 72. 74.

Weingarten 130.

Werkzeuge 8.

Wien, Belvedere 79. 120.

- Johanneskapelle 80 .

- Ministerium des Innern 81.

- Schönbrunn 78. 80.

- Theresianum 67.

- Ungarisches Ministerium 136.

Wilhelmsthal 126

Wren, Christopher 52. 54.

Würzburg, Dom 118. 122. 123. 129.

- Juliushospital 124.

- Residenzschloss 118.

Z.

Zainhämmer 4.

Zipper, Jacob 135.

Zwickaul, Marienkirche 59.

Zwiefalten 134 . 


\section{MAX KLINGERS BEETHOVEN}

\section{Eine kunsttechnische Studie ELSA ASENIJEFF $\oint_{\hat{Q}}^{\text {von }}$ und 23 Beilagen und Textbildern}

Preis in vornehmem Liebhaberband geb. M. 20,-

Die Vollendung des "Beethoven" durch Meister Klinger wird als ein künstlerisches Ereignis allerersten Ranges empfunden. Fünfzehn Jahre lang trug der Leipziger Künstler den grossen Gedanken seines Werkes mit sich herum, und staunender Bewunderung voll blickt jetzt die Welt auf das erhabene Monument Beethovens. Keiner war mehr berufen, dem Heros der Musik ein Denkmal aufzurichten, als Klinger; nackt, mit ineinandergekrampften Händen, in den Schauern der Inspiration, den grüblerischen Blick in dämmernde Fernen bohrend, sitzt Beethoven auf dem mit kunstvollen Reliefs, Edelsteinen und Elfenbein reich verzierten Thron, ein Mantel von herrlichem Onyx schlingt sich über sein Knie, und zu seinen Füssen sträubt der zu ihm aufblickende Adler des Zeus seine mächtigen Flügel.

Das Werk, das im gesamten Schaffen Klingers einen Gipfel bedeutet, wird von Frau Elsa Asenijeff in einem trefflichen Text erklärt, der die zahlreichen Illustrationen - 8 Heliogravüren, 23 Beilagen und Abbildungen im Text - wirksam unterstützt, zumal Frau Asenijeff in der Lage ist, auch zu der Entstehungsgeschichte des Werkes die interessantesten Ausführungen beizubringen, insonderheit über die grosse Schwierigkeit, den Thronsessel in Bronze zu giessen, was erst in Pierre Bingens Werkstatt in Paris gelungen ist, und von Frau Asenijeff in den einzelnen Stadien ausserordentlich dramatisch erzählt wird.

Die interessanten technischen Aufschlüsse über die Schwierigkeiten in der Beschaffung der Marmorsorten, über die Behandlung des Elfenbeins, des tirolischèn Onyx, der venezianischen Glasflüsse werden mit besonderer Freude begrüsst werden.

Vor allem ist die Schilderung des Bronzegusses eine Meisterleistung, der in der modernen kunstgewerblichen Litteratur kaum etwas Gleiches an die Seite gestellt werden kann, und $z u$ deren tiefster Würdigung man schon bis auf Cellini zurückgehen muss.

Dass das Werk in seinen verschiedenen Stadien vorgeführt wird, sowohl illustrativ als auch textlich, vom Gipsmodell bis zur vollendeten Bronze und bis zum ausgeführten Marmorbilde, das verleiht dem auch äusserlich überaus vornehm ausgestatteten Werke seine überragende Bedeutung, an der kein Kunstfreund, kein Aesthetiker, kein Sammler, überhaupt kein Kulturmensch unserer Zeit vorübergehen darf. 


\title{
Verlag von Hermann Seemann Nachfolger in Leipzig
}

\section{ITALIENISCHE KUNST}

Studien und Betrachtungen von BERNHARD BERENSON

\author{
Einzig autorisierte Ausgabe \\ Aus dem Englischen übertragen \\ von

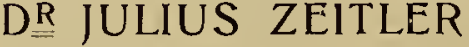

Preis broschiert M. 6,-, geb. M. 8,-

Berenson, ein bedeutender englischer Kunstforscher, der auch in den kunsthistorischen und ästhetischen Kreisen Deutschlands wohl bekannt ist, bietet in diesem Band über die "Italienische Kunst" eine Anzahl trefflicher Essays, in denen Gründlichkeit der Forschung mit feinem Urteil und hoher Kennerschaft gepaart ist. Die Essays behandeln Vasari, die Dante-1llustrationen, Correggio, Giorgione, Tizian, Amico di Sandro, dessen Persönlichkeit Berenson überhaupt erst festgestellt hat, und endlich eine reiche Fülle von venezianischen Gemälden, die sich in Londoner Privatbesitz befinden. Die Abbildungen derselben, die zum Teil in nur schwer zugänglichen Privatgalerien stecken, verleihen dem Buch noch einen ganz besonderen Wert.

\section{BILDNISKUNST \\ UND

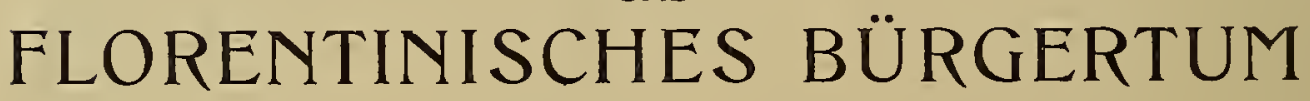

Bd. I: Domenico Ghirlandajo in Santa Trinitá: Die Bildnisse des Lorenzo de' Medici und seiner Angehörigen von

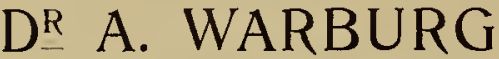

Grossquart mit 5 Lichtdruckbeilagen und 6 Textillustrationen

Preis geb. M. 6,-

Diese Arbeit des bekannten Kunstgelehrten eröffnet eine Reihe kunstgeschichtlicher Studien, die die Wechselbeziehungen zwischen Publikum, Fürsten, Gelehrten und Künstlern durch die Zusammenstellung direkter Zeugnisse in Kunstwerken der Frührenaissance veranschaulichen wollen. Die erste kultur- und kunstgeschichtliche Spezialstudie dieses Unternehmens behandelt einige bisher unbeachtete Meisterstücke der Porträtkunst des Ghirlandajo, die darin zum ersten Male genau publiziert und auch in der Beurteilung, die sie in ihrer eigenen Zeit fanden - vor allem durch die gewichtige Stimme des Lorenzo de' Medici selbst - gewürdigt werden. Fünf vorzüglich gelungene Lichtdrucke und ebenso viel Textillustrationen bringen das interessante Problem, das der Verfasser in seinem Text aufrollt, zur wirksamsten Anschauung. 

HERMANN SEEMANN NACHFOLGER in LEIPZIG:

Hpulejus, Amor und Psyche. Ein Märchen, ins Deutsche übertragen von Prof. Dr. Norden, mit Bildern von Walter Tiemann. Geb. M. 6,-

Marie Cuise Becker, Der Tanz. Mit ca. 100 Beilagen und Textbildern. Br. M. 8,-, geb. M. 10,-

Joseph Bédier, Der Roman von Tristan und 1solde. Mit Geleitwort von Gaston Paris, aus dem Französischen übertragen von Dr. Julius Zeitler. Textausgabe br. M. 4,-, geb. M. 5,- Illustrierte Prachtausgabe mit ca. 150 lllustr. von Robert Engels geb. M. 18,--, Liebhaber-Ausgabe (50 numer. Exemplare) geb. M. 50,-

Бans Bélart, Nietzsches Ethik. M. 2,-

Georg Biedenkapp, Kleine Geschichten und Plaudereien philosophischen, pädagogischen und satirischen Inhalts. Br. M. 3,-

đailhelm Bölsche, Ernst Haeckel. Ein Lebensbild. Geb. M. 3,60

fritz Burger, Gedanken über die Darmstädter Kunst. (In Eckmannschrift.) Br. M.,- 75

Challemel-Cacour, Studien und Betrachtungen eines Pessimisten. Autoris. Uebersetzung aus dem Franz. von M. Blaustein. Br. M.6,-, geb. M. 7,50

Douglas Cockerell, Der Bucheinband und die Pflege des Buches. Ein Handbuch für Buchbinder und Bibliothekare. Mit Zeichnungen von Noël Roobe und zahlreichen anderen lllustrationen in Lichtdruck und Aetzung. Deutsche Ausgabe von Felix Hübel. Br. M. 5,-, geb M. 6,50

Band I der "Handbücher des Kunstgewerbes". Herausgegeben von W. R. Lethaby am South Kensington Museum, deutsche Ausgabe besorgt von Dr. Julius Zeitler.

Michael Georg Conrad, Von Emile Zola bis Gerhart Hauptmann. Erinnerungen zur Geschichte der Moderne. Br. M. 2,50

Calter Crane, Dekorative lllustration des Buches in alter und neuer Zeit. 11. Auflage. Br. M. 7,50, geb. M. 9,-, Liebhaberausgabe geb. M. 12,-

Linie und Form. Br. M. 10,-, geb. M. 12,-

Grundlagen des Zeichnens. Br.12,-, geb. M. 14,-

zalter Crane, Cobden-Sanderson, Cewis f. Day, Emery zalker, cailliam Morris u. a. Kunst und Handwerk (Arts and Crafts Essays).

I. Die dekorativen Künste.

I1. Die Buchkunst.

III. Keranik, Metallarbeiten, Gläser.

IV. Wohnungsausstattung.

V. Gewebe und Stickereien.

Jeder Band br. M. 2,-

Бerman frank, Das Abendland und das Morgenland. Eine ZwischenreichBetrachtung. M. 2,50

Dr. Sigismund friedmann, Ludwig Anzengruber. Br. M. 5,-, geb. M. 6,50

Das deutsche Drama des neunzehnten Jahrhunderts in seinen Hauptvertretern. 1. Band br. M. 5,-, geb. M. 7,-

Otto Grautoff, Die Entwicklung der modernen Buchkunst in Deutschland. Br. M. 7,50, geb. M. 9,-

Zuilh. Бauff, Zwerg Nase. Märchen mit Bildern von Walter Tiemann. Geb. M. 4,felix Бübel, In einer Winternacht. Eine Gespenstergeschichte. Br. M. 2,-, geb. M. 3,-

Und häte der Liebe nicht! Roman. Br. M. 4,-, geb. M. 5,-

Dr. Kans Candsberg. Friedrich Nietzsche und die deutsche Litteratur. Br. M. 2,50

Otto Ludwig, Die Heiterethei. Erzählung aus dem Thüringer Volksleben. Mit Illustr. von Ernst Liebermann. Geb. M. 6,- 
Paul Moos, Moderne Musikästhetik in Deutschland. Br. M. 10,-, geb. M.12,Zailliam Morris, Kunsthoffnungen und Kunstsorgen (Hopes and Fears for Art).

I. Die niederen Künste.

II. Die Kunst des Volkes.

1II. Die Schönheit des Lebens.

IV. Wie wir aus dem Bestehenden das Beste machen können.

V. Die Aussichten der Architektur in der Civilisation. Jeder Band br. M. 2,-

Neues aus Nirgendland. Utopischer Roman. Br. M. 6,-, geb. M. 7,50 Kunstgewerbliches Sendschreiben. M.2,-

Die Kunst und die Schönheit der Erde. M. 2,-

Joseph Pennell, Moderne lllustration. Br. M. 7,50, geb. M. 9,-

Dr. Бeinrich Pudor, Laokoon. Asthetische Studien. Br. M. 6,-, geb. M. 7,50

Die neue Erziehung. Essays über die Erziehung zur Kunst und zum Leben. Br. M. 4,-, geb. M. 5,50

Eduard Platzhoff, Ernest Renan. Ein Lebensbild. Geb. M. 3,60

Dr. Robert Riemann, Goethes Romantechnik. Br. M. 6,一, geb. M. 7,50.

Ríchard Schaukal, Pierrot und Colombine. Mit Buchschmuck von VogelerWorpswede. M. 3,-

Das Buch der Tage und Träume. Verbesserte und durch neue Gedichte vermehrte 1l. Auflage mit dem Bild des Autors. Mit Titelzeichnung von Heinrich Vogeler. M. 3,50

Dr. Бeinr. v. Schoeler, Fremdes Glück. Eine venetianische Novelle. Br. M. 2,50

Ernst Schur, Vom Sinn und von der Schönheit der japanischen Kunst. M.2,Grundzüge und Ideen zur Ausstattung des Buches. M. 4,-

Paraphrasen über das Werk Melchior Lechters. M. 2,-

Gedanken über Tolstoi. M. 2,-

Das Buch der dreizehn Erzählungen. M. 3,-

Dichtungen und Gesänge. M. 3,-

Dr. Jean Louis Sponsel, Kabinettstücke der Meissner Porzellanmanufaktur von Johann Joachim Kändler. Prachtwerk in $4^{0}$ Format mit zahlreichen Beilagen und Textbildern. Br. M. 30,-, geb. in eleg. Liebhabereinband M. 32,50

Die Abteikirche zu Amorbach, ein Prachtwerk deutscher Rokokokunst. Mit 3 Textbildern und 40 Lichtdrucktafeln. Fol. In Mappe M. 50,-

Prof. Dr. Zailh. Stieda, $11 \mathrm{menau}$ und Stützerbach. Eine Erinnerung an die Goethezeit. Br. M. 2,-, geb. M. 3,-

Dr. Chiele, Hinauf zur bildenden Kunst. Laiengedanken. Brosch. M. 1,-

Zuilhelm ahde, Vor den Pforten des Lebens. Aus den Papieren eines Dreissig. jährigen. Br. M. 3,-

Dr. Julius $\nabla$ ogel, Goethes Leipziger Studentenjahre. Ein Bilderbuch zu "Dichtung und Wahrheit". 2. Ausgabe. Elegant geb. M. 4,一.

Böcklins Toteninsel und Frühlings-Hymne. 2 Gemälde Böcklins im Leipziger Museum mit 7 lllustrationen, darunter 5 Darstellungen der "Toteninsel" M.1, - In feinem Liebh.-Band mit Pergamentrücken geb.M. 2,50

John Jack" Vrieslander, Variété. 12 Kunstblätter auf Japankarton in eleganter Mappe M. 6,-

Prof. Dr. Gustav đustmann, Der Wirt von Auerbachs Keller: Dr. Heinrich Stromer von Auerbach. 1842-1542. M. 1,一.

Dr. Ludwig đä̈llner, Byrons Manfred. Liebhaber-Ausgabe mit Buchschmuck von Walter Tiemann. M. 4,-

Dr. Julius Zeitler, Nietzsches Aesthetik. Br. M. 3,一, geb. M.4,Die Kunstphilosophie von Hippolyte Adolphe Taine. Br. M. 6,-, geb. M. 7,- 


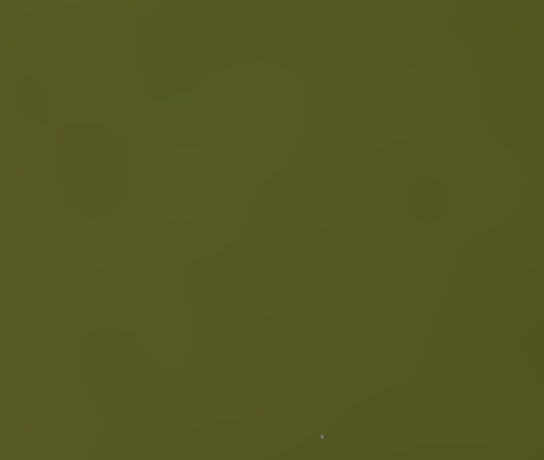



